\title{
ONTOGENIA CRANEANA POSTNATAL EN CÁNIDOS Y FÉLIDOS NEOTROPICALES: FUNCIONALIDAD Y PATRONES EVOLUTIVOS
}

\author{
Tesis Doctoral
}

Lic. Alda Valentina Segura Gago

Director: Dr. Francisco Juan Prevosti

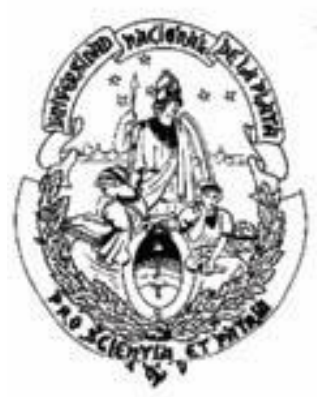

Facultad de Ciencias Naturales y Museo, Universidad Nacional de La Plata 2014 


\section{AGRADECIMIENTOS}

Quiero agradecer a mi Director Francisco (Pancho) Prevosti, que me brindó su ayuda y su dirección en un momento muy difícil de mi vida y que no solo es un excelente director en lo académico, que me enseñó muchísimo, sino que además es un ejemplo de moral y de ética difícil de encontrar en este tiempo.

A los jurados, Dres. Iván Pérez, Alfredo Carlini y Norberto Giannini, que mejoraron esta Tesis con sus valiosos aportes. Muchas gracias por el tiempo y el esfuerzo en corregirla.

A mi mamá y a mi papá, quienes me hicieron lo que soy, quiero agradecerles por el apoyo incondicional que me brindaron toda la vida, para que concretara mis sueños. Ellos me inculcaron el amor por lo que uno hace, me enseñaron a esforzarme para conseguir mis objetivos y me transmitieron su pasión en cosas tan disímiles como la anatomía y los derechos humanos. Nuestro vínculo trascenderá esta existencia.

A mis familiares que son un pilar indispensable de mi vida y a quienes extraño profundamente: Mi hermana Loly, Mamá Potata, Tía Chela, Tío Quique, Fer, Ruso, Ceci, Zaffi, Emi, Tuti, Tía Titina, Gabo, Ofe, Lisandro, Romi, Tía Vicky, Tío Julio, Diego, Anita, Igna, Nicky, Reni, por todos los buenos augurios y comentarios alentadores que siempre me brindaron. No imagino otra familia más perfecta para mí. Un recuerdo especial para mis abuelitos, Tía Susana, Tía Marta, Tío Mario y Tía Jenny, tan queridos por mí y que ya no están.

A mis amigos de hoy y de siempre, con los que compartí el colegio, la facultad, el campo, la ciudad, la vida: Florencia Garrocho, Verónica Suárez, Sofía Veiga, Mariana Perez, Gertrudis Carmelich, Romina Gronda, Celsa Civardi, María Sandoval, Gabriel Rodriguez, Miriam Morales, Luz Carrizo, Mariano Sánchez, Marcos Mollerach, Ignacio Ferro, Norberto Giannini, Cecilia Guerra, Luciana Díaz Briz, Silvina Enrietti, Pablo Guzmán, Andrea Brizuela, Miriam Profilo, Julián Faivovich, Sergio Lucero, Guillermo Cassini, Bárbara Tarnawski, Mariana Viglino, Laura Barone, Mariano Ramirez, Sebastián Echarri, Ignacio Legari, Marcos Ercoli, Alicia Alvarez, Daniela Castro, Pancho Prevosti, Amelia Chemisquy, Pablo Teta. Muchas gracias por las salidas, las comilonas, los asaditos domingueros, las clases, los mates, los viajes en tren, el café, las golosinas, las charlas, las "horrendas" compartidas, por las tardes/mañanas de laburo, por ayudarme en todo lo que pudieron, por estar. Porque siempre que nos reencontramos es como si nos hubiéramos visto ayer. Por toda esta vida compartida juntos, muchas gracias. A Paul Velazco, Miguel Pinto, Noe de la Sancha, Cirene Gutierrez, Luis Escobedo, 
Roberto Rossi, Bárbara Andrade Costa, Daniela Munhoz Rossoni y Patti Pérez por alivianar mis mañanas y tardes de laburo en Estados Unidos. Un agradecimiento especial para Paulito Velazco que se hizo responsable de mi persona, para que me pudiera quedar más horas trabajando en New York. A Silvina Enrietti por bancarme tantos días en su casa cuando buscaba departamento en Buenos Aires y a Andrea y Negro por aclararme las ideas sobre la ciudad. A mis primas Anita, Ceci, Fer y Lilí y a mi compañera de gabinete Barbi, por las charlas/terapia/consejos necesarios para la vida de un becario de Conicet.

Me gustaría agradecer a curadores y técnicos vinculados a las colecciones, por el acceso al material bajo su cuidado y porque siempre me hicieron sentir como en casa: A Robert Voss y Eileen Westwig del American Museum of Natural History; a Martín Monteverde del Centro de ecología aplicada de Neuquén, a Sergio Bogan y Yolanda Davies de la Colección Félix de Azara, A Ricardo Ojeda y Agustina Ojeda de la Colección de Mamíferos Iadiza; Rubén Barquez y Mónica Díaz de la Colección de Mamíferos Lillo; a Ulyses Pardiñas de la Colección del Centro Nacional Patagónico, a Bruce Patterson y Bill Stanley del Field Museum of Natural History, a Emma Casanave, Mauro Lucherini y Estela Luengos de la Colección del Grupo de Ecología Comportamental de Mamíferos; a Gabriel Martin y Mauro Schiaffini de la Colección de Mamíferos del Laboratorio de Investigaciones en Evolución y Biodiversidad, A David Flores y Sergio Lucero del Museo Argentino de Ciencias Naturales Bernardino Rivadavia, a Marcelo Carrera por el acceso a su colección en Puerto Madryn, a Diego Verzi e Itatí Olivares del Museo de La Plata, a Damián Romero y Natalia Martino del Museo Municipal Lorenzo Scaglia; a Enrique Gonzalez del Museo Nacional de Historia Natural, a Kris Helgen y Darrin Lunde del National Museum of Natural History, Smithsonian Institution. También a las personas que tienen lugar de trabajo en esas colecciones y aunque no era su obligación se acercaron a conversar, a convidar un mate, un cafecito, algo rico, y que hicieron que la experiencia de laburar allí no se sienta un trabajo.

Deseo agradecer a las instituciones y personas que solventaron parcialmente mi investigación: CONICET, ANPCyT (PICT 2011-307), Field Museum of Natural History, Smithsonian Institution. A Bruce Patterson y Kris Helgen por ser mis sponsors en las presentaciones a premios de afuera y comprometerse en serio con esa tarea. A la Facultad de Ciencias Naturales y Museo, Universidad Nacional de La Plata, en especial, a la Secretaría de Postgrado por el trabajo realizado.

Quiero agradecer especialmente a Sergio Vizcaíno por prestarme el microscribe cuando comencé a trabajar en 3 dimensiones, a Iván Pérez por permitir que yo tome

$$
\sim \text { ii }
$$


una clase práctica con el microscribe de su laboratorio. A los que destinaron su valioso tiempo como Alicia Alvarez que me enseñó a usarlo y a armar los archivos, a Guille Cassini que creó scripts para resolver mis problemas, me ayudó con los análisis, con los gráficos, y me enseñó mucho, tomándose mañanas y tardes enteras para mis asuntos. A Noe de la Sancha que tomó nuevamente fotos que yo había extraviado y eran muy importantes para mí. A David Flores por su ayuda con el resumen y a Amelia Chemisquy por su ayuda con el inglés del abstract. A Néstor Toledo que siempre se tomó el tiempo de responder mis dudas sobre terminología anatómica. A los que me ayudaron consiguiéndome bibliografía que necesitaba como Miriam Morales, Sergio Lucero, Alejandra Hurtado, Gregor Breton y Néstor Toledo. A Néstor López que compartió información del ejemplar de Leopardus geoffroyi que vivió con él, y a Miriam Morales que compartió fotografías propias de especímenes que me sirvieron mucho. A María Sandoval y Miriam Morales por la ayuda con la edición de muchas de las tablas, bibliografía y apéndices de esta tesis y a David Flores por la ayuda con el montaje de las fotos de los cráneos, los MannWhitney y sus correcciones, y su invaluable paciencia en el momento de la impresión. Muchas gracias Néstor Toledo, Guillermo Cassini, Amelia Chemisquy, Daniela Castro, Sergio Lucero y David Flores por las discusiones que enriquecieron esta tesis. Muchísimas gracias a los docentes y colegas que me inspiraron y alentaron: Aldo Vasallo, Guillermo Rougier, Fernando Abdala, Iván Pérez, Luis Marone y Analía Forasiepi.

\section{TODOS fueron muy generosos conmigo!}

Finalmente, a mi novio, mi marido, mi compañero el Turco, por ser mi sostén y contención, por despertarme de mi letargo y ponerme a andar, por compartir conmigo a las dos mujeres más importantes de su vida (Emita y Zoe a quienes amo), por ayudarme en todo lo que necesité siempre, dejando de lado sus cosas para hacerle un tiempito a las mías, por su aliento infinito. Nada de esto hubiera sido posible sin vos.

Dedico esta tesis a los cánidos y félidos que formaron parte de mi vida, en especial a los 3 fantásticos: Ash, Filothe y Rogelia. 


\section{ÍNDICE}

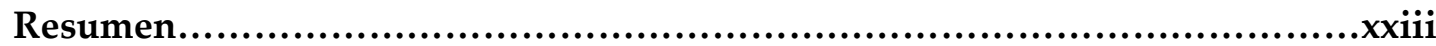

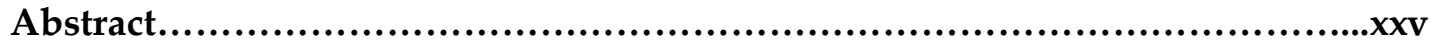

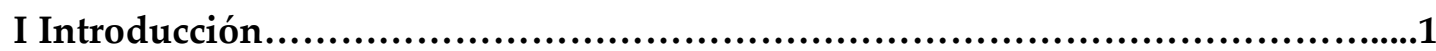

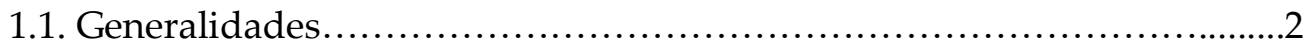

1.2. Familia Canidae..........................................................

1.3. Familia Felidae.....................................................6

1.4. Ontogenia craneana: Antecedentes................................... 8

1.5. Funcionalidad y patrones evolutivos................................11

1.6. Objetivos generales...................................................

1.7. Objetivos particulares...............................................13

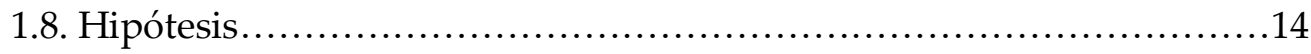

II Materiales y métodos..........................................................15

2.1. Especímenes............................................................ 16

2.2. Consideraciones taxonómicas.........................................17

2.3. Consideraciones acerca de la terminología anatómica....................18

2.4. Caracterización de la muestra........................................19

2.5. Clases de edad..................................................20

2.5.1. Clases de edad para cánidos...............................21

2.5.2. Clases de edad para félidos...................................21

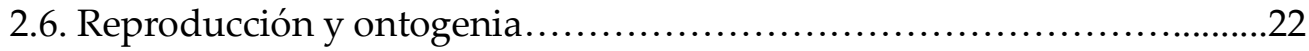

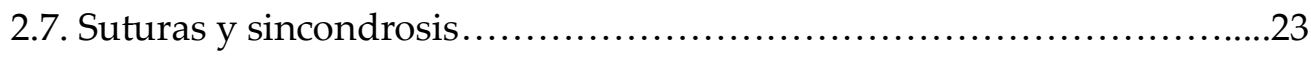

2.8. Análisis cualitativo de las suturas y sincondrosis.........................25

2.9. Medidas craneanas...................................................26

2.10. Análisis multivariado..............................................26

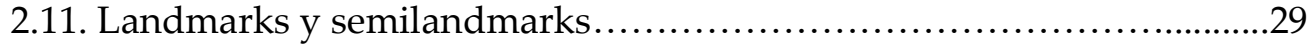

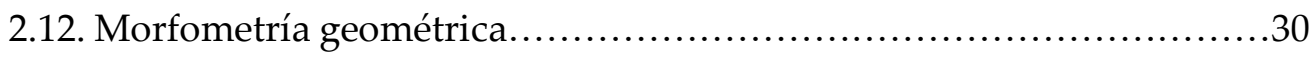

2.13. Variación alométrica de la forma....................................31 
2.14. Tamaño de centroide y distancia de Procrustes.........................32

2.15. Cambio de tamaño y de forma durante la ontogenia...................32

2.16. Medidas de ventaja mecánica.......................................33

2.17. Análisis de Ventajas mecánicas........................................34

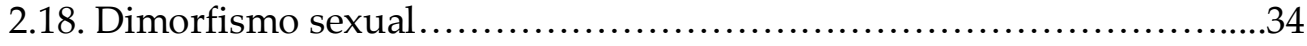

2.19. "Caracteres" ontogenéticos.......................................

2.20. Mapeo de caracteres y señal filogenética.............................37

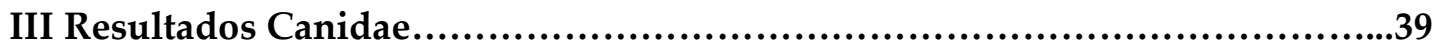

3.1. Atelocynus microtis.................................................40

3.1.1. Reproducción y ontogenia....................................40

3.1.2. Suturas y sincondrosis....................................40

3.1.3. Análisis multivariado.........................................41

3.1.4. Morfometría geométrica................................42

3.1.5. Variación alométrica de la forma.............................43

3.1.6. Cambio de tamaño y de forma durante la ontogenia...............44

3.1.7. Ventajas mecánicas..........................................45

3.2. Cerdocyon thous.................................................46

3.2.1. Reproducción y ontogenia..................................46

3.2.2. Suturas y sincondrosis..........................................

3.2.3. Análisis multivariado.....................................47

3.2.4. Morfometría geométrica...................................48

3.2.5. Variación alométrica de la forma.............................49

3.2.6. Cambio de tamaño y de forma durante la ontogenia............51

3.2.7. Ventajas mecánicas.......................................51

3.3. Chrysocyon brachyurus........................................... 52

3.3.1. Reproducción y ontogenia.................................52

3.3.2. Suturas y sincondrosis...................................53

3.3.3. Análisis multivariado.......................................53

$$
\sim \mathrm{V} \sim
$$


3.3.4. Morfometría geométrica....................................54

3.3.5. Variación alométrica de la forma.............................55

3.3.6. Cambio de tamaño y de forma durante la ontogenia............56

3.3.7. Ventajas mecánicas........................................57

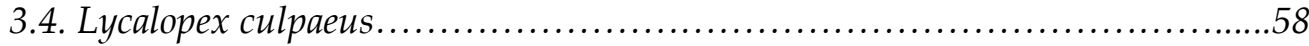

3.4.1. Reproducción y ontogenia.................................58

3.4.2. Suturas y sincondrosis.....................................59

3.4.3. Análisis multivariado.......................................59

3.4.4. Morfometría geométrica....................................60

3.4.5. Variación alométrica de la forma.............................61

3.4.6. Cambio de tamaño y de forma durante la ontogenia............62

3.4.7. Ventajas mecánicas.........................................63

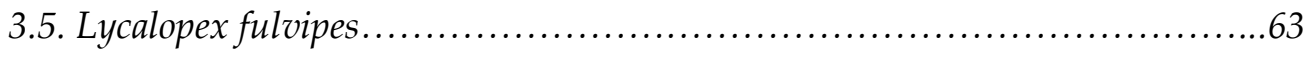

3.5.1. Reproducción y ontogenia...................................63

3.5.2. Suturas y sincondrosis...................................64

3.6. Lycalopex griseus.................................................65

3.6.1. Reproducción y ontogenia...................................65

3.6.2. Suturas y sincondrosis...................................65

3.6.3. Análisis multivariado.........................................66

3.6.4. Morfometría geométrica..................................67

3.6.5. Variación alométrica de la forma.............................68

3.6.6. Cambio de tamaño y de forma durante la ontogenia............69

3.6.7. Ventajas mecánicas.........................................70

3.7. Lycalopex gymnocercus...........................................71

3.7.1. Reproducción y ontogenia.................................71

3.7.2. Suturas y sincondrosis..................................71

3.7.3. Análisis multivariado....................................72

3.7.4. Morfometría geométrica.................................73 
3.7.5. Variación alométrica de la forma...........................73

3.7.6. Cambio de tamaño y de forma durante la ontogenia............74

3.7.7. Ventajas mecánicas..........................................75

3.8. Lycalopex sechurae..............................................76

3.8.1. Reproducción y ontogenia...................................76

3.8.2. Suturas y sincondrosis...................................

3.8.3. Análisis multivariado.......................................77

3.8.4. Morfometría geométrica..................................78

3.8.5. Variación alométrica de la forma.............................79

3.8.6. Cambio de tamaño y de forma durante la ontogenia.............80

3.8.7. Ventajas mecánicas........................................80

3.9. Lycalopex vetulus................................................ 81

3.9.1. Reproducción y ontogenia.................................81

3.9.2. Suturas y sincondrosis.................................... 82

3.9.3. Análisis multivariado........................................82

3.9.4. Morfometría geométrica..................................83

3.9.5. Variación alométrica de la forma.............................84

3.9.6. Cambio de tamaño y de forma durante la ontogenia............84

3.9.7. Ventajas mecánicas.........................................85

3.10. Speothos venaticus................................................. 85

3.10.1. Reproducción y ontogenia...................................85

3. 10.2. Suturas y sincondrosis.................................. 86

3. 10.3. Análisis multivariado....................................87

3. 10.4. Morfometría geométrica.................................88

3. 10.5. Variación alométrica de la forma.............................89

3. 10.6. Cambio de tamaño y de forma durante la ontogenia...........90

3. 10.7. Ventajas mecánicas....................................90

3.11. Urocyon cinereoargenteus...........................................91 
3. 11.1. Reproducción y ontogenia..............................91

3. 11.2. Suturas y sincondrosis................................92

3. 11.3. Análisis multivariado......................................92

3. 11.4. Morfometría geométrica................................93

3. 11.5. Variación alométrica de la forma...........................94

3. 11.6. Cambio de tamaño y de forma durante la ontogenia...........95

3. 11.7. Ventajas mecánicas.........................................96

IV Resultados Felidae........................................................97

4.1. Leopardus colocolo.................................................98

4.1.1. Reproducción y ontogenia...................................99

4.1.2. Suturas y sincondrosis..................................98

4.1.3. Análisis multivariado..........................................99

4.1.4. Morfometría geométrica..................................100

4.1.5. Variación alométrica de la forma............................101

4.1.6. Cambio de tamaño y de forma durante la ontogenia............102

4.1.7. Ventajas mecánicas...........................................104

4.2. Leopardus geoffroyi.................................................. 104

4.2.1. Reproducción y ontogenia..................................104

4.2.2. Suturas y sincondrosis.....................................105

4.2.3. Análisis multivariado.....................................106

4.2.4. Morfometría geométrica...................................107

4.2.5. Variación alométrica de la forma............................108

4.2.6. Cambio de tamaño y de forma durante la ontogenia............109

4.2.7. Ventajas mecánicas.......................................111

4.3. Leopardus guigna............................................... 112

4.3.1. Reproducción y ontogenia.................................112

4.3.2. Suturas y sincondrosis..................................112

4.3.3. Análisis multivariado.....................................113 
4.3.4. Morfometría geométrica..................................114

4.3.5. Variación alométrica de la forma.............................115

4.3.6. Cambio de tamaño y de forma durante la ontogenia............116

4.3.7. Ventajas mecánicas......................................117

4.4. Leopardus jacobita................................................117

4.4.1. Reproducción y ontogenia................................117

4.4.2. Suturas y sincondrosis.....................................118

4.5. Leopardus pardalis................................................118

4.5.1. Reproducción y ontogenia.................................118

4.5.2. Suturas y sincondrosis....................................120

4.5.3. Análisis multivariado........................................121

4.5.4. Morfometría geométrica..................................122

4.5.5. Variación alométrica de la forma.............................123

4.5.6. Cambio de tamaño y de forma durante la ontogenia............124

4.5.7. Ventajas mecánicas......................................125

4.6. Leopardus tigrinus................................................ 126

4.6.1. Reproducción y ontogenia.................................126

4.6.2. Suturas y sincondrosis.....................................127

4.6.3. Análisis multivariado......................................127

4.6.4. Morfometría geométrica.................................128

4.6.5. Variación alométrica de la forma............................129

4.6.6. Cambio de tamaño y de forma durante la ontogenia............130

4.6.7. Ventajas mecánicas.........................................131

4.7. Leopardus wiedii.................................................. 132

4.7.1. Reproducción y ontogenia...................................132

4.7.2. Suturas y sincondrosis....................................133

4.7.3. Análisis multivariado.....................................134

4.7.4. Morfometría geométrica..................................134 
4.7.5. Variación alométrica de la forma...........................135

4.7.6. Cambio de tamaño y de forma durante la ontogenia............137

4.7.7. Ventajas mecánicas.........................................138

4.8. Herpailurus yagouaroundi........................................ 138

4.8.1. Reproducción y ontogenia..................................138

4.8.2. Suturas y sincondrosis...................................139

4.8.3. Análisis multivariado........................................140

4.8.4. Morfometría geométrica...................................141

4.8.5. Variación alométrica de la forma.............................142

4.8.6. Cambio de tamaño y de forma durante la ontogenia............143

4.8.7. Ventajas mecánicas......................................144

4.9. Puma concolor .................................................... 144

4.9.1. Reproducción y ontogenia...............................144

4.9.2. Suturas y sincondrosis.....................................146

4.9.3. Análisis multivariado.....................................146

4.9.4. Morfometría geométrica....................................147

4.9.5. Variación alométrica de la forma...........................148

4.9.6. Cambio de tamaño y de forma durante la ontogenia............149

4.9.7. Ventajas mecánicas.........................................150

4.10. Panthera onca..................................................151

4.10.1. Reproducción y ontogenia..................................151

4.10.2. Suturas y sincondrosis.................................152

4.10.3. Análisis multivariado.......................................152

4.10.4. Morfometría geométrica................................153

4.10.5. Variación alométrica de la forma.............................154

4.10.6. Cambio de tamaño y de forma durante la ontogenia..........155

4.10.7. Ventajas mecánicas......................................156

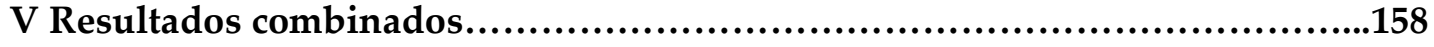


5.1. Análisis de morfometría geométrica.

5.1.1. Análisis de morfometría geométrica en cráneos y mandíbulas

de cánidos 159

5.1.2. Análisis de morfometría geométrica en cráneos y mandíbulas de félidos. .161

5.1.3. Análisis combinado de morfometría geométrica en cráneos y mandíbulas de las Familias Canidae y Felidae..............................163

5.2. Análisis filogenéticos. Mapeos......................................165

5.2.1. Intervalos de confianza......................................165

5.2.2. Suturas: Considerando la semi-fusión como no fusión.........169

5.2.3. Suturas: Considerando la semi-fusión como fusión.............170

5.2.4. Crecimiento y desarrollo definitivos..........................173

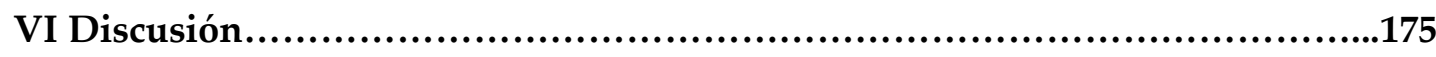

6.1. Aspectos funcionales y estructurales................................176

6.1.1. El Cráneo como un todo. División funcional.....................176

6.1.2. Crecimiento y desarrollo de la caja craneana..................177

6.1.3. Crecimiento y desarrollo de la placa occipital..................180

6.1.4. Crecimiento y desarrollo del basicráneo......................183

6.1.5. Crecimiento y desarrollo de las cápsulas sensoriales y estructuras que las alojan: Órbitas, bullas, nasales...........................185

6.1.6. Crecimiento y desarrollo del rostro y paladar....................188

6.1.7. Crecimiento y desarrollo del aparato masticatorio:

Musculatura.

6.1.8. Crecimiento y desarrollo del aparato masticatorio:

Mandíbula

6.1.9. Crecimiento y desarrollo del aparato masticatorio: Ventajas

mecánicas............................................................196

6.1.10. Crecimiento y desarrollo del cráneo como un todo.............197 
6.2. Aspectos evolutivos.............................................200

6.2.1. Comparación inter-Familias..............................200

6.2.2. Comparación intra-Familia Canidae..........................207

6.2.3. Comparación intra-Familia Felidae........................211

VII Conclusiones..........................................................216

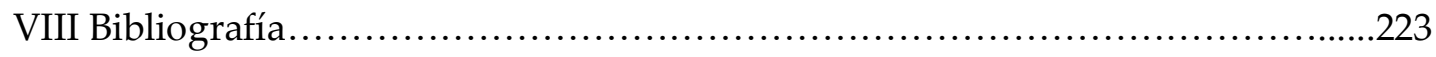

LISTA DE APÉNDICES, TABLAS Y FIGURAS...............................247

Apéndices.......................................................................247

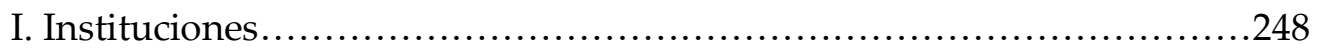

II. Material examinado..................................................249

III. Abreviaturas anatómicas..........................................259

IV. Suturas y sincondrosis.........................................261

V. Medidas craneanas y mandibulares................................264

VI. Landmarks y semilandmarks ....................................265

VII. Matriz de intervalos de confianza................................267

VIII. Matriz de edad de fusión de suturas (tomando la semi-fusión como no

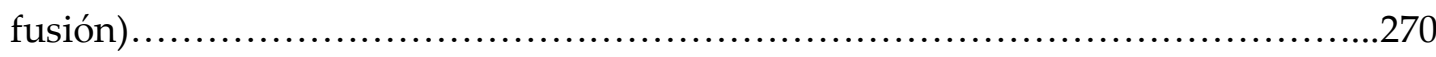

IX. Matriz de edad de fusión de suturas (tomando la semi-fusión como

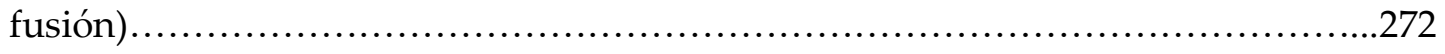

X. Matriz de edad de crecimiento y desarrollo definitivos.................274

XI. Árbol Filogenético incluyendo las especies Neotropicales de las Familias Canidae y Felidae......................................................... 275

XII. Mapeos de Intervalos de confianza (sobre el árbol del apéndice XI)...2276

XII. (continuación) Mapeos de fusión de suturas (tomando la semi-fusión

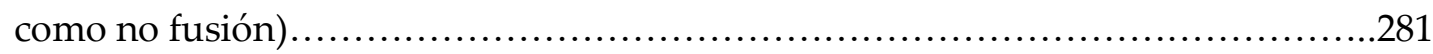


XII. (continuación) Mapeos de fusión de suturas (tomando la semi-fusión como fusión) .283

XII. (continuación) Mapeos de edad de crecimiento y desarrollo definitivos .287

Tablas .288

1. Clases de edad, erupción y recambio dentario para la Familia Canidae .288

2. Clases de edad, erupción y recambio dentario para la Familia Felidae .291

3. Atelocynus microtis. Suturas y sincondrosis 293

4. Atelocynus microtis. Alometría multivariada..............................295

5. Atelocynus microtis. Test U de Mann Whitney............................297

6. Cerdocyon thous. Suturas y sincondrosis...............................299

7. Cerdocyon thous. Alometría multivariada..................................301

8. Cerdocyon thous. Test U de Mann Whitney ................................303

9. Chrysocyon brachyurus. Suturas y sincondrosis..........................306

10. Chrysocyon brachyurus. Alometría multivariada..........................308

11. Chrysocyon brachyurus. Test U de Mann Whitney.........................310

12. Lycalopex culpaeus. Suturas y sincondrosis.............................312

13. Lycalopex culpaeus. Alometría multivariada.............................314

14. Lycalopex culpaeus. Test U de Mann Whitney............................316

15. Lycalopex fulvipes. Suturas y sincondrosis..............................319

16. Lycalopex griseus. Suturas y sincondrosis..............................321

17. Lycalopex griseus. Alometría multivariada...............................323

18. Lycalopex griseus. Test U de Mann Whitney...............................325 
19. Lycalopex gymnocercus. Suturas y sincondrosis........................327

20. Lycalopex gymnocercus. Alometría multivariada..........................329

21. Lycalopex gymnocercus. Test U de Mann Whitney.........................331

22. Lycalopex sechurae. Suturas y sincondrosis.............................335

23. Lycalopex sechurae. Alometría multivariada.............................337

24. Lycalopex sechurae. Test U de Mann Whitney.............................339

25. Lycalopex vetulus. Suturas y sincondrosis.............................341

26. Lycalopex vetulus. Alometría multivariada..............................343

27. Speothos venaticus. Suturas y sincondrosis............................345

28. Speothos venaticus. Alometría multivariada............................347

29. Speothos venaticus. Test U de Mann Whitney..............................349

30. Urocyon cinereoargenteus. Suturas y sincondrosis.......................351

31. Urocyon cinereoargenteus. Alometría multivariada.......................353

32. Urocyon cinereoargenteus. Test U de Mann Whitney.......................355

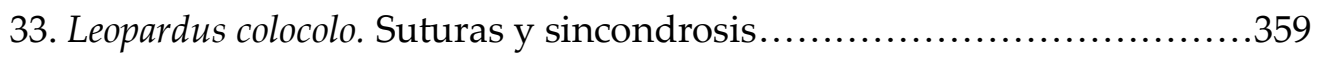

34. Leopardus colocolo. Alometría multivariada.............................361

35. Leopardus colocolo. Test U de Mann Whitney...............................363

36. Leopardus geoffroyi. Suturas y sincondrosis............................364

37. Leopardus geoffroyi. Alometría multivariada............................366

38. Leopardus geoffroyi. Test U de Mann Whitney...........................368

39. Leopardus guigna. Suturas y sincondrosis............................370

40. Leopardus guigna. Alometría multivariada............................372

41. Leopardus guigna. Test U de Mann Whitney............................374 
42. Leopardus jacobita. Suturas y sincondrosis............................375

43. Leopardus pardalis. Suturas y sincondrosis.............................377

44. Leopardus pardalis. Alometría multivariada.............................379

45. Leopardus pardalis. Test U de Mann Whitney.............................381

46. Leopardus tigrinus. Suturas y sincondrosis.............................385

47. Leopardus tigrinus. Alometría multivariada............................387

48. Leopardus tigrinus. Test U de Mann Whitney............................389

49. Leopardus wiedii. Suturas y sincondrosis................................391

50. Leopardus wiedii. Alometría multivariada.............................393

51. Leopardus wiedii. Test U de Mann Whitney..............................395

52. Herpailurus yagouaroundi. Suturas y sincondrosis.......................397

53. Herpailurus yagouaroundi. Alometría multivariada.......................399

54. Herpailurus yagouaroundi. Test U de Mann Whitney.....................401

55. Puma concolor. Suturas y sincondrosis...............................404

56. Puma concolor. Alometría multivariada................................406

57. Puma concolor. Test U de Mann Whitney...............................408

58. Panthera onca. Suturas y sincondrosis...............................410

59. Panthera onca. Alometría multivariada..............................412

60. Panthera onca. Test U de Mann Whitney...............................414

61. Señal filogenética de los intervalos de confianza......................416

62. Señal filogenética para suturas y sincondrosis (Fusión).................416

63. Señal filogenética para suturas y sincondrosis (Semifusión)............417

64. Señal filogenética para los arribos a la forma y tamaño definitivos...........................................................4 418 
Figuras.........................................................................420

1. Dentición de jóvenes y adultos.......................................420

2. Medidas craneanas..................................................421

3. Landmarks y semilandmarks....................................422

4. Línea temporal para cánidos y félidos...................................423

5. Atelocynus microtis. Suturas y sincondrosis...........................444

6. Atelocynus microtis. Componentes principales.........................435

7. Atelocynus microtis. Variación alométrica de la forma craneal.............436

8. Atelocynus microtis. Variación alométrica de la forma mandibular.......................................................437

9. Atelocynus microtis. Cambio de tamaño y de forma craneal................438

10. Atelocynus microtis. Cambio de tamaño y de forma mandibular..........439

11. Atelocynus microtis. Ventajas mecánicas..............................440

12. Cerdocyon thous. Suturas y sincondrosis..............................441

13. Cerdocyon thous. Componentes principales...........................442

14. Cerdocyon thous. Variación alométrica de la forma craneal...............443

15. Cerdocyon thous. Variación alométrica de la forma mandibular...........444

16. Cerdocyon thous. Cambio de tamaño y de forma craneal..................445

17. Cerdocyon thous. Cambio de tamaño y de forma mandibular..............446

18. Cerdocyon thous. Ventajas mecánicas................................447

19. Chrysocyon brachyurus. Suturas y sincondrosis........................448

20. Chrysocyon brachyurus. Componentes principales......................449

21. Chrysocyon brachyurus. Variación alométrica de la forma craneal........450 
22. Chrysocyon brachyurus. Variación alométrica de la forma mandibular.

23. Chrysocyon brachyurus. Cambio de tamaño y de forma craneal.

24. Chrysocyon brachyurus. Cambio de tamaño y de forma mandibular. 453

25. Chrysocyon brachyurus. Ventajas mecánicas .454

26. Lycalopex culpaeus. Suturas y sincondrosis .455

27. Lycalopex culpaeus. Componentes principales. .456

28. Lycalopex culpaeus. Variación alométrica de la forma craneal. .457

29. Lycalopex culpaeus. Variación alométrica de la forma mandibular. .458

30. Lycalopex culpaeus. Cambio de tamaño y de forma craneal .459

31. Lycalopex culpaeus. Cambio de tamaño y de forma mandibular .460

32. Lycalopex culpaeus. Ventajas mecánicas .461

33. Lycalopex fulvipes. Suturas y sincondrosis... .462

34. Lycalopex griseus. Suturas y sincondrosis 463

35. Lycalopex griseus. Componentes principales...........................464

36. Lycalopex griseus. Variación alométrica de la forma craneal...............465

37. Lycalopex griseus. Variación alométrica de la forma mandibular..........466

38. Lycalopex griseus. Cambio de tamaño y de forma craneal.................467

39. Lycalopex griseus. Cambio de tamaño y de forma mandibular.............468

40. Lycalopex griseus. Ventajas mecánicas.....................................469

41. Lycalopex gymnocercus. Suturas y sincondrosis........................470

42. Lycalopex gymnocercus. Componentes principales.......................471

43. Lycalopex gymnocercus. Variación alométrica de la forma craneal 472 
44. Lycalopex gymnocercus. Variación alométrica de la forma mandibular.......................................................473

45. Lycalopex gymnocercus. Cambio de tamaño y de forma craneal...........474

46. Lycalopex gymnocercus. Cambio de tamaño y de forma mandibular .475

47. Lycalopex gymnocercus. Ventajas mecánicas.............................476

48. Lycalopex sechurae. Suturas y sincondrosis...........................477

49. Lycalopex sechurae. Componentes principales.........................478

50. Lycalopex sechurae. Variación alométrica de la forma craneal.............479

51. Lycalopex sechurae. Variación alométrica de la forma mandibular........480

52. Lycalopex sechurae. Cambio de tamaño y de forma craneal...............481

53. Lycalopex sechurae. Cambio de tamaño y de forma mandibular...........482

54. Lycalopex sechurae. Ventajas mecánicas...............................483

55. Lycalopex vetulus. Suturas y sincondrosis.............................484

56. Lycalopex vetulus. Componentes principales..........................485

57. Lycalopex vetulus. Variación alométrica de la forma craneal..............486

58. Lycalopex vetulus. Variación alométrica de la forma mandibular.........487

59. Lycalopex vetulus. Cambio de tamaño y de forma craneal.................488

60. Lycalopex vetulus. Cambio de tamaño y de forma mandibular............489

61. Lycalopex vetulus. Ventajas mecánicas................................490

62. Speothos venaticus. Suturas y sincondrosis...........................491

63. Speothos venaticus. Componentes principales.........................492

64. Speothos venaticus. Variación alométrica de la forma craneal............493

65. Speothos venaticus. Variación alométrica de la forma mandibular........494 
66. Speothos venaticus. Cambio de tamaño y de forma craneal...............495

67. Speothos venaticus. Cambio de tamaño y de forma mandibular...........496

68. Speothos venaticus. Ventajas mecánicas...............................497

69. Urocyon cinereoargenteus. Suturas y sincondrosis......................498

70. Urocyon cinereoargenteus. Componentes principales......................499

71. Urocyon cinereoargenteus. Variación alométrica de la forma craneal.....500

72. Urocyon cinereoargenteus. Variación alométrica de la forma mandibular..........................................................501

73. Urocyon cinereoargenteus. Cambio de tamaño y de forma craneal........502

74. Urocyon cinereoargenteus. Cambio de tamaño y de forma mandibular.......................................................503

75. Urocyon cinereoargenteus. Ventajas mecánicas...........................504

76. Leopardus colocolo. Suturas y sincondrosis.............................505

77. Leopardus colocolo. Componentes principales............................506

78. Leopardus colocolo. Variación alométrica de la forma craneal.............507

79. Leopardus colocolo. Variación alométrica de la forma mandibular.........508

80. Leopardus colocolo. Cambio de tamaño y de forma craneal................509

81. Leopardus colocolo. Cambio de tamaño y de forma mandibular...........510

82. Leopardus colocolo. Ventajas mecánicas.................................511

83. Leopardus geoffroyi. Suturas y sincondrosis...........................512

84. Leopardus geoffroyi. Componentes principales..........................513

85. Leopardus geoffroyi. Variación alométrica de la forma craneal.............514

86. Leopardus geoffroyi. Variación alométrica de la forma mandibular....................................................... 515

87. Leopardus geoffroyi. Cambio de tamaño y de forma craneal...............516

$$
\sim \text { xix } ~
$$


88. Leopardus geoffroyi. Cambio de tamaño y de forma mandibular 517

89. Leopardus geoffroyi. Ventajas mecánicas.................................518

90. Leopardus guigna. Suturas y sincondrosis..............................519

91. Leopardus guigna. Componentes principales.........................520

92. Leopardus guigna. Variación alométrica de la forma craneal..............521

93. Leopardus guigna. Variación alométrica de la forma mandibular........522

94. Leopardus guigna. Cambio de tamaño y de forma craneal.................523

95. Leopardus guigna. Cambio de tamaño y de forma mandibular............524

96. Leopardus guigna. Ventajas mecánicas................................5525

97. Leopardus jacobita. Suturas y sincondrosis...........................5 526

98. Leopardus pardalis. Suturas y sincondrosis...........................527

99. Leopardus pardalis. Componentes principales..........................528

100. Leopardus pardalis. Variación alométrica de la forma craneal............529

101. Leopardus pardalis. Variación alométrica de la forma

mandibular........................................................5 530

102. Leopardus pardalis. Cambio de tamaño y de forma craneal...............531

103. Leopardus pardalis. Cambio de tamaño y de forma mandibular.........532

104. Leopardus pardalis. Ventajas mecánicas................................533

105. Leopardus tigrinus. Suturas y sincondrosis..........................534

106. Leopardus tigrinus. Componentes principales........................535

107. Leopardus tigrinus. Variación alométrica de la forma craneal............536

108. Leopardus tigrinus. Variación alométrica de la forma mandibular.......537

109. Leopardus tigrinus. Cambio de tamaño y de forma craneal...............538 
110. Leopardus tigrinus. Cambio de tamaño y de forma mandibular..........................................................539

111. Leopardus tigrinus. Ventajas mecánicas.................................540

112. Leopardus wiedii. Suturas y sincondrosis..............................541

113. Leopardus wiedii. Componentes principales...........................542

114. Leopardus wiedii. Variación alométrica de la forma craneal..............543

115. Leopardus wiedii. Variación alométrica de la forma mandibular.........544

116. Leopardus wiedii. Cambio de tamaño y de forma craneal.................545

117. Leopardus wiedii. Cambio de tamaño y de forma mandibular............546

118. Leopardus wiedii. Ventajas mecánicas..................................547

119. Herpailurus yagouaroundi. Suturas y sincondrosis......................548

120. Herpailurus yagouaroundi. Componentes principales....................549

121. Herpailurus yagouaroundi. Variación alométrica de la forma craneal....550

122. Herpailurus yagouaroundi. Variación alométrica de la forma mandibular................................................................551

123. Herpailurus yagouaroundi. Cambio de tamaño y de forma craneal.......552

124. Herpailurus yagouaroundi. Cambio de tamaño y de forma mandibular............................................................ 553

125. Herpailurus yagouaroundi. Ventajas mecánicas...........................554

126. Puma concolor. Suturas y sincondrosis..............................555

127. Puma concolor. Componentes principales.............................556

128. Puma concolor. Variación alométrica de la forma craneal...............557

129. Puma concolor. Variación alométrica de la forma mandibular...........558

130. Puma concolor. Cambio de tamaño y de forma craneal.................559

131. Puma concolor. Cambio de tamaño y de forma mandibular.............560

$$
\sim \mathrm{xxi} \sim
$$


132. Puma concolor. Ventajas mecánicas.....................................561

133. Panthera onca. Suturas y sincondrosis..............................562

134. Panthera onca. Componentes principales............................563

135. Panthera onca. Variación alométrica de la forma craneal................564

136. Panthera onca. Variación alométrica de la forma mandibular...........565

137. Panthera onca. Cambio de tamaño y de forma craneal...................566

138. Panthera onca. Cambio de tamaño y de forma mandibular...............567

139. Panthera onca. Ventajas mecánicas....................................568

140. Componentes principales de cráneos en la Familia Canidae............569

141. Componentes principales de mandíbulas en la Familia Canidae........570

142. Componentes principales de cráneos en la Familia Felidae.............571

143. Componentes principales de mandíbulas en la Familia Felidae........572

144. Componentes principales de cráneos incluyendo Familia Canidae y

Felidae...............................................................573

145. Componentes principales de mandíbulas incluyendo Familia Canidae y

Felidae..........................................................5 574

146. Sinapomorfías de Intervalos de confianza...........................575

147. Sinapomorfías de suturas y sincondrosis (tomando la semi-fusión como

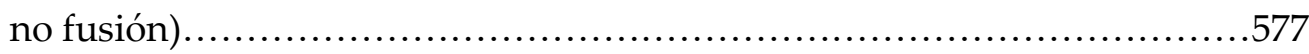

148. Sinapomorfías de suturas y sincondrosis (tomando la semi-fusión como

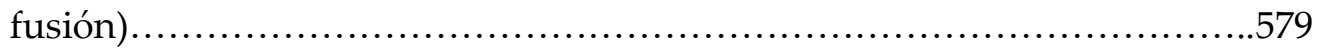

149. Sinapomorfías de edad de crecimiento y desarrollo definitivos........581

150. Porcentaje de fusión de suturas y sincondrosis en Familia Canidae....582

151. Porcentaje de fusión de suturas y sincondrosis en Familia Felidae......582 


\section{RESUMEN}

En la región Neotropical, los dos grandes Subórdenes del Orden Carnivora, Caniformia y Feliformia, se encuentran muy bien representados por las Familias Canidae y Felidae, con 11 y 10 especies respectivamente. En esta región, ingresaron en su mayoría durante el Mioceno-Pleistoceno, por lo que representan un grupo alóctono. Los cánidos y félidos representan morfotipos que ocupan diferentes lugares en el espacio morfológico, aunque su rol ecológico como depredadores es muchas veces similar en diferentes ecosistemas. Ambos forman grupos monofiléticos con robustas filogenias disponibles con información molecular, morfológica y combinada e incluyen linajes que evolucionaron puramente en el Neotrópico (e.g. Lycalopex, Leopardus).

Los cánidos tienen un cráneo alargado, con un rostro y mandíbula largos, donde se ubica una dentición uniforme y no especializada, con una fórmula dentaria no reducida, en relación al plan ancestral de los Carnivora. Poseen dietas muy versátiles, variando desde carnívoros estrictos (hiper-carnívoros), hasta especies omnívoras. Los félidos presentan cráneos más cortos y robustos, con dentición altamente reducida, que se ubica en un rostro y una mandíbula breves, lo cual les permite mejorar la eficiencia de la musculatura masticatoria y tener una de las mordidas más poderosas entre los carnívoros. Son muy variables en cuanto a tamaño, aunque no en cuanto a la dieta, ya que todos son hiper-carnívoros. Sin embargo, las 2 Familias sufren grandes modificaciones en sus cráneos y mandíbulas desde que son juveniles y lactantes, hasta que son adultos y predadores activos. Por estos motivos, resultó interesante estudiar las tendencias ontogenéticas del cráneo y la mandíbula en la Familia Canidae y Felidae de la región Neotropical, desde una perspectiva cualitativa y cuantitativa. Se buscó detectar si los cambios ontogenéticos principales son explicables por ancestralidad común y están asociados a determinados clados, o si tienen un correlato funcional asociado al cambio de dieta que presentan las distintas especies durante la ontogenia.

$$
\sim \text { xxiii }
$$


Con este fin, se colectó información de cráneos y mandíbulas de 1367 cánidos y 1218 félidos Neotropicales, cubriendo la totalidad de especies en esta región. Además se recopilaron datos de 93 ejemplares de cánidos y 630 de félidos de otras regiones zoogeográficas para ampliar la muestra taxonómica. Como la edad absoluta no fue un dato disponible para la mayoría de los especímenes comprendidos en esta muestra, se los agrupó en clases de edad. Se realizaron: Análisis cualitativos de 42 suturas y sincondrosis, determinado grado de fusión y cambio de tipo; análisis de alometría multivariada de 22 medidas craneanas y mandibulares; análisis de componentes principales de 38 landmarks craneales y 18 mandibulares; regresiones multivariadas entre el tamaño (tamaño de centroide logtransformado) y la forma (distancia de Procrustes); obtención del tamaño de centroide (como proxi de tamaño) y distancia de Procrustes (como proxi de forma) y generación de gráficos de boxplots que permitieran conocer las clases de edad en donde se detiene el crecimiento y el desarrollo; análisis de ventajas mecánicas de 5 medidas craneanas y mandibulares; mapeos de intervalos de confianza, suturas y de edad de crecimiento y desarrollo definitivos, y obtención de señal filogenética.

Se observó que conforme aumentó la edad de los individuos, las suturas y sincondrosis aumentaron su grado de fusión y de complejidad, al igual que el tamaño de los músculos masticatorios se incrementó. Las primeras suturas y sincondrosis en fusionarse fueron las correspondientes a la placa occipital, y las rostrales fueron las últimas. Para la Familia Canidae, el grado de fusión de suturas estuvo vinculado con la dieta, mientras que para la Familia Felidae, estuvo relacionado con el tamaño. Las medidas neurocraneales y las correspondientes a las cápsulas sensoriales escalaron negativamente, mientras que aquellas vinculadas al esplacnocráneo escalaron positivamente, tanto en cánidos como en félidos. Los juveniles mostraron cráneos redondeados, cortos, anchos y altos, hocicos cortos y anchos, paladares anchos, basicráneos breves y ensanchados y foramen magnum más grande y ventral. Además, presentaron órbitas y bullas más grandes y arcos 
zigomáticos débiles y no expandidos. Las mandíbulas tuvieron el cuerpo mandibular más elongado y ancho, el borde anterior de la fosa masetérica retrasado, la rama mandibular poco desarrollada y estrecha, con los 3 procesos (coronoides, condiloideo y angular) más cortos. El proceso coronoides fue poco desarrollado y dirigido hacia atrás. Los adultos, exhibieron la configuración opuesta. La obtención del tamaño definitivo del cráneo y de la mandíbula fueron sincrónicos, alcanzándose siempre en clases de adultos, mientras que la obtención de la forma definitiva del cráneo y la mandíbula fueron asincrónicos, ocurriendo tanto en las clases de juveniles como en clases de adultos. Cánidos y félidos ocuparon lugares diferentes en el morfo-espacio, de modo tal que tuvieron dos trayectorias completamente diferentes que no se solaparon ni en juveniles ni en adultos, y esto está relacionado con el hecho de que pertenecen a clados diferentes. De esta manera, los factores que dieron forma al cráneo y a la mandíbula estuvieron vinculados con la función, la filogenia, y una serie de factores combinados que incluyeron además a la dieta, el tamaño de presa, el tamaño corporal de los individuos y el modo de vida de éstos.

\footnotetext{
ABSTRACT

In the Neotropical region, the two major suborders of Order Carnivora, Caniformia and Feliformia, are well represented by Families Canidae and Felidae, including 11 and 10 species respectively. This group occupied the Neotropics during the Miocene-Pleistocene, being an allochthonous group. Canids and felids are morphologically different, occupying different places in a multivariate morphospace, although their ecological role as predators in different ecosystems is similar. Both Families form monophyletic groups, supported by robust phylogenies that include molecular, morphological and combined information. They also comprise lineages that evolved exclusively in the Neotropics such as Lycalopex and Leopardus.
} 
Canids have an elongated skull with a large muzzle, where a uniform dentition is placed, with a complete dental formula compared to the ancestral plan of Carnivora. They have versatile diets; from hyper-carnivorous to omnivorous. Felids have short and massive skulls, with a highly reduced dentition that is placed in a short muzzle, allowing to accentuate the masticatory muscles and developing the most powerful bite between carnivores. Felids have a wide variety of sizes, but when it comes to diet they are all hyper-carnivores. However, the two Families exhibit great modifications from juveniles that feed on milk, to adults with active predation. For this reason, it is interesting to study the ontogenetic trends of crania and mandible in the Family Canidae and Felidae of the Neotropical region, from a qualitative and quantitative approach. In this work I intended to demonstrate if the principal ontogenetic changes are explained by common ancestry, or if they are linked to functional demands of the changes on diet observed in all species during ontogeny.

Under this scope, I collected information of 1367 skulls of canids and 1218 of felids from the Neotropics, covering the complete taxonomic diversity of both groups in this Region. I also collected data from 93 canid skulls and 630 felids from other zoogeographic regions, in order to get a more specious taxonomic sample. Because the absolute age was rarely available for most of the analyzed sample, I defined age classes. I conducted qualitative analyses for 42 sutures and synchondroses, determining the levels of fusion and morphological changes; multivariate analyses of allometry for 22 cranial measurements; principal component analyses for 38 cranial and 18 mandibular landmarks; multivariate regressions of size (log expression of centroid size) and shape (Procrustes distance); generation of boxplot graphics of the centroid size (as a size proxy) and Procrustes distance (as a proxy of shape) showing the age stage where growth and development stabilizes; analyses of mechanical advantages of 5 cranial and mandibular measurements; phylogenetic mapping of confidence intervals, sutures 
and ages of definitive growth and development, and calculation of their phylogenetic signal.

As a general pattern, sutures and synchondroses trend to fuse or acquire more complexity with age, in relation to the increment of areas of origin and insertion of masticatory muscles. The first fused sutures and synchondroses were those corresponding to the occipital plate, and the rostral sutures were the latest to fuse. For Canidae, the degree of suture fusion was linked to diet, whereas for Felidae was more related to size. The neurochranial measurements scaled negatively, whereas those linked to the splachnochranium scaled positively both in felids and canids. In general, young showed rounded, short, and broad skulls, with taller and shorter muzzle, wider palate and basichranium, broad and ventrally placed foramen magnum, larger orbits and bullae, and weak and not laterally expanded zygomatic arches. The mandibles showed elongated and wide mandibular body, backwardly oriented anterior border of the masseteric fossa, little developed and closed mandibular ramus, with its three processes (i.e. coronoid, condyloid and angular processes) shorter. The coronoid process was poorly developed and posteriorly directed. Adults showed the opposite configuration. The definitive (i.e. final) size of skull and mandible were synchronic, which was reached always in the adult stages, whereas the definitive shape in cranial and mandible were asynchronous, occurring both in adult and juvenile stages. Canids and felids occupied different places in the multivariate morpho-space, so both groups showed trajectories completely different and not overlapped in juvenile nor adult stages, which is related to belonging to two different clades. In this way, the factors that shaped the cranial and mandible were linked to function, phylogeny, and a series of combined causes such as diet, prey size, body size and natural history. 


\section{INTRODUCCIÓN}

Los animales fueron

Imperfectos,

Largos de cola, tristes

De cabeza.

Poco a poco se fueron

Componiendo,

Haciéndose paisaje,

Adquiriendo lunares, gracia, vuelo. 


\subsection{Generalidades}

Los carnívoros son un grupo de mamíferos extremadamente diverso en tamaño, dieta, comportamiento social, locomoción y patrones de actividad (Meiri et al. 2005). Esta variabilidad está reflejada en sus dientes, y en el tamaño y forma de sus cráneos, que presentan una anatomía especializada para capturar, asir, matar y procesar otros vertebrados (Ewer 1973, Christiansen \& Wroe 2007). Se distribuyen en casi todos los continentes (Redford \& Eisenberg 1992) y, en el Neotrópico, ingresaron en su mayoría durante el Mioceno-Pleistoceno, por lo que representan un grupo alóctono (Soibelzon \& Prevosti 2007). De todas maneras, pudieron encontrar hábitats y nichos disponibles para su radiación adaptativa y esto dio como resultado una fauna Neotropical que abarca una muy completa variedad taxonómica, morfológica y ecológica (Turner \& Antón 1997, Prevosti \& Soibelzon 2012). En esta región, los dos grandes Subórdenes del Orden Carnivora, Caniformia y Feliformia, se encuentran muy bien representados por las Familias Canidae y Felidae, con 11 y 10 especies respectivamente (Wozencraft 2005, Sunquist \& Sunquist 2009).

Las Familias Canidae y Felidae representan morfotipos que ocupan diferentes lugares en el espacio morfológico, lo cual puede evidenciarse en su estructura y biomecánica cráneo-dentaria (e.g. Biknevicius \& Van Valkenburgh 1996), aunque su rol ecológico como depredadores es muchas veces similar en diferentes ecosistemas (Ewer 1973). Ambas forman grupos monofiléticos con robustas filogenias disponibles con información molecular, morfológica y combinada (e.g. Mattern \& Mc Lennan 2000, Lindblad-Toh et al. 2005, Johnson et al. 2006, Prevosti 2006, Sakamoto \& Ruta 2012, Austin et al. 2013) e incluyen linajes que evolucionaron puramente en el Neotrópico (e.g. Lycalopex, Leopardus). Son 
limitados en cuanto a su variación morfológica, pero suficientemente disímiles para mostrar una gran diversidad funcional en aspectos cruciales como la adquisición de recursos alimentarios (Goswami 2010).

Las crías en ambas Familias son altriciales y altamente dependientes del cuidado parental, en distintos niveles, ya que nacen con los ojos cerrados y con coordinación motora y control de la termorregulación muy pobres (Kitchener 1991, Feldman 1993, Webb et al. 1999). Los jóvenes sufren drásticos cambios morfológicos-morfométricos, desde una lactancia funcionalmente restrictiva (Langer 2003), hasta alcanzar en los adultos una morfología craneana adecuada para resistir al alto estrés mecánico impuesto por el tipo de alimentación, que puede diverger hacia dietas más carnívoras u omnívoras. Por otra parte, se producen también modificaciones vinculadas con los patrones de comportamiento relacionados con el aprendizaje de métodos de caza (Ewer 1973, Binder \& Van Valkenburgh 2000). Los depredadores altamente especializados necesitan un tiempo entre el fin de la lactancia y la independencia de las crías, durante el cual los padres deben matar las presas para ellas y enseñarles a cazar, hasta que éstas sean lo suficientemente fuertes y hábiles para alimentarse por sí mismas (Ewer 1973, Fox 1969).

\subsection{Familia Canidae}

Los cánidos modernos, pertenecientes a la subfamilia Caninae, se originaron en Norteamérica durante el Mioceno Tardío, hace 10 millones de años atrás (Prevosti 2009a), con un representante del tamaño de un zorro pequeño, Leptocyon (Wang et al. 2004). Los Caninae estuvieron restringidos en su distribución a Norteamérica hasta el final del Mioceno (6 millones de años atrás), cuando los eventos geológicos como la unión de Asia con Norteamérica, a través de lo que 
actualmente es el estrecho de Bering, y la formación del istmo de Panamá (que unió Norte y Sudamérica) 3 millones de años después, le permitieron dispersarse a nuevos continentes (Berta 1987, Wang et al. 2008). Su dispersión hacia Sudamérica derivó en una gran diversidad de especies (Prevosti 2009a). En la actualidad, los cánidos constituyen la Familia más ampliamente distribuida del orden Carnivora. Incluye 35 especies (36 si se tiene en cuenta al Dingo como una especie separada), presentes en todo el mundo, con excepción de Antártida (Sillero-Zubiri 2009). En la Región Neotropical, los cánidos están desde el Plioceno Tardío y principios del Pleistoceno (+/-2,6 millones de años) e incluyen 11 especies vivientes: Atelocynus microtis, Cerdocyon thous, Chrysocyon brachyurus, Lycalopex culpaeus, Lycalopex fulvipes, Lycalopex griseus, Lycalopex gymnocercus, Lycalopex sechurae, Lycalopex vetulus, Speothos venaticus y Urocyon cinereoargenteus (Wozencraft 2005, SilleroZubiri 2009).

Comparados con la mayoría de los mamíferos, en términos generales, los cánidos tienen grandes camadas y largos períodos de dependencia de las crías (Kleiman \& Eisenberg 1973), comparten el alimento que regurgitan con todos los miembros de su familia y cuidan de los jóvenes (Moehlman 1996). Se caracterizan por tener un comportamiento oportunista, adaptable y gregario, ya que forman manadas con complejos sistemas sociales (Sillero-Zubiri 2009, Goswami 2010). En relación a sus hábitos, los más pequeños tienden a ser nocturnos, mientras que los más grandes tienden a ser diurnos (Sillero-Zubiri 2009).

Los cánidos tienen tamaño variable, aunque esta variación no es tan marcada como en félidos. En algunos casos, esta variabilidad es geográfica y obedece a las diferencias en la posibilidad de obtener comida (Sillero-Zubiri 2009), por ejemplo Vulpes zerda y otros zorros del desierto se encuentran asociados con 
ambientes poco productivos y son pequeños (1 kg, Larivière 2002), mientras que Canis lupus y otros grandes cánidos (80 kg, Mech 1974), están asociados a sitios con mayor abundancia de presas. Las dietas están entre las más versátiles de los carnívoros, variando desde carnívoros estrictos (hiper-carnívoros) hasta algunas especies que contienen menos del 5\% de proteína animal (Sillero-Zubiri 2009). Las especies más pequeñas, en general son omnívoras y comen pequeños mamíferos, aves, reptiles, insectos, frutas y carroña, mientras que las más grandes, son hipercarnívoras (Sillero-Zubiri 2009). La mayoría de sus estrategias de caza, están basadas en matar a sus presas con varias mordidas superficiales en combinación con el trabajo en equipo. Esto les permite acceder a presas de mayor tamaño que su peso corporal individual (Ewer 1973, Biknevicius \& Van Valkenburgh 1996, Van Valkenburgh 1996, Slater \& Van Valkenburgh 2009).

Tienen una morfología craneana característica (Slater \& Van Valkenburgh 2009) y relativamente conservativa (Martin 1996, Wozencraft 1996). Presentan cabezas cónicas, hocicos largos y mandíbulas bien desarrolladas. El cráneo es elongado, con bullas prominentes pero usualmente no infladas, órbitas óseas que no forman un anillo completo, amplios arcos zigomáticos, crestas temporales y sagitales donde se insertan músculos mandibulares, resultando en una efectiva mordida para un depredador (Nowak 2005, Sillero-Zubiri 2009). El rostro es largo y la dentición completa, con los incisivos y caninos ubicados más hacia adelante (Wang et al. 2008). Tienen una dentición no especializada y una fórmula dentaria no reducida en relación al morfotipo ancestral de Carnivora (Moore 1981, Wang et al. 2008, Sillero-Zubiri 2009). La característica más prominente, además de los dientes carniceros (cuarto premolar superior y el primer molar inferior) con los que cortan la carne, es la presencia de molares con superficies para triturar y caninos largos y puntiagudos (Ewer 1973, Biknevicius \& Van Valkenburgh 1996, Van 
Valkenburgh 1996). Al tener un largo rostro, presentan también una cavidad nasal más grande, y de esta manera, presumiblemente enfatizan las funciones olfativas, ya que tienen un excelente sentido del olfato (Wang et al. 2008, Sillero-Zubiri 2009).

\subsection{Familia Felidae}

Su historia evolutiva estuvo marcada por una rápida especiación y una alta tasa de extinción. Todos los félidos modernos descienden de Pseudaelurus spp., que vivió en Asia hace 11 millones de años atrás (Johnson et al. 2006, O’Brien \& Johnson 2007). Se realizaron estudios de ADN de secuencias de 30 genes en todas las especies de félidos vivientes, que determinaron las ramas del árbol filogenético, y técnicas de reloj molecular para establecer cuánto tiempo atrás dos ramas habrían divergido (O’Brien \& Johnson 2007). Estos estudios soportaron la hipótesis de que todas las especies de félidos pueden ser divididas en 8 linajes: Panthera, Bay cat, Caracal, Ocelote, Lynx, Puma, Leopard cat y Gato doméstico (Johnson et al. 2006, O'Brien \& Johnson 2007). En la actualidad, la Familia incluye 37 especies distribuidas en todo el mundo, con excepción de Australasia y las regiones polares (Sunquist \& Sunquist 2009). En el Neotrópico los félidos están presentes desde hace 3-5 millones de años según el reloj molecular (Johnson et al. 2006, O’Brien \& Johnson 2007) e incluyen 10 especies actualmente presentes: Leopardus colocolo, Leopardus geoffroyi, Leopardus guigna, Leopardus jacobitus, Leopardus pardalis, Leopardus tigrinus, Leopardus wiedii, Herpailurus yagouaroundi, Puma concolor y Panthera onca (Wozencraft 2005, Sunquist \& Sunquist 2009). Sin embargo, los registros fósiles más antiguos son del Pleistoceno temprano-Medio (1,8-0,5 millones de años antes del presente), por lo que las fechas obtenidas con datos moleculares pueden ser o sobreestimaciones, o existir un defecto de registro en latitudes bajas de América del Sur. 
En términos generales, los félidos tienen camadas pequeñas y los jóvenes también dependen de sus madres, quienes les llevan las presas que capturan a la madriguera en que viven, y permanecen con ellos hasta que pueden cazar por sí mismos (Leyhausen 1979, Nowak 2005). Aunque la mayoría de ellos son solitarios, están inmersos en un sistema social mantenido por marcas de olor, vocalizaciones y encuentros ocasionales (Sunquist \& Sunquist 2002). Son mayoritariamente crepusculares a nocturnos en sus actividades, aunque también cazan durante el día, dependiendo de la actividad de sus presas (Kitchener 1991).

Esta Familia probablemente sea más variable en tamaño que ninguna otra dentro de los mamíferos, con un rango de pesos que incluye a Leopardus guigna (1.7-3 kg, Oliveira 1993) dentro de los más pequeños y a Panthera tigris (90-258 kg, Mazák 1981) dentro de los más grandes. En cuanto a la dieta, son carnívoros estrictos (hiper-carnívoros) y requieren una alta proporción de proteína animal en su dieta (Sunquist \& Sunquist 2002, 2009). Las estrategias de caza en este grupo, generalmente consisten en matar de una sola mordida penetrante a sus presas (Biknevicius \& Van Valkenburgh 1996, Van Valkenburgh 1996), que puede ir dirigida hacia el cuello o a la cabeza (e.g. Panthera onca Sicuro \& Oliveira 2011), o matar por sofocación (Ewer 1973, Slater \& Van Valkenburgh 2009).

En cuanto a sus hábitos alimentarios y anatomía craneana, los félidos muestran una variación morfológica mucho más limitada que los cánidos, lo cual seguramente ha influido en la evolución del grupo (Van Valkenburgh 1991). Probablemente esta uniformidad sea el resultado de la relativamente joven edad de diferenciación de este grupo (Mioceno tardío) y el hecho de que son depredadores muy especializados (Sunquist \& Sunquist 2002, Wroe \& Milne 2007). La dentición está altamente reducida en relación al plan de los Carnivora, dejando poco lugar 
para la variación, mientras que la función se ha mantenido (Sunquist \& Sunquist 2009). Los incisivos son espatulados, romos, pequeños y sirven para sostener las presas, los caninos son largos, ovales en sección cruzada y ligeramente recurvados (Nowak 2005, Sunquist \& Sunquist 2009); además, presentan carniceros (P4y m1) y molares reducidos (Sunquist \& Sunquist 2009). La reducción de la dentición junto a la disminución de la longitud del cráneo, particularmente la zona facial, están vinculados con mejorar la eficiencia mecánica de la musculatura masticatoria, que le permite tener una de las mordidas más poderosas entre los carnívoros (Radinsky 1981a, Sunquist \& Sunquist 2009). Coincidentemente, las mandíbulas son cortas y poderosas, y los fuertes arcos zigomáticos proveen un firme anclaje del músculo masetérico, y delimitan un amplio espacio en la fosa temporal que permite el paso del músculo temporal. El área de inserción para este último suele ser ampliada por el desarrollo de una fuerte cresta sagital, y una caja craneana alta y ancha, que provee un área occipital generosa de anclaje para los músculos del cuello (Ewer 1973). Las bullas auditivas son grandes, especialmente las de los animales de desierto, aumentando la precisión de la audición (Sunquist \& Sunquist 2009), los ojos también los son y están posicionados relativamente alto en el cráneo permitiendo que éste sea el sentido más importante a la hora de capturar las presas (Kitchener 1991, Sunquist \& Sunquist 2002).

\subsection{Ontogenia craneana y mandibular: Antecedentes}

La ontogenia es la secuencia de eventos involucrados en el crecimiento y desarrollo de un organismo individual en el tiempo, y su modificación es una fuente interna de variación morfológica, sobre la cual puede actuar la selección. Por lo tanto, es un importante componente de los cambios filogenéticos en la morfología (Bastir \& Rosas 2004). Su estudio es importante para entender las 
relaciones entre forma y función en contextos ecológicos, de desarrollo y evolutivos (Cardini \& Thorington 2006, Segura \& Prevosti 2012).

El cráneo es una es una estructura compleja que además de alojar al cerebro y a los órganos de los sentidos, brinda áreas de anclaje para los músculos relacionados con la apertura y cierre de la mandíbula, la captura y el procesamiento de alimento (Moore 1981, Emerson \& Bramble 1993). La mandíbula, por otro lado, juega un rol clave en la masticación, ya que también lleva dientes y provee anclaje para los músculos involucrados (Meloro et al 2008, Meloro \& O’Higgins 2011, Prevosti et al. 2011). El diseño del cráneo (visto como un todo, i.e.: cráneo y mandíbula) en las dos Familias, resulta de la acción de fuerzas selectivas y patrones de desarrollo, los cuales son plásticos frente a la dieta y cambian con la filogenia. Esa versatilidad, aunque no es irrestricta (Figueirido et al. 2011, Prevosti et al. 2011), provee material crudo para que la diversidad se exprese y les permite a los individuos explorar distintos recursos (Meiri et al. 2005).

El cráneo y la mandíbula son estructuras que despertaron el interés de muchos investigadores previamente, por lo que se realizaron estudios ontogenéticos en Carnivora, de donde se conocen los trabajos en mustélidos (e.g. Enhydra lutris: Garshelis 1984, Hattori et al. 2003; Pteronura brasiliensis: Cruz de Oliveira et al. 2007; Mustela nigripes: Santymire et al. 2012), hiénidos (e.g. Crocuta crocuta: Binder \& Van Valkenburgh 2000, Van Horn et al. 2003), y procyónidos (e.g. Procyon lotor: Fiero \& Verts 1986). Además, se han llevado a cabo en animales de otros órdenes con una alimentación altamente carnívora, como marsupiales didélfidos (e.g. Didelphis albiventris, Lutreolina crassicaudata, Caluromys philander: Abdala et al. 2001, Flores et al. 2003, Flores et al. 2010), microbiotéridos (e.g. 
Dromiciops gliroides: Giannini et al. 2004) y dasyúridos australianos (e.g. Dasyurus albopunctatus: Flores et al. 2006).

Trabajos previos de ontogenia en cánidos y félidos se enfocaron principalmente en la cronología de la erupción, el reemplazo dentario y la estimación de la edad (e.g. Canis familiaris: Kremenak 1969, Kremenak et al. 1969; C. latrans: Bekoff \& Jamieson 1975; C. lupus: Landon et al. 1998; Lycalopex culpaeus: Crespo \& De Carlo 1963, Zapata et al. 1997; L. gymnocercus: Crespo 1971, Prevosti \& Lamas 2006; Urocyon cinereoargenteus: Wood 1958, Root \& Payne 1984; Vulpes lagopus: Prestrud \& Nilssen 1995; Acinonyx jubatus: Broom 1949, Caro 1994; Caracal caracal: Stuart \& Stuart 1985; Felis silvestris: García-Perea \& Baquero 1999; Lynx rufus: Crowe 1975, Tumlison \& McDaniel 1984, Jackson et al. 1988, Johnson et al. 1981; Panthera pardus: Stander 1997; Panthera leo: Smuts et al. 1978; Prionailurus bengalensis: Nakanishi et al. 2009; Puma concolor: Gay \& Best 1996, Laundré et al. 2000, Shaw et al. 2007). Sin embargo, algunos trabajos en cánidos fueron más profundos: Wayne (1986) estudió las trayectorias ontogenéticas del crecimiento craneal del perro doméstico (Canis familiaris), revelando que había diferencias con otras especies de cánidos silvestres; La Croix et al. (2011a, b) examinaron el crecimiento y desarrollo en coyotes (Canis latrans), detectando patrones de crecimiento sincrónico y desarrollo asincrónico entre los cráneos y las mandíbulas, y Drake (2011) investigó patrones heterocrónicos en la morfología craneana de $C$. familiaris, revelando que la forma del cráneo de los adultos no refleja la forma craneal de una serie ontogenética de lobos (Canis lupus). Entre los trabajos más notables en félidos están: el de Fagen \& Wiley (1978), quienes trataron la heterocronía en el género Leopardus; el de Petersen \& Petersen (1978), quienes estudiaron las tasas de crecimiento en Leopardus wiedii y el de García-Perea (1996) que estudió los patrones de osificación de las sincondrosis craneanas en el género 
Lynx. Además, Biknevicius (1996) y Biknevicius \& Leigh (1997) se enfocaron en los patrones de osificación de la mandíbula en relación al reemplazo dentario en Puma concolor y el hiénido Crocuta crocuta, haciendo hincapié en sus diferentes dietas y modos de vida.

Finalmente, la ontogenia craneana y mandibular postnatal, como modificaciones estructurales, fue abordada en un contexto integral, buscando explicaciones ecológicas o evolutivas en cánidos y félidos Neotropicales para Lycalopex culpaeus (e.g. Segura \& Prevosti 2012, Segura 2013), dentro de cánidos, y para Puma concolor (e.g. Segura \& Flores 2009, Giannini et al. 2010) y P. concolor junto a Herpailurus yagouaroundi (Segura et al. 2013), dentro de félidos.

\subsection{Funcionalidad y patrones evolutivos}

Los cambios funcionales y fisiológicos que ocurren durante el crecimiento postnatal, como el fin de la lactancia y la pubertad, producen grandes modificaciones en los cráneos y mandíbulas (Zelditch \& Carmichael 1989). La forma de ambos es diferente en los distintos momentos de la vida, porque la selección natural actúa sobre alguna característica en particular, variando de acuerdo a la edad (Zelditch \& Carmichael 1989, Galatius et al. 2011). Especialmente en el Orden Carnivora, donde sus miembros ocupan una variedad amplia de nichos ecológicos (Meloro \& O’ Higgins 2011), la forma puede estar relacionada con las condiciones ambientales y el modo de vida (e.g. Phocoenidae pelágicos o costeros: Galatius et al. 2011), o con variables ecológicas (e.g. Otaridae y Phocidae historia de vida, estrategias reproductivas: Jones \& Goswami 2010). La variación de tamaño también juega un papel importante en la diversidad morfológica de la forma cráneo-mandibular (Morales \& Giannini 2010), podría estar relacionada a mecanismos para reducir el solapamiento de nichos y reducir la presión ecológica 
de competencia (Sicuro 2011, Sicuro \& Oliveira 2011), o estar relacionado con el tamaño de las presas (Werdelin 1983). De todas maneras, la preferencia del tamaño de presas está correlacionado con el tamaño del depredador en sí mismo, por los requerimientos energéticos mayores propios de los grandes depredadores (Slater \& Van Valkenburgh 2009).

La dieta y la filogenia, por otra parte, son representaciones de la correlación potencial de la función y la historia evolutiva, y diferentes investigadores han tratado los efectos de ambas como factores que dan forma al cráneo y la mandíbula. Los resultados fueron diversos, en algunos casos han demostrado que ambos efectos fueron importantes, o que uno de los dos lo fue [e.g. Figueirido et al. (2011) consideran a ambos factores importantes; Goswami (2006) que los Feliformia tuvieron más relación con la filogenia y los Caniformia con la dieta; y Wroe \& Milne (2007) y Meloro \& O' Higgins (2011), que las Familias Canidae y Felidae tuvieron correlaciones muy altas entre la forma y la dieta]. Radinsky (1981a, b) y Goswami (2006) postularon que cuando la muestra es más pequeña, taxonómicamente hablando, la forma cráneo-mandibular se relaciona más con la función y la ecología, mientras que cuando la muestra es mayor, se relacionan más con la filogenia. Para Wroe \& Milne (2007), quienes trabajaron con marsupiales y carnívoros, y encontraron una fuerte relación con la dieta a cualquier escala taxonómica, está claro que esto ocurre porque las estrategias de caza y comportamiento alimenticio de los marsupiales son menos plásticos que en los carnívoros. Cuando homogeneizaron las estrategias de caza entre los carnívoros, quitando de la muestra los cánidos que cazaban en manadas, la correlación entre dieta y forma se hizo mayor. 


\subsection{Objetivos generales}

El objetivo central de esta tesis es estudiar las tendencias ontogenéticas del cráneo y la mandíbula en la Familia Canidae y Felidae de la región Neotropical. En vista de que estas Familias muestran adultos con diferentes adaptaciones morfológicas para una alimentación basada en el consumo de presas vivas y secundariamente otros tipos de alimentos, se explora el cambio de tamaño y de forma craneal y mandibular, y la comparación de la diversidad morfológica alcanzada. Esto es sumado al análisis de los factores que generan e influencian la forma definitiva del cráneo como un todo, y que resultan cruciales para entender la evolución de la carnivoría en mamíferos. La variación de la forma y el tamaño son relacionadas con 2 variables que pueden influenciarla y que representan la función y la historia evolutiva: la dieta y la filogenia.

\subsection{Objetivos particulares}

a). Estudiar las trayectorias ontogenéticas de cánidos y félidos neotropicales desde una perspectiva cualitativa y cuantitativa.

b). Relacionar estos cambios con eventos puntuales ocurridos en la vida de los individuos (e.g. fin de la lactancia, recambio dentario, madurez sexual, etc.).

c). Interpretar las tendencias ontogenéticas craneales y mandibulares en las distintas especies de cánidos y félidos Neotropicales (tanto los cambios cualitativos como cuantitativos observados) en un contexto funcional, asociado al cambio de dieta (desde la lactancia común a todos los linajes, hasta la divergencia hacia dietas omnívoras o carnívoras estrictas) y al consecuente reordenamiento muscular derivado. 
d). Interpretar las tendencias ontogenéticas craneales y mandibulares en las distintas especies de cánidos y félidos Neotropicales (tanto los cambios cualitativos como cuantitativos observados) en un contexto evolutivo, mediante el mapeo de las tendencias en las más recientes hipótesis de relaciones filogenéticas en el Orden Carnivora.

\subsection{Hipótesis}

1. Las trayectorias ontogenéticas del cráneo y la mandíbula en las especies de cánidos y félidos estudiadas resultan de tendencias interespecíficas compartidas y trazables en la filogenia de cada grupo. Los cambios ontogenéticos principales son explicables por ancestralidad común y están asociados a determinados clados.

2. Las trayectorias ontogenéticas del cráneo y la mandíbula en las especies de cánidos y félidos estudiadas tienen un correlato funcional asociado al cambio de dieta que presentan las distintas especies durante la ontogenia. Esto es, desde la lactancia, común a todos los mamíferos, hasta la alimentación adulta que puede incluir ítems más carnívoros o más omnívoros. 


\title{
II MATERIALES Y MÉTODOS
}

\author{
El gato, \\ Sólo el gato \\ Apareció completo \\ Yorgulloso:
}

Nació completamente terminado,

Camina solo y sabe lo que quiere.

El hombre quiere ser pescado y pájaro,

La serpiente quisiera tener alas,

El perro es un león desorientado,

El ingeniero quiere ser poeta,

La mosca estudia para golondrina,

El poeta trata de imitar la mosca,

Pero el gato

Quiere ser sólo gato

$Y$ todo gato es gato

Desde bigote a cola,

Desde presentimiento a rata viva,

Desde la noche hasta sus ojos de oro. 


\subsection{Especímenes}

Esta tesis se basó fundamentalmente en el análisis de ejemplares de las Familias Canidae y Felidae depositados en colecciones sistemáticas de Argentina, Uruguay y Estados Unidos (Apéndice I).

Dentro de la Familia Canidae se estudiaron las siguientes especies:

1. Atelocynus microtis

2. Cerdocyon thous

3. Chrysocyon brachyurus

4. Lycalopex culpaeus

5. Lycalopex fulvipes

6. Lycalopex griseus $^{* 1}$

7. Lycalopex gymnocercus ${ }^{* 1}$

8. Lycalopex sechurae

9. Lycalopex vetulus

10. Speothos venaticus

11. Urocyon cinereoargenteus

Dentro de la Familia Felidae se estudiaron las siguientes especies:

1. Leopardus colocolo ${ }^{* 2}$

2. Leopardus geoffroyi 
3. Leopardus guigna

4. Leopardus jacobitus

5. Leopardus pardalis

6. Leopardus tigrinus

7. Leopardus wiedii

8. Herpailurus yagouaroundi ${ }^{* 3}$

9. Puma concolor

10. Panthera onca

\subsection{Consideraciones taxonómicas}

*1Se trata aquí a Lycalopex griseus y L. gymnocercus como dos especies separadas, aunque es importante mencionar que un estudio morfométrico previo, basado en medidas cráneo-dentarias y caracteres diagnósticos de estas especies, concluyó que se trata de una sola que presenta una variación clinal, disminuyendo de tamaño de NE a SO (Zunino et al. 1995).

*2 Se trata aquí a L. colocolo como una sola especie. García-Perea (1994) separa a la especie Leopardus colocolo en 3 diferentes: L. colocolo (para Chile), L. braccatus (para Brasil, Paraguay y Uruguay) y L. pajeros (para Ecuador, Bolivia y Argentina), basándose en características del pelaje y medidas craneanas. Sin embargo, Johnson et al. (1999) en su análisis filogenético muestra que los linajes de ADN mitocondrial en el oeste de Argentina y Chile central son distintos de los linajes de Brasil y Uruguay, lo cual soporta la partición comúnmente aceptada en subespecies, pero no las divisiones a nivel de especie (Sunquist \& Sunquist 2009). Análisis realizados 
por Morales \& Giannini 2010 (que las consideran tres especies distintas) muestran separación geográfica, pero solapadas en el morfoespacio, concordando con la idea de que son subespecies.

*3Se mantiene aquí el nombre Herpailurus yagouaroundi, en una postura conservativa, ya que dos terminales, dos grupos hermanos en un clado no necesariamente deben llevar el mismo nombre genérico (Prevosti 2009b, Sicuro \& Oliveira 2010).

\subsection{Consideraciones acerca de la terminología anatómica}

Como es de conocimiento general, no existe en lengua castellana diferenciación de terminología para hacer referencia al cráneo de manera integral, incluyendo a la mandíbula, que equivaldría a skull en inglés, y el cráneo separado de la mandíbula, que equivaldría a cranial en inglés.

Por este motivo, cada vez que se menciona aquí la palabra cráneo, se informa sobre éste de manera independiente a la mandíbula. La única excepción es el título de esta Tesis, donde se hace mención a la Ontogenia craneana postnatal, y se toma al cráneo como una estructura completa que incluye la mandíbula.

Por otra parte, cuando se utiliza el término neurocráneo, se hace referencia a la porción craneana que involucra al cerebro y cápsulas sensoriales, y cuando se emplea la palabra esplacnocráneo, se refiere a las estructuras asociadas al aparato masticatorio. Estas definiciones aluden al complejo funcional que interactúa, y no existen segundas interpretaciones para ninguno de estos dos términos en esta Tesis. 


\subsection{Caracterización de la muestra}

Se colectó información de cráneos y mandíbulas de 3308 especímenes. De este total 1367 fueron cánidos y 1218 félidos Neotropicales que cubrieron la totalidad de las 11 especies de cánidos y 10 especies de félidos presentes en esta región, considerados válidos en esta Tesis. Además, se recopilaron datos de 93 ejemplares de cánidos y 630 de félidos de otras regiones zoogeográficas para ampliar la muestra taxonómica (Apéndice II).

Se buscó obtener series ontogenéticas adecuadas, con el máximo número de especímenes posible y de diferentes estadios de edad de las especies incluidas, de modo que la muestra fuera significativa. En especies donde existió la posibilidad, la muestra fue uniforme con respecto a la taxonomía y biogeografía (misma subespecie en taxones politípicos, misma región geográfica en taxones monotípicos), aunque esto no fue posible para la mayoría de las especies. Para algunas, por su amplia distribución y disponibilidad en colecciones (e.g. Puma concolor) fue muy sencillo obtener especímenes, como también lo fue obtener información bibliográfica acerca de la historia de vida. Sin embargo, para otras (e.g. Lycalopex fulvipes o Leopardus jacobita) la muestra fue pequeña y los datos sobre reproducción y ontogenia fueron realmente escasos o inexistentes. De acuerdo al requerimiento de cada uno de los análisis realizados, la especie debió ser eliminadas de la muestra o no (e.g. Lycalopex fulvipes y Leopardus jacobita, con 2 y 3 especímenes cada una, fueron eliminadas del análisis multivariado).

Para las clases jóvenes como B, J1, J2 y J3, las muestras no son homogéneas (Apéndice II) porque corresponden a edades en las que los jóvenes no tienen vida 
libre o independiente, permanecen en las madrigueras donde los dejaron sus padres, o salen de ésta por lapsos muy cortos de tiempo y con supervisión materna y/o paterna según la especie. En el otro extremo, en la clase A3, es raro encontrar animales en la naturaleza que lleguen a ser tan viejos. Estas características disminuyen la posibilidad de encontrarlos naturalmente, que hayan sido colectados y que estén bien representados en colecciones sistemáticas. Estos dos extremos suelen hallarse mejor representados en zoológicos o instituciones de cría. Sin embargo, en estos sitios los animales pueden mostrar anomalías craneanas, producidas por el sobre ejercicio de los músculos (e.g. en especímenes de Panthera tigris se observó una cresta sagital que se deforma por el acicalamiento excesivo, consecuencia del estrés del cautiverio, Duckler 1998). Estos ejemplares también pueden tener menor tamaño cerebral producto de los sucesivos entrecruzamientos que disminuyen la variabilidad genética (e.g. en $P$. tigris y $P$. leo tuvieron un menor tamaño de la caja craneana, O’Regan \& Kitchener 2005, Yamaguchi et al. 2009). Además, como resultado de la dieta más blanda del cautiverio, los cráneos pueden crecer más, como se observó en cachorros de P. leo (Smuts et al. 1978) o tener un menor desarrollo de los huesos maxilares y mandibulares porque la dieta esfuerza menos la musculatura y los huesos (e.g. se observó en adultos de P. leo, Zuccarelli 2004, O’Regan \& Kitchener 2005). Cuando se encontraron este tipo de especímenes que fueron outliers en los análisis realizados o presentaban una morfología claramente anómala, fueron eliminados de la muestra.

\subsection{Clases de edad}

Como la edad absoluta no fue un dato disponible para la mayoría de los especímenes comprendidos en esta muestra, se los agrupó en clases de edad. A pesar de que existían trabajos previos datando la edad en estas especies (e.g. Puma 
concolor Gay \& Best 1996, Laundré at al. 2000, Shaw et al. 2007; Lycalopex culpaeus Crespo \& De Carlo 1963, Zapata et al. 1997; L. gymnocercus Crespo 1971; Urocyon cinereoargenteus: Wood 1958, Root \& Payne 1984), resultaron ser incoherentes entre sí, impracticables para esta muestra, o hacían hincapié en los adultos. Por este motivo se clasificaron los especímenes en base a la secuencia de erupción y desgaste dentario. El objetivo fue comparar la información obtenida intra e inter específicamente, y maximizar la información sobre los cambios ocurridos en los estadios juveniles, ya que es en este período donde se observan las mayores modificaciones.

\subsubsection{Clases de edad para cánidos (Apéndice III, Tabla 1, Fig. 1)}

B: Dentición decidua incompleta, por falta de erupción de piezas;

J1: Dentición decidua completa presente, con I1, i1, P1 y p1 erupcionando;

J2: Dientes definitivos I1, i1, i2, P1, y p1 erupcionados. I2, I3, i3, M1 y m1 erupcionando;

J3: I2, i3 y M1 erupcionados, C, c, P2, p2, P4, M2 y m2 erupcionando;

J4: Incisivos permanentes superiores e inferiores erupcionados al igual que p2, m1, M2 y m2. Con P3, p3, p4 y m3 en procesos de erupción;

A1: Dentición definitiva completa y sin desgaste;

A2, Dentición definitiva completa con ligero desgaste. Presenta cúspides romas de incisivos, caninos, premolares y molares;

A3, Dentición definitiva completa con dentina expuesta en las cúspides de premolares y molares, y con I3 al mismo nivel que el I1 y I2. 
2.5.2. Clases de edad para félidos (Apéndice III, Tabla 2, Fig. 1)

B: Dentición decidua incompleta, por falta de erupción de piezas;

J1: Dentición decidua completa presente, con o sin I1 y i1 erupcionando;

J2: Con I1, i1 y i2 erupcionados y con I2, I3, i3, M1 y m1 en proceso de erupción;

J3: Con I2, M1 e i3 erupcionados y C, c, P2 y P4 erupcionando;

J4: Dientes incisivos definitivos superiores e inferiores, P2, P4 y m1 erupcionados, y dientes P3, p3, p4 erupcionando;

A1: Dentición definitiva superior e inferior erupcionada y sin desgaste;

A2: Dentición con un desgaste ligero; con cúspides romas de incisivos, caninos, premolares y molares;

A3: Dentición con desgaste muy marcado, con exposición de dentina en las cúspides de premolares y molares y con I 3 al mismo nivel que los restantes incisivos superiores.

\subsection{Reproducción y ontogenia}

La información sobre la historia de vida, enfocada en datos reproductivos y ontogenéticos, es muy importante porque permite anclar la evidencia obtenida por las diferentes metodologías, a hechos puntuales de la vida de estas especies (e.g. madurez sexual). Con esta información combinada, para el caso de las especies donde estuvo disponible, se ofrece un panorama más completo de los eventos observados en la morfología y su relación con eventos concretos de la vida de los individuos. Estos párrafos fueron recopilados a través de una búsqueda 
bibliográfica intensiva, ya que son muy escasos y de difícil acceso. Apuntaron fundamentalmente a conocer el período de gestación, peso al nacer, edad de destete, erupción dentaria, madurez sexual y edad de dispersión y se complementaron con todos aquellos que pudieran correlacionarse. La información existente y disponible se expone en las figuras de líneas de tiempo correspondientes a cada especie tratada.

\subsection{Suturas y sincondrosis}

Las suturas son articulaciones de tejido conectivo entre huesos mineralizados (Jaslow 1990, Mao 2002) que existen solamente en el cráneo (Mao 2002). Las sincondrosis son articulaciones cartilaginosas, con uniones de cartílago hialino, cartílago fibroso, o una combinación de ambos (Evans 1993). Ambas son importantes sitios de crecimiento en estadios tempranos del desarrollo (Wagemans et al. 1988, Sun et al 2007, Wilson \& Sánchez Villagra 2009), pero cuando se alcanza el tamaño adulto, el crecimiento de ellas disminuye o cesa, y muchas se fusionan (Wagemans et al. 1988, Jaslow 1990, Opperman 2000, Sun et al. 2007, Wilson \& Sánchez Villagra 2009). Otra función que tienen es absorber y transmitir el estrés mecánico de las actividades exógenas como el nacimiento o un trauma, o de las endógenas como la expansión neurocraneal y la masticación (Mao 2002, Mao et al. 2003, Popowics \& Herring 2007, Zollikofer \& Weissmann 2011). Estos son los dos mayores factores biomecánicos que influencian las propiedades mecánicas y que afectan el crecimiento y la morfología de las suturas (Mao et al. 2003, Nicolay \& Vaders 2006, Popowics \& Herring 2007).

Las propiedades específicas de las suturas y sincondrosis varían con la edad y con la zona donde se encuentran, dependiendo también si experimentan fuerzas del tipo compresivas o tensivas (Nicolay \& Vaders 2006, Popowics \& Herring 
2007), así como también varía su forma. Las suturas más simples (planas, escamosas) se encuentran en áreas que están sujetas a una mayor compresión (Swischuk 1974, Jaslow 1990, Evans 1993, Nakahara et al. 2006), las suturas foliadas se forman donde se necesita una estabilidad extrema (Evans 1993) y las aserradas (con proyecciones interdigitadas de hueso) son encontradas en zonas donde el cráneo sufre un estrés más alto (Wilson \& Sánchez Villagra 2009). Esas interdigitaciones permiten incrementar el área de superficie de anclaje de las fibras de colágeno (Rafferty \& Herring 1999), y por lo tanto, incrementar la absorción del stress, ya que el colágeno puede absorber al menos 100 veces más energía por unidad de volumen que el hueso (Jaslow 1990, Nicolay \& Vaders 2006). La densidad de las fibras de colágeno se incrementa con la edad durante el desarrollo temprano, aunque en la adultez esta densidad decrece (Wagemans et al. 1988). Como las suturas y sincondrosis representan un aspecto de la ontogenia craneal que puede exhibir correlatos tanto funcionales como filogenéticos (Wilson \& Sánchez Villagra 2009), se examinaron 42 suturas y sincondrosis (Apéndice IV), que fueron tomadas de literatura específica para cánidos y félidos (e.g. Evans 1993 y Gilbert 1997). Aunque para la Familia Canidae, la lista inicial se reduce a 40, ya que dos de estas suturas: occipitointerparietalis y parietointerparietalis no están presentes (ambas están vinculadas al hueso interparietal, que se fusiona prenatalmente con el hueso occipital).

Las suturas se clasificaron (siguiendo a Evans 1993) de acuerdo a la forma de los bordes de aposición en:

-Plana. Cuando los huesos contactan en superficie o ángulo recto;

-Escamosa. Cuando los huesos articulan por solapamiento de bordes biselados recíprocamente; 
-Aserrada. Las cuales articulan por medio de procesos y depresiones recíprocas y

-Foliada. En las cuales los bordes de un hueso encastran en la fisura o depresión del hueso adyacente.

También se encontraron combinaciones de dos de los tipos anteriores de suturas (e.g. escamosa/aserrada) en donde ambos forman parte de una sola unidad, en proporciones de un $40-60 \%$ del total.

Las suturas y las sincondrosis se clasificaron también de acuerdo al grado de fusión en:

-No fusionada: Cuando fue visible completamente;

-Fusionada: Cuando no fue visible, y

-Parcialmente fusionada: Es una categoría intermedia, que incluye una fusión del $20-80 \%$ del total.

\subsection{Análisis cualitativo de las suturas y sincondrosis}

Las comparaciones morfológicas se llevaron a cabo mediante la observación directa del grado de fusión y tipo de forma (enunciadas previamente) de las diferentes suturas y sincondrosis craneanas en las series ontogenéticas formadas. Para la nomenclatura osteológica se siguió a Evans (1993) y Gilbert (1997). La información acerca del cambio de suturas y sincondrosis se integró en tablas para cada especie, donde se observan cambios tanto en fusión como en el tipo de sutura. Para ambas Familias las suturas y sincondrosis fueron ordenadas cronológicamente por grado de fusión, aunque manteniendo el número del listado original para poder rastrear cada una de ellas en las diferentes tablas. 


\subsection{Medidas craneanas}

La interacción entre el esplacnocráneo (que lleva la dentición) y el neurocráneo (que lleva el cerebro y las cápsulas sensoriales) produce un patrón ontogenético específico y tiene un profundo impacto en la morfología y función del cráneo de los adultos (Segura \& Flores 2009). Para el análisis del cráneo y la mandíbula se eligieron 22 medidas (Apéndice V, Fig. 2), siguiendo trabajos previos en alometría y ontogenia craneana en mamíferos (e.g. Abdala et al. 2001, Flores et al. 2003, 2006, 2010, Giannini et al. 2004, 2010, Flores \& Casinos 2011, Segura \& Prevosti 2012). Estas medidas tienen en cuenta aspectos funcionales del cráneo (i.e. áreas de orígenes e inserciones musculares, tamaños de cápsulas sensoriales, etc.) y representaran las 3 dimensiones craneales (altura, ancho y profundidad). Se midieron con un calibre digital Mitutoyo Absolute Digimatic 500-171-20B (Mitutoyo Sul Americana Ltda., São Paulo, Brasil), el cual tiene una precisión de $0,02 \mathrm{~mm}$.

\subsection{Análisis multivariado}

La alometría es la relación entre la forma y el tamaño, que se origina a partir de tasas de crecimiento diferentes entre distintas partes del cuerpo (Klingenberg 1998, McNamara 2012). La alometría cuantitativa permite distinguir estructuras que crecen a una tasa similar al tamaño de aquellas que están aceleradas, alometría positiva, o desaceleradas, alometría negativa (Niklas 1994). Para el estudio de la alometría y el análisis de los patrones de variación ontogenética, se analizaron los datos desde una perspectiva cuantitativa, aplicando métodos multivariados basados en la ecuación de alometría de Jolicoeur (1963a, b). En alometría 
multivariada, el tamaño es estimado como una variable latente que afecta todas las variables simultáneamente. A partir de una matriz de varianza-covarianza de variables log-transformadas y escaladas a la unidad (i.e. con todos los elementos escalados tal que la suma de los cuadrados es igual a uno, Jolicoeur 1963a), se realizó un análisis de componentes principales (PCA), del cual se obtuvo el primer autovector que expresa las relaciones alométricas de las variables con el tamaño latente. Para una variable dada, la alometría será la desviación estadística de su correspondiente autovector con respecto al valor hipotético de isometría, el cual se espera sea igual para todos los elementos si el patrón de crecimiento global es isométrico (tamaño invariante). El valor de isometría está dado por la ecuación $1 / p^{0.5}(0,2132$ en esta Tesis) donde $p$ es el numero de variables incluidas en el análisis. La desviación estadística de la isometría se estimó usando la aplicación de Jackknife (Quenouille 1956, Tukey 1956, Manly 1997) adaptada al análisis alométrico por Giannini et al. (2004). El objetivo de esta técnica es generar intervalos de confianza para los autovectores, que puedan incluir el valor estimado de isometría, y por lo tanto ser considerado isométrico (si el elemento observado tiene el valor $=0,2132$ ), o excluir dicho valor y ser considerado alométrico positivo (si el elemento observado es $>0,2132$ ) o alométrico negativo (si el elemento observado es $<0,2132)$. Esto significa tasa de cambio más alta o más baja para la variable específica, comparada con el crecimiento total. Para calcular el intervalo de confianza, se generaron $n$ pseudomuestras removiendo un espécimen a la vez (con un $n$ igual al número de especímenes) de la matriz de datos y recalculando el PCA sobre esta nueva matriz. Por cada remoción, se obtiene un pseudovalor para cada elemento del autovector, usando la fórmula de Jackknife:

$$
\hat{e}^{*}=n \hat{e}-(n-1) \hat{e}-j
$$


Donde un pseudovalor $\hat{e}^{*}$ corresponde a la remoción del espécimen $j$ de la muestra de tamaño $n, \hat{e}$ es el elemento observado del autovector que corresponde al coeficiente multivariado de alometría de la variable craneana $x$, y $\hat{e}-j$ es el valor del coeficiente obtenido con el espécimen $j$ removido (Manly 1997). A partir de la colección de $n$ seudovalores, la media y la desviación estándar son calculadas para cada elemento correspondiente a una variable craneana. La media representa la estimación del Jackknife del coeficiente de alometría multivariada para esta variable. La diferencia entre el estimado y el valor actual para la muestra completa es una medida del sesgo; nosotros reportamos una estimación no sesgada de Jackknife del coeficiente de alometría que se obtiene de sustraer el sesgo de la estimación cruda (Manly 1997). La desviación estándar y el intervalo de confianza al 99\% (para $n-1$ grados de libertad) son calculados para cada coeficiente de alometría. Giannini et al. $(2004,2010)$ y Flores et al. (2006) siguieron las sugerencias de Manly (1997) de usar los seudovalores recortados (trimmed) para el cálculo del intervalo de confianza. Recortando (trimming) los seudovalores $m$ más grandes y $m$ más pequeños para cada variable, puede disminuir significativamente la desviación estándar y permitir estimaciones alométricas más realistas. Si los intervalos de confianza recortados (trimmed) y no (untrimmed) difieren demasiado en amplitud, puede tomarse como indicador de que los seudovalores extremos afectan el error estándar. Para realizar el análisis estadístico multivariado (PCA+ remuestreo de Jackknife) se utiliza un script de R 2.9.2 (R Development Core Team 2004) de Giannini et al. (2010). A partir de éste se obtuvieron valores para cada variable que se combinaron en una tabla detallada para cada una de las especies de la muestra. Estas tablas enlistan los siguientes resultados de la alometría craneal multivariada: Las 3 primeras columnas muestran los resultados utilizando todos los especímenes: 
-Coeficiente de alometría esperado: Es el valor esperado bajo isometría (es igual para todas las variables).

-Coeficiente de alometría observado: Es el valor obtenido con todos los especímenes incluidos.

-Desviación: Es la diferencia entre el coeficiente esperado y el observado.

Las siguientes columnas muestran los resultados de Jackknife calculados con un set de seudovalores Untrimmed y Trimmed

-No sesgado: Es la diferencia entre el sesgo y la estimación cruda de Jackknife.

-Sesgo: Es la diferencia entre el coeficiente remuestreado y el observado.

-Intervalo de confianza 99\%: Es el intervalo y muestra los valores más bajos y más altos.

-Tendencia: Es la tendencia de crecimiento, es el resumen de la alometría de cada variable presentado en símbolos: = Isometría, + alometría positiva, -alometría negativa.

\subsection{Landmarks y semilandmarks}

Se utilizaron 38 landmarks craneales y 18 mandibulares para describir el cráneo como un todo (Apéndice VI, Fig. 3). Los landmarks digitalizados corresponden a los de tipo 1 y 2 de Bookstein (1991) y los semi-landmarks al tipo 3 de este mismo autor (véase también Bookstein, 1997). Los criterios de definición de los landmarks incluyen la identificación de puntos de sutura tripartitos, procesos, implantaciones dentarias y otras estructuras de homología cierta en todas las especies de la muestra. Los semi-landmarks fueron colocados solamente en la 
mandíbula, cubriendo el cuerpo mandibular, tanto en su cara dorsal (2) como ventral (4), de manera equidistante entre landmarks definidos (Fig. 3). Fueron digitalizados con un Microscribe MX6DOF System (GoMeasured3D, Amherst, VA, USA), el cual tiene una precisión de 0,0508 mm. Se utilizó la mitad del cráneo para maximizar la muestra, de modo que si estuviera rota o dañada una mitad se pudiera usar la que no lo estaba.

\subsection{Morfometría geométrica}

El desarrollo de la morfometría geométrica ha resultado en importantes avances en la comprensión de la interacción forma-tamaño (e.g. Cardini \& Thorington, 2006) y en comparaciones interespecíficas dentro de grandes clados (e.g. Goswami 2006, 2007). El análisis de morfometría geométrica basado en landmarks en 3 dimensiones, preserva las relaciones espaciales, permitiendo el análisis simultáneo de dimensión y posición relativa (Rohlf \& Marcus 1993). Por esto, permite separar el factor tamaño, de la forma definida geométricamente (Zelditch et al. 2004, Cardini \& Thorington, 2006), que es un problema básico que se presenta en todos los análisis cuantitativos de ontogenia. Además, tiene la ventaja de permitir la visualización directa de las tendencias de forma (tanto alométricas como no alométricas) en el espacio original de los especímenes, y facilita así la descripción de los resultados (Singleton 2002). Por este motivo, se estudia aquí el patrón ontogenético utilizando también esta metodología.

Para mejorar la visualización y evitar artefactos del alineamiento de Procrustes, la configuración del hemi-cráneo fue reflejada en el plano de simetría definido por los landmarks sagitales. Para hacerlo se utilizó R-function AMP.r escrito por Annat Haber, University of Chicago (Cassini \& Vizcaíno, 2012). Los semilandmarks que fueron tomados para caracterizar las curvas de la mandíbula, 
fueron relajados utilizando el programa "Resample" of NYCEP (Reddy et al. 2007). Para remover la información que no corresponde a la forma, se llevó a cabo un Análisis Generalizado de Procrustes (GPA: Goodall 1991, Rohlf 1999). Este procedimiento minimiza la suma de las distancias al cuadrado entre landmarks homólogos, trasladando, rotando y reescalando a la unidad (tamaño de centroide) estas configuraciones (Dryden \& Mardia 1998). La forma entonces, queda definida como las relaciones espaciales de los landmarks que no son alteradas cuando se aplica este análisis. Asimismo, se realizó un análisis de componentes principales (PCA) para identificar los mayores componentes de variación en un análisis individual para cada una de las especies Neotropicales, reuniendo a jóvenes y adultos de la misma especie en el mismo análisis, aunque examinando el cráneo y la mandíbula por separado. Esto permite la visualización de los cambios de forma, que ocurren a lo largo del desarrollo ontogenético de cada especie, basados en la posición de los especímenes en el morfoespacio, a lo largo del componente principal que sea de interés. Posteriormente, se realizó el mismo análisis para cada Familia (Canidae, Felidae) de manera independiente, sumando ejemplares de otras regiones geográficas. Finalmente, se realizó un análisis integrando a cánidos y félidos del Neotrópico y otras regiones geográficas en el mismo PCA. Para todos estos análisis se utilizó el programa Morphologika 2 v2.5 (O’ Higgins \& Jones 2006).

\subsection{Variación alométrica de la forma}

Para investigar cuanta variación en la forma está asociada con el tamaño, se realizaron regresiones multivariadas entre las coordenadas de Procrustes y el logaritmo del tamaño de centroide (Tanner et al. 2010). La significancia de la regresión fue testeada con un test de permutaciones con 10000 remuestreos 
(Bookstein 1991, Mitteroecker et al. 2004). Este análisis fue realizado para cada especie de manera individual, integrando juveniles y adultos, con el software MorphoJ 1.05a (Klingenberg 2011). Se obtuvo un gráfico de esta regresión para cráneo y mandíbula de cada una de las especies.

\subsection{Tamaño de centroide y distancia de Procrustes}

El tamaño de centroide se utiliza como un estimador del tamaño y se calcula como la raíz cuadrada de la suma de las distancias al cuadrado, desde un conjunto de landmarks al centro geométrico (centroide) del objeto (Bookstein 1996, Zelditch et al. 2004, Tanner et al. 2010). El tamaño de centroide para cada espécimen de cada especie se obtuvo a partir del programa Morphologika 2 v2.5 (O' Higgins \& Jones 2006).

La distancia de Procrustes se usa como un índice de cambio de forma y se calcula como la raíz cuadrada de la suma de las distancias al cuadrado entre las configuraciones de landmarks de cada espécimen y el consenso de la categoría más joven (Zelditch et al. 2003, Tanner et al. 2010). Para obtener esta información se utilizó un script de R 2.9.2 (R Development Core Team 2004) diseñado para hacer este cálculo a partir de la información básica de coordenadas que brinda el programa Morphologika 2 v2.5 (O’ Higgins \& Jones 2006).

\subsection{Cambio de tamaño y de forma durante la ontogenia}

Para todas las especies se realizaron gráficos de boxplots con el programa Statistica 7.0 (StatSoft Inc. 2004), ilustrando la relación de los estimadores de tamaño (tamaño de centroide) o de forma (distancia de Procrustes) y las clases de edad. Los boxplots incluyeron cuartiles medios, superiores e inferiores (75 y 25\%, respectivamente), mínimo y máximo. Esta información fue utilizada para conocer 
en qué clase de edad se obtiene el tamaño y la forma definitivas. Se testearon las diferencias entre las distintas clases de edad, cuando el tamaño de la muestra lo permitió ( $\geq 4$ ), con el test U de Mann-Whitney (Zar 1999), utilizando el programa Statistica 7.0 (StatSoft Inc. 2004). Para controlar la probabilidad global de presenciar un error vinculado al número de hipótesis que comprobar, se utilizó el método de Holm-Bonferroni o Bonferroni escalado, que modifica los criterios de rechazo, ajustando el $P$ (Holm 1979).

\subsection{Medidas de ventaja mecánica}

Las medidas de ventaja mecánica (Apéndice V, Fig. 2) equivalen a medidas de la eficiencia mecánica de la palanca (la relativa efectividad de la fuerza o empuje que causa movimiento en relación con la fuerza de resistencia). La ventaja mecánica provee el entendimiento de la relación entre el torque (fuerza multiplicada por la longitud del brazo de palanca) de una fuerza externa y el torque de una fuerza muscular (Levangie 2005). Con el objetivo de inferir la fuerza de mordida relativa, se siguió a Radinsky (1981a) y Tanner et al. (2010) y se calculó la ventaja mecánica y el tamaño de los músculos masticatorios temporal y masetero. La ventaja mecánica fue estimada como el brazo de palanca interno (inlever) de cada músculo, dividido en el brazo de palanca externo (out-lever) medido para cada músculo (i.e. temporal o masetero). El brazo de palanca interno del temporal (MAT) fue medido como la distancia desde la punta del proceso coronoides al cóndilo mandibular, y el del masetero (MAM), fue medido como la distancia del cóndilo mandibular a la mitad de la fosa masetérica. Los brazos de palanca externos para ambos músculos fueron medidos como la distancia desde el cóndilo mandibular al punto de mordida. Se tomaron 2 puntos de mordida: la muesca del carnicero (Jcar) y el centro de la corona del canino inferior (Jcan). El 
tamaño de los músculos masticatorios se estimó como el ancho máximo entre los arcos zigomáticos (AZ).

\subsection{Análisis de Ventajas mecánicas}

Para todas las especies se realizaron gráficos de boxplots con el programa Statistica 7.0 (StatSoft Inc. 2004) ilustrando la relación entre las diferentes ventajas mecánicas y las clases de edad. Los boxplots incluyeron cuartiles medios, superiores e inferiores ( 75 y 25\%, respectivamente), mínimo y máximo. Esta información fue utilizada para conocer en qué clase de edad se obtiene la estabilización de las ventajas mecánicas (i.e. la obtención de las ventajas mecánicas definitivas) de los diferentes músculos. Se testearon las diferencias entre las distintas clases de edad (cuando el tamaño de la muestra lo permitió, $\geq 4$ ) con el test U de Mann-Whitney (Zar 1999), utilizando el programa Statistica 7.0 (StatSoft Inc. 2004), y se aplicó la corrección de Holm-Bonferroni o Bonferroni escalado descripta previamente.

\subsection{Dimorfismo sexual}

Existen trabajos previos que sugieren dimorfismo sexual en medidas corporales o craneanas de adultos para algunas de estas especies como Puma concolor: Gay \& Best 1995, 1996; Herpailurus yagouaroundi: Oliveira 1998; Lycalopex culpaeus: Crespo \& De Carlo 1963, Johnson \& Franklin1994, Travaini et al. 2000; Panthera onca: Seymour 1989; Leopardus pardalis: Murray \& Gardner 1997, en todos los casos reportando a las hembras más pequeñas que los machos. Para todos los ejemplares que se examinaron en esta Tesis, se registraron las medidas corporales y sexo que brindaban las etiquetas y catálogos de colecciones, sin embargo esta información fue muy escasa. 
Para el análisis de suturas, se compararon cráneos y mandíbulas de ejemplares con sexo conocido, aunque no se hallaron diferencias entre sexos para las distintas clases de edad y las distintas suturas y sincondrosis muestreadas. Para el análisis multivariado, al igual que para las de ventajas mecánicas se realizaron análisis bivariados entre las diferentes medidas que se emplearon, comparando entre machos y hembras con el programa PAST (Hammer et al. 2001). En algunos casos mostraron a los machos más grandes que las hembras (ver resultados), pero en todos los casos exhibieron la misma trayectoria ontogenética, sin diferencias en la pendiente o el intercepto. Para los análisis de componentes principales (con información de morfometría geométrica) se realizaron análisis visuales de la disposición de las configuraciones, con el programa Morphologika 2 v2.5 ( $\mathrm{O}^{\prime}$ Higgins \& Jones 2006). En todos los casos los ejemplares con sexo conocido no se agruparon o segregaron, sino que se distribuyeron de manera homogénea en el morfoespacio. Para el tamaño de centroide y la distancia de Procrustes, se testeó el dimorfismo sexual en las clases donde fue posible (con un $n \geq 4$ ) utilizando el test $U$ de Mann Whitney (Zar 1999), pudiéndose observar en algunos casos que los machos fueron significativamente más grandes o diferentes en forma que las hembras (ver resultados), aunque obtuvieron sus formas y tamaños definitivos en las mismas clases de edad. Los análisis de regresiones multivariadas, se realizaron también teniendo en cuenta los sexos con el programa Statistica 7.0 (StatSoft Inc. 2004), y aunque en algunos casos mostraron a los machos más grandes que las hembras, en todos ellos estuvieron distribuidos sobre la misma trayectoria.

Por todos estos motivos (i.e. escasa posibilidad de conocer los sexos, resultados de los análisis invariables) se realizaron análisis conjuntos sin separar por sexos, tendientes a maximizar el tamaño muestral por encima de las escasas diferencias mostradas entre machos y hembras. 


\subsection{9. “Caracteres" ontogenéticos}

Se realizaron diferentes matrices utilizando los siguientes caracteres:

-Intervalos de confianza. Se eligieron los que representaron el 99\%, generados a partir de los valores trimmed de los análisis multivariados para las 22 medidas tomadas a todas las especies de esta muestra. No se incluyó a Lycalopex fulvipes (entre los cánidos) y a Leopardus jacobita (entre los félidos) porque el tamaño de la muestra fue insuficiente para realizar este análisis y no se contó con esta información para confeccionar la matriz (Apéndice VII). Los caracteres fueron del tipo continuo y son más conservativos porque representan la variación completa. Como en algunos casos los valores de los intervalos tuvieron números negativos, se tomó el más negativo de éstos $(-0,3326)$ como una constante que se sumó a todos los intervalos de modo que fuera posible realizar los análisis con el programa TNT 1.1 (Goloboff et al. 2008) que no toma números negativos.

-Suturas y sincondrosis. Para no perder la información ontogenética de las 42 suturas analizadas previamente, se eligió la clase de edad en la que la sutura se fusiona como carácter, en lugar del tipo de sutura o la presencia/ausencia de ésta. Como existieron suturas que se fusionaron parcialmente durante el desarrollo de los especímenes, se confeccionaron dos matrices: una considerando la semi-fusión como no fusión y otra considerándola como fusión. En ambos casos la no fusión fue considerada un dato inaplicable (Apéndice VIII y IX, respectivamente). En ambos casos se incluyen a todas las especies sin excepción. Estos caracteres son discretos y fueron tratados como multiestado aditivo. Los estados de carácter 
fueron representados con 1 (clase B); 2 (clase J1); 3 (clase J2); 4 (clase J3); 5 (clase J4); 6 (clase A1); 7(clase A2); 8 (clase A3) y - (no fusión).

-Crecimiento y desarrollo definitivos. Se eligió la clase de edad en la que se arriba al tamaño y forma definitivos de cráneo y mandíbula, así como también de los músculos masticatorios y ventajas mecánicas (Apéndice X). Se incluyen a todas las especies sin excepción, aunque para Lycalopex fulvipes y Leopardus jacobita hubieron datos faltantes. Estos caracteres son discretos y fueron tratados como multiestado aditivo. Los estados de carácter fueron representados con 1 (clase B); 2 (clase J1); 3 (clase J2); 4 (clase J3); 5 (clase J4); 6 (clase A1); 7(clase A2); 8 (clase A3) y - la ausencia de información para comparar.

Se construyeron 2 árboles filogenéticos: uno que incluyó a todas las especies de cánidos y félidos estudiadas y el otro que excluyó a Lycalopex fulvipes (entre los cánidos) y a Leopardus jacobita (entre los félidos) (Apéndice XI). Estas hipótesis filogenéticas se basaron en diferentes fuentes bibliográficas como Prevosti (2009) y Austin et al. (2013) para cánidos, y Johnson et al. (2006) y Davis et al. (2010) para félidos.

\subsection{Mapeo de caracteres y señal filogenética}

El mapeo u optimización de caracteres se basa en la reconstrucción de los estados de carácter para los nodos internos, o ancestros hipotéticos, de la filogenia (Wiley et al. 1991, Kitching et al. 1998). Con el fin de explorar el cambio de las tendencias alométricas, de los grados de fusión de suturas y de la obtención del tamaño y forma definitivos a lo largo de la evolución en estas dos Familias, se realizaron optimizaciones de los distintos caracteres o mapeo de caracteres (descriptos previamente) sobre los árboles mencionados (Apéndice XI), con el 
programa TNT 1.1 (Goloboff et al. 2008). Se tomaron optimizaciones no ambiguas (Wiley et al. 1991, Kitching et al. 1998) y los caracteres continuos (como los intervalos de confianza), fueron optimizados con el algoritmo desarrollado por Goloboff et al. (2006). Para los discretos, tratados como multiestado aditivos (como las suturas y el crecimiento y desarrollo), se utilizó la optimización de Farris o Wagner (Farris 1970). La señal filogenética es la tendencia que tienen especies relacionadas a parecerse más entre sí que lo que podría obtenerse por el simple azar (Blomberg \& Garland 2002, Münkemüller et al. 2012). Se puso a prueba permutando al azar 20.000 veces los estados de carácter de los caracteres mencionados arriba, entre los taxones terminales de las filogenias, calculando la cantidad de pasos de cada carácter en cada permutación, mediante un script realizado por Prevosti et al. (2010), utilizando el programa TNT 1.1 (Goloboff et al. 2008). A partir de esto se calcula la probabilidad de obtener la cantidad de pasos originales (sin permutar) en la filogenia utilizada. Si el número de pasos del carácter de interés es menor que el 95\% de los árboles generados por azar (el valor es significativo con un $\mathrm{P}<0,05)$, se concluye que la evolución de este carácter está asociada con el árbol (i.e. hay señal filogenética en ese carácter) (Laurin 2004). 


\section{RESULTADOS CANIDAE}

No hay unidad

Como él,

No tienen

La luna ni la flor

Tal contextura:

Es una sola cosa

Como el sol o el topacio,

Y la elástica línea en su contorno

Firme y sutil es como

La línea de la proa de una nave.

Sus ojos amarillos

Dejaron una sola

Ranura

Para echar las monedas de la noche. 


\subsection{Atelocynus microtis (Sclater 1883)}

\subsubsection{Reproducción y ontogenia}

No existe mucha información acerca de la reproducción y ontogenia de Atelocynus microtis (Berta 1986). Considerando los cadáveres de cachorros encontrados en Perú (Madre de Dios), se estima que los partos ocurren en la estación seca (entre Abril y Octubre). Se han encontrado también madrigueras con 2 a 3 cachorros, pero no existen datos de longevidad en vida silvestre, aunque se ha reportado que pueden vivir por 11 años en cautiverio (Leite Pitman \& Williams 2004) (Fig. 4A).

\subsubsection{Suturas y sincondrosis}

Si bien la muestra carece de juveniles (Apéndice II), se pudo observar (Apéndice IV, Tabla 3, Fig. 5) que las sincondrosis de la placa occipital (intraoccipitalis squamolateralis y basilateralis) ya están fusionadas en la primera clase de adultos, aunque podrían haberse fusionado antes en el tiempo. La sincondrosis spheno-occipitalis, por otro lado, se fusiona más tardíamente, en la clase A2. Otras suturas occipitales como occipitomastoidea y occipitoparietalis, al igual que las suturas squamosa y sagittalis caudal, se fusionan parcialmente en la clase A2. El resto de las suturas no estuvieron fusionadas en la muestra observada. En relación al tipo de sutura, no se observó ningún cambio, pero esto no resulta llamativo por las escasas clases de edad que presenta la muestra consultada. No se observaron cambios vinculados al sexo, ni en el grado de fusión, ni en el tipo de suturas presentadas por esta especie (Apéndice IV, Tabla 3, Fig. 5). 


\subsubsection{Análisis multivariado}

En esta especie no se observaron agrupaciones vinculadas al sexo para este análisis. El primer componente principal, incluyó el 51,07\% del total de la varianza. De las 22 variables tomadas (Fig. 2), 8 mostraron tendencias diferentes al analizar los valores trimmed y untrimmed, con un intervalo de confianza del 99\% (Tabla 4). Éstas fueron: altura de la placa occipital (HPO), ancho de la caja craneana (AC), ancho de los arcos zigomáticos (AZ), longitud de los nasales (LN), altura de la bulla auditiva (HB), ancho del paladar (Apal), longitud del paladar (Lpal) y longitud de la hilera dentaria inferior (LHI). Sin embargo, el sesgo más reducido (usando el valor absoluto del Jackknife) fue el de los valores trimmed $(0,0133)$, por lo tanto serán los resultados que se discutirán. El 59,10\% de las variables fueron isométricas (13): Longitud cóndilo-incisiva (LCI), constricción postorbitaria (CPO), longitud de la órbita (LO), longitud del rostro (LR), ancho de los caninos (Acan), altura del hocico $(\mathrm{HH})$, ancho de la bulla auditiva (AB), longitud de la bulla (LB), longitud de la hilera dentaria superior (LHS), longitud del dentario (LD), altura del dentario (HD), altura del proceso coronoides (HC) y longitud del coronoides (LC). Siete variables $(31,81 \%)$ se alejan de la isometría negativamente: Altura de la placa occipital (HPO), ancho del proceso mastoideo (AM), ancho de la caja craneana (AC), ancho de los arcos zigomáticos (AZ), ancho del paladar (Apal), longitud del paladar (Lpal) y longitud de la hilera dentaria inferior (LHI). Sólo 2 de ellas (9,09\%) fueron alométricas positivas, longitud de los nasales (LN) y altura de la bulla auditiva (HB). Quien más se alejó de la isometría fue la altura de la bulla auditiva (HB), con un valor de 0,1474 y quien menos lo hizo fue la longitud de la bulla (LB), con un valor de 0,0084 (Tabla 4). 


\subsubsection{Morfometría geométrica}

En relación al cráneo, el PC1 representó un porcentaje del 18,16\%, el PC2 un 12,65\% y el PC3 un 10,52\% de la varianza total. En esta especie no se observó diferenciación en cuanto a las clases de edad, ni a los sexos en su distribución en el morfoespacio (Fig. 6A). En relación al PC1 la mayoría de los especímenes se encuentran ubicados sobre los valores positivos, mientras que en relación al PC2, al igual que en el PC3, se ubicaron más uniformemente. Hacia los valores negativos del PC1, se encuentran los especímenes con caja craneana, basicráneo, bullas y arcos zigomáticos más estrechos, hocicos más anchos, torus palatino cóncavo. Hacia los valores positivos del PC1, se encuentran los especímenes con caja craneana, basicráneo, bullas y arcos zigomáticos más anchos y torus palatino convexo. Hacia los valores negativos del PC2 se observan cajas craneanas y nasales ensanchados y rectos, frontales más amplios, rostros más altos y paladares más estrechos. Hacia los valores positivos del PC2 se observa una caja craneana más estrecha, y ahusada hacia el extremo rostral por la reducción en el ancho de los frontales, nasales más delgados y estrechados por las maxilas y paladar más ancho vinculado a éstas, procesos nasales más puntiagudos, el inion adopta una posición más posterior y el basicráneo y paladar que se curvan ligeramente (Fig. 6A). El PC3 aportó hacia los valores positivos una caja craneana con posición más frontal y hacia los valores negativos la conformación contraria.

En relación a la mandíbula, el PC1 representó un porcentaje del 35,60\%, el PC2 un 14,99\% y el PC3 un 8,72\% de la varianza total. Al igual que lo que ocurrió con el cráneo, la mayoría de los especímenes se encuentran ubicados en el PC1 sobre los valores positivos, mientras que en relación al PC2, al igual que en el PC3, se ubicaron de manera más homogénea (Fig. 6B). Tampoco aquí se hallaron 
diferencias en cuanto a sexos o entre clases. En relación al PC1, que fue el único de interés, se observó que hacia los valores negativos la parte inferior del cuerpo mandibular es recto y continuo con la rama mandibular, presentándose ambos en el mismo plano. La rama ascendente tiene una posición posterior. Hacia los valores positivos el cuerpo mandibular y la rama mandibular se presentan en distintos planos porque el proceso angular tiene una posición más elevada. La rama mandibular tuvo procesos muy robustos y estuvo dirigida más hacia arriba (Fig. $6 B)$.

\subsubsection{Variación alométrica de la forma}

Para el cráneo, el tamaño explicó el 6,03\% de la forma ( $\mathrm{P}<0,5171)$, por lo que no hay un patrón alométrico estadísticamente significativo (Fig. 7). Al no incluir juveniles (Fig. 7A), los adultos más jóvenes (A1) presentan los valores más bajos de tamaño de centroide, luego se solapan extensamente con la clase A2, y ésta a su vez lo hace con la clase de adultos más viejos (A3). Esto revela, que aunque el tamaño explicó un porcentaje muy bajo de la forma, aun así existe un componente alométrico que puede ser percibido observando la regresión. Con respecto a los sexos (Fig. 7B), se observa a machos, hembras e indeterminados distribuidos de manera homogénea en la recta. A pesar de no ser significativo, este análisis mostró que los especímenes más pequeños poseen órbitas más abiertas, la porción frontal de los nasales más estrecha, rostro más ancho y la lira con reborde convexo y redondeado. Las formas más grandes mostraron nasales anchos y rostro estrecho, aunque más alto. La lira con forma cóncava, producto del desarrollo del proceso supraorbital. Este proceso, junto al infraorbital, produce un mayor cierre de la órbita (Fig. 7). 
Para la mandíbula (Fig. 8), el tamaño explicó el 12,68\% de la forma $(\mathrm{P}<0,0276)$ y el solapamiento entre los adultos de esta muestra es intenso, como ocurrió con el cráneo (Fig. 8A). Los sexos también estos se hallaron distribuidos homogéneamente (Fig. 8B). Para las formas más pequeñas, la mandíbula presentó un extremo rostral más ancho y recto, un proceso coronoides más delgado y dirigido hacia la parte posterior. El contorno inferior de la rama mandibular es recto y el del cuerpo mandibular es curvado. Para las formas más grandes, la mandíbula exhibió un extremo rostral más estrecho y curvado, con un proceso coronoides ancho y dispuesto verticalmente. El contorno inferior de la rama mandibular es también recto y el del cuerpo mandibular es recto y ascendente (Fig. $8 B)$.

\subsubsection{Cambio de tamaño y de forma durante la ontogenia}

Cuando se analizó la muestra completa, sin discriminar por sexos, el tamaño del cráneo (Fig. 9A) y el de la mandíbula (Fig. 10A) mostraron un aumento progresivo desde la clase A1 a la A3, donde alcanzaron el valor definitivo. La forma mostró un cambio entre la clase A1 y A2, valores con mucha variación en este último estadio, y obtención del valor definitivo en A2 para el cráneo (Fig. 9B) y A3 para la mandíbula (Fig. 10B). A pesar de las diferencias observadas, el test $\mathrm{U}$ de Mann-Whitney mostró que no fueron significativas entre las clases A1 y A2 en cuanto a tamaño y forma, tanto para cráneo como para mandíbula (Tabla 5). Lamentablemente la clase A3 presentó un tamaño de muestra muy bajo para poder ser testeada. Cuando el sexo de los individuos fue tenido en cuenta, el tamaño y la forma mostraron la misma tendencia que cuando no se tuvo en cuenta el sexo. Tanto para el tamaño del cráneo (Fig. 9C) como de la mandíbula (Fig. 10C) las medianas de las hembras parecieron mayores que las de los machos, aunque estas 
diferencias no resultaron significativas (Tabla 5). Para la forma, tanto craneal como mandibular, existió un cambio visible en la clase A2 (Figs. 9D, 10D) aunque fue significativo sólo para cráneos y entre machos de las clases de edad A1 y A2 (Tabla $5)$.

\subsubsection{Ventajas mecánicas}

La estabilización del tamaño de los músculos masticatorios (AZ), parece haber ocurrido (Fig. 11) antes de arribar a las clases de adultos, dado que A1 y A2 tienen valores similares. En A3 se puede observar un pequeño incremento en la ventaja mecánica que hace que la mediana esté por encima de las demás clases. La ventaja mecánica para el masetero, medida en el canino, se presenta mucho más clara, aumentando progresivamente en las distintas clases de edad, hasta estabilizarse en A3, aunque la clase A2 presenta mucha variación. La ventaja mecánica para el mismo músculo, pero tomada en relación al molar carnicero, muestra el mismo patrón. Las clases A1 y A2 tienen valores muy parecidos y luego existe un agudo incremento hacia la clase A3 (Fig. 11). La ventaja mecánica del temporal medida en el canino presenta una gran estabilidad en estas 3 clases, con valores similares, aunque la clase A2 presente mayor variación. La ventaja del mismo músculo medida en el carnicero muestra un patrón bastante similar, las 3 clases poseen valores parecidos (Fig. 11). Sin embargo, el test U de Mann-Whitney no mostró diferencias significativas entre las clases de edad A1-A2 y A2-A3 para ninguna de las ventajas mecánicas, ni se observaron diferencias entre sexos en las evoluciones de las distintas ventajas mecánicas para las distintas clases de edad (Tabla 5). 


\subsection{Cerdocyon thous (Linnaeus 1766)}

\subsubsection{Reproducción y ontogenia}

El período de gestación es de 56 días y el tamaño de camada es de 2 a 3 cachorros (Sillero-Zubiri 2009). En presencia de la hembra dominante, la ovulación de la hembra subordinada se ve disminuida (Brady 1978, Courtenay \& Maffei 2004). El tamaño de los neonatos es de 120-160 g (Berta 1982, Sillero-Zubiri 2009) y ganan peso rápidamente (Brady 1978). Comienzan a tener interacciones sociales a los 11 días y abren los ojos a los 14 días (Biben 1982b, Nowak 2005). Los dientes deciduos erupcionan de la siguiente manera: dI1 entre los 22-26 días, dI2 entre los 20-23, dI3 entre los 17-23, dC entre 14-16 días, dP3 entre 30-35, dP4 entre 20-25. Los di1 erupcionan entre los 20-26 días, los di2 entre 20-23, di3 entre los 18-23 días, de entre los 14-16, dp2 entre los 28-32, dp3 entre los 27-30, dp4 erupcionan entre los 25-28 días (Brady 1978). Salen de la madriguera por primera vez entre los 2-3 meses. La crianza de los cachorros es responsabilidad de ambos padres (Brady 1978), que les llevan comida sólida (en pedazos completos porque no regurgitan) que comen desde los 16-20 días. Son destetados a los 3 meses, aunque los adultos matan las presas para ellos hasta que tienen casi 4 meses, sugiriendo que tal vez no tengan capacidad de hacerlo por sí mismos hasta esta edad. Sin embargo, cuando los testearon de manera individual a los 50 días de edad, los cachorros mataron ratones orientando la mordida de manera correcta (Biben 1982b). La dependencia postdestete dura hasta los 5 meses, inclusive hasta la madurez sexual. Machos y hembras son maduros sexualmente a partir del año de edad, lo cual se puede observar porque coincide con el comienzo de la costumbre de orinar levantando la pata, común a ambos sexos (Berta 1982). La dispersión de las crías se produce cuando tienen entre el año y medio y los dos años de edad (Sillero-Zubiri 2009). La 
esperanza de vida en cautividad es de 11 años (Nowak 2005), mientras que el animal más viejo capturado en vida silvestre tuvo 9 años (Courtenay \& Maffei 2004) (Fig. 4B).

\subsubsection{Suturas y sincondrosis}

Para esta especie no se observaron diferencias entre machos y hembras. De las 40 suturas y sincondrosis analizadas (Apéndice IV, Tabla 6, Fig. 12), 11 se fusionaron $(27,5 \%)$ y, en particular, 2 lo hicieron completamente en estadios tempranos del desarrollo (J2 y J3 respectivamente) y corresponden a la placa occipital: sincondrosis intraoccipitalis squamolateralis y basilateralis. Nueve de ellas se fusionaron recién en la clase de adultos A2 ó A3, siendo en su mayoría relacionadas con la parte posterior del cráneo. Dos de ellas (5\%) permanecieron parcialmente fusionadas en la última clase (A3) estando relacionadas con los arcos zigomáticos. Las restantes 27 (67,5\%) no se fusionaron en ningún momento del desarrollo y están vinculadas con el área rostral del cráneo. En relación al tipo de suturas, sólo cambiaron su configuración 3 de ellas (7,5\%): la sutura occipitoparietalis que era plana (en las clases B y J1) cambió a escamosa/aserrada y la sutura interfrontalis que se mostró escamosa durante la clase B, pero que a partir de la clase J1 en su porción craneal fue plana y en su porción caudal fue aserrada (Tabla 6).

\subsubsection{Análisis multivariado}

Tanto machos como hembras, tuvieron la misma tendencia alométrica, hallándose distribuidos homogéneamente, sin agruparse por sexos. El primer componente principal, incluyó el 78,80\% del total de la varianza. Ninguna de las 22 variables analizadas (Fig. 4) mostraron diferencias entre el análisis trimmed y 
untrimmed realizado con $99 \%$ de intervalo de confianza (Tabla 7). Esto significa que no existen seudovalores extremos que afecten la estimación de Jackknife. El 50\% de las variables resultaron negativas (11) y son: altura de la placa occipital (HPO), ancho del proceso mastoideo (AM), ancho de la caja craneana (AC), constricción postorbitaria (CPO), longitud de la órbita (LO), ancho de los caninos (Acan), altura del hocico $(\mathrm{HH})$, ancho de la bulla auditiva $(\mathrm{AB})$, altura de la bulla auditiva (HB), longitud de la bulla (LB), ancho del paladar (Apal). Nueve de ellas $(40,90 \%)$ son positivas: longitud cóndilo-incisiva (LCI), longitud de los nasales (LN), longitud del rostro (LR), longitud del paladar (Lpal), longitud de la hilera dentaria superior (LHS), longitud del dentario (LD), altura del proceso coronoides (HC), longitud del coronoides (LC) y longitud de la hilera dentaria inferior (LHI). Dos variables (9,10\%) son isométricas: ancho de los arcos zigomáticos (AZ) y altura del dentario (HD). Quien más se alejó de la isometría fue la longitud del coronoides (LC), con un valor de 0,1624 y quien menos lo hizo, fue el ancho de los arcos zigomáticos (AZ) con un valor de 0,0062 (Tabla 7).

\subsubsection{Morfometría geométrica}

Para el cráneo, el PC1 explica un porcentaje de 36,02\%, el PC2 un 6\% y el PC3 un porcentaje del 4,64\% de la varianza total (Fig. 13A). Los jóvenes están distribuidos en el PC1 hacia los valores negativos y los adultos hacia los valores positivos. En el área del morfoespacio ocupada por los jóvenes, se observan cajas craneanas más anchas y altas, arcos zigomáticos más estrechos, hocicos más cortos, anchos y altos, basicráneos y bullas más anchos y cortos, paladares anchos y cortos que forman una línea más recta, órbitas más grandes y foramen magnum más grande y de posición ventral. Donde los adultos se agruparon se observaron cajas craneanas alargadas y bajas, arcos zigomáticos muy expandidos, hocicos largos, 
más bajos y estrechos, basicráneos y bullas más gráciles, paladares estrechos, alargados y ligeramente curvados, órbitas más pequeñas y foramen magnum más pequeño y de posición posterior. En relación al PC2, adultos y jóvenes se encuentran distribuidos sin orden aparente, al igual que ocurre en el PC3. En ninguno de los casos estuvieron agrupados por sexo (Fig. 13A).

En relación a la mandíbula, el PC1 representó un porcentaje del 22,65\%, el PC2 un 13,26\% y el PC3 un 8,92\% de la varianza total. En este caso no se hallaron diferencias entre sexos o clases de edad y el único PC de interés fue el primero (Fig. 13B). Al igual que en el cráneo, los jóvenes se hallaron hacia los valores negativos del primer PC, donde se observaron cuerpos mandibulares completamente curvados y rama ascendente de la mandíbula más débil, con procesos coronoides, condiloideo y angular poco desarrollados. Rama mandibular con posición posterior y elevada del plano del cuerpo mandibular. Hacia los valores positivos se encontraron los adultos, que presentaron cuerpos mandibulares completamente rectos y rama ascendente de la mandíbula fortalecida, con procesos coronoides, condiloideo y angular bien desarrollados. Rama mandibular dispuesta dorsalmente y elevada del plano del cuerpo mandibular, aunque en menor ángulo que los juveniles (Fig. 13B).

\subsubsection{Variación alométrica de la forma}

Para el cráneo (Fig. 14A), el tamaño explicó el 31,21\% de la forma $(\mathrm{P}<0,001)$. Los especímenes más jóvenes son los que presentan menor valor de tamaño de centroide, solapándose en la clase J4 con los adultos que se muestran muy homogéneos en cuanto a su distribución. Con respecto a los sexos, machos, hembras e indeterminados se mostraron distribuidos de manera equivalente (Fig. 14B). Las formas pequeñas mostraron nasales cortos y anchos, hocicos cortos, 
paladares cortos y anchos, cajas craneanas altas, fosas temporales pequeñas, liras cortas y anchas. La sutura coronal se localizó anteriormente y la placa occipital se mostró amplia y ubicada (en proporción) más posteriormente. Esto genera una imagen del cráneo con una región posterior más alargada. Las bullas son más grandes y tienen posición dorso-ventral y las órbitas son más amplias. Las formas más grandes mostraron nasales, hocicos y paladares largos y estrechos, cajas craneanas bajas, fosas temporales más amplias, liras estrechas y largas. La sutura coronal se localizó más posteriormente y la placa occipital se mostró más estrecha y ubicada en una posición ligeramente anterior, lo cual acorta la parte posterior del cráneo. Las bullas son más pequeñas y de posición antero-posterior y las órbitas son más estrechas (Fig. 14A).

Para la mandíbula (Fig. 15A), el tamaño explicó el 11,18\% de la forma $(\mathrm{P}<0,001)$. Los ejemplares más jóvenes tuvieron tamaños de centroide menores y se ubicaron progresivamente por clases de edad, solapándose sólo escasamente. Los adultos, en cambio, tuvieron los mayores tamaños de centroide y se solaparon completamente sin diferenciarse por clase de edad. No se hallaron distribuciones que estén relacionadas con los sexos (Fig. 15B). Las formas más pequeñas mostraron un cuerpo mandibular más ancho y curvado tanto dorsal como ventralmente, con un proceso coronoides más delgado y dirigido hacia atrás, un proceso angular más corto y la parte inferior de la rama mandibular más recta y elevada del plano del cuerpo mandibular. Las más grandes exhibieron un cuerpo mandibular más estrecho y más recto dorsalmente, mientras que ventralmente siguió siendo curvado. Presentaron un proceso coronoides más desarrollado y de posición más vertical, un proceso angular expandido y la parte inferior de la rama mandibular más curvada (Fig. 15A). 


\subsubsection{Cambio de tamaño y de forma durante la ontogenia}

Cuando no se tuvo en cuenta el sexo, se observó un aumento progresivo del tamaño que alcanza su valor definitivo, tanto para el cráneo (Fig. 16A) como para la mandíbula (Fig. 17A), en la clase A1. Esto resulta coherente con los resultados arrojados por el test U de Mann-Whitney que mostró diferencias significativas entre las clases J1-J2, y J2-J3 en cuanto a tamaño de cráneo y de mandíbula, pero no entre las clases de adultos (Tabla 8). El desarrollo de la forma también es progresivo, alcanzando la definitiva en la clase A1 para el cráneo (Fig. 16B) y A2 para la mandíbula (Fig. 17B), clase en la que se observa una gran variación en los valores. Las diferencias entre J1-J2 y J2-J3, resultaron significativas para el cráneo, mientras que para la forma mandibular solamente lo fueron las diferencias entre las clases A1 y A2 (Tabla 8). Cuando se analiza la muestra teniendo en cuenta el sexo, los arribos se obtienen en la misma edad que cuando no fue tenido en cuenta. Para el tamaño del cráneo se observa una diferencia entre machos y hembras, siendo los primeros más grandes (Fig. 16C). Sin embargo, no hubo diferencias significativas entre sexos (Tabla 8). En el caso de la mandíbula, el tamaño también es progresivo y parece tener diferencias entre machos y hembras (Fig. 17C), aunque estas no son verdaderamente significativas (Tabla 8). En cuanto a la forma no parecieron existir diferencias entre machos y hembras ni para cráneo (Fig. 16D) ni para mandíbula (Fig. 17D) y de hecho, no existió ninguna que fuera significativa (Tabla 8).

\subsubsection{Ventajas mecánicas}

El tamaño de los músculos masticatorios (Fig. 18A) muestra un aumento progresivo desde la clase B a la clase A3. Se percibe una asíntota en la clase A2 donde se obtiene el valor definitivo, aunque A3 mostró cuartiles más altos. En este 
caso, el test U de Mann-Whitney mostró diferencias significativas entre todas clases de edad (Tabla 8). El patrón de la ventaja mecánica del masetero medida al canino (Fig. 18B) es poco claro, mostrando mucha variación en las clases de edad que presentan valores similares. Una situación parecida se observa en la ventaja mecánica del masetero medida al carnicero (Fig. 18C), donde todos los estadios de edad muestran valores similares y exhiben también mucha variación. La ventaja mecánica del músculo temporal medida al canino (Fig. 18D) y al carnicero (Fig. $18 \mathrm{E})$, es semejante a las observadas para el masetero, mostrando valores similares para todas las clases de edad. Para los músculos sólo fue significativa la diferencia del temporal al carnicero entre las clases J2 y J3. No se observaron diferencias entre sexos en las distintas ventajas mecánicas para ninguna clase de edad (Tabla 8).

\subsection{Chrysocyon brachyurus (Illiger 1815)}

\subsubsection{Reproducción y ontogenia}

Se conoce poco acerca de poblaciones silvestres de esta especie. El período de gestación dura entre 60-65 días, a partir del cual las hembras paren de 1 a 3 cachorros (Ewer 1973, Sillero-Zubiri 2009). Los cachorros pesan 390-456 g al nacer (Sillero-Zubiri 2009) y se desarrollan rápidamente, aunque tienen tamaño de adultos recién al año de edad (Dietz 1985). A los 10 días pesan 543 g, a los 20 días pesan 766 g, a los 30 días 1226 g, a los 60 días 3527 g y a los 80 días 5349 g (Bekoff \& Jamieson 1975). Abren los ojos entre los 8-9 días (Sillero-Zubiri 2009) y comienzan a mostrar interacciones sociales entre los 8-18 días de edad. Los caninos deciduos erupcionan entre los 11-14 días (Biben 1983). A los 45 días de edad los cachorros no han dejado aún la madriguera y pesan $2 \mathrm{~kg}$ (hembras) y 2,25 kg (machos). Los cachorros empiezan a comer sólidos regurgitados por sus padres alrededor del mes de edad y son destetados por completo a los 4 meses. Se registró 
que ambos padres regurgitan para los cachorros hasta que estos tienen 7 meses. Algunas hembras con cachorros fueron documentadas cazando durante 8 horas a 3 $\mathrm{km}$ de la madriguera donde estaban los cachorros. Los cachorros permanecen dentro del territorio de sus madres hasta el año, tiempo en que comienzan a dispersarse y que obtienen la madurez sexual, aunque usualmente sólo se reproducen en el segundo año (Sillero-Zubiri 2009). Es común que los cachorros sean criados por ambos padres, que los machos regurgiten para sus crías, las acicalen y aumenten su supervivencia (Nowak 2005, Veado 2005, Sillero-Zubiri 2009). La esperanza de vida en cautividad es de 15 años (Nowak 2005) (Fig. 4C).

\subsubsection{Suturas y sincondrosis}

De las 40 suturas estudiadas, (Apéndice IV, Tabla 9, Fig. 19), 8 se fusionan en algún momento de la vida (20\%). Las más precoces son las sincondrosis intraoccipitalis squamolateralis y basilateralis que ya están fusionadas en la clase J4, aunque por el tipo de muestra no es posible saber si comienzan a fusionarse en esta clase, o lo hicieron en clases juveniles más tempranas como J2 ó J3. Las suturas fusionadas son básicamente del área occipital y posterior del cráneo. Cuatro de ellas $(10 \%)$ se fusionaron parcialmente durante el desarrollo, y las $28(70 \%)$ restantes no se fusionaron nunca durante la vida de los individuos muestreados. No se registraron cambios en el tipo de sutura en toda la muestra analizada, ni se registraron diferencias ligadas al sexo en la morfología sutural de los especímenes (Tabla 9, Fig. 19).

\subsubsection{Análisis multivariado}

Tanto machos como hembras se encuentran en la misma trayectoria, mostrando idéntica tendencia alométrica, con una zona de superposición entre 
ambos sexos, y luego machos que adoptaron valores ligeramente mayores. El primer componente principal, incluyó el 60,96\% del total de la varianza. Nueve de las variables analizadas muestran diferentes tendencias cuando se analizan trimmed y untrimmed con un intervalo de confianza del 99\% (Tabla 10). Éstas fueron: altura de la placa occipital (HPO), ancho de los arcos zigomáticos (AZ), longitud de la órbita ( $\mathrm{LO})$, altura del hocico $(\mathrm{HH})$, ancho de la bulla auditiva (AB), altura de la bulla auditiva (HB), ancho del paladar (Apal), longitud del dentario (LD) y altura del dentario (HD). De todas maneras, el sesgo más reducido fue el obtenido en el análisis trimmed $(0,0058)$ por lo que se discutirán estas tendencias. Nueve variables $(40,91 \%)$ resultaron negativas: altura de la placa occipital (HPO), ancho del proceso mastoideo (AM), ancho de la caja craneana (AC), constricción postorbitaria (CPO), longitud de la órbita ( $\mathrm{LO})$, ancho de la bulla auditiva (AB), altura de la bulla auditiva (HB), longitud de la bulla (LB) y ancho del paladar (Apal). Ocho variables (36,36\%) fueron alométricamente positivas: ancho de los arcos zigomáticos (AZ), longitud de los nasales (LN), altura del hocico (HH), longitud de la hilera dentaria superior (LHS), longitud del dentario (LD), altura del dentario (HD), altura del proceso coronoides (HC) y longitud del coronoides (LC). Cinco (22,73\%) fueron isométricas: longitud cóndilo-incisiva (LCI), longitud del rostro (LR), ancho de los caninos (Acan), longitud del paladar (Lpal), longitud de la hilera dentaria inferior (LHI). Quien más se alejó de la isometría fue el ancho de la caja craneana (AC) con un valor de 0,1631 y quien menos lo hizo, fue la longitud del paladar (Lpal), con un valor de 0,0033 (Tabla 10).

\subsubsection{Morfometría geométrica}

Para el cráneo (Fig. 20A), el PC1 explicó un porcentaje de 22,42\%, el PC2 el 11,05\% y el PC3 representó un porcentaje del 8,36\% de la varianza total. El PC1 
mostró hacia los valores negativos a los adultos, que se distribuyeron de manera homogénea. Se observaron cajas craneanas más bajas y estrechas posteriormente, así como también las placas occipitales, foramen magnum más pequeños y basicráneos más estrechos. Presentaron rostros alargados, paladares estrechos y largos, arcos zigomáticos expandidos, bullas gráciles y órbitas más pequeñas. Hacia los valores positivos, los juveniles mostraron cajas craneanas más altas, con su parte posterior ensanchada, foramen magnum más grandes y basicráneos más anchos. Los rostros fueron cortos, con paladares cortos y anchos, arcos zigomáticos poco expandidos, bullas más anchas y órbitas más amplias. El PC2 y PC3 exhibieron a jóvenes y adultos distribuidos sin ningún orden aparente. Ninguno de los 3 PCs mostraron diferenciación en cuanto al sexo.

En relación a la mandíbula (Fig. 20B), el PC1 representó un porcentaje del 26,22\%, el PC2 un 15,67\% y tercero un 9,98\% de la varianza total. En este caso no se hallaron diferencias entre sexos o por clases de edad. Si bien el PC1 y el PC3 mostraron los especímenes distribuidos sin separarse en grupos, el PC2 mostró hacia los valores negativos a los juveniles. Éstos exhibieron mandíbulas con dentarios completamente curvados, mientras los adultos que se encontraron hacia los valores positivos de este $\mathrm{PC}$, mostraron la parte superior del dentario recta y la parte inferior menos curvada.

\subsubsection{Variación alométrica de la forma}

Para el cráneo (Fig. 21), el tamaño explicó el 17,41\% de la forma ( $\mathrm{P}<0,001)$. Los especímenes más jóvenes se ubicaron en zonas donde el tamaño de centroide fue menor, sin solaparse con los adultos. Éstos se distribuyeron progresivamente de acuerdo al tamaño y clase de edad, aunque existieron zonas de solapamiento intenso. En lo que respecta a los sexos, no se observa que los especímenes estén 
orientados en relación a ellos de alguna manera en particular (Fig. 21B). En cuanto a las formas más pequeñas, mostraron una caja craneana más alta y corta, nasales y hocicos más cortos y paladares anchos y cortos. Los arcos zigomáticos son más estrechos, lo que le da al cráneo un aspecto más redondeado. La placa occipital asume una ubicación posterior al inion, y las bullas y las órbitas son proporcionalmente más grandes. Las formas más grandes exhibieron una caja craneana más estrecha y baja, y hocicos y paladares más alargados y estrechos. Los arcos zigomáticos muy expandidos y robustos y el inion que se extiende posterior al foramen magnum. Las bullas y las órbitas son proporcionalmente más pequeñas (Fig. 21).

Para la mandíbula (Fig. 22), el tamaño explicó el 6,85\% de la forma $(\mathrm{P}<0,0002)$. Los especímenes más jóvenes se ubican en la zona de valores más bajos de tamaño de centroide, y se disponen gradualmente de acuerdo a las clases de edad. Los adultos de la clase A1 se dividieron en 2 y algunos de ellos se solaparon con la última clase de juveniles y otros con el resto de los adultos, que se encontraron distribuidos homogéneamente. Los sexos no produjeron ninguna agrupación evidente (Fig. 22B). Los especímenes más pequeños exhibieron un proceso coronoides más corto, un borde anterior de la fosa masetérica con posición más posterior y un proceso angular no tan expandido. Los especímenes más grandes mostraron un proceso coronoides más largo, un borde anterior de la fosa masetérica con posición más anterior y un proceso angular más expandido (Fig. 22).

\subsubsection{Cambio de tamaño y de forma durante la ontogenia}

Cuando se analizó esta especie sin tener en cuenta el sexo, se observó un aumento progresivo del tamaño tanto del cráneo (Fig. 23A), como de la mandíbula 
(Fig. 24A), que alcanza su valor definitivo en la clase A3. El test de Mann Whitney consideró significativas las diferencias entre las clases A1-A2 y A2-A3 para el cráneo, pero sólo entre A1-A2 para la mandíbula (Tabla 11). La forma sufrió un importante salto entre las clases $\mathrm{J} 1$ y J2, alcanzando el valor definitivo en la clase A1, para el cráneo (Fig. 23B), y A2 para la mandíbula (Fig. 24B). Para el cráneo, hay una diferencia significativa entre las clases A1 y A2 (Tabla 11), que provoca dudas acerca de la obtención en la clase A1. De todas formas, el descenso en la clase A3 tanto de la media, como de los cuartiles, muestran que el equilibrio se obtuvo en la clase A1 (Fig. 23B). Teniendo en cuenta las diferencias en relación al sexo, la obtención del tamaño definitivo ocurrió en la misma clase de edad que cuando no se tuvo en cuenta el sexo. Para el tamaño del cráneo (Fig. 23C) se observaron diferencias entre machos y hembras, teniendo los primeros un tamaño ligeramente mayor, aunque éstas no resultaron significativas (Tabla 11). Para la mandíbula, esas variaciones no fueron observables (Fig. 24C), ni significativas (Tabla 11). En cuanto a la forma, está claro que se obtiene la máxima y definitiva, en la clase A1 tanto para el cráneo (Fig. 23D) como para la mandíbula (Fig. 24D), aunque en realidad, no existen diferencias significativas en cuanto a los valores de las clases de edad de adultos (Tabla 11).

\subsubsection{Ventajas mecánicas}

En relación a la ventaja mecánica vinculada al tamaño de los músculos masticatorios (AZ), se puede observar su aumento progresivo, con una asíntota en la clase A2 (Fig. 25A). El test U de Mann-Whitney consideró que existían diferencias significativas entre las clases A1 y A2, pero no entre A2 y A3 (Tabla 11). Las ventajas mecánicas del masetero medida al canino (Fig. 25B) y al carnicero (Fig. 25 C), mostraron mucha variación en las clases de edad y valores similares de 
cuartiles entre todas ellas, aunque ambas se estabilizaron en la clase A2. Sin embargo, las diferencias solo fueron significativas entre las clases A1 y A2 para la ventaja medida al canino (Tabla 11). Las ventajas mecánicas del temporal medido al canino (Fig. 25 D) y al carnicero (Fig. 25 E) mostraron un aumento progresivo hasta la clase A3, donde se obtiene la ventaja máxima y definitiva. La única diferencia significativa que se halló fue entre las clases de edad A2-A3 para la ventaja medida al canino (Tabla 11). No se observaron diferencias entre sexos en las distintas ventajas mecánicas para ninguna clase de edad, y los valores incoherentes observados para las clases J1 y J2 probablemente obedezcan a la baja muestra de estos estadios de edad.

\subsection{Lycalopex culpaeus (Molina 1782)}

\subsubsection{Reproducción y ontogenia.}

El período de gestación es entre 55-60 días y el tamaño de camada es de entre 3-8 cachorros. Los cachorros nacen con los ojos cerrados y a los 2 días los machos pesan alrededor de $166 \mathrm{~g}$ y miden un total de $165 \mathrm{~mm}$, mientras que las hembras pesan alrededor de $170 \mathrm{~g}$ con una longitud total de $161 \mathrm{~mm}$ (Crespo \& De Carlo 1963, Novaro 1997). A los 4 meses pesan 3650 g (Crespo \& De Carlo 1963). Las crías son cuidadas por ambos padres (Novaro 1997) y destetadas a los 2 meses de edad. Post-destete son aún dependientes y comienzan a cazar con sus padres, lo hacen hasta que están fuertes para alimentarse por sí mismas. Los cachorros se desarrollan rápidamente tanto en el largo como en el peso del cuerpo, y en las medidas craneanas, alcanzando el tamaño de adultos a los 7 meses y la madurez sexual durante el primer año de edad (Crespo \& De Carlo 1963; Ewer 1973, SilleroZubiri 2009). El ejemplar más viejo encontrado en vida silvestre tenía 11 años, determinado por conteo de anillos de cemento (Jiménez \& Novaro 2004) (Fig. 4D). 


\subsubsection{Suturas y sincondrosis}

Del total de suturas presentes, 16 (40\%) se fusionaron en algún momento del desarrollo, siendo las más precoces las sincondrosis intraoccipitalis squamolateralis y basilateralis y la sutura sagittalis caudal que se fusionaron en los estadios J1, J2 y J3, respectivamente (Apéndice IV, Tabla 12, Fig. 26). La mayoría de las fusionadas se correspondieron con el área occipital o posterior del cráneo. Doce se fusionaron parcialmente (30\%) durante la ontogenia, y estuvieron vinculadas a los arcos zigomáticos y al escamoso. Otras 12 no se fusionaron jamás (30\%) en ningún estadio de desarrollo de esta especie, y se correspondieron con regiones frontales y rostrales. El cambio en el tipo de sutura sólo se observa en una de ellas: sutura palatomaxillaris (lateral), donde la estructura pasa de ser escamosa a una combinación de escamosa/aserrada (Tabla 12, Fig. 26).

\subsubsection{Análisis multivariado}

En este análisis se observó a machos y hembras distribuidos en el espacio de manera homogénea, ambos con la misma tendencia alométrica. El primer componente principal, incluyó el 69,33\% del total de la varianza. De las 22 variables observadas, sólo 2 mostraron diferentes tendencias al hacer un análisis trimmed y untrimmed con un intervalo de confianza del 99\% (Tabla 13). Éstas fueron: altura de la placa occipital (HPO) y ancho de los caninos (Acan). El análisis untrimmed mostró un sesgo menor $(0,0015)$, por lo que se discutirán las tendencias asociadas a esta opción de análisis. Las variables alométricas negativas fueron las siguientes 8 (36,36\%): ancho del proceso mastoideo (AM), ancho de la caja craneana ( $\mathrm{AC})$, constricción postorbitaria (CPO), longitud de la órbita (LO), ancho de la bulla auditiva $(\mathrm{AB})$ altura de la bulla auditiva (HB), longitud de la bulla (LB) y ancho del paladar (Apal). Las variables positivas resultaron 7 (31,82\%): longitud 
cóndilo-incisiva (LCI), ancho de los arcos zigomáticos (AZ), longitud de los nasales (LN), longitud del dentario (LD), altura del dentario (HD), altura del proceso coronoides (HC) y longitud del coronoides (LC). Las variables isométricas fueron 7 (31,82\%): altura de la placa occipital (HPO), longitud del rostro (LR), ancho de los caninos (Acan), altura del hocico (HH), longitud del paladar (Lpal), longitud de la hilera dentaria superior (LHS) y longitud de la hilera dentaria inferior (LHI). Quien más se alejó de la isometría fue la longitud del coronoides (LC), con un valor de 0,1686 y quien menos lo hizo fue la longitud de la hilera dentaria superior (LHS), con un valor de 0,0030 (Tabla 13).

\subsubsection{Morfometría geométrica}

Para el cráneo (Fig. 27A) el PC1 explica un porcentaje de 17,26\%, el PC2 un 9,43\% y el PC3 un 6,30\% de la varianza total. Hacia los valores negativos, el PC1 mostró a los juveniles con cajas craneanas posteriormente ensanchadas y altas, paladares anchos y largos con torus palatino cóncavo, basicráneos anchos, arcos zigomáticos débiles y no expandidos, y hocicos y basicráneo que se curvan hacia abajo, brindando forma curvada a todo el cráneo. Hacia el lado positivo de este componente principal se ubicaron los adultos con cajas craneanas alargadas y uniformes en cuanto a su ancho, bajas como también lo fue el rostro, paladares cortos con torus palatino convexo, basicráneos estrechos, arcos zigomáticos expandidos, y hocicos y basicráneos completamente rectos (Fig. 27A). Adultos y jóvenes se distribuyeron de manera uniforme dentro de su grupo, como se vio también en relación a los sexos. Los restantes PCs no mostraron ninguna distribución organizada.

En relación a la mandíbula (Fig. 27B), el PC1 representó un porcentaje del 17,70\%, el PC2 un 13,41\% y el PC3 un 10,70\% de la varianza total. En este caso no 
se hallaron diferencias entre sexos o clases de edad y el PC1 y 3 mostraron los especímenes distribuidos sin separarse en grupos. El PC2 en cambio, mostró hacia los valores negativos a la mayoría de los juveniles y hacia los valores medios y positivos a los adultos. Donde estuvieron los jóvenes el cuerpo mandibular más largo y completamente curvado, y la rama mandibular ascendente más corta y de posición vertical. Los adultos en cambio, mostraron la configuración inversa, mandíbulas con cuerpo mandibular más recto y corto, y rama mandibular alargada y dirigida más posteriormente (Fig. 27B).

\subsubsection{Variación alométrica de la forma}

Para el cráneo (Fig. 28A), el tamaño explicó el tamaño explicó el 14,24\% de la forma $(\mathrm{P}<0,001)$. Los especímenes más jóvenes tuvieron menor tamaño de centroide y se hallaron solapados (J4) con los adultos que están homogéneamente distribuidos. Con respecto a los sexos, machos, hembras e indeterminados se mostraron distribuidos de manera equivalente (Fig. 28B). Las formas pequeñas mostraron tener un cráneo más redondeado y alto, inion que no sobrepasa la vertical del foramen magnum, placa occipital de posición más posterior, paladar ancho y largo. Arcos zigomáticos poco desarrollados y fosas temporales más estrechas. Las formas más grandes exhibieron cráneos más estrechos y bajos, inion de posición posterior a la vertical del foramen magnum, placa occipital de posición anterior, paladares más cortos. Arcos zigomáticos expandidos y fosas temporales más amplias (Fig. 28).

Para la mandíbula (Fig. 29A), el tamaño explicó el 8,58\% de la forma $(\mathrm{P}<0,001)$. Los jóvenes se ubicaron hacia los valores menores de tamaño de centroide y se fueron ordenando progresivamente de acuerdo a las clases, aunque las últimas se solapan con los adultos que están dispuestos sin respetar los 
distintos estadios de edad. Los sexos no se agruparon de ninguna manera evidente (Fig. 29B). Las formas más pequeñas tuvieron un proceso coronoides más corto y delgado, y un borde anterior de la fosa masetérica con una posición posterior. Las formas más grandes tuvieron un proceso coronoides más alto y ancho, y un borde anterior de la fosa masetérica con una posición anterior (Fig. 29).

\subsubsection{Cambio de tamaño y de forma durante la ontogenia}

Sin tener en cuenta el sexo, se observó un aumento progresivo del tamaño del cráneo (Fig. 30A) y mandíbula (Fig. 31A) que se estabiliza en la clase A2. De todas maneras, el test de Mann-Whitney mostró diferencias significativas entre las clases J3-J4, J4-A1 y A1-A2, tanto para el cráneo como para mandíbula (Tabla 14). La forma mostró un cambio entre la clase J1 y J2, luego valores sostenidos hasta el final de las clases de jóvenes y un pequeño salto hacia la clase A1. Finalmente, la forma definitiva se obtuvo para el cráneo en la clase A2 (Fig. 30B) y para la mandíbula en la clase A1 (Fig. 31B). Las clases de edad diferenciadas significativamente fueron J4-A1 y A1-A2, y sólo para el cráneo (Tabla 14). Al tener presente el sexo de los especímenes, se observa en relación al tamaño del cráneo (Fig. 30C) y de la mandíbula (Fig. 31C), que a partir del estadio de edad J4, los machos son más grandes que las hembras, aunque estas diferencias solo fueron significativas entre machos y hembras de la clase A3 (Tabla 14). Para la forma craneal (Fig. 30D) y mandibular (Fig. 31D) se observó un cambio progresivo, que mostró a los machos distintos de las hembras en algunas clases de edad como J4, A2 y A3, siendo siempre los machos los que presentan un mayor valor de distancia de Procrustes, aunque ninguna de estas diferencias fueron estadísticamente significativas entre los sexos (Tabla 14). 


\subsubsection{Ventajas mecánicas}

La ventaja mecánica en relación al tamaño de los músculos masticatorios (AZ), se mostró estable en las clases de edad J1, J2 y J3, con valores similares entre todas ellas. Hay un aumento progresivo desde J4 a la clase A2 donde se observa una asíntota (Fig. 32A). Las clases de edad que resultaron significativas fueron J3J4, J4-A1 y A1-A2 (Tabla 14). El patrón de ventaja mecánica del masetero medido al canino (Fig. 32B) muestra gran variación en las distintas clases de edad y valores similares entre todas ellas, ocurriendo lo mismo para la ventaja mecánica del masetero medida al carnicero (Fig. 32C). Ambas ventajas llegan a la estabilidad en la clase A2 y no existen diferencias significativas entre estos estadios de edad (Tabla 14). La ventaja mecánica del temporal medida al canino (Fig. 32D), muestra valores similares y una importante variación entre todos los estadios de edad, que se estabilizan en la clase A1. Finalmente, la ventaja mecánica del temporal al carnicero (Fig. 32E), muestra un aumento sutil desde la clase J1 hasta la A2 donde se percibe la asíntota. No hubo diferencias significativas ni entre las distintas clases de edad ni entre sexos (Tabla 14). La disminución de los valores en J2 probablemente obedezca a un tamaño de muestra demasiado bajo.

\subsection{Lycalopex fulvipes (Martin 1837)}

\subsubsection{Reproducción y ontogenia}

El tamaño de camada es estimado entre 2-3 cachorros. Algunas hembras lactantes fueron capturadas en Octubre, y los cachorros fueron documentados saliendo del área de la madriguera en Diciembre, mientras que los destetes ocurrieron en Febrero, es decir a los 3 ó 4 meses (Jiménez \& McMahon 2004). Cuando el destete comienza, las hembras tienen un comportamiento más agresivo 
con los cachorros, mientras que los machos juegan con ellos y los acicalan (SilleroZubiri 2009). El mantenimiento de un gran grupo familiar puede estar influenciado por la escasez de territorios donde potencialmente se puedan dispersar los juveniles. Si esto ocurre, la dispersión entonces se ve retrasada, encontrándose jóvenes de entre 2 y 3 años recién trasladándose a nuevos territorios, a menudo adyacentes a los de sus padres. Los animales más viejos capturados y monitoreados tuvieron 7 años de edad. (Jiménez \& McMahon 2004) (Fig. 4E).

\subsubsection{Suturas y sincondrosis}

Si bien la muestra carece de juveniles y de clases de adultos intermedias (A2, Apéndice II), se pudo observar que 6 suturas (15\%) se fusionaron completamente en algún momento de la vida de los individuos de esta especie (Tabla 15, Fig. 33). Durante la clase A1, la sincondrosis spheno-occipitalis, intraoccipitalis squamolateralis y basilateralis (vinculadas todas ellas con el área occipital) ya se encuentran fusionadas, aunque no es claro si se fusionaron en esta clase o previamente en clases juveniles. En la clase A3, las sincondrosis intermandibularis y las suturas sagittalis caudal y sphenosquamosa ya están fusionadas, aunque podrían haberlo hecho en la clase A2. Algunas sincondrosis y suturas (5) se encontraron parcialmente fusionadas en la última clase de edad, constituyendo el 12,5\%. De todos modos, al igual que en los casos anteriores, no es posible saber si lo hicieron en la clase anterior (A2). Las 29 suturas restantes (72,5\%) no presentaron fusión en ningún momento del desarrollo. Con respecto al tipo de sutura, no se observó ningún cambio en la muestra analizada, aunque esto puede ser un artefacto de una muestra tan acotada (Tabla 15, Fig. 33). 
No fue posible realizar los restantes análisis con una muestra acotada a los 2 especímenes a los que se tuvo acceso: una hembra FMNH 23814 y un macho FMNH 23815 (Apéndice II).

\subsection{Lycalopex griseus (Gray 1837)}

\subsubsection{Reproducción y ontogenia}

El período de gestación es de 53-58 días y el tamaño de camada es de 4-6 cachorros. Los primeros días desde el parto, la madre raramente deja la madriguera, es el macho el que le lleva comida. Los cachorros son cuidados por ambos padres y dejan la madriguera al mes de edad (Sillero-Zubiri 2009). La lactancia termina entre los 4 y los 5 meses de edad. La edad de la madurez sexual es desconocida, pero por estudios de campo se infiere que ocurre alrededor del año de edad (González del Solar \& Rau 2004) y comienzan a dispersarse a los 6-7 meses de edad (Sillero-Zubiri 2009). En esta especie se observan 2 fenómenos: camadas combinadas y la presencia de hembras helpers (ayudantes). Ambos están relacionados con una alta disponibilidad de alimento y la posibilidad de criar grandes camadas, ya que con una hembra extra se puede llevar más comida a la madriguera, incrementar la vigilancia anti-predadores y sustituir una hembra por otra si una de ellas muere (González del Solar \& Rau 2004). Se desconoce la longevidad en vida silvestre, pero en cautiverio se conocen animales que llegaron a vivir hasta los 6 años de edad (González del Solar \& Rau 2004) (Fig. 4F).

\subsubsection{Suturas y sincondrosis}

De las suturas analizadas, 8 de ellas se fusionaron (20\%) en algún momento del desarrollo (Tabla 16, Fig. 34), siendo las fusiones más tempranas las de las sincondrosis intraoccipitalis squamolateralis y basilateralis que lo hicieron en la clase 
juvenil (J4), aunque al no tener en la muestra juveniles de las clases J2 y J3 (Apéndice II), no es posible saber si la obliteración ocurrió antes. Las restantes fusiones ocurrieron en alguna de las 3 clases de adultos. La mayoría de las suturas y sincondrosis fusionadas estuvieron vinculadas con el área occipital y con la parte posterior del cráneo. Cuatro se fusionaron parcialmente (10\%) durante la ontogenia y tuvieron que ver con el occipital y el paladar. Veintiocho, que corresponden al 70\%) nunca se fusionaron y estuvieron relacionadas con todas las restantes áreas del cráneo no mencionadas previamente. Se encontraron 5 cambios de tipo de sutura en toda la muestra, relacionados a un aumento de complejidad en el caso de las suturas sagittalis caudal y cranial, que cambiaron de planas a aserradas, al igual que la sutura interfrontalis caudal. La sutura occipitoparietalis cambió de plana a escamosa y la sutura palatomaxillaris mesial presentó un sorprendente patrón de cambio, siendo escamosa en la clase B, aserrada durante las clases juveniles y nuevamente escamosa en las clases de adultos (Tabla 16, Fig. $34)$.

\subsubsection{Análisis multivariado}

La distribución de machos y hembras en el espacio fue homogénea, mostrando la misma tendencia alométrica ambos. El primer componente principal, incluyó el 41,87\% del total de la varianza. Ninguna de las 22 variables analizadas (Tabla 17) mostraron diferencias entre el análisis trimmed y untrimmed realizado con 99\% de intervalo de confianza. Esto significa que no existen seudovalores extremos que afecten la estimación de Jackknife. Quince variables de las analizadas fueron isométricas $(68,18 \%)$ : altura de la placa occipital (HPO), ancho de los arcos zigomáticos (AZ), longitud de la órbita (LO), ancho de los caninos (Acan), altura del hocico $(\mathrm{HH})$, ancho de la bulla auditiva $(\mathrm{AB})$, altura de la bulla auditiva $(\mathrm{HB})$, 
longitud de la bulla auditiva (LB), ancho del paladar (Apal), longitud del paladar (Lpal), longitud de la hilera dentaria superior (LHS), altura del dentario (HD), altura del coronoides (HC), longitud del coronoides (LC) y longitud de la hilera dentaria inferior (LHI). Cuatro variables fueron alométricas positivas $(18,18 \%)$ : longitud cóndilo-incisiva (LCI), longitud de los nasales (LN), longitud del rostro (LR) y longitud del dentario (LD). Finalmente, 3 resultaron negativas (13,64\%): ancho del proceso mastoideo (AM), ancho de la caja craneana (AC) y constricción postorbitaria (CPO). Quien más se alejó de la isometría fue la constricción postorbitaria (CPO), con un valor de 0,1964 y quien menos lo hizo fue la longitud de la hilera dentaria inferior (LHI), con un valor de 0,0062 (Tabla 17).

\subsubsection{Morfometría geométrica}

Para el cráneo (Fig. 35A), el PC1 explica un porcentaje de 30,82\%, el PC2el 6,97\% y el PC3 el 5,53\% de la varianza total. No se observó ninguna distribución en el morfoespacio vinculada a los sexos. Hacia los valores negativos se encontraron principalmente los adultos, sin que se distingan entre distintas clases de edad, mientras que hacia los valores positivos se encontraron los juveniles. El espécimen de la clase J4 se encontró muy cercano a los restantes adultos. Hacia los valores negativos la caja craneana fue más estrecha y baja, el paladar estrecho y largo, el torus palatino cóncavo, el hocico largo, delgado y bajo, el basicráneo estrecho, los arcos zigomáticos fuertes y expandidos, y las órbitas y bullas más pequeñas. Hacia los valores positivos la caja craneana fue ancha, corta y alta, el paladar ancho y corto, el torus palatino recto, el hocico y el rostro cortos y altos, los arcos zigomáticos muy débiles y no expandidos, y las órbitas y bullas más grandes. Los restantes componentes no mostraron una distribución clara (Fig. 35A). 
En relación a la mandíbula (Fig. 35B), el PC1 representó un porcentaje del 19,17\%, el PC2 un 12,49\% y el 3 un 10,23\% de la varianza total. No se hallaron diferencias entre sexos o clases de edad y el PC2 fue el único de interés. Mostró hacia los valores negativos a los juveniles y algunos especímenes de la clase A1. Hacia los valores medios y positivos se agruparon los adultos de manera homogénea, sin distinguirse entre clases. Hacia donde estuvieron los jóvenes, el cuerpo mandibular fue ancho y completamente curvado, y la rama mandibular ascendente fue débil y tuvo posición posterior. Hacia donde estuvieron los adultos, la configuración fue la contraria, el cuerpo mandibular fue más estrecho y recto, la rama mandibular ascendente fue más fuerte y tuvo una posición dorso-ventral (Fig. 35B).

\subsubsection{Variación alométrica de la forma}

Para el cráneo (Fig. 36A), el tamaño explicó el 25,73\% de la forma ( $\mathrm{P}<0,0001)$. Los especímenes jóvenes, como los de la clase J1, exhibieron los menores valores de tamaño de centroide, mostrando una gran diferencia con el tamaño de los de la clase J4 y las clases de adultos, que se dispusieron homogéneamente en esta regresión. Con respecto a los sexos (Fig. 36B), machos, hembras e indeterminados se mostraron distribuidos de manera equivalente. Las formas pequeñas mostraron sus cráneos cortos, anchos y altos, los nasales y hocicos fueron cortos, anchos, altos y curvados ventralmente. Los paladares fueron anchos y cortos, la sutura coronal tuvo una posición anterior, y las liras fueron anchas y cortas. La placa occipital tuvo una posición posterior al inion, y las órbitas y bullas fueron más grandes. En las formas más grandes se observó lo contrario: los cráneos fueron largos, estrechos y bajos, los nasales y hocicos fueron largos, estrechos, bajos y rectos, sin curvatura ventral. Los paladares fueron largos y estrechos, la sutura coronal tuvo una 
posición posterior, y las liras fueron estrechas y largas. La placa occipital tuvo una posición anterior al inion, y las órbitas y bullas fueron más pequeñas (Fig. 36).

Para la mandíbula (Fig. 37A), el tamaño explicó el 6,97\% de la forma $(\mathrm{P}<0,0001)$ y entre sexos no hubo ningún agrupamiento evidente (Fig. 37B). Los juveniles de la clase J1 tuvieron menores valores de tamaño de centroide. Los de la clase J4 y los adultos tuvieron mayores tamaños y se solaparon en la trayectoria, sin distinguirse entre clases (Fig. 37A). Las formas más pequeñas exhibieron un dentario más ancho, el borde anterior de la fosa masetérica retrasado, un proceso coronoides más estrecho y con posición más posterior, y el proceso angular más corto. Las formas más grandes mostraron un dentario más delgado, el borde anterior de la fosa masetérica adelantado, un proceso coronoides más desarrollado y con posición más dorsal, y el proceso angular más elongado (Fig. 37).

\subsubsection{Cambio de tamaño y de forma durante la ontogenia}

Si no se tienen en cuenta los sexos, para el tamaño craneal (Fig. 38A) y mandibular (Fig. 39A), existió un gran salto entre los valores de la clase J1 y los de la J4, luego un aumento hasta la clase A1, un pequeño aumento en la clase A2, que es en donde se obtiene el tamaño definitivo, para luego decrecer también ligeramente en la clase A3. Las diferencias que resultaron significativas fueron entre las clases A1-A2, para cráneo y mandíbula, y A2-A3 sólo para la mandíbula (Tabla 18). Para la forma craneal (Fig. 38B) y mandibular (Fig. 39B), también se observa una diferencia importante entre las clases J1 y J4, y luego un ligero aumento hasta la clase A1 para el cráneo, mientras que para la mandíbula es un descenso. Finalmente, la estabilización de la forma llega para ambos en la clase A2. En cuanto a forma, para el cráneo fue significativa la diferencia entre las clases A1 y A2 (Tabla 18), aunque para la mandíbula no se encontraron valores 
significativos. Tomando en cuenta un posible dimorfismo sexual, se observó para el tamaño craneal (Fig. 38C) y mandibular (Fig. 39C) un patrón similar al obtenido con la muestra completa sin diferenciarla por sexo. Sin embargo, en la clase de edad A2 hubo diferencias absolutas entre sexos, siendo los machos un poco mayores que las hembras, aunque esta diferencia no resultó significativa ni para el cráneo ni para la mandíbula (Tabla 18). Para la forma, se pudo ver el mismo patrón en el cráneo (Fig. 38D) y en la mandíbula (Fig. 38D), que cuando no se consideró el sexo. Aunque se observaron diferencias entre los machos y hembras de las clases de adultos, para la mandíbula, éstas no fueron significativas (Tabla 18).

\subsubsection{Ventajas mecánicas}

Para el tamaño de los músculos masticatorios (Fig. 40A), se observa un brusco salto, entre la clase más pequeña de edad (B) y la clase de juveniles J4. Luego, el aumento es paulatino y la estabilización llega en la clase A2. El test de Mann-Whitney mostró diferencias significativas entre las clases A1-A2 y A2-A3 (Tabla 18). La ventaja mecánica del músculo masetero medida al canino (Fig. 40B) al igual que la medida al carnicero (Fig. 40C), muestra una serie de valores similares y una gran variación para algunas de las clases de edad. La clase J4 es donde se estabiliza el aumento de esta ventaja, aunque esto podría ocurrir más tempranamente en la clase B, pero la escasez de esta muestra hace difícil la apreciación (Apéndice II). No existieron diferencias significativas entre las distintas clases (Tabla 18). La ventaja mecánica del temporal medida al canino (Fig. 40D) y al carnicero (Fig. 40E) muestra un aumento en los valores desde la clase B a la A1, donde los valores se estabilizan, aunque con mucha variación en los valores. El test de Mann-Whitney no mostró diferencias significativas entre las distintas clases, y para ninguna ventaja se observaron diferencias entre sexos (Tabla 18). 


\subsection{Lycalopex gymnocercus (Fischer 1814)}

\subsubsection{Reproducción y ontogenia}

El período de gestación es de 55-60 días y el tamaño de camada es de 3-5 cachorros. Ambos padres cuidan a los cachorros y los machos aprovisionan tanto a hembras como a cachorros durante el tiempo que pasan en la madriguera (SilleroZubiri 2009). Los jóvenes dejan la madriguera entre los 1-3 meses. La lactancia termina alrededor de los 2 meses (Lucherini \& Luengos Vidal 2008), momento en el que pesan entre 1-2,5 $\mathrm{kg}$ (Crespo 1971). Los valores de peso corporal son muy variables y sobre todo de rápido incremento en los primeros 8-9 meses de vida, tiempo en que se encontraron ejemplares con el peso definitivo de adultos. Entre los 8-12 meses obtienen su dentición definitiva (Crespo 1971). No existen datos de longevidad en vida silvestre, pero se reportaron animales cautivos que vivieron alrededor de 14 años (Lucherini et al. 2004a) (Fig. 4G).

\subsubsection{Suturas y sincondrosis}

El patrón de fusión de suturas y sincondrosis en esta especie fue muy similar al hallado para L. griseus y descripto previamente. De las suturas analizadas, 8 de ellas se fusionaron (20\%) en algún momento del desarrollo (Tabla 19, Fig. 41), siendo las fusiones más tempranas las de las sincondrosis intraoccipitalis squamolateralis y basilateralis que lo hicieron en la clase juvenil (J2). La mayoría de las suturas y sincondrosis fusionadas estuvieron vinculadas con el área occipital y la parte posterior del cráneo. Cuatro se fusionaron parcialmente $(10 \%)$ durante la ontogenia y tuvieron que ver con el occipital y el paladar. Veintiocho (que corresponden al 70\%) nunca se fusionaron y estuvieron relacionadas con todas las restantes áreas del cráneo no mencionadas previamente. Se encontraron 2 
cambios de tipo de sutura en toda la muestra, relacionados a un aumento de complejidad, en el caso de las sutura occipitoparietalis que cambió de plana a escamosa, y la sutura palatomaxillaris mesial que fue aserrada durante las clases juveniles y escamosa en las clases de adultos (Tabla 19, Fig. 41).

\subsubsection{Análisis multivariado}

Se observó a ambos sexos distribuidos en el espacio de manera homogénea, mostrando la misma tendencia alométrica. El primer componente principal, incluyó el 57,47\% del total de la varianza. Sólo 4 variables mostraron diferencias en las tendencias cuando fueron examinadas con trimmed y untrimmed con un $99 \%$ de confianza (Tabla 20). Éstas fueron: ancho de los caninos (Acan), altura del hocico $(\mathrm{HH})$, altura del dentario (HD) y longitud de la hilera dentaria inferior (LHI). Al ser menor el sesgo producido con el análisis untrimmed (0,0017), se discutirán estos resultados. Nueve variables resultaron alométricas negativas (40,91\%): altura de la placa occipital (HPO), ancho del proceso mastoideo (AM), ancho de la caja craneana (AC), constricción postorbitaria (CPO), longitud de la órbita (LO), ancho de la bulla auditiva (AB), altura de la bulla auditiva (HB), longitud de la bulla (LB) y ancho del paladar (Apal). Ocho de ellas fueron alométricas positivas (36,36\%): longitud cóndilo-incisiva (LCI), ancho de los arcos zigomáticos (AZ), longitud de los nasales (LN), longitud del rostro (LR), longitud del paladar (Lpal), longitud del dentario (LD), altura del proceso coronoides (HC) y longitud del coronoides (LC). Las restantes 5 fueron isométricas (22,73\%): ancho de los caninos (Acan), altura del hocico $(\mathrm{HH})$, longitud de la hilera dentaria superior (LHS), altura del dentario (HD) y longitud de la hilera dentaria inferior (LHI). Quien más se alejó de la isometría fue la constricción postorbitaria (CPO), con un valor de 0,2096 y quien menos lo hizo fue el ancho de los caninos (Acan), con un valor de 0,0183 . 


\subsubsection{Morfometría geométrica}

Para el cráneo (Fig. 42A), el primer PC explicó un porcentaje del 10,97\%, El PC2 el 8,09\% y el PC3 representó un porcentaje del 5,68\% de la varianza total. En el PC1 se observó hacia los valores negativos a los adultos de las distintas clases de edad y hacia los positivos a los juveniles distribuidos de manera homogénea. En donde se ubicaron los adultos, la caja craneana se presentó más estrecha posteriormente y baja, el rostro estrecho y largo, el paladar estrecho con torus palatino recto, el basicráneo estrecho, los arcos zigomáticos expandidos, el foramen magnum posterior, y las órbitas y bullas más estrechas. En la región del morfoespacio donde se ubicaron los jóvenes, la caja craneana fue más ancha posteriormente y alta, el rostro corto y ancho, el paladar y basicráneo anchos y curvados ventralmente, los arcos zigomáticos menos desarrollados, el foramen magnum ventral y las órbitas y bullas más grandes. No se observó ningún agrupamiento que mostrara separación entre machos y hembras. Los restantes componentes principales no mostraron ninguna diferenciación de interés (Fig. $42 \mathrm{~A})$.

Para la mandíbula (Fig. 42B), el PC1 representó un porcentaje del 17,36\%, el PC2 un 14,75\% y el PC3 un 8,43\% de la varianza total. En ninguno de los PCs estudiados se hallaron agrupamientos en relación al sexo o a la edad. Tanto juveniles, como adultos de las diferentes clases, se ubicaron de manera homogénea en el morfoespacio (Fig. 42B).

\subsubsection{Variación alométrica de la forma}

Para el cráneo (Fig. 43), el tamaño explicó el 8,03\% de la forma ( $\mathrm{P}<0,0001)$. Los especímenes más jóvenes tuvieron menor tamaño de centroide, y los de la 
clase J4 estuvieron solapados con los adultos que se distribuyeron de manera homogénea (Fig. 43A). Tantos machos como hembras e indeterminados se mostraron distribuidos de manera equivalente, sin presentar ningún agrupamiento (Fig. 43B). Las formas pequeñas presentaron un cráneo más ancho, corto y alto, hocico más corto, paladar más largo, fosas temporales más pequeñas, inion que no sobrepasa posteriormente la vertical del foramen magnum, bullas más altas y anchas, y órbitas más amplias. Las formas más grandes presentaron un cráneo más estrecho, alargado y bajo, hocico más largo, paladar ligeramente más corto, fosas temporales más amplias, inion que sobrepasa el foramen magnum, bullas más bajas y pequeñas y órbitas más pequeñas (Fig. 43).

Para la mandíbula (Fig. 44A), el tamaño explicó el 3,20\% de la forma $(\mathrm{P}<0,0001)$ y las diferencias entre sexos no produjeron ningún agrupamiento evidente (Fig. 44B). Los juveniles se dispusieron de manera progresiva, mezclándose los de las últimas clases (J3 y J4) con los adultos. Las formas más pequeñas exhibieron un cuerpo mandibular más ancho, el borde anterior de la fosa masetérica retrasado, el proceso coronoides más estrecho, la separación entre el

proceso coronoides y condiloideo de posición más anterior y el proceso angular más corto. Las formas más grandes mostraron la inversa de estas características, i.e.: un cuerpo mandibular más estrecho, el borde anterior de la fosa masetérica adelantado, el proceso coronoides más amplio, la separación entre el proceso coronoides y condiloideo de posición más posterior, y el proceso angular más alargado (Fig. 44).

\subsubsection{Cambio de tamaño y de forma durante la ontogenia}

Sin tener en cuenta el sexo de los especímenes, se pudo observar que el tamaño craneal (Fig. 45A) y mandibular (Fig. 46A) fueron aumentando 
progresivamente, desde la clase J1 hasta A2, donde el crecimiento se detuvo y se obtuvo el tamaño definitivo, aunque luego existe un pequeño descenso en la clase A3. Cuando estos valores entre las distintas clases de edad fueron testeados, las diferencias significativas se encontraron entre las clases: J2-J3 y A1-A2 para el cráneo, y J2-J3, J4-A1 y A1-A2 para la mandíbula (Tabla 21). Para la forma, se observa un cambio en el desarrollo, estabilizándose en la clase de juveniles J4, tanto para cráneo (Fig. 45B) como para mandíbula (Fig. 46B), aunque en ninguno de estos casos las diferencias entre estadios de edad resultaron significativas (Tabla 21). Al tener en cuenta los sexos presentes en la muestra, el tamaño también aumenta de manera progresiva y se estabiliza en la misma clase de edad que cuando el sexo no fue tenido en cuenta, tanto en el cráneo (Fig. 45C), como en la mandíbula (Fig. 46C). De todas formas, se percibe que los machos son más grandes que las hembras. Esas diferencias fueron significativas entre machos y hembras de las clases de adultos A2 y A3 para el cráneo, y A3 para la mandíbula (Tabla 21). La forma presenta también este caso mucha variación entre los valores, tanto para el cráneo (Fig. 45D), como para la mandíbula (Fig. 46D). No se observó dimorfismo sexual, al no ser significativos los valores al comparar entre machos y hembras dentro de cada clase de edad (Tabla 21).

\subsubsection{Ventajas mecánicas}

El tamaño de los músculos masticatorios (Fig. 47A) aumenta progresivamente desde la clase J1 hasta A2 donde se observa la asíntota. De todas formas, el test de Mann-Whitney mostró diferencias significativas entre las clases J1-J2, J2-J3, J4-A1 y A1-A2 (Tabla 21).

La ventaja mecánica para el masetero medido al canino (Fig. 47B), muestra una serie de valores similares, una importante variación entre el valor mínimo y 
máximo en las clases de edad, y un arribo a la ventaja definitiva en la clase A1. Un patrón semejante se observa en la ventaja mecánica del masetero medida al carnicero (Fig. 47C), aunque la ventaja definitiva ocurre en la clase J3. De acuerdo con esto, las diferencias entre las clases, resultaron no significativas (Tabla 21). La ventaja mecánica del temporal medida al canino (Fig. 47D) muestra una gran variación en los valores en cada clase de edad, aunque no existe mucha diferencia entre las distintas clases de edad y ninguna de éstas resultó significativa (Tabla 21). Sin embargo, la ventaja mecánica definitiva se alcanzó en la clase de edad A1, al igual que ocurrió para la ventaja mecánica del temporal medida al carnicero (Fig. 47E). En esta ventaja, se observó un aumento progresivo desde la clase J1, y no existieron diferencias significativas entre clases de edad (Tabla 21).

\subsection{Lycalopex sechurae (Thomas 1900)}

\subsubsection{Reproducción y ontogenia}

Casi nada es conocido acerca de la reproducción y ontogenia de esta especie. Al parecer, los nacimientos ocurren en Octubre y Noviembre (Birdseye 1956, Sillero-Zubiri 2009), y se observó una hembra preñada acompañada de 2 cachorros del año anterior (Asa \&Wallace 1990), lo que sugiere que crías de distintos años pueden permanecer junto a su madre al mismo tiempo (Cossíos 2006). No se conocen datos de longevidad de esta especie (Asa \& Cossíos 2004) (Fig. 4H).

\subsubsection{Suturas y sincondrosis}

De las suturas y sincondrosis estudiadas (Tabla 22, Fig. 48), 7 de ellas $(17,5 \%)$ se fusionaron en algún momento de la ontogenia, siendo las sincondrosis spheno-occipitalis, intraoccipitalis squamolateralis y basilateralis (relacionadas con la placa occipital) las que se fusionaron antes en el tiempo. Esto ocurrió en la clase J4 
para la primera mencionada, y en la clase J3 para las dos restantes. El resto de las suturas y sincondrosis fusionadas, lo hicieron en la última clase de adultos (A3). Once suturas $(27,5 \%)$ se fusionaron parcialmente y estuvieron relacionadas con la placa occipital y el paladar, y 22 de ellas, que corresponden al 55\%, no se fusionaron en ningún momento del desarrollo. En el análisis realizado no se advirtió ningún cambio en el tipo de sutura (Tabla 22, Fig. 48).

\subsubsection{Análisis multivariado}

Machos y hembras mostraron la misma tendencia alométrica, se solaparon en una porción del morfo-espacio, y luego los machos se desplazaron a la derecha, alcanzando mayores tamaños que las hembras (Tabla 23). El primer componente principal, incluyó el 70,05\% del total de la varianza. Seis de las variables estudiadas, presentan una diferencia en la tendencia entre las modalidades trimmed y untrimmed con un $99 \%$ de confianza, ellas son: ancho del proceso mastoideo (AM), ancho de la bulla auditiva (AB), longitud de la bulla (LB), longitud del paladar (Lpal), altura del proceso coronoides (HC) y longitud del coronoides (LC). De todas maneras, el análisis trimmed presenta un menor valor de sesgo $(0,0078)$, por lo que es el que se discutirá. Ocho variables de las analizadas fueron isométricas (36,36\%): ancho de los arcos zigomáticos (AZ), constricción postorbitaria (CPO), longitud de la órbita (LO), longitud del rostro (LR), altura del hocico $(\mathrm{HH})$, altura de la bulla auditiva (HB), ancho del paladar (Apal) y altura del dentario (HD). Ocho resultaron alométricas positivas (36,36\%): longitud cóndiloincisiva (LCI), longitud de los nasales (LN), longitud del paladar (Lpal), longitud de la hilera dentaria superior (LHS), longitud del dentario (LD), altura del proceso coronoides (HC), longitud del coronoides (LC) y longitud de la hilera dentaria inferior (LHI). Las 6 restantes fueron negativas (27,28\%): altura de la placa occipital 
(HPO), ancho del proceso mastoideo (AM), ancho de la caja craneana (AC), ancho de los caninos (Acan), ancho de la bulla auditiva (AB) y longitud de la bulla (LB). Quien más se alejó de la isometría fue el ancho de la caja craneana (AC), con un valor de 0,1414 y quien menos lo hizo fue altura de la bulla auditiva (HB) con un valor de 0,0109 (Tabla 23).

\subsubsection{Morfometría geométrica}

Para el cráneo (Fig. 49A), el PC1 explica un porcentaje de 17,41\% de la varianza total, el PC2 un 10,62\% y el PC3 el 8,20\%. Sobre el PC1 se observaron los pocos juveniles que componen esta muestra, ubicados hacia los valores negativos, exhibiendo cajas craneanas redondeadas, cortas, anchas y altas, hocicos cortos, rostros curvados hacia la parte ventral, paladares anchos, basicráneos anchos, arcos zigomáticos poco expandidos, y bullas timpánicas más grandes. Hacia los valores positivos, donde los adultos se distribuyeron homogéneamente, las cajas craneanas fueron estrechas, rectas, bajas y alargadas, los rostros largos, los paladares y basicráneos elongados y estrechos, los arcos zigomáticos más expandidos, y bullas timpánicas más pequeñas. En ninguno de los componentes principales se observó separación acorde a los sexos, y los PC2 y 3 no revelaron ninguna distribución de interés (Fig. 49A).

Para la mandíbula (Fig. 49B), el primer PC explica un porcentaje de 19,93\%, el segundo un 13,03\% y el tercero un 9,39\% de la varianza total. No se hallaron diferencias en cuanto a sexos o entre clases en ninguno de ellos, y el PC2 fue el único de interés. Hacia los valores negativos se ubicó el juvenil de clase J1, que exhibió una mandíbula con un cuerpo mandibular alto, y curvado en su parte inferior y un proceso coronoides de posición posterior. Hacia los valores positivos se ubicó el juvenil más avanzado (J3), junto a los adultos de las distintas clases de 
edad distribuidos de manera uniforme, y se observaron cuerpos mandibulares completamente curvados y procesos coronoides de posición vertical (Fig. 49B).

\subsubsection{Variación alométrica de la forma}

Para el cráneo (Fig. 50), el tamaño explicó el 12,87\% de la forma $(\mathrm{P}<0,0001)$. Los especímenes más jóvenes tuvieron menor tamaño de centroide (Fig. 50A), y un cráneo redondeado, corto, ancho y alto, hocico corto, lira ancha y corta, órbitas más abiertas, bullas más altas, e inion que no sobrepasa la vertical del foramen magnum. Las formas más grandes presentaron un cráneo más estrecho, alargado y bajo, hocico más largo, lira ligeramente más larga, órbitas más cerradas, bullas más pequeñas y menos altas e inion que sobrepasa al foramen magnum. Machos, hembras e indeterminados se distribuyeron homogéneamente sin agruparse por sexos (Fig. 50B).

Para la mandíbula (Fig. 51), el tamaño explicó el 4,82\% de la forma $(\mathrm{P}<0,0533)$. La clase de juveniles J1 tuvo menores valores de tamaño de centroide y se halló separada del resto, que se encuentra totalmente integrado (Fig. 51A). Los sexos se encontraron distribuidos homogéneamente (Fig. 51B). Las formas más pequeñas presentaron un cuerpo mandibular más ancho, con el borde anterior de la fosa masetérica retrasado, el proceso coronoides recto, el punto interno del proceso condiloideo adelantado (landmark 14, Apéndice VI), el punto externo retrasado (landmark 15, Apéndice VI), y el proceso angular más corto. Para las formas más grandes la situación fue la contraria: exhibieron un cuerpo mandibular más estrecho, con el borde anterior de la fosa masetérica adelantado, el proceso coronoides con su extremo biselado, el punto interno del proceso condiloideo retrasado (landmark 14, Apéndice VI), el punto externo adelantado (landmark 15, Apéndice VI), y el proceso angular más largo (Fig. 51A). 


\subsubsection{Cambio de tamaño y de forma durante la ontogenia}

Cuando no se tuvo en cuenta el sexo de los individuos que compusieron la muestra, se observó un gran salto en el crecimiento craneal (Fig. 52A) y mandibular (Fig. 53A) desde la clase J1 a J3, y desde esta última a la clase A1, donde se alcanza el tamaño definitivo. Al observar la forma craneal (Fig. 52B) y mandibular (Fig. 53B), los resultados fueron similares. Al testear las diferencias entre clases de edad para cráneo y mandíbula, no existió ninguna que fuera significativa (Tabla 24). Al tener en cuenta los datos sobre sexo recopilados para los especímenes, se observa que arriban al tamaño y forma definitiva en la misma clase de edad que cuando no se tuvo en cuenta el sexo (Figs. 52C, 52D, 53C, 53D). Sin embargo, parece haber una diferencia en los valores absolutos entre machos y hembras, siendo los primeros más grandes. Estas diferencias resultaron ser significativas sólo entre machos y hembras de la clase A1 (Tabla 24).

\subsubsection{Ventajas mecánicas}

El tamaño de los músculos masticatorios (Fig. 54A) aumentó desde la clase J1 a la A1, donde se observa una estabilización del crecimiento. Inclusive, es visible un pequeño descenso en la clase A3. El test de Mann-Whitney no mostró diferencias significativas entre las clases de edad (Tabla 24). La ventaja mecánica del masetero medida al canino (Fig. 54B) y al carnicero (Fig. 54C), muestra a los jóvenes con valores mayores que el de los adultos. Este hecho está probablemente relacionado con la baja muestra para las primeras clases de edad, con solo un espécimen en cada una. En las 3 clases de adultos los valores se mantuvieron parecidos, mostrando que la estabilización ocurre en la clase A1. No existieron diferencias significativas para estas ventajas (Tabla 24). La ventaja del temporal medida en relación al canino (Fig. 54D) y al carnicero (Fig. 54E), muestra valores 
similares entre los distintos estadios de edad hasta su estabilización en la clase A2. Para ambas existieron diferencias significativas entre las clases A1 y A2, y en ningún caso se observaron diferencias entre sexos en las distintas ventajas mecánicas para las distintas clases de edad (Tabla 24).

\subsection{Lycalopex vetulus (Lund 1842)}

\subsubsection{Reproducción y ontogenia}

En vida silvestre, las hembras tienen un período de gestación de 50 días (Dalponte 2008) y producen camadas de 4-5 cachorros una vez al año (Nowak 2005, Sillero-Zubiri 2009). Los cachorros nacen en madrigueras y son cuidados tanto por el padre como la madre (Dalponte \& Courtenay 2004). Mientras dura la lactancia la madre va a la madriguera 1 ó 2 veces por noche, para alimentar a los cachorros. En su ausencia, el macho los cuida, los acicala y los defiende de potenciales predadores. Alrededor de los 2 meses los cachorros pesan $450 \mathrm{~g}$, y a los 3 meses son destetados. Después de esto, el contacto de la hembra con ellos disminuye sustancialmente, mientras el macho juega y caza con ellos cerca de la madriguera (Sillero-Zubiri 2009). Entre los 3-5 meses exploran el medio que los

rodea alejándose de la madriguera a lo sumo $300 \mathrm{~m}$, entre los 5-8 meses exploran el territorio de sus padres y entre los 8-10 meses, realizan excursiones regulares fuera del territorio de sus padres (Courtenay et al. 2006). Los juveniles de ambos sexos se dispersan entre los 9-10 meses y pueden establecerse en territorios adyacentes a su territorio natal (Sillero-Zubiri 2009). No hay información acerca de la longevidad en vida silvestre, pero en cautiverio se registró una hembra de 8 años de edad (Dalponte \& Courtenay 2004) (Fig. 4I). 


\subsubsection{Suturas y sincondrosis}

A pesar de que esta muestra no incluye información de juveniles (Apéndice II), podemos observar (Tabla 25, Fig. 55) que la primera en fusionarse es la sutura sagittalis caudal, en la clase A1, aunque no se puede determinar si se fusionó antes en el tiempo. Si bien esta sutura no está incluida en el área occipital, corresponde a la parte posterior del cráneo. Otras catorce, que conforman junto a la anterior un 37,5\% del total, se obliteraron completamente en otros estadios de adultos (A2 ó A3). Nueve (22,5\%), se fusionaron parcialmente durante la ontogenia, y las 16 restantes (40\%) no se fusionaron nunca en los individuos de esta muestra. Sólo 2 suturas presentaron cambios en el tipo, palatomaxillaris mesial e interfrontalis caudal, que se hicieron más complejas, pasando de escamosa y plana (respectivamente) a aserrada (Tabla 25, Fig. 55).

\subsubsection{Análisis multivariado}

Para esta especie, machos y hembras se distribuyeron de manera uniforme, mostrando la misma tendencia alométrica, sin formar agrupaciones vinculadas al sexo. El primer componente principal, incluyó el $66,64 \%$ del total de la varianza. Las variables que fueron diferentes al comparar los resultados de los análisis trimmed y untrimmed fueron 4 (Tabla 26): ancho del proceso mastoideo (AM), ancho de la bulla auditiva $(\mathrm{AB})$, altura del proceso coronoides $(\mathrm{HC})$ y longitud de la hilera dentaria inferior (LHI). Al presentar el análisis trimmed el valor absoluto más bajo de sesgo $(0,0117)$, se eligieron estos valores para discutir. Los resultados mostraron tendencias isométricas para 14 variables (63,64\%): longitud cóndiloincisiva (LCI), altura de la placa occipital (HPO), ancho de los arcos zigomáticos (AZ), longitud de la órbita (LO), longitud de los nasales (LN), longitud del rostro (LR), ancho de los caninos (Acan), altura del hocico (HH), altura de la bulla 
auditiva (HB), longitud de la bulla (LB), ancho del paladar (Apal), longitud del paladar (Lpal), longitud del dentario (LD) y altura del dentario (HD). Seis tendencias fueron alométricas negativas $(27,27 \%)$ : ancho del proceso mastoideo (AM), ancho de la caja craneana (AC), constricción postorbitaria (CPO), ancho de la bulla auditiva $(\mathrm{AB})$, longitud de la hilera dentaria superior (LHS) y longitud de la hilera dentaria inferior (LHI). Solo 2 (9,09\%) fueron alométricas positivas: altura del proceso coronoides (HC) y longitud del coronoides (LC). Quien más se alejó de la isometría fue la constricción postorbitaria (CPO), con un valor de 0,2050 y quien menos lo hizo fue la longitud del dentario (LD) con un valor de 0,0113 (Tabla 26).

\subsubsection{Morfometría geométrica}

En el cráneo (Fig. 56A), el PC1 explica un porcentaje de 20,94\%, el PC2 el 16,99\% y el PC3 representó un porcentaje del 11,91\% de la varianza total. No se observó ninguna distribución en el morfoespacio que esté vinculada a los sexos, o que esté relacionada a las distintas clases de edad para ninguno de los 3 componentes principales, por lo que no se describen diferencias entre formas.

Para la mandíbula (Fig. 56B), el PC1 explica un porcentaje de 22,78\%, el PC2 un $19,48 \%$ y el PC3 un 15,55\% de la varianza total. No se hallaron agrupaciones vinculadas a los sexos. El único PC que mostró resultados de interés fue el segundo en el que se observó una separación entre los adultos de las clases A1 y A3, ubicados hacia los valores positivos y medios, y la clase A2, ubicada hacia los valores negativos de éste. En esta última clase la mandíbula mostró un cuerpo mandibular recto y robusto, y una rama mandibular dispuesta dorsoventralmente, mientras que en las restantes clases la configuración fue la opuesta: un cuerpo mandibular curvado y débil, y una rama mandibular dispuesta en posición posterior (Fig. 56B). 


\subsubsection{Variación alométrica de la forma}

Para el cráneo (Fig. 57A), el tamaño explicó el 8,52\% de la forma $(\mathrm{P}<0,3167)$ $\mathrm{y}$, a pesar de no ser valores significativos, se pudo apreciar a las clases de adultos distribuidas en todo el espacio sin agrupamiento alguno, al igual que los sexos (Fig. 57B). Las formas más pequeñas y más grandes no tuvieron diferencias muy fuertes, aunque las primeras mostraron un cráneo con el hocico más ancho, y la fosa temporal ligeramente más pequeña, las bullas y órbitas más pequeñas y las formas más grandes mostraron la conformación contraria (Fig. 57).

Para la mandíbula (Fig. 58A), el tamaño explicó el 14,15\% de la forma $(\mathrm{P}<0,0262)$. Al igual que lo que ocurrió con el cráneo, las 3 clases de edad están distribuidas homogéneamente, de la misma manera que ocurre con los sexos (Fig. 58B). Las mandíbulas de las formas más pequeñas mostraron tener un cuerpo mandibular más curvado y ancho, el borde anterior de la fosa masetérica retrasado, el proceso coronoides con posición más vertical y el proceso angular más corto. Para las formas más grandes estos caracteres tuvieron la configuración opuesta: un cuerpo mandibular más recto y estrecho, el borde anterior de la fosa masetérica adelantado, el proceso coronoides con posición posterior y el proceso angular más alargado (Fig. 58).

\subsubsection{Cambio de tamaño y de forma durante la ontogenia}

Para el tamaño craneal (Fig. 59A) y mandibular (Fig. 60A), sin tener en cuenta los sexos de los individuos, se observó que el tamaño definitivo ya fue obtenido en la clase de edad A1 para el cráneo, y en la clase A3 para la mandíbula. $\mathrm{Al}$ analizar la forma, el desarrollo de ésta parece haberse detenido en la clase A2 para el cráneo (Fig. 59B) y en la clase A3 para la mandíbula (Fig. 60B). Cuando se 
analizó el crecimiento del cráneo (Fig. 59C) teniendo en cuenta los sexos de los individuos, el patrón fue confuso, mostrando una hembra de la clase A3 con valores inesperadamente muy bajos y un macho de esta misma clase con valores más altos, al igual que lo que ocurrió con la mandíbula (Fig. 60C). La forma mostró mucha variación en los valores, con las hembras presentando mayores valores que los machos para la clase A3, tanto para el cráneo (Fig. 59D), como para la mandíbula (Fig. 60D). Por el tamaño muestral no fue posible testear ni las diferencias entre clases sin tener en cuenta el sexo, ni las diferencias entre éstas teniendo en cuenta el dimorfismo sexual.

\subsubsection{Ventajas mecánicas}

El tamaño de los músculos masticatorios (Fig. 61A), muestra un aumento desde la clase de adultos A1 hasta la clase A3, donde se estabiliza el crecimiento. La ventaja mecánica del masetero en relación al canino (Fig. 61B), muestra valores muy similares entre las dos clases de adultos extremas, mostrando que la estabilización para esta ventaja ya existe en la clase A1. La ventaja mecánica del masetero al carnicero (Fig. 61C) aumenta con la edad y se estabiliza en la última clase de adultos A3. La ventaja del temporal tanto si se mide al canino (Fig. 61D) como al carnicero (Fig. 61E), se incrementa con la edad y alcanza su óptimo de manera definitiva en la clase de edad A2. El bajo número de esta muestra impidió testear las diferencias entre clases y entre sexos.

\subsection{Speothos venaticus (Lund 1842)}

\subsubsection{Reproducción y ontogenia}

El carácter altamente social de este cánido influencia el patrón reproductivo de la especie. Las hembras jóvenes no entran en estro cuando viven con sus madres 
o sus hermanas mayores (hembras más dominantes), pero lo hacen rápidamente cuando se encuentran con un macho (Beisiegel \& Ades 2002). El período de gestación es de 67 días, y el tamaño de camada es entre 1-6 crías (Nowak 2005, Sillero-Zubiri 2009). El peso de los recién nacidos es de 130-190 g (Nowak 2005), aumentando a 210 a los 20 días, 382 a los 30 días, y a 515 a los 40 días (Bekoff \& Jamieson 1975). A los 3 meses pesaron entre 3,6-3,8 kg, mientras que al año y 3 meses pesaron entre 7,7-8,8 kg (Jantschke 1973). Abren los ojos entre los 8-17 días y comienzan a tener interacciones sociales entre los 9-18 días (Biben 1982b). Los caninos erupcionan entre los 23 y los 25 días (Biben 1982b) y son lactantes hasta los 2 meses (Zuercher et al. 2004), aunque comen sólidos a partir de los 38 días (Biben 1982b). Los padres regurgitan comida para los cachorros a partir de la sexta semana. Ellos participan en cacerías con sus padres desde los 44 días y se interesan por colaborar cuando están con ellos, aunque se muestran muy precavidos con las presas cuando se la ofrecen en ausencia de los adultos (Biben 1982b). Son maduros sexualmente a partir del año de edad (Sillero-Zubiri 2009) y la esperanza de vida en cautividad es de 13 años (Nowak 2005) (Fig. 4J).

\section{10.2. Suturas y sincondrosis}

Además de las suturas y sincondrosis que no existen típicamente en cánidos (Apéndice IV, Tabla 27, Fig. 62), hay una tercera sutura que no está presente exclusivamente en esta especie, en ningún momento de la vida y es la sutura nasomaxillaris. De las restantes, 23 (79,31\%) se fusionaron en algún momento de la vida, siendo las sincondrosis intraoccipitalis squamolateralis y basilateralis las más tempranas, que se obliteraron en la clase J1. A estas les siguen las suturas sagittalis cranial y caudal, que lo hicieron en la clase J3, y la sutura occipitoparietalis, que se fusionó en la clase J4. Las restantes suturas y sincondrosis se fusionaron en las 
clases de adultos. Tres suturas (10,34\%) se fusionaron parcialmente durante la ontogenia y estuvieron relacionadas con los arcos zigomáticos. Trece (44,83\%) nunca se fusionaron y estuvieron relacionadas con las áreas frontales y rostrales de los cráneos. Cinco suturas presentaron cambios de tipo cuando fueron analizadas: las suturas sagittalis cranial y caudal, interfrontalis caudal e interpalatina, que cambiaron de plana a aserrada y occipitoparietalis que cambió de plana a escamosa. Es decir, en todos los casos con tendencia a aumentar la complejidad (Tabla 27, Fig. $62)$.

\section{10.3. Análisis multivariado}

Machos y hembras mostraron la misma tendencia alométrica, distribuyéndose de manera homogénea. El primer componente principal, incluyó el 63,74\% del total de la varianza. De las 22 variables observadas (Tabla 28), 4 muestran diferentes tendencias al comparar los resultados de los análisis trimmed y untrimmed: ancho del proceso mastoideo (AM), longitud de la bulla (LB), longitud del dentario (LD) y longitud de la hilera dentaria inferior (LHI). De todas maneras, al ser el sesgo del análisis trimmed el menor $(0,0055)$, se discutirán estos resultados. Doce de las variables analizadas fueron isométricas (54,55\%): longitud cóndiloincisiva (LCI), altura de la placa occipital (HPO), longitud de los nasales (LN), longitud del rostro (LR), ancho de los caninos (Acan), altura del hocico (HH), ancho de la bulla auditiva ( $\mathrm{AB})$, altura de la bulla auditiva (HB), ancho del paladar (Apal), longitud del paladar (Lpal), longitud de la hilera dentaria superior (LHS) y altura del dentario (HD). Seis fueron alométricas negativas $(27,27 \%)$ : ancho del proceso mastoideo (AM), ancho de la caja craneana (AC), constricción postorbitaria (CPO), longitud de la órbita (LO), longitud de la bulla (LB) y longitud de la hilera dentaria inferior (LHI). Cuatro de ellas fueron positivas (18,18\%): ancho de los 
arcos zigomáticos (AZ), longitud del dentario (LD), altura del proceso coronoides (HC) y longitud del coronoides (LC). Quien más se alejó de la isometría fue la longitud del coronoides (LC), con un valor de 0,1890 y quien menos lo hizo fue la altura del dentario (HD), con un valor de 0,0003 (Tabla 28).

\section{10.4. Morfometría geométrica}

Para el cráneo (Fig. 63A), el PC1, explica un porcentaje de 30,10\% de la varianza total, el PC2 el 9,06\% y el PC3 el 8,09\%. En el PC1 se observó hacia los valores negativos a los juveniles distribuidos de manera homogénea. Las cajas craneanas fueron redondeadas, cortas, anchas y altas, al igual que el rostro. Los paladares y basicráneos fueron cortos y anchos, los arcos zigomáticos poco expandidos y el foramen magnum fue grande y adoptó una posición ventral. Las órbitas y bullas fueron grandes. Hacia los valores positivos, los adultos se distribuyeron de manera indistinta, sin relación a la clase de edad, mostrando cajas craneanas estrechas, bajas y alargadas, al igual que los rostros. Los paladares y basicráneos fueron elongados y más estrechos, los arcos zigomáticos expandidos y el foramen magnum es pequeño y de posición posterior. Las órbitas y bullas fueron más pequeñas. No se observó separación entre machos y hembras, y los restantes componentes principales no mostraron distribuciones que sean de interés (Fig. $63 \mathrm{~A})$.

En relación a la mandíbula (Fig. 63B), el PC1 representó un porcentaje del 20,08\%, el PC2 un 16,16\% y el PC3 un 11,36\% de la varianza total. No se hallaron diferencias en cuanto a sexos o a clases de edad y el único PC que resultó de interés fue el primero. Hacia sus valores negativos se encontraron los jóvenes y hacia los valores medios y positivos la mayoría de los adultos. Hacia el área del morfoespacio donde se ubicaron los juveniles, las mandíbulas tuvieron cuerpos 
mandibulares más largos con la parte inferior más recta, y la rama ascendente más pequeña y orientada posteriormente. Hacia los valores donde estuvieron los adultos la configuración fue la opuesta, con cuerpos mandibulares más cortos con la parte ventral curvada y la rama ascendente más grande y orientada dorsoventralmente (Fig. 63B).

\section{10.5. Variación alométrica de la forma}

Para el cráneo (Fig. 64), el tamaño explicó el 25,46\% de la forma ( $\mathrm{P}<0,0001)$. Los especímenes más jóvenes mostraron valores de tamaño de centroide menores (Fig. 64A), alejándose mucho la clase B de los restantes juveniles. La clase de juveniles J3 se integra junto a los adultos quienes se distribuyen de manera homogénea. Machos, hembras e indeterminados no formaron grupos por sexo (Fig. 64B). Las formas más pequeñas mostraron cráneos más anchos y cortos, cajas craneanas altas, hocicos más cortos, anchos, altos y curvados ventralmente, liras más anchas y largas, arcos zigomáticos poco expandidos y posición del foramen magnum más posterior en relación al inion. Las formas más grandes mostraron cráneos más estrechos y largos, cajas craneanas bajas, hocicos más elongados, estrechos, bajos y rectos, liras más alargadas, arcos zigomáticos expandidos y posición del foramen magnum anterior en relación al inion (Fig. 64).

Para la mandíbula (Fig. 65), el tamaño explicó el 9,76\% de la forma $(\mathrm{P}<0,0001)$. Las clases que incluyeron especímenes jóvenes (Fig. 65A), se dispusieron de manera progresiva, en los valores más bajos de tamaño de centroide, en tanto los adultos lo hicieron homogéneamente hacia los valores más altos. En cuanto a los sexos también se distribuyeron indistintamente (Fig. 65B), sin que se produjeran agrupaciones. Las formas más pequeñas se diferenciaron muy poco de la grandes, y sólo en el cuerpo mandibular más ancho, el borde anterior de 
la fosa masetérica retrasado, el proceso coronoides más débil y proyectado hacia atrás, y la parte inferior de la rama mandibular más estrecha (Fig. 65).

\section{10.6. Cambio de tamaño y de forma durante la ontogenia}

Si no se tiene en cuenta el sexo de los especímenes, el tamaño craneal (Fig. 66A) y mandibular (Fig. 67A) muestra un brusco salto entre la clase de edad B y J1 y un paso más moderado entre las clases J2 y J3. Esta progresión cesa al obtenerse el tamaño definitivo en la clase A2. Al analizar las diferencias entre clases de edad, en tamaño se obtuvo significancia entre las clases A1 y A2 para el cráneo, aunque no se obtuvo significancia para la mandíbula (Tabla 29). La forma se ve muy distinta entre la clase de los más jóvenes B y J1. Luego, los valores se presentan muy parecidos, obteniéndose la forma definitiva en la clase A1, tanto para el cráneo (Fig. 66B), como para la mandíbula (Fig. 67B). El test U de Mann-Whitney no mostró significancia para las diferentes clases de edad de la muestra (Tabla 29). Teniendo en cuenta el sexo, el tamaño también se muestra progresivo, y se estabiliza en la misma clase de edad que cuando no fue tenido en cuenta, tanto para el cráneo (Fig. 66C), como para la mandíbula (Fig. 67C). No hubo diferencias significativas entre machos y hembras, para las distintas clases de edad (Tabla 29). Para la forma se observó el mismo patrón que cuando no se tuvo en cuenta el sexo, tanto para el cráneo (Fig. 66D), como para la mandíbula (Fig. 67D). No se observaron diferencias que fueran significativas testeándolas con el test U de Mann Whitney (Tabla 29).

\section{10.7. Ventajas mecánicas}

El tamaño de los músculos masticatorios (Fig. 68A) se incrementó conforme aumentó la edad, llegando a la asíntota en la clase A2. Se encontraron diferencias 
significativas entre las clases de edad A1 y A2, testeando esta medida con el test $\mathrm{U}$ de Mann-Whitney (Tabla 29). La ventaja mecánica del masetero al canino (Fig. 68B) y al carnicero (Fig. 68C) se observó similar en las primeras clases, mostrando un aumento significativo desde la clase A1 a la A2, donde se obtuvo la asíntota para esta medida. Se encontraron diferencias significativas entre los estadios de edad A1 y A2, exclusivamente para la ventaja del masetero al canino (Tabla 29). La ventaja mecánica del temporal al canino (Fig. 68D) muestra gran similitud con las ventajas observadas para el músculo masetero. En las primeras clases los valores se muestran parecidos, produciéndose la asíntota en la clase A1. La ventaja del temporal al carnicero (Fig. 68E) se incrementa conforme aumenta la edad, produciéndose la asíntota en la clase A1. No se hallaron diferencias que fueran significativas entre las distintas clases de edad (Tabla 29).

\subsection{Urocyon cinereoargenteus (Schreber 1775)}

\section{11.1. Reproducción y ontogenia}

El período de gestación dura 60 días, mientras que el tamaño de camada es de 1-10 cachorros, siendo 4 lo más común (Sillero-Zubiri 2009, Nowak 2005). Los jóvenes pesan $100 \mathrm{~g}$ al nacer y abren los ojos entre los 9-12 días. Pueden trepar troncos al mes de edad y empiezan a comer sólidos a los 2 meses y medio (Nowak 2005). Acompañan a sus padres a buscar comida a los 3 meses y lo hacen solos a los 4 meses. Los cachorros son alimentados principalmente por hembras, pero el cuidado parental recae en ambos padres (Sillero-Zubiri 2009). Los juveniles alcanzan el tamaño y peso adulto a los 7 meses (Fuller \& Cypher 2004). Alcanzan la madurez sexual a los 10 meses de edad (Sillero-Zubiri 2009). Los cachorros se dispersan entre los 9-10 meses de edad, y aunque pueden hacerlo a grandes distancias, suelen establecerse cerca del territorio de los padres (Fuller \& Cypher 
2004). La esperanza de vida de manera silvestre no sobrepasa los $4-5$ años (Fuller \& Cypher 2004), aunque en cautividad es de 13 años (Nowak 2005) (Fig. 4K).

\section{11.2. Suturas y sincondrosis}

De las suturas y sincondrosis analizadas (Tabla 30, Fig. 69), 10 se fusionaron completamente representando el $25 \%$ del total de la muestra. Dos sincondrosis se fusionaron en un estadio temprano del desarrollo (J2) y corresponden a la placa occipital: sincondrosis intraoccipitalis squamolateralis y basilateralis. Cinco de ellas, relacionadas con el extremo posterior del cráneo, se fusionaron en la clase de adultos A2, aunque podrían haberlo hecho en la clase A1, pero la ausencia de ejemplares de esta clase en la muestra no permite tener seguridad sobre esto. Tres de ellas se fusionaron completamente en la clase de adultos más viejos (A3) y están relacionadas con la base del cráneo y el paladar. Catorce de ellas (35\%) se fusionaron parcialmente, y las restantes 16 (40\%) no se fusionaron en ningún momento del desarrollo y corresponden a la zona del hocico, del paladar y de los arcos zigomáticos. En relación al tipo de suturas, sólo cambiaron su configuración 3 de ellas: la sutura occipitoparietalis que era plana durante las clases B y J1, cambió a escamosa; mientras que las suturas interfrontalis caudal y sagittalis (cranial) se mostraron planas durante el estadio B y a partir de J1 se complejizaron volviéndose aserradas (Tabla 30, Fig. 69).

\section{11.3. Análisis multivariado}

Tanto machos como hembras mostraron la misma tendencia alométrica, y se ubicaron homogéneamente sin tener en cuenta los sexos. El primer componente principal, incluyó el 88,38\% del total de la varianza. Ninguna de las variables analizadas (Tabla 31) mostró diferencias entre el análisis trimmed y untrimmed 
realizado con $99 \%$ de intervalo de confianza. Esto significa que no existen seudovalores extremos que afecten la estimación de Jackknife. De las variables observadas, 12 fueron negativas (54,55\%): altura de la placa occipital (HPO), ancho del proceso mastoideo (AM), ancho de la caja craneana (AC), constricción postorbitaria (CPO), longitud de la órbita (LO), ancho de los caninos (Acan), altura del hocico $(\mathrm{HH})$, ancho de la bulla auditiva $(\mathrm{AB})$, altura de la bulla auditiva (HB), longitud de la bulla (LB), ancho del paladar (Apal) y altura del dentario (HD). Nueve de ellas (40,91\%), fueron alométricas positivas: longitud cóndilo-incisiva (LCI), longitud de los nasales (LN), longitud del rostro (LR), longitud del paladar (Lpal), longitud de la hilera dentaria superior (LHS), longitud del dentario (LD), altura del proceso coronoides (HC), longitud del coronoides (LC) y longitud de la hilera dentaria inferior (LHI). Sólo 1 (4,54\%) resultó isométrica y fue el ancho de los arcos zigomáticos (AZ). Quien más se alejó de la isometría fue la longitud del rostro (LR), con un valor de 0,1823 y quien menos lo hizo fue el ancho de los arcos zigomáticos (AZ) con un valor de 0,0158 (Tabla 31).

\section{11.4. Morfometría geométrica}

En relación al cráneo (Fig. 70A), el PC1 explica un porcentaje de 32,83\%, el PC2 un 8,01\% y el PC3 un porcentaje del 6,07\% de la varianza total. Hacia los valores negativos se encontraron los adultos, y hacia el centro y hacia los valores positivos, los juveniles. En ambos casos están distribuidos sin agruparse de acuerdo a las clases de edad o sexo. Hacia donde se encontraron los adultos, la forma que adoptaron los cráneos incluyó una caja craneana estrecha, elongada y baja, hocico largo y delgado al igual que el paladar, que fue también recto. Los arcos zigomáticos fueron expandidos, las órbitas más estrechas y las bullas más pequeñas. Hacia donde se ubicaron los jóvenes, la caja craneana fue ancha, corta y 
alta, el hocico alto, ancho, corto, al igual que el paladar, que fue curvado hacia la región ventral. Los arcos zigomáticos no estuvieron expandidos, las órbitas y las bullas fueron más grandes (Fig. 70A).

En relación a la mandíbula (Fig. 70B), el PC1 representó un porcentaje del 16,41\%, el PC2 un $15,47 \%$ y el PC3 un 9,04\% de la varianza total. No hubo agrupaciones relativas a los sexos o las clases de edad y el PC1 fue el que resultó de interés. Hacia los valores negativos se encontraron los jóvenes y hacia los valores medios y positivos la mayoría de los adultos. Hacia donde estuvieron los juveniles, las mandíbulas tuvieron cuerpos mandibulares más anchos y cortos, con la parte inferior más recta y rama ascendente más pequeña y orientada posteriormente. Hacia los valores donde estuvieron los adultos la configuración fue la opuesta: cuerpos mandibulares más estrechos y largos, con la parte inferior curvada y la rama ascendente bien desarrollada y orientada dorso-ventralmente (Fig. 70B).

\section{11.5. Variación alométrica de la forma}

Para el cráneo (Fig. 71), el tamaño explicó el 28,84\% de la forma $(\mathrm{P}<0,0001)$. Se observó (Fig. 71A) a los especímenes jóvenes ubicados hacia los valores más bajos de tamaño de centroide y una diferencia importante entre la clase $\mathrm{B}$ y el resto de los juveniles que parecen estar ubicados en otra recta. Los especímenes de J3 y J4 se solapan con los adultos que se distribuyen de manera homogénea sin distinción entre clases. Con respecto a los sexos (Fig. 71B), no hubo distinción alguna entre ellos. Las formas más pequeñas mostraron cráneos más anchos, altos y cortos, hocicos más cortos, anchos y altos, curvados ventralmente. Las liras fueron más anchas y cortas, los cóndilos occipitales se ubicaron paralelos a la placa occipital. El foramen magnum tuvo posición posterior al inion, las órbitas y bullas fueron más amplias. Las formas más grandes mostraron cráneos más estrechos, 
bajos y largos, hocicos más elongados, estrechos y bajos, rectos ventralmente. Las liras fueron alargadas y estrechas, los cóndilos occipitales tuvieron posición oblicua con respecto a la placa occipital. El foramen magnum estuvo en la misma línea del inion, y las órbitas y bullas fueron más estrechas (Fig. 71).

Para la mandíbula (Fig. 72), el tamaño explicó el 9,48\% de la forma $(\mathrm{P}<0,0001)$. Los especímenes de las clases juveniles se ubicaron (Fig. 72A) de manera progresiva en los valores de tamaño de centroide más bajos, mientras las clases de adultos, distribuidos más homogéneamente, ocuparon los valores más altos de tamaño de centroide. Con respecto a los sexos (Fig. 72B), no se observaron agrupaciones o distribuciones vinculadas a ellos. Las formas más pequeñas fueron muy similares a las más grandes, mostrando diferencias sólo en el cuerpo mandibular que fue más ancho, la parte anterior de la fosa masetérica ligeramente retrasada, el proceso coronoides fue más delgado y dirigido hacia atrás, al igual que el proceso condiloideo (Fig. 72).

\section{11.6. Cambio de tamaño y de forma durante la ontogenia}

Cuando no se tiene en cuenta el sexo, el tamaño craneal (Fig. 73A) y mandibular (Fig. 74A) es progresivo, mostrando un gran salto entre la clase B y J1. El aumento se mantiene hasta la clase A2 donde se establece el tamaño definitivo para ambos. Las comparaciones que resultaron significativas fueron J4-A1 y A1-A2 para el cráneo y J1-J2, J2-J3, J4-A1 y A1-A2 para el tamaño mandibular (Tabla 32). Con respecto a la forma tanto craneal (Fig. 73B) como mandibular (Fig. 74B), se muestra muy diferente entre la clase B y la clase J1, luego los valores son similares y, finalmente la estabilización llega en la clase A1. Para la forma, las diferencias significativas estuvieron entre las clases J4-A1, en relación al cráneo, y no existieron para ninguna de las clases de edad, en relación a la mandíbula (Tabla 
32). Teniendo en cuenta el sexo de los especímenes, el aumento progresivo del tamaño también es perceptible, además de un valor ligeramente mayor de los machos por sobre las hembras de su misma clase, tanto para el cráneo (Fig. 73C), como para la mandíbula (Fig. 74C). De todas maneras, estas diferencias no resultaron significativas para ninguno de los estadios de edad (Tabla 32). En cuanto a la forma, los valores de los machos parecen ser mayores que los de las hembras, tanto para el cráneo (Fig. 73D) como para la mandíbula (Fig. 74D). Sin embargo, el test de Mann-Whitney no mostró diferencias significativas entre sexos en ninguna de las clases de edad (Tabla 32).

\section{11.7. Ventajas mecánicas}

El tamaño de los músculos masticatorios (Fig. 75A) se incrementa conforme avanza la edad, estabilizándose en la clase de adultos A2. El test de Mann-Whitney mostró diferencias significativas entre estas clases: J1-J2, J3-J4, J4-A1 y A1-A2 (Tabla 32). La ventaja mecánica del masetero al canino (Fig. 75B), al igual que al carnicero (Fig. 75C), mostró valores similares en todas las clases de edad, presentando una gran variación en la mayoría de sus estadios y estabilizándose en la clase A2. Ninguna de estas ventajas resultó significativa al ser testeada con Mann-Whitney (Tabla 32). Lo mencionado antes, también ocurrió con la ventaja mecánica del músculo temporal al canino (Fig. 75D) y al carnicero (Fig. 75E). Aunque en este último caso se pudo observar un valor diferente, y más bajo que el resto en la clase $\mathrm{J} 1 \mathrm{y}$, finalmente, un incremento que muestra una asíntota en la clase J4. La única diferencia significativa fue entre las clases J1-J2 para la ventaja mecánica del temporal al carnicero (Tabla 32). 


\title{
IV RESULTADOS FELIDAE
}

\author{
Oh pequeño \\ Emperador sin orbe, \\ Conquistador sin patria, \\ Mínimo tigre de salón, sultán del cielo \\ De las tejas eróticas, \\ El viento del amor \\ En la intemperie \\ Reclamas \\ Cuando pasas \\ Y posas \\ Cuatro pies delicados \\ En el suelo, \\ Oliendo, \\ Desconfiando \\ De todo lo terrestre, \\ Porque todo \\ Es inmundo
}

Para el inmaculado pie del gato. 


\subsection{Leopardus colocolo (Molina 1782)}

\subsubsection{Reproducción y ontogenia}

Existe poca información acerca de la reproducción y ontogenia para esta especie. El período de gestación dura 83 días y es más largo que el de los demás félidos de su mismo tamaño (Callahan \& Dulaney 1997). La camada puede tener de 1 a 3 cachorros (Sunquist \& Sunquist 2009), que pesan unos $132 \mathrm{~g}$ al nacer (Sunquist \& Sunquist 2002) y recién cerca de los 2 meses de edad la madre les permite explorar su entorno (Callahan \& Dulaney 1997). En cautiverio, las hembras son sexualmente maduras a los 2 años de edad (Sunquist \& Sunquist 2002) (Fig. $4 \mathrm{~L})$.

\subsubsection{Suturas y sincondrosis}

De las suturas y sincondrosis analizadas (Apéndice IV, Tabla 33, Fig. 76), 8 se fusionaron (19,04\%): 2 de ellas lo hicieron completamente en estadios tempranos del desarrollo (J2) y corresponden a sincondrosis vinculadas a la placa occipital: sincondrosis intraoccipitalis squamolateralis y basilateralis; dos de ellas se fusionaron parcialmente durante los estadios J4 y A1 y luego se fusionaron completamente, correspondiendo al área del basicráneo: sincondrosis spheno-occipitalis e intersphenoidalis, y las 4 restantes se fusionaron completamente en las clases de adultos A2 y A3, siendo en su mayoría relacionadas con la parte posterior del cráneo. Las 34 suturas y sincondrosis restantes (80,95\%) no se fusionaron en ningún momento del desarrollo. En relación al tipo de suturas, 7 cambiaron de configuración: Las suturas occipitointerparietalis y occipitoparietalis que cambiaron de plana a escamosa o a escamosa/aserrada; la sutura parietointerparietalis, intermaxillaris (=Palatina mediana) e interpalatina (=Palatina transversa) que cambiaron 
de plana a aserrada, y las suturas Palatomaxillaris mesial y lateral, que cambiaron de escamosa a aserrada. En todas ellas se observa una tendencia a la mayor complejidad de la sutura, aumentando la superficie de contacto entre las dos zonas unidas (Tabla 33, Fig. 76).

\subsubsection{Análisis multivariado}

Machos y hembras tuvieron idéntica tendencia alométrica, solapándose en el morfo-espacio, y luego con machos desplazados a la derecha, alcanzando tamaños más grandes que las hembras. El primer componente principal, incluyó el $75,60 \%$ del total de la varianza. De las 22 variables analizadas (Tabla 34), 10 muestran diferentes tendencias al realizar un análisis trimmed y untrimmed al 99\% de confianza, éstas son: altura de la placa occipital (HPO), ancho de la caja craneana (AC), altura del hocico $(\mathrm{HH})$, ancho de la bulla auditiva $(\mathrm{AB})$, altura de la bulla auditiva (HB), ancho del paladar (Apal), longitud del dentario (LD), altura del dentario (HD), longitud del coronoides (LC) y longitud de la hilera dentaria inferior (LHI). De todas maneras, se discutirán las tendencias del análisis trimmed, que mostró el valor más bajo de sesgo $(0,0065)$. Diez variables resultaron alométricas negativas (45,45\%): altura de la placa occipital (HPO), ancho del proceso mastoideo $(\mathrm{AM})$, ancho de la caja craneana (AC), constricción postorbitaria $(\mathrm{CPO})$, altura del hocico $(\mathrm{HH})$, ancho de la bulla auditiva $(\mathrm{AB})$, altura de la bulla auditiva (HB), longitud de la bulla (LB), ancho del paladar (Apal), y longitud de la hilera dentaria inferior (LHI). Siete fueron isométricas (31,82\%): longitud cóndiloincisiva (LCI), longitud de la órbita (LO), longitud de los nasales (LN), longitud del rostro (LR), ancho de los caninos (Acan), longitud del paladar (Lpal) y longitud de la hilera dentaria superior (LHS). Finalmente, 5 resultaron ser alométricas positivas (22,73\%): ancho de los arcos zigomáticos (AZ), longitud del dentario (LD), altura 
del dentario (HD), altura del proceso coronoides (HC) y longitud del coronoides (LC). Quien más se alejó de la isometría fue la longitud del coronoides (LC), con un valor de 0,2101 y quien menos lo hizo fue el ancho de los caninos (Acan), con un valor de 0,0041 (Tabla 34).

\subsubsection{Morfometría geométrica}

En relación al cráneo (Fig. 77A), el PC1 explica un porcentaje de 18,20\% de la varianza total, el PC2, el 12,73\% y el PC3 el 9,31\%. Sobre el PC1 la distribución de jóvenes y adultos es bastante homogénea, sin embargo, sobre el PC2 se presentó mayor diferenciación entre jóvenes y adultos, agrupando a los primeros más concentrados en los valores positivos. Hacia estos valores se observaron cráneos más redondeados, cajas craneanas anchas y altas, hocicos más estrechos y aperturas nasales ubicadas frontalmente al igual que las órbitas. También se percibieron arcos zigomáticos no expandidos y débiles, paladares más estrechos con torus palatino convexo, basicráneo y paladar más cercanos entre sí. Los adultos mostraron cajas craneanas más estrechas y bajas, hocicos anchos y aperturas nasales más dorsales, al igual que ocurre con las órbitas, arcos zigomáticos expandidos y fuertes, paladares más anchos con torus palatino cóncavo, basicráneo y paladar más alejados entre sí. El PC3 no mostró ninguna configuración de interés y en ninguno de los PCs se observó ninguna agrupación vinculada al sexo (Fig. 77A).

En relación a la mandíbula (Fig. 77B), el PC1 representó un porcentaje del 29,90\%, el PC2 un 14,14\% y el PC3 un 9,59\% de la varianza total. Al igual que lo

que ocurrió con el cráneo, la mayoría de la diversificación entre los especímenes se encontró en el PC2, mientras que en relación al PC1, al igual que en el PC3, se ubicaron de manera más homogénea. Tampoco aquí se hallaron diferencias en 
cuanto a sexos o entre clases. En relación al PC2, que fue el único de interés, se observó que hacia los valores negativos se dispusieron los especímenes juveniles de la clase J1, y luego en los valores negativos, intermedios y ligeramente positivos se agruparon, junto a los adultos, los especímenes de las clases J3 y J4. Hacia los valores negativos, el cuerpo mandibular fue más importante que la rama mandibular, mostrando la mandíbula un dentario curvado y ancho, y los tres procesos (coronoides, condiloideo y angular) de la misma longitud. Hacia los valores positivos, se invirtió la importancia de cuerpo y rama mandibular, siendo la rama mandibular más importante que el cuerpo. La mandíbula presentó un dentario delgado, recto en su parte inferior y el proceso coronoides más desarrollado que los restantes procesos (Fig. 77B).

\subsubsection{Variación alométrica de la forma}

Para el cráneo (Fig. 78), el tamaño explicó el 10,30\% de la forma, con un $\mathrm{P}<0,0001$. Los jóvenes se ubicaron (Fig. 78A) en los valores más bajos del tamaño de centroide, solapándose los de la clase J3 y J4 con algunos adultos de la primera clase (A1). A su vez, éstos se yuxtapusieron con los de la clase A2. Si bien muchos especímenes no contaban con información de sexo (Fig. 78B), los que sí la presentaron, mostraron una distribución homogénea y compartieron la misma pendiente, sin diferencias entre machos y hembras. De todas maneras, algunos machos de las clases A1 y A2 tuvieron un offset bastante mayor que la última hembra de clase A2, lo cual podría implicar que los machos crecen más que las hembras, aunque no puede testearse esta hipótesis por tener escaso número de individuos sexados. El análisis mostró que los especímenes más pequeños poseen cajas craneanas altas y anchas, nasales con una constricción en la parte media, lira más corta, bullas y órbitas más grandes, arcos zigomáticos poco expandidos, 
cóndilos occipitales paralelos a la placa occipital y foramen magnum de posición posterior al inion. Las formas más grandes mostraron cajas craneanas más bajas y estrechas, nasales rectos, lira más larga, bullas y órbitas más pequeñas, arcos zigomáticos muy expandidos, cóndilos occipitales de posición oblicua en relación a la placa occipital y foramen magnum a la misma altura que el inion (Fig. 78).

Para la mandíbula (Fig. 79), el tamaño explicó el 12,99\% de la forma $(\mathrm{P}<0,0001)$. Los juveniles tuvieron los menores valores de tamaño de centroide y los de las últimas clases se solaparon con los adultos de mayor tamaño de centroide (Fig. 79A). Con respecto a los sexos (Fig. 79B), se encontraron distribuidos de manera homogénea, sin agruparse en relación a ellos. Las formas más pequeñas tuvieron un dentario con el extremo anterior más recto, un cuerpo mandibular más ancho, una hilera dentaria más larga, una rama mandibular más estrecha, con la superficie inferior comprimida dorso-ventralmente. Tuvieron un proceso coronoides más corto y dirigido hacia atrás, el punto interno del proceso condiloideo retrasado, y un proceso angular más corto. Las formas más grandes tuvieron la configuración opuesta: un dentario con el extremo anterior más curvado y dirigido hacia arriba, un cuerpo mandibular más estrecho, una hilera dentaria más corta, una rama mandibular más ancha, con la superficie inferior ligeramente curvada. Tuvieron un proceso coronoides más largo y dirigido hacia arriba, el punto interno del proceso condiloideo adelantado, y un proceso angular más elongado (Fig. 79).

\subsubsection{Cambio de tamaño y de forma durante la ontogenia}

Cuando se analiza la muestra completa, sin discriminar por sexo, el tamaño del cráneo (Fig. 80A), mostró un crecimiento sostenido desde la clase de edad J1, hasta J3 donde se observa una primera asíntota. Luego se observa otra asíntota a 
partir de la clase A1, donde el crecimiento se estabiliza. El test U de Mann-Whitney no mostró diferencias significativas para las distintas clases de edad (Tabla 35). El crecimiento de la mandíbula (Fig. 81A) también fue sostenido, aunque el tamaño definitivo se obtiene en la clase A2. Tampoco se hallaron diferencias significativas para las distintas clases de edad (Tabla 35). La forma del cráneo (Fig. 80B) mostró una primera meseta en el desarrollo, durante las clases J3 y J4, aunque la estabilización ocurre a partir de la clase A2. No se observaron diferencias significativas (Tabla 35) al comparar entre clases. Existe un cambio de forma mandibular (Fig. 81B) entre la clase J1 y J3, luego una serie de valores similares y la estabilización llega en la clase A2. El test U de Mann-Whitney mostró diferencias significativas entre los estadios de edad A1 y A2 (Tabla 35). Cuando se analiza la muestra separando los especímenes por sexo, el tamaño del cráneo (Fig. 80C) presenta diferencias entre hembras y machos en la clase A1, siendo estos últimos más grandes. De todas formas, no se hallaron diferencias significativas entre clases de edad y sexos de los especímenes (Tabla 35). La mandíbula (Fig. 81C) se observa en crecimiento, hasta una primera asíntota en la clase J3, un nuevo aumento para los machos de la clase A1 y luego un decrecimiento en el último estadio de edad. Nuevamente, no se hallaron diferencias significativas entre clases de edad y sexos de los especímenes (Tabla 35). La forma craneana (Fig. 80D) presenta un importante desarrollo desde las clases juveniles hasta la clase A1, mostrando diferencias entre machos y hembras. Para ésta, no se hallaron diferencias significativas entre clases de edad y sexos de los especímenes (Tabla 35). Para la mandíbula (Fig. 81D), se observó un cambio en la forma y diferencias pequeñas entre los dos sexos. No se hallaron diferencias significativas entre clases de edad y sexos de los especímenes (Tabla 35). 


\subsubsection{Ventajas mecánicas}

El tamaño de los músculos masticatorios (Fig. 82A) se incrementó conforme aumentó la edad, mostrando una asíntota en la clase A2. El test U de Mann Whitney no reveló significancia para las diferencias entre las distintas clases de edad comparadas (Tabla 35). Para la ventaja mecánica del masetero medida en el canino (Fig. 82B), se observaron valores similares entre todas las clases de edad, y mucha variación en cada clase, aunque la estabilización llega en la clase A3. No se observaron diferencias significativas entre las distintas clases (Tabla 35). La ventaja mecánica del masetero medida en el carnicero (Fig. 82C), muestra una asíntota en la clase J4 y una elevación en los valores en la clase A3, donde se estabiliza el crecimiento. Tampoco se hallaron diferencias significativas entre las distintas clases (Tabla 35). La ventaja mecánica del temporal medida en el canino (Fig. 82D) tanto como la del medida en el carnicero (Fig. 82E), reflejan valores semejantes en las clases juveniles, seguido de un incremento en relación a la edad, desde la clase A1 a A3. Para ambas se hallaron diferencias significativas entre las clases A1 y A2, al ser testeadas con Mann-Whitney (Tabla 35).

\subsection{Leopardus geoffroyi (D’Orbigny \& Gervais 1844)}

\subsubsection{Reproducción y ontogenia}

En cautividad el período de gestación es de 62-76 días (Nowak 2005). El tamaño de camada varía entre 1-3 cachorros (Ximenez 1975) que al nacer, pesan 65$90 \mathrm{~g}$ (Sunquist \& Sunquist 2002) y miden unos $135 \mathrm{~mm}$ (Scheffel \& Hemmer 1975).

Al igual que los cachorros de L. tigrinus, reportados por Leyhausen \& Falkena (1966), los cachorros de L. geoffroyi también tienen un desarrollo retardado en comparación con los gatos domésticos. (Scheffel \& Hemmer 1975, Sunquist \& 
Sunquist 2009). Abren los ojos alrededor de los 13 días, comienzan a caminar a partir de los 14 días, dejan la madriguera a los 23 días, y desde los 26 días son capaces de moverse dentro y fuera de ella libremente (Foreman 1997, Sunquist \& Sunquist 2009). A los 20 días comienzan a emerger los incisivos y caninos deciduos. A los 4 meses aparecen incisivos superiores definitivos, a los 5 meses comienza a reemplazar los incisivos inferiores y los caninos inferiores deciduos por los definitivos, a los 6 meses aparecen los caninos superiores y a los 8 meses erupcionan los premolares superiores (Néstor López, observación personal). El destete comienza a los 2 meses de edad y el peso de las crías en ese momento es de 900-1000 g (Sunquist \& Sunquist 2009). A los 3 meses son hábiles para matar presas con mordidas bien dirigidas al cuello, por lo que son totalmente independientes (Scheffel \& Hemmer 1975). Alrededor de las dos semanas de edad, triplican su peso (Sunquist \& Sunquist 2002) y el peso promedio ganado por día es de $10 \mathrm{~g}$., alcanzando el tamaño de su madre aproximadamente a los 6 meses (Sunquist \& Sunquist 2009). Tanto machos como hembras son sexualmente maduros alrededor del año y medio de edad (Oliveira 1993, Sunquist \& Sunquist 2009) y tienen una expectativa de vida en cautiverio de 21 años (Nowak 2005) (Fig. 4M).

\subsubsection{Suturas y sincondrosis}

De las suturas y sincondrosis analizadas (Tabla 36, Fig. 83), 15 se fusionaron completamente (35,71\%): 2 sincondrosis lo hicieron muy temprano (intraoccipitalis squamolateralis y basilateralis), en la clase J2 y J4, respectivamente; 7 de ellas se obliteraron en la clase de adultos A2, y estuvieron relacionadas al hueso esfenoides, y las restantes 6, que se fusionaron en la última clase de edad (A3), estando en su mayoría vinculadas con la parte posterior del cráneo. Once $(26,19 \%)$ permanecieron parcialmente fusionadas durante el desarrollo, y las 16 remanentes 
(38,09\%) no se obliteraron y están relacionadas con el paladar y la región rostral. En relación al tipo de suturas, 12 cambiaron de tipo, mostrando siempre una tendencia a la complejidad, yendo en aumento desde la sutura plana a la aserrada. La sutura que pasó por más estados fue la parietointerparietalis que cambió de plana/aserrada a escamosa, y luego a la combinación escamosa/aserrada. La sutura occipitoparietalis cambió de plana/escamosa a escamosa; la sutura occipitointerparietalis cambió de plana a la combinación escamosa/aserrada; las suturas sagittalis cranial, sagittalis caudal e intermaxillaris cambiaron de plana a aserrada; la sutura nasomaxillaris cambió de plana a escamosa; las suturas coronalis y palatolacrimalis cambiaron de escamosa a la combinación escamosa/aserrada y finalmente, las suturas palatomaxillaris dorsal, mesial y lateral cambiaron de escamosa a aserrada (Tabla 36, Fig. 83).

\subsubsection{Análisis multivariado}

Machos y hembras mostraron la misma tendencia alométrica, se solaparon en una porción del espacio, y luego los machos se desplazaron a la derecha, alcanzando mayores tamaños que las hembras. El primer componente principal, incluyó el 78,79\% del total de la varianza (Tabla 37). De las variables que se analizaron (Fig. 2), 7 presentan diferentes tendencias cuando son analizadas utilizando trimmed y untrimmed, éstas son: altura de la placa occipital (HPO), longitud de la órbita (LO), altura de la bulla auditiva (HB), longitud de la bulla (LB), longitud de la hilera dentaria superior (LHS), altura del dentario (HD) y longitud de la hilera dentaria inferior (LHI). El valor más bajo de sesgo lo tuvo el análisis untrimmed $(0,0035)$, por lo que se discutirán las tendencias obtenidas con éste. Diez variables resultaron isométricas (45,45\%): longitud cóndilo-incisiva (LCI), altura de la placa occipital (HPO), ancho de los arcos zigomáticos (AZ), 
longitud de la órbita (LO), ancho de los caninos (Acan), altura de la bulla auditiva (HB), longitud de la bulla (LB), longitud de la hilera dentaria superior (LHS), altura del dentario (HD) y longitud de la hilera dentaria inferior (LHI). Siete fueron alométricas positivas $(31,82 \%)$ : longitud de los nasales (LN), longitud del rostro (LR), altura del hocico $(\mathrm{HH})$, longitud del paladar (Lpal), longitud del dentario (LD), altura del proceso coronoides (HC) y longitud del coronoides (LC). Las 5 restantes fueron alométricas negativas (22,73\%): ancho del proceso mastoideo $(\mathrm{AM})$, ancho de la caja craneana (AC), constricción postorbitaria (CPO), ancho de la bulla auditiva $(\mathrm{AB})$ y ancho del paladar (Apal). Quien más se alejó de la isometría fue la constricción postorbitaria (CPO), con un valor de 0,1991 y quien menos lo hizo fue el ancho de los caninos (Acan), con un valor de 0,0015 (Tabla 37).

\subsubsection{Morfometría geométrica}

En relación al cráneo (Fig. 84A), el PC1 explica un 23,47\% de la varianza de la muestra, el PC2 un 11,14\%, y el PC 3 un porcentaje del 7,86\%. Tanto la configuración del PC1 como del 2, no presentaron un patrón ontogenético claro. Diferente es la situación del PC3, donde se puede observar, hacia los valores positivos a los jóvenes y hacia los valores medios y negativos, a los adultos. Los jóvenes mostraron un cráneo redondeado con una caja craneana corta, alta y ancha en su parte posterior, hocico corto y ancho con aperturas nasales frontales y fosas temporales estrechas, el basicráneo y las bullas fueron anchos y cortos. Los adultos, por otra parte, mostraron un cráneo uniforme en ancho y largo, de baja altura, hocico más elongado y estrecho, con aperturas nasales de posición dorsal y arcos zigomáticos expandidos. El basicráneo y las bullas fueron alargados y estrechos. En relación al sexo, se encontraron distribuidos de manera homogénea, aunque en el grupo que estuvo ubicado en la zona positiva del morfoespacio del PC1, PC2 y 
PC3, se encontraron sólo machos e indeterminados y no hembras. De todas maneras los especímenes no sexados podrían ser femeninos (Fig. 84A).

En relación a la mandíbula (Fig. 84B), el PC1 representó un porcentaje del 24,84\%, el PC2 un 9,68\% y el PC3 un 8,27\% de la varianza total. Los especímenes jóvenes se ubicaron en el PC1, hacia los valores positivos los de las clases más bajas y hacia los valores intermedios los de la clase J4. Los adultos se ubicaron más homogéneamente en los valores medios y negativos. La configuración de la mandíbula de los juveniles reflejó una rama y cuerpo mandibular más delgados, la superficie inferior de la rama mandibular curvada, un cuerpo mandibular más elongado y recto, y un proceso coronoides dirigido hacia atrás. La configuración de los adultos fue la opuesta, esto es, una rama y cuerpo mandibular más anchos, la superficie inferior de la rama mandibular recta, un cuerpo mandibular más corto y curvado hacia arriba y un proceso coronoides más grande dirigido hacia arriba. No se hallaron agrupaciones que estén relacionadas con el sexo de los especímenes (Fig. 84B).

\subsubsection{Variación alométrica de la forma}

Para el cráneo, el tamaño explicó el 8,38\% de la forma, con un $\mathrm{P}<0,0001$. Los jóvenes tuvieron los valores más bajos de tamaño de centroide (Fig.85A), y los de la clase B se alejaron mucho en tamaño de los de la clase J1. El resto de los juveniles se solaparon con los adultos de las 2 clases de edad de la muestra. Tanto machos como hembras (Fig.85B) se distribuyeron de manera uniforme en la recta, sin mostrar agrupaciones. Sin embargo, algunos machos de la clase A2 mostraron un offset mayor que los de las hembras de esta misma clase. Los especímenes más pequeños mostraron un cráneo corto, ancho y alto, nasales más cortos, arcos zigomáticos poco expandidos, con placa occipital más ancha, foramen magnum 
posterior al inion y cóndilos occipitales de posición paralela en relación a la placa occipital. Las órbitas y las bullas fueron más grandes. Los especímenes más grandes exhibieron un cráneo largo, estrecho y bajo, nasales más largos, arcos zigomáticos muy expandidos, con placa occipital más estrecha, foramen magnum a la altura del inion y cóndilos occipitales de posición oblicua a la placa occipital. Las órbitas y bullas fueron más pequeñas (Fig.85).

Para la mandíbula, el tamaño explicó el 8,10\% de la forma ( $\mathrm{P}<0,0001)$. Las clases de juveniles (Fig.86A) tienen un tamaño de centroide menor que las de adultos. La que incluye a los más pequeños, $\mathrm{B}$, se encuentra muy alejada del resto e inclusive parece estar en una trayectoria diferente. El resto de los jóvenes están dispuestos de manera progresiva, a menudo solapándose con los adultos. En lo que respecta a los sexos (Fig.86B), no se hallaron agrupaciones que estén referidas a ellos, sino que se distribuyeron de manera homogénea. Las configuraciones más pequeñas, mostraron una mandíbula con un cuerpo mandibular más largo y recto anteriormente y una rama mandibular más estrecha y curvada en su superficie inferior. La parte anterior de la fosa masetérica retrasada, con un proceso coronoides más estrecho y dispuesto hacia la parte posterior y un proceso angular más corto. Las más grandes, mostraron una mandíbula con un cuerpo mandibular más corto y más curvado hacia arriba anteriormente y una rama mandibular más ancha y recta en su superficie inferior. La parte anterior de la fosa masetérica se observó adelantada, el proceso coronoides más desarrollado y dispuesto hacia arriba y un proceso angular más elongado (Fig.86).

\subsubsection{Cambio de tamaño y de forma durante la ontogenia}

Al analizar la muestra sin tener en cuenta el sexo, el tamaño craneal (Fig. 87A) mostró una gran diferencia de valores entre la clase B y J1, a partir de donde 
los valores fueron más similares. Se mostró una primera asíntota entre las clases J3 y J4, y luego se presenta una segunda entre las clases A1 y A2, estabilizándose el crecimiento en la clase A1. El test $\mathrm{U}$ de Mann Whitney reveló que solo hubo significancia en las diferencias entre la clase de edad J4 y A1 (Tabla 38). Para la mandíbula (Fig. 88A) hubo un crecimiento escalonado, que aumentó conforme aumentó la edad de los individuos, y que se estabilizó en la clase A1. No se hallaron diferencias significativas entre las distintas clases (Tabla 38). En los valores de la forma craneal (Fig. 87B), se observa también una brusca diferencia entre las clases de edad B y J1, en tanto que al alcanzar esta última no se produce ningún otro cambio, obteniéndose la forma adulta definitiva. Tampoco se hallaron diferencias significativas entre los distintos estadios de edad (Tabla 38). Para la mandíbula (Fig. 88B), el patrón de desarrollo fue similar, aunque se detuvo en la clase A1. Para las clases J4 y A1, se hallaron diferencias significativas, al testear la muestra con Mann Whitney (Tabla 38). Cuando el sexo de los especímenes fue tenido en cuenta, se observó que tanto el tamaño craneal (Fig. 87C) como el mandibular (Fig. 88C) de los machos, es más grande que el de las hembras, lo cual ocurre a partir de la clase J4. Sin embargo, las diferencias entre sexos sólo resultaron significativas en las clases A1 y A2 (Tabla 38). En el caso de la forma craneana (Fig. 87D), el patrón no fue tan claro como cuando no se tuvo en cuenta el sexo. Las clases A1 y A2 mostraron a los machos con valores más grandes que los de las hembras. La forma mandibular (Fig. 88D) se mostró confusa en las primeras clases de edad y luego se observó a los machos con mayores valores que las hembras. Esto no se vio reflejado en el testeo de dimorfismo sexual, en el que ninguna clase de edad mostró diferencias significativas entre sexos, ni para cráneo ni para mandíbula (Tabla 38). 


\subsubsection{Ventajas mecánicas}

El tamaño de los músculos masticatorios (Fig. 89A) muestra un salto desde la clase B a la clase J1, seguido de un incremento que parece detenerse en una primera asíntota en la clase J2, y luego un aumento desde la clase J4 a A3, donde alcanza su valor definitivo. El test de Mann Whitney mostró significancia para las diferencias encontradas entre las clases J4-A1 y A1-A2 (Tabla 38). La ventaja mecánica del masetero medido en el canino (Fig. 89B) muestra valores semejantes, aunque claramente las medias aumentan con la edad, estableciéndose el valor definitivo en la clase A3. No se hallaron diferencias significativas para las distintas clases de edad (Tabla 38). La ventaja mecánica del masetero tomando como punto de mordida el carnicero (Fig. 89C), muestra un valor poco claro para el estadio de edad B, el cual podría estar relacionado con el hecho de que esta clase presenta un solo espécimen. Se puede observar un aumento en la ventaja desde la clase de juveniles J1 hasta J3, y un incremento en A3, donde se establece la ventaja definitiva. Para esta ventaja, tampoco se hallaron diferencias significativas entre los distintos estadios de edad (Tabla 38). A pesar de los valores de las clases B y J4, se observa un aumento de la ventaja del temporal medido en el canino (Fig. 89D). En la clase J3 se observa la asíntota, mientras que a la altura de la clase A3 se observa un leve descenso en los valores. $\mathrm{Al}$ testearse las diferencias entre las distintas clases para esta ventaja, se halló significancia entre los estadios J4 y A1 (Tabla 38). La ventaja mecánica del músculo temporal medida en el carnicero (Fig. 89E) aumenta, alcanzando su valor definitivo en la clase A1, aunque se observa también un ligero decrecimiento en el estadio de edad final, A3. El test de Mann Whitney no mostró significancia para las diferencias encontradas entre las distintas clases de edad y tampoco se hallaron diferencias entre sexos en las distintas ventajas mecánicas para las distintas clases de edad (Tabla 38). 


\subsection{Leopardus guigna (Molina 1782)}

\subsubsection{Reproducción y ontogenia}

Es muy poca la información disponible sobre esta especie. El período de gestación es de 72-78 días y el tamaño de camada varía entre 1 y 3 cachorros (Freer 2004, Sunquist \& Sunquist 2009). En cautiverio, la madurez sexual de las hembras se obtiene a los 2 años de edad (Oliveira 1993) y está documentado que los individuos pueden vivir hasta los 11 años (Freer 2004, Sunquist \& Sunquist 2009) (Fig. 4N).

\subsubsection{Suturas y sincondrosis}

Aún faltando completamente las clases de edad J3 y A3, es posible analizar qué ocurrió con las suturas y sincondrosis en esta especie (Tabla 39, Fig. 90). Once se fusionaron completamente $(26,19 \%)$ en algún momento del desarrollo, siendo las primeras las sincondrosis intraoccipitalis squamolateralis y basilateralis que se fusionaron en las clases J1 y J2 respectivamente, y están relacionadas con la placa occipital; las otras 9, se fusionaron en la clase A2 y corresponden a los huesos occipital, frontal y parietal. Catorce $(33,33 \%)$ se fusionaron parcialmente durante la vida de los individuos de esta especie. Al no tener una muestra que incluyera la clase A3 no fue posible determinar si alguna otra sutura se fusionó completamente en esa clase. Las 17 restantes (40,48\%), no se fusionaron nunca y están vinculadas con el rostro. Con relación al tipo de suturas, 7 de ellas cambiaron su conformación. Si bien existió una tendencia al aumento en la complejidad del tipo de sutura, no existieron tantas combinaciones como en otras especies, y se observó un cambio de plana a aserrada en las suturas occipitointerparietalis, parietointerparietalis, sagittalis cranial, sagittalis caudal, interfrontalis caudal e 
intermaxillaris, y un cambio de plana a escamosa en la sutura occipitoparietalis (Tabla 39, Fig. 90).

\subsubsection{Análisis multivariado}

Tanto los machos como las hembras tuvieron la misma tendencia alométrica y se ubicaron en la misma recta, aunque los primeros tuvieron tamaño mayor, por lo que se dispusieron más hacia la derecha que ellas. El primer componente principal, incluyó el 89,11\% del total de la varianza (Tabla 40). De las 22 variables analizadas, 9 mostraron diferentes tendencias cuando se analizaron con trimmed y untrimmed, con un intervalo de confianza del 99\%. Éstas fueron: altura de la placa occipital (HPO), ancho de la caja craneana (AC), longitud del rostro (LR), ancho de los caninos (Acan), altura de la bulla auditiva (HB), longitud de la bulla (LB), ancho del paladar (Apal), altura del dentario (HD) y altura del proceso coronoides (HC). El sesgo más pequeño resultó ser el obtenido a través del análisis trimmed $(0,0047)$, por lo que se discuten los valores obtenidos de esta manera. Nueve resultaron alométricas negativas (40,91\%): altura de la placa occipital (HPO), ancho del proceso mastoideo (AM), ancho de la caja craneana (AC), constricción postorbitaria (CPO), ancho de los caninos (Acan), ancho de la bulla auditiva (AB), longitud de la bulla (LB), ancho del paladar (Apal), y longitud de la hilera dentaria superior (LHS). Ocho tendencias resultaron ser isométricas (36,36\%): longitud cóndilo-incisiva (LCI), ancho de los arcos zigomáticos (AZ), longitud de la órbita (LO), longitud de los nasales (LN), altura del hocico (HH), longitud del paladar (Lpal), longitud del dentario (LD), y longitud de la hilera dentaria inferior (LHI). Finalmente, otras 5 fueron alométricas positivas (22,73\%): longitud del rostro (LR), altura de la bulla auditiva (HB), altura del dentario (HD), altura del proceso coronoides (HC), y longitud del coronoides (LC). Quien más se alejó de la 
isometría fue la constricción postorbitaria (CPO), con un valor de 0,1569 y quien menos lo hizo fue la altura del hocico $(\mathrm{HH})$, con un valor de presentó una desviación de 0,0010 (Tabla 40).

\subsubsection{Morfometría geométrica}

Para el cráneo (Fig. 91A), el PC1 explica un porcentaje de 25,41\% de la varianza total, el PC2 un 16,83\% y el PC3 un 12,26\%. Sobre el PC1, se encuentran ubicados hacia los valores negativos los adultos y hacia los positivos los juveniles. Los cráneos de los adultos mostraron cajas craneanas más estrechas, alargadas y bajas, paladares rectos, arcos zigomáticos más expandidos, órbitas y aperturas nasales más dorsales. Las bullas y las órbitas fueron más pequeñas y el foramen magnum más pequeño y de posición posterior. Los de los jóvenes en cambio, exhibieron cajas craneanas redondeadas, cortas y altas, paladares anchos con torus palatino convexo, arcos zigomáticos no expandidos, órbitas y aperturas nasales de posición frontal. Las bullas y las órbitas fueron relativamente más grandes y el foramen magnum más grande y de posición ventral. El PC2 y 3 no mostraron distribuciones de interés, y ninguno de los PCs mostraron agrupaciones relacionadas con los sexos (Fig. 91A).

Para la mandíbula (Fig. 91B), el PC1 representó un porcentaje del 28,36\%, el PC2 un 23,70\% y el PC3 un 11,90\% de la varianza total. Los especímenes se hallaron en una disposición interesante sólo en el PC2. Los jóvenes se ubicaron hacia los valores positivos de este PC, y los adultos hacia los medios y negativos sin que existan verdaderas diferenciaciones entre clases. Las mandíbulas de los juveniles tuvieron un cuerpo mandibular más ancho, más recto y más elongado, y una rama mandibular más corta con todos los procesos dirigidos hacia atrás y la superficie inferior curvada. La configuración de los adultos incluyó un cuerpo 
mandibular más delgado, más corto y más curvado hacia arriba en su extremo anterior, y una rama mandibular más corta y desarrollada, con el proceso coronoides dirigido hacia arriba y la superficie inferior recta. En relación a los sexos, no se encontraron agrupaciones vinculadas con alguno en particular (Fig. 91B).

\subsubsection{Variación alométrica de la forma}

Para el cráneo (Fig. 92), el tamaño explicó el 18,06\% de la forma, con un $\mathrm{P}<0,0006$. Los juveniles tuvieron los valores más bajos de tamaño de centroide, y se separaron de los adultos que se encontraron agrupados sin segregarse en clases y tuvieron mayores tamaños de centroide (Fig. 92A). Hembras y machos se hallaron distribuidos de manera homogénea en el espacio (Fig. 92B). Las formas más pequeñas exhibieron un cráneo ancho, corto y alto, lira y nasales más cortos y anchos, bullas y órbitas grandes, arcos zigomáticos no expandidos; la sutura coronal adquirió una posición anterior y los cóndilos occipitales se mostraron paralelos a la placa occipital. Las formas más grandes mostraron un cráneo estrecho, largo y bajo, lira y nasales más largos y estrechos, bullas y órbitas más pequeñas, arcos zigomáticos expandidos. La sutura coronal adquirió una posición posterior y los cóndilos occipitales se mostraron oblicuos en relación a la placa occipital (Fig. 92).

Para la mandíbula (Fig. 93), el tamaño explicó el 14,94\% de la forma $(\mathrm{P}<0,0347)$. Los juveniles tuvieron menores tamaños de centroide, aunque progresivamente se solaparon con los adultos que se distribuyeron sin agruparse en clases (Fig. 93A). En cuanto al sexo, se distribuyeron homogéneamente (Fig. 93B). Las formas más pequeñas tuvieron un cuerpo mandibular más largo y ancho, con el borde anterior de la fosa masetérica retrasado y una rama mandibular más 
estrecha, con la superficie inferior curvada. El proceso coronoides fue más ancho y corto, el punto interno del proceso condiloideo estuvo adelantado, la separación entre el proceso condiloideo y el angular se observó adelantada y el proceso angular fue más corto. Las formas más grandes exhibieron un cuerpo mandibular más corto y estrecho, con el borde anterior de la fosa masetérica adelantado y una rama mandibular más ancha, con la superficie inferior recta. El proceso coronoides fue más estrecho y largo, y orientado hacia el área posterior, el punto interno del proceso condiloideo estuvo retrasado, la separación entre el proceso condiloideo y el angular se observó retrasada y el proceso angular fue más elongado (Fig. 93).

\subsubsection{Cambio de tamaño y de forma durante la ontogenia}

$\mathrm{Al}$ analizar la muestra sin tener en cuenta el sexo, se pudo observar un aumento en el tamaño del cráneo (Fig. 94A) y la mandíbula (Fig. 95A), que fue progresivo y cesa en la clase A1, donde se obtiene el tamaño definitivo. Las diferencias entre las distintas clases de edad no fueron significativas (Tabla 41). En los valores de la forma, se observa un desarrollo progresivo hasta que se obtiene la forma definitiva craneal (Fig. 94B) y mandibular (Fig. 95B) en la clase A2. El test de Mann Whitney nuevamente, no muestra diferencias significativas entre las distintas clases de edad (Tabla 41). Cuando el sexo de los especímenes fue tenido en cuenta, para el tamaño craneal (Fig. 94C) y mandibular (Fig. 95C), exhibieron los machos mayores tamaños que las hembras. En lo que respecta a la forma del cráneo (Fig. 94D) y de la mandíbula (Fig. 95D), ambos se desarrollaron sin diferencias aparentes entre sexos. Lamentablemente, no hubo tamaño muestral suficiente para hacer comparaciones entre sexos y estadios de edad, y poder determinar la significancia de las disimilitudes (Tabla 41). 


\subsubsection{Ventajas mecánicas}

El tamaño de los músculos masticatorios (Fig. 96A), se incrementa con la edad, mostrando estar estabilizado en la clase A1, aunque no es posible determinar si esto ocurre antes, por la escasa muestra de las clases juveniles que lo preceden. La ventaja mecánica del masetero medida en el canino (Fig. 96B), muestra valores similares para las clases de juveniles, que se elevan en la clase A1, donde se obtiene la ventaja definitiva. Un patrón diferente se observa en la estimación de la ventaja mecánica del músculo masetero tomada en el carnicero (Fig. 96C), donde existe un aumento progresivo en los valores, alcanzándose una asíntota en la clase J2. La ventaja mecánica del temporal en el canino (Fig. 96D), aunque con mucha variación en la clase de adultos A1, muestra valores similares para todas las clases, con una asíntota en la clase de juveniles J2, y luego otra cuando cesa el crecimiento, en la clase A2. Finalmente, la ventaja del temporal en el carnicero (Fig. 96E), muestra un aumento progresivo, con un importante salto desde la clase J1 a J2, un valor alto para la clase J2, que incluye un solo espécimen, y luego, una continua progresión desde J4 al estadio de edad A1 donde se estabiliza el aumento. No se hallaron diferencias significativas entre clases de edad cuando fueron testeadas con el test de Mann Whitney, y tampoco se observaron diferencias entre sexos en las distintas ventajas mecánicas para las distintas clases de edad (Tabla 41).

\subsection{Leopardus jacobita (Cornalia 1865)}

\subsubsection{Reproducción y ontogenia}

No existen datos de reproducción y ontogenia para esta especie (Sunquist \& Sunquist 2009) (Fig. 4O). 


\subsubsection{Suturas y sincondrosis}

De las suturas/sincondrosis analizadas, 18 estuvieron completamente fusionadas, lo que corresponde a un $42,86 \%$ del total (Tabla 42, Fig. 97). Tres de ellas aparecen fusionadas en el estadio más joven de los adultos (A1), pero al no presentar especímenes juveniles no es posible determinar si se fusionaron en ese estadio o previamente. Estas son: intraoccipitalis basilateralis, sagittalis cranial y caudal y corresponde a la placa occipital y parte posterior del cráneo. Nueve se fusionaron con seguridad en la clase A2, y 5 de ellas en la última clase de adultos (A3). Diez de las restantes $(23,81 \%)$ se fusionaron parcialmente durante el desarrollo y corresponden a suturas vinculadas al paladar y los arcos zigomáticos. Catorce de ellas (33,33\%) no se fusionaron en ningún momento de la vida de los individuos de esta especie, y estuvieron vinculadas tanto a la región rostral como a la placa occipital. No se observó cambio en el tipo de suturas, pero es imposible determinar si esto es producto de la ontogenia o un artefacto de la muestra, ya que durante las primeras clases de edad es cuando se produjeron los cambios más drásticos (en las otras especies) y no se contó con esos estadios (Tabla 42, Fig. 97).

A pesar de que se le tomaron medidas a los ejemplares de esta especie que estuvieron a disposición (CEAN 3, GECM 27), no fue posible realizar los restantes análisis con una muestra tan acotada.

\subsection{Leopardus pardalis (Linnaeus 1758)}

\subsubsection{Reproducción y ontogenia}

Las hembras tienen un período de gestación de 79-82 días (Sunquist \& Sunquist 2002) y un tamaño de camada entre 1-2 cachorros (Ewer 1973, Nowak 2005), aunque lo común es uno solo (Sunquist \& Sunquist 2009). En cautiverio,

$$
\text { 118 }
$$


cuando la preñez es verificada, hay que separar machos de hembras, para evitar la reabsorción del feto (Murray \& Gardner 1997). Los jóvenes pesan al nacer alrededor de 250 g, abren los ojos entre los 10-14 días (Gittleman 1986, Murray \& Gardner 1997) y caminan a los 21 días (Laack 1991). Después del mes de edad, están en condiciones de acompañar a su madre para cazar, y alrededor de los 2 meses comienzan a comer alimentos sólidos (Laack 1991, Murray \& Gardner 1997, Sunquist \& Sunquist 2009). Sin embargo, son dependientes para alimentarse hasta el final del amamantamiento, entre los 3-9 meses (Tewes 1986, Dillon 2005, Sunquist \& Sunquist 2009). A los 14-15 días ya tienen erupcionados 2 incisivos superiores y 3 inferiores, a los 24-25 días están erupcionados todos los incisivos y caninos deciduos (Laack 1991), y a los 8 meses de edad se adquirieren los caninos permanentes (Oliveira 1993, Dillon 2005). Obtienen el peso de adultos entre los 22,5 años de edad, alcanzándolo antes las hembras que los machos, como ocurre en Leopardus wiedii (Petersen \& Petersen 1978, Tewes 1986, Sunquist \& Sunquist 2009). También entre los 2-2,5 años de edad, adquieren la madurez sexual (Fagen \& Wiley 1978, Laack 1991, Murray \& Gardner 1997), aunque la primera reproducción puede estar influenciada por factores como la nutrición y la abundancia de otras hembras/machos adultas/os (Laack 1991, Dillon 2005). Alrededor del año de edad ellos son independientes para dispersarse (Oliveira 1993), pero permanecen en el territorio de sus madres, como ocurre en Leptailurus serval, Lynx rufus, Panthera onca, P. pardus, P. tigris y Puma concolor. Esto les permite volverse experimentados cazadores en un área conocida y ganar peso, antes de dispersarse y encontrarse con adultos agresivos (Laack 1991). En cautividad se sabe que viven 20 años, aunque la longevidad en vida silvestre probablemente sea la mitad de este tiempo (Laack 1991, Dillon 2005, Sunquist \& Sunquist 2009). Laack (1991) ofreció una clave para determinar la edad en relación al peso corporal, basada en subadultos machos y 
hembras: 3,4 kg $\leq 0-5$ meses; 3,4-6,0 kg = 6-11 meses; 5,1-6,6 kg = 12-17 meses; 6,2$7,2 \mathrm{~kg}=18-23$ meses. No hubo diferencias significativas entre sexos cuando se pesaron menores a los 2 años de edad. Según Emmons (1988), el pequeño tamaño de camada y la lenta maduración sexual, sugieren una adaptación a una tasa baja de adquisición de energía, para vivir en hábitats donde la disponibilidad de presas es baja. Mientras que para Laack et al. (2005), esto también caracteriza a otros medianos y pequeños félidos Neotropicales como Leopardus tigrinus (Fagen \& Wiley 1978). Durante la crianza de los cachorros, la demanda energética de la madre se incrementa un 50-150\%, por lo que ellas incrementan sus actividades de caza. En Perú, una hembra con un cachorro de 1 mes, duplicó su actividad normal y pasó 17 horas diarias buscando alimento, aunque a pesar de esto el cachorro murió (Emmons 1987, 1988) (Fig. 4P).

\subsubsection{Suturas y sincondrosis}

De las 42 suturas (Tabla 43, Fig. 98), presenta 11 completamente fusionadas, representando el $26,19 \%$ del total. Las que más temprano se fusionaron son las sincondrosis intraoccipitalis squamolateralis y basilateralis, que lo hicieron en la clase J2 y están vinculadas con la placa occipital. La sutura parietointerparietalis se fusionó en la clase J3 y la occipitointerparietalis en la última clase de juveniles, J4. El resto de las que se obliteraron (7), lo hicieron en las clases de adultos. Sólo una sutura se encontró parcialmente fusionada en la última clase de adultos (A3), correspondiendo al 2,38\% del total. Esta fue la sutura squamosa, que se encuentra en el hueso del mismo nombre. Las 30 restantes $(71,43 \%)$ no se fusionaron en ningún momento del desarrollo. En relación al cambio del tipo de suturas, solo 5 sufrieron un cambio de configuración, pero siempre con tendencia al aumento de complejidad de las suturas. De esta manera, la sutura sagittalis cranial e 
intermaxillaris cambiaron de plana a aserrada, la sutura occipitoparietalis de plana a escamosa, y las suturas palatomaxillaris mesial y lateral lo hicieron de escamosa a aserrada (Tabla 43, Fig. 98).

\subsubsection{Análisis multivariado}

Tanto los machos como las hembras tuvieron la misma tendencia alométrica y se ubicaron en la misma recta. El primer componente principal, incluyó el 85,31\% del total de la varianza. De las 22 variables analizadas (Tabla 44), 3 presentan diferencias al ser analizadas con trimmed y untrimmed. Estas son: longitud cóndiloincisiva (LCI), altura del hocico (HH) y longitud del paladar (Lpal). El sesgo más pequeño fue el del análisis untrimmed $(0,0005)$, por lo que se discutirán esos resultados. Diez fueron alométricas negativas (45,45\%): altura de la placa occipital (HPO), ancho del proceso mastoideo (AM), ancho de la caja craneana (AC), constricción postorbitaria (CPO), longitud de la órbita (LO), ancho de la bulla auditiva ( $\mathrm{AB})$, altura de la bulla auditiva (HB), longitud de la bulla (LB), ancho del paladar (Apal), y longitud de la hilera dentaria inferior (LHI). Siete tendencias resultaron isométricas (31,82\%): longitud cóndilo-incisiva (LCI), longitud de los nasales (LN), ancho de los caninos (Acan), altura del hocico (HH), longitud del paladar (Lpal), longitud de la hilera dentaria superior (LHS) y altura del dentario (HD). Las restantes 5 resultaron alométricas positivas (22,73\%): ancho de los arcos zigomáticos (AZ), longitud del rostro (LR), longitud del dentario (LD) altura del proceso coronoides (HC) y longitud del coronoides (LC). Quien más se alejó de la isometría fue la constricción postorbitaria (CPO), con un valor de 0,1797 y quien menos lo hizo fue la longitud de la hilera dentaria superior (LHS), con un valor de 0,0023 (Tabla 44). 


\subsubsection{Morfometría geométrica}

En relación al cráneo (Fig. 99A), el PC1 explicó un porcentaje de 25,22\%, El PC2 el 10,26\% y E1 PC3 el 5,90\% de la varianza total. El PC1 mostró hacia los valores negativos, a los juveniles en general, sin separar por clases, con excepción de los de la clase J4 que se encontraron hacia el centro y hacia los valores positivos a los adultos. Los jóvenes exhibieron un cráneo redondo, corto, ancho y alto, rostro corto con posición más vertical, con hocico ancho y corto, paladar con torus palatino convexo, basicráneo corto y ancho, y arcos zigomáticos no expandidos. Órbitas y bullas más grandes. Los adultos, mostraron un cráneo más estrecho, elongado y bajo, rostro con una posición más oblicua, paladar con torus palatino recto, basicráneo estrecho y alargado, arcos zigomáticos expandidos, y órbitas y bullas más pequeñas. Los restantes PCs no mostraron distribuciones interesantes y ninguno de los 3 PCs exhibieron agrupaciones vinculadas a los sexos (Fig. 99A).

En relación a la mandíbula (Fig. 99B), el PC1 representó un porcentaje del 27,43\%, el PC2 un 17,74\% y el PC3 un 9,11\% de la varianza total. El PC1 fue el único de interés ontogenético, mostrando hacia los valores positivos a los jóvenes y hacia los medios y negativos a los adultos. Las mandíbulas de los juveniles tuvieron un cuerpo mandibular más largo y recto, y la rama mandibular menos desarrollada, con la superficie inferior curvada y un proceso coronoides más débil y dirigido hacia atrás. La configuración para los adultos fue la contraria: las mandíbulas tuvieron un cuerpo mandibular más corto y curvado hacia arriba, la rama mandibular muy desarrollada, con la superficie inferior recta, con un proceso coronoides bien desarrollado y dirigido hacia arriba. No se encontraron agrupamientos vinculados a los sexos, hallándose a todos los especímenes distribuidos homogéneamente (Fig. 99B). 


\subsubsection{Variación alométrica de la forma}

Para el cráneo (Fig. 100), el tamaño explicó el 18,50\% de la forma, con un $\mathrm{P}<0,0001$. Los ejemplares juveniles se hallaron hacia los valores más bajos de tamaño de centroide (Fig. 100A). Se puede observar que los de la clase B se encuentran separados de los restantes jóvenes de la muestra, y que estos últimos se ubican en la recta solapándose entre sí. Tanto los especímenes de la clase J3 como $\mathrm{J} 4$, se solaparon con los adultos que estuvieron dispuestos de manera uniforme y combinada en la recta. En relación a los sexos (Fig. 100B), no se observó que hubiera alguna disposición de los especímenes vinculada a esto. Las formas más pequeñas exhibieron un cráneo ancho, corto y alto, nasales cortos y anchos, lira más corta, sutura coronal ubicada anteriormente, placa occipital más ancha, foramen magnum de posición posterior al inion, cóndilos occipitales paralelos a la placa occipital y arcos zigomáticos no expandidos. Rostro más corto y recto, órbitas y bullas más grandes. Los ejemplares más grandes mostraron un cráneo más estrecho, elongado y bajo, nasales más alargados, lira más elongada, sutura coronal ubicada posteriormente, placa occipital más estrecha, foramen magnum anterior al inion, cóndilos occipitales de posición oblicua en relación a la placa occipital, y arcos zigomáticos bien expandidos. Rostro más alargado y curvado ventralmente, órbitas y bullas más pequeñas (Fig. 100).

Para la mandíbula (Fig. 101), el tamaño explicó el 16,80\% de la forma $(\mathrm{P}<0,0001)$. Los juveniles tuvieron menor tamaño de centroide que los adultos (Fig. 101A). Los de la clase más temprana, B, estuvieron ubicados en una trayectoria diferente a los demás y los de las últimas clases juveniles se solaparon con los adultos que no tuvieron una distribución agrupada por clases, sino uniforme. Con respecto a los sexos (Fig. 101B), estuvieron distribuidos de forma homogénea sin 
agruparse de acuerdo a ellos. Las formas más pequeñas presentan un cuerpo mandibular más largo y ligeramente más ancho, con el borde anterior de la fosa masetérica retrasado. Con una rama mandibular más corta y estrecha, que presenta su superficie inferior curvada. Un proceso coronoides más estrecho y posterior, un proceso condiloideo adelantado, y un proceso angular más corto y vertical. Las formas más grandes mostraron un cuerpo mandibular más corto y estrecho, con el borde anterior de la fosa masetérica adelantado. Con una rama mandibular más larga y desarrollada, que presenta su superficie inferior recta. Un proceso coronoides más amplio y dispuesto hacia arriba, un proceso condiloideo retrasado, y un proceso angular del mismo largo que el proceso condiloideo y dispuesto hacia atrás (Fig. 101).

\subsubsection{Cambio de tamaño y de forma durante la ontogenia}

Cuando no se tuvo en cuenta el sexo, tanto el tamaño craneal (Fig. 102A) como el mandibular (Fig. 103A) aumentaron progresivamente, entre la clase B y J1 de manera abrupta, luego el crecimiento fue moderado, estableciéndose el tamaño definitivo en la clase de adultos A2. El test U de Mann Whitney mostró significancia en las diferencias entre las clases de edad: B-J1, J2-J3, J4-A1 y A1-A2 para el tamaño craneal, mientras que para el tamaño mandibular fue significativa sólo la diferencia entre las clases B y J1 (Tabla 45). La forma craneal (Fig. 102B) y mandibular (Fig. 103B) se desarrollaron progresivamente hasta estabilizarse en la clase A2. Cuando la forma fue testeada, resultó significativa sólo la diferencia entre los estadios de edad J2-J3 (Tabla 45). Cuando se tuvo en cuenta el sexo de los especímenes de la muestra, el tamaño del cráneo (Fig. 102C) fue en aumento, mostrando a los adultos machos de las clases A1 y A2 más grandes que las hembras. Para la mandíbula (Fig. 103C), también se observó un incremento 
progresivo. Sin embargo, las diferencias observadas no fueron significativas cuando fueron testeadas con el test de Mann Whitney (Tabla 45). Para la forma del cráneo (Fig. 102D) se observan diferencias entre sexos en los individuos de las clases A1 y A2, mientras que para la mandíbula (Fig. 103D), se observó un aumento en los valores del cambio de forma, pero no fueron tan visibles las disimilitudes entre machos y hembras. De todas maneras, ninguna de estas diferencias resultaron significativas (Tabla 45).

\subsubsection{Ventajas mecánicas}

El tamaño de los músculos masticatorios (Fig. 104A) se incrementó conforme aumentó la edad, mostrando una asíntota en la clase A2. El test U de Mann Whitney reveló significancia para las diferencias halladas entre las clases BJ1, J2-J3, J4-A1 y A1-A2 (Tabla 45). La ventaja mecánica del músculo masetero en relación al canino (Fig. 104B) mostró mucha variación en los valores de la mayoría de las clases de edad, y valores de media muy similares en todas ellas. No se hallaron diferencias significativas entre las distintas clases de edad para esta ventaja (Tabla 45). La ventaja del masetero medida en el carnicero (Fig. 104C) revela un aumento progresivo del valor desde la clase B a la J1, valores bajos para la clase J2, para finalmente continuar creciendo y estabilizar su progresión en la clase A2. Para esta ventaja resultaron significativas las diferencias entre las clases J2-J3 (Tabla 45). La ventaja mecánica del temporal medida en el canino (Fig. 104D) muestra valores similares entre las clases juveniles y luego un pequeño crecimiento desde la última clase de jóvenes (J4) a la segunda de adultos (A2), donde se percibe una asíntota, aunque existe un pequeño decrecimiento en la última clase de adultos (A3). La única diferencia que resultó significativa entre estas clases de edad fue entre las clases J4 y A1 (Tabla 45). En la ventaja del temporal en el carnicero 
(Fig. 104E) se puede ver mucha variación en los valores de las clases de edad, sobre todo en la J1. Hay valores uniformes en las 3 primeras clases, y luego un aumento desde la clase J3 a la de adultos A2 donde se produce la estabilización, aunque luego se pueda observar un decrecimiento en la clase A3. Sin embargo, no se hallaron diferencias significativas entre las distintas clases de edad ni entre sexos en las distintas ventajas mecánicas para las distintas clases de edad (Tabla 45).

\subsection{Leopardus tigrinus (Schreber 1775)}

\subsubsection{Reproducción y ontogenia}

La información sobre reproducción y ontogenia de esta especie está limitada a animales cautivos, y sugiere que la gestación dura 74-76 días, y el tamaño de camada es de 1-2 cachorros, siendo 1 lo común (Leyhausen \& Falkena 1966, Redford \& Eisenberg 1992, Sunquist \& Sunquist 2009). Los cachorros se desarrollan lentamente (Leyhausen \& Falkena 1966, Sunquist \& Sunquist 2009). Al nacer pesan entre 90-134 g, incrementando su peso 7 gramos por día, y alrededor de los 11 meses tienen casi el tamaño de un adulto (Leyhausen \& Falkena 1966). La apertura de los ojos ocurre a los 17 días y la erupción de los dientes deciduos ocurre entre los 15-21 días (Leyhausen \& Falkena 1966, Ewer 1973). Empiezan a comer alimentos sólidos a los 56 días, una edad en la que un gato doméstico (Felis catus) ya está cazando ratones (Leyhausen \& Falkena 1966, Ewer 1973, Sunquist \& Sunquist 2002). El destete ocurre a los 2-3 meses. Los machos protegen los cachorros inclusive más que las hembras (Oliveira 1993). La madurez sexual es obtenida después de los 2-2,5 años, mientras que la expectativa de vida puede exceder los 17 años (Nowak 2005) (Fig. 4Q). 


\subsubsection{Suturas y sincondrosis}

Aún cuando la muestra carece de clases B, J2, J3, J4 y A3, es posible inferir qué ocurrió con la fusión y cambio de tipo de suturas y sincondrosis en esta especie (Tabla 46, Fig. 105). De las suturas analizadas, 10 (23,81\%) se fusionaron completamente, aunque no es posible determinar si hubieran sido más las fusionadas de contar con la última clase de edad. Las que más temprano lo hicieron (durante la clase A1), fueron las suturas occipitointerparietalis, parietointerparietalis y sagittalis caudal, relacionadas con la parte posterior del cráneo y el hueso interparietal. Las que se fusionaron en la clase A2 fueron principalmente sincondrosis y suturas relacionadas con la placa occipital y el hueso esfenoides. Solo 2 suturas (4,76\%) se fusionaron parcialmente y lo hicieron en la clase A2. Las restantes 30 (71,43\%) no se fusionaron en ningún momento del desarrollo. En relación al cambio del tipo de suturas, solo 5 sufrieron un cambio de configuración, siempre mostrando la tendencia a un aumento de complejidad en el tipo. La sutura occipitoparietalis cambia de plana a escamosa/aserrada, la interfrontalis caudal y la sutura sagittalis cranial de plana a aserrada, y la coronalis y palatomaxillaris mesial cambian de escamosa a la combinación escamosa/aserrada (Tabla 46, Fig. 105).

\subsubsection{Análisis multivariado}

Tanto los machos como las hembras tuvieron la misma tendencia alométrica. El primer componente principal, incluyó el 74,41\% del total de la varianza. De las 22 variables analizadas con trimmed y untrimmed al 99\% de intervalo de confianza (Tabla 47), sólo 3 tuvieron tendencias diferentes comparando ambos análisis, y fueron: ancho de los caninos (Acan), longitud del coronoides (LC) y longitud de la hilera dentaria inferior (LHI). El valor más bajo de sesgo lo presentó el análisis trimmed $(0,0036)$, por lo que serán los resultados que se 
discutirán. Nueve tendencias fueron isométricas (40,91\%): longitud cóndiloincisiva (LCI), ancho de los arcos zigomáticos (AZ), longitud de la órbita (LO), longitud de los nasales (LN), altura del hocico $(\mathrm{HH})$, altura de la bulla auditiva (HB), longitud del paladar (Lpal), longitud de la hilera dentaria superior (LHS) y longitud del dentario (LD). Nueve variables fueron alométricas negativas $(40,91 \%)$ : altura de la placa occipital (HPO), ancho del proceso mastoideo (AM), ancho de la caja craneana $(\mathrm{AC})$, constricción postorbitaria (CPO), ancho de los caninos (Acan), ancho de la bulla auditiva (AB), longitud de la bulla (LB), ancho del paladar (Apal) y longitud de la hilera dentaria inferior (LHI). Las restantes 4 fueron alométricas positivas (18,18\%): longitud del rostro (LR), altura del dentario (HD), altura del proceso coronoides (HC) y longitud del coronoides (LC). Quien más se alejó de la isometría fue la longitud del coronoides (LC), con un valor de 0,2183 y quien menos lo hizo fue el ancho de los arcos zigomáticos (AZ), que presentó una desviación de 0,0038 (Tabla 47).

\subsubsection{Morfometría geométrica}

Para el cráneo (Fig. 106A), el PC1 explicó un porcentaje de 19,05\% de la varianza total, el PC2 el 11,67\% y el PC3 el 7,43\%. El PC1 y 2 mostraron hacia los valores negativos a los juveniles de esta especie, y hacia los valores centrales y positivos, a los adultos. Los jóvenes mostraron un cráneo ancho, corto y alto, hocico y rostro cortos y rectos, paladar ancho con torus palatino convexo y arcos zigomáticos no expandidos. Basicráneo corto y ancho, órbitas y bullas más grandes. Los adultos exhibieron un cráneo elongado, estrecho y bajo, hocico y rostro más largos y ligeramente curvados ventralmente, paladar más estrecho con torus palatino recto y arcos zigomáticos más expandidos. Basicráneo alargado y estrecho, órbitas y bullas más pequeñas. El PC3 no mostró ninguna distribución 
interesante y tanto machos, como hembras e indeterminados se distribuyeron homogéneamente (Fig. 106A).

En relación a la mandíbula (Fig. 106B), el PC1 representó un porcentaje del 30,77\%, el PC2 un 13,26\% y el PC3 un 10,91\% de la varianza total. El único PC de interés fue el primero, donde se ubicaron los juveniles hacia los valores positivos y los adultos hacia los medios y negativos, en ninguno de ellos se hallaron diferencias en cuanto a sexos o entre clases. Los jóvenes mostraron cuerpos mandibulares más largos y curvados, ramas mandibulares más débiles y cortas y un proceso coronoides ubicado hacia atrás. Los adultos presentaron la configuración opuesta: i.e. cuerpos mandibulares más cortos y rectos, ramas mandibulares más desarrolladas y elongadas y un proceso coronoides ubicado hacia arriba (Fig. 106B).

\subsubsection{Variación alométrica de la forma}

Para el cráneo (Fig. 107), el tamaño explicó el 11,82\% de la forma, con un $\mathrm{P}<0,0001$. Los especímenes más jóvenes estuvieron ubicados hacia los valores más bajos de tamaño de centroide (Fig. 107A), y los de la última clase (J4), se solaparon con los adultos que se encontraron ubicados homogéneamente en el espacio. En cuanto a los sexos (Fig. 107B), no se observaron agrupamientos vinculados a ellos en ninguno de los casos. Los especímenes más pequeños tuvieron un cráneo corto, ancho y alto, con nasales y lira más cortos y rostro corto y recto, las bullas y órbitas más grandes, arcos zigomáticos delgados y no expandidos, cóndilos occipitales paralelos a la placa occipital, y foramen magnum posterior al inion. Los especímenes más grandes mostraron un cráneo estrecho, elongado y bajo, con nasales y lira más alargados y rostro largo con extremo anterior curvado ventralmente. Bullas y órbitas más pequeñas, arcos zigomáticos más robustos y 
expandidos, cóndilos occipitales oblicuos en relación a la placa occipital, y foramen magnum a la misma altura del inion (Fig. 107).

Para la mandíbula (Fig. 108), el tamaño explicó el 20,16\% de la forma $(\mathrm{P}<0,0001)$. Las clases juveniles se encuentran hacia los menores valores de tamaño de centroide, bastante alejadas de las de adultos, tal vez porque no existen estadios de desarrollo intermedios (Fig. 108A). Los adultos se distribuyeron sin agruparse por clases, y los sexos (Fig. 108B) no produjeron agrupaciones destacables. Las formas más pequeñas mostraron cuerpos mandibulares más anchos, largos y con la parte anterior más recta, borde anterior de la fosa masetérica retrasada. Rama mandibular más estrecha y con su borde inferior cóncavo, proceso coronoides ancho y de posición posterior, punto interno y externo del proceso condiloideo de posición paralela al proceso coronoides y proceso angular más corto. Las formas más grandes tuvieron configuraciones opuestas: cuerpos mandibulares más estrechos, cortos y con el extremo anterior curvado, borde anterior de la fosa masetérica adelantada. Rama mandibular más ancha y con su borde inferior curvado, proceso coronoides estrecho y de posición más dorsal, punto interno y externo del proceso condiloideo en ángulo con el proceso coronoides y proceso angular más elongado (Fig. 108).

\subsubsection{Cambio de tamaño y de forma durante la ontogenia}

$\mathrm{Al}$ analizar la muestra sin tener en cuenta el sexo, se observa un gran salto entre la clase J1 y A1 en el caso del cráneo (Fig. 109A), producto de la falta de datos de clases intermedias, y luego la obtención del tamaño definitivo en esta última clase. En el caso de la mandíbula (Fig. 110A), el patrón fue similar, pero con arribo al tamaño definitivo en la clase A2. Cuando se realizó el test de Mann Whitney, buscando conocer la significancia de las diferencias entre clases de edad, éstas 
resultaron no significativas (Tabla 48). La forma del cráneo (Fig. 109B), aumentó progresivamente estableciéndose en la clase A1, aunque posteriormente hay un ligero descenso en la media de la clase A2. Sin embargo, tampoco se hallaron diferencias significativas entre estas clases de edad (Tabla 48). Para la mandíbula (Fig. 110B), la forma se incrementó, estabilizándose en la clase A2. Existieron diferencias significativas entre las clases A1 y A2 (Tabla 48). Cuando se tuvo en cuenta el sexo de los especímenes de la muestra, el tamaño craneal (Fig. 109C) presentó el mismo patrón que cuando no se tuvo en cuenta. Además, los machos fueron más grandes que las hembras, al igual que lo que ocurrió con el tamaño mandibular (Fig. 110C). Solamente se hallaron diferencias entre machos y hembras de la clase A2 para los cráneos de esta muestra (Tabla 48). Para la forma craneal (Fig. 109D) y mandibular (Fig. 110C), el patrón fue similar al que se obtuvo cuando el sexo no fue tenido en cuenta. Hubo un gran salto entre la clase J1 y A1, al que le siguieron valores similares. Al ser testeadas las diferencias con Mann Whitney, resultaron no significativas (Tabla 48).

\subsubsection{Ventajas mecánicas}

El tamaño de los músculos masticatorios (Fig. 111A) crece bruscamente desde la clase J1 a la A1, tal vez por faltar las clases intermedias. Se observa que la estabilidad se obtiene recién en la clase A2. El test U de Mann Whitney reveló significancia para las diferencias halladas entre las clases A1 y A2 (Tabla 48). La ventaja del músculo masetero, medida en el canino (Fig. 111B) y en el carnicero (Fig. 111C), se incrementó en relación a la edad y se estabilizó en la clase A2. Para la ventaja del músculo masetero medida en el canino hubo significancia en las diferencias entre las clases A1 y A2, mientras que no se hallaron diferencias significativas para la ventaja medida en el carnicero (Tabla 48). La ventaja 
mecánica del músculo temporal medida en el canino (Fig. 111D) mostró un crecimiento desde la clase J1 a la clase A1, donde el crecimiento se estabiliza, aunque luego presenta un leve descenso de los valores en la clase A2. No se hallaron diferencias significativas entre los distintos estadios de edad (Tabla 48). Este patrón es similar al que ocurre con la ventaja del mismo músculo, medida en el carnicero (Fig. 111E). Para esta ventaja se hallaron diferencias significativas entre las clases A1 y A2 (Tabla 48), aunque no se observaron diferencias entre sexos en las distintas ventajas mecánicas para las distintas clases de edad.

\subsection{Leopardus wiedii (Schinz 1821)}

\subsubsection{Reproducción y ontogenia}

El período de gestación es de 76-84 días y el tamaño de camada es usualmente de 1 cachorro (Oliveira 1998b, Sunquist \& Sunquist 2002, Sunquist \& Sunquist 2009). Cada cachorro al nacer pesa $85-125 \mathrm{~g}$, mide $380 \mathrm{~mm}$ de largo total y 270 mm de cola (Green 1991, Oliveira 1993, Oliveira 1998b, Nowak 2005). Los cachorros son relativamente grandes, lo cual es esperable por el largo período de gestación y el tamaño pequeño de la camada (Sunquist \& Sunquist 2002). Abren sus ojos entre los 7-15 días (Redford \& Eisenberg 1992) y al mes comienzan a dejar la madriguera. Los caninos deciduos aparecen a los 20 días, mientras que los permanentes erupcionan entre los 3-5,5 meses (Green 1991, Oliveira 1993, Oliveira 1998b). El destete ocurre aproximadamente a los 2 meses (Green 1991, Nowak 2005). El peso diario ganado en las primeras 4 semanas de vida fue de 16,2 g. La hembra obtuvo la madurez corporal alrededor del año, antes que el macho, que lo obtuvo alrededor de los 2 años. El peso de un macho maduro es $36,4 \%$ más que el de la hembra (Petersen \& Petersen 1978). La tasa de crecimiento es similar para machos y hembras, aunque las hembras obtienen alrededor del $90 \%$ del tamaño 
corporal a los 8 meses y los machos a los 10 meses. La madurez sexual es alcanzada a los 2 años de edad (Petersen \& Petersen 1978, Oliveira 1993, Oliveira 1998b). Un individuo cautivo vivió más de 21 años (Nowak 2005) y no existen datos sobre la expectativa de vida en libertad. El hecho de que se desarrolle físicamente tan rápido, está relacionado con que los cachorros necesitan acompañar a la madre en sus cacerías arbóreas, como ocurre con otros cachorros de mamíferos arborícolas (Sunquist \& Sunquist 2002) (Fig. 4R).

\subsubsection{Suturas y sincondrosis}

De las suturas analizadas (Tabla 49, Fig. 112), 15 (que representan un 35,72\% del total) se mostraron completamente fusionadas en la clase A3. Las que más temprano aparecen fusionadas son las sincondrosis intraoccipitalis squamolateralis y basilateralis, relacionadas con la placa occipital. Trece suturas y sincondrosis $(30,95 \%)$ se observaron parcialmente fusionadas en algún momento del desarrollo y se vincularon con los arcos zigomáticos, el paladar, los huesos esfenoides y maxilar. Las restantes $14(33,33 \%)$ no se fusionaron en ningún momento del desarrollo en esta especie, y estuvieron mayormente relacionadas con el área rostral. En relación al cambio del tipo de suturas, solo $6(14,28 \%)$ sufrieron un cambio de configuración, mostrando claramente la tendencia a aumentar la complejidad de la sutura. De esta manera, las suturas occipitointerparietalis, occipitoparietalis, sagittalis cranial, e intermaxillaris, cambiaron de Plana a Aserrada. Mientras que las suturas coronalis y palatomaxillaris mesial, lo hicieron de escamosa a escamosa/aserrada (Tabla 49, Fig. 112). 


\subsubsection{Análisis multivariado}

Para esta especie, machos y hembras tuvieron el mismo patrón alométrico. El primer componente principal, incluyó el 71,23\% del total de la varianza. De las 22 variables analizadas con trimmed y untrimmed (Tabla 50), 5 mostraron diferencias entre los 2 análisis: altura del hocico $(\mathrm{HH})$, altura de la bulla auditiva (HB), longitud de la hilera dentaria superior (LHS), altura del dentario (HD) y longitud de la hilera dentaria inferior (LHI). De todas maneras el valor más bajo de sesgo fue el del análisis untrimmed $(0,0019)$, por lo que se discuten los valores de este análisis. Once tendencias fueron isométricas (50\%): longitud cóndilo-incisiva (LCI), longitud de la órbita (LO), longitud de los nasales (LN), ancho de los caninos (Acan), altura del hocico $(\mathrm{HH})$, altura de la bulla auditiva (HB), longitud de la bulla (LB), longitud del paladar (Lpal), longitud de la hilera dentaria superior (LHS), altura del dentario (HD), y longitud de la hilera dentaria inferior (LHI). Seis fueron alométricas negativas (27,27\%): altura de la placa occipital (HPO), ancho del proceso mastoideo $(\mathrm{AM})$, ancho de la caja craneana (AC), constricción postorbitaria (CPO), ancho de la bulla auditiva (AB), y ancho del paladar (Apal). Cinco resultaron alométricas positivas (22,73\%): ancho de los arcos zigomáticos (AZ), longitud del rostro (LR), longitud del dentario (LD), altura del proceso coronoides (HC) y longitud del coronoides (LC). Quien más se alejó de la isometría fue la constricción postorbitaria (CPO), con un valor de 0,1532 y quien menos lo hizo fue la longitud de la órbita (LO) que presentó una desviación de 0,0048 (Tabla 50).

\subsubsection{Morfometría geométrica}

En relación al cráneo (Fig. 113A), el PC1 explica un porcentaje de 14,87\%, el PC2 un 10,08\% y el PC3 un 8,32\% de la varianza total. En el PC1 se pueden

observar a los juveniles hacia el extremo de los valores negativos, y a los adultos en 
el extremo de los valores positivos. Los cráneos de los jóvenes fueron redondeados, cortos, anchos y altos con poco desarrollo de los arcos zigomáticos y de los procesos supraorbitales. Hocico corto, paladar ancho, basicráneo corto y ancho y foramen magnum de posición ventral, órbitas y bullas más grandes. Los cráneos de los adultos fueron elongados, estrechos y bajos con mayor desarrollo de los arcos zigomáticos y de los procesos supraorbitales. Hocico más alargado, paladar estrecho, basicráneo más elongado y estrecho y foramen magnum de posición posterior, órbitas y bullas más pequeñas. Ninguno de los restantes PCs mostraron distribuciones vinculadas a la ontogenia, o a los diferentes sexos (Fig. 113A).

En relación a la mandíbula (Fig. 113B), el PC1 representó un porcentaje del 21,33\%, el PC2 un 11,58\% y el PC3 un 8,88\% de la varianza total. Ninguno de los PCs mostraron distribuciones atribuibles a la ontogenia, aunque en el PC1 se observa mejor que los juveniles están dispuestos hacia los valores negativos de éste, aunque el resto de las clases de edad están distribuidas homogéneamente. De un extremo a otro de este PC, existen cambios muy sutiles, con un cuerpo mandibular más corto y un proceso coronoides más débil hacia donde los más jóvenes se hallaron, y hacia el otro extremo la configuración opuesta, i.e.: cuerpo mandibular más elongado y un proceso coronoides más desarrollado. No se hallaron agrupaciones vinculadas a los sexos (Fig. 113B).

\subsubsection{Variación alométrica de la forma}

Para el cráneo (Fig. 114), el tamaño explicó el 10,04\% de la forma, con un $\mathrm{P}<0,0001$. Los especímenes juveniles tuvieron el tamaño de centroide más bajo (Fig. 114A). Sin embargo, los ejemplares de la clase J4 se superpusieron con las clases de adultos, que están distribuidas de manera homogénea en el espacio. En relación a los sexos (Fig. 114B), no se hallaron agrupaciones para ningún estadio de edad. Las 
formas más pequeñas exhibieron un cráneo más redondeado, ancho, con caja craneana alta, rostro, nasales y lira más cortos, órbitas y bullas grandes, arcos zigomáticos débiles y no expandidos, cóndilos occipitales paralelos a la placa occipital y foramen magnum posterior al inion. Los ejemplares más grandes mostraron un cráneo más estrecho, con caja craneana baja, premaxila, rostro y lira más elongadas, nasales ligeramente más anchos y largos, órbitas y bullas más pequeñas, arcos zigomáticos reforzados y expandidos, cóndilos occipitales oblicuos a la placa occipital y foramen magnum de posición anterior al inion (Fig. 114).

Para la mandíbula (Fig. 115), el tamaño explicó el 3,79\% de la forma $(\mathrm{P}<0,0001)$. Los juveniles de la clase $\mathrm{B}$ y los restantes se encontraron en diferentes trayectorias (Fig. 115A). Todos los ejemplares jóvenes se ubicaron en los valores más bajos de tamaño de centroide, y los de los estadios más avanzados se mezclaron con los adultos, que no se agruparon en clases. Con respecto a los sexos (Fig. 115B), hubo una distribución homogénea de todos ellos. Entre las formas más pequeñas y más grandes hubo sutiles diferencias que incluyeron, para las primeras, un cuerpo mandibular más largo y ligeramente más ancho, con el borde anterior de la fosa masetérica retrasado, rama mandibular ligeramente más estrecha, con el proceso coronoides más estrecho, el angular más corto, y la parte ventral de la rama mandibular cóncava. Entre las formas más grandes se pudo observar un cuerpo mandibular más corto y ligeramente más estrecho, con el borde anterior de la fosa masetérica adelantado, rama mandibular ligeramente más ancha, con el proceso coronoides más ancho, el angular más elongado, y la parte ventral de la rama mandibular convexa (Fig. 115). 


\subsubsection{Cambio de tamaño y de forma durante la ontogenia}

$\mathrm{Al}$ analizar la muestra sin tener en cuenta el sexo de los especímenes, se observó el crecimiento progresivo del cráneo (Fig. 116A) y mandíbula (Fig. 117A), que tuvieron su asíntota en la clase A2, donde se obtuvo el valor definitivo. Tanto para el cráneo como para la mandíbula, el test de Mann Whitney detectó la significancia en las diferencias entre las clases de edad J4 y A1 (Tabla 51). La forma se mostró muy diferente entre los especímenes de la clase B y J1, y luego se observaron una serie de valores similares que se estabilizaron y alcanzaron su valor definitivo en la clase A2 para el cráneo (Fig. 116B) y J4 para la mandíbula (Fig. 117B). Para el cráneo se hallaron significancias en las diferencias entre las clases J4-A1 y A1-A2, mientras que para la mandíbula no se hallaron diferencias significativas (Tabla 51). Cuando se tuvieron en cuenta los sexos, el tamaño también fue progresivo y se observaron diferencias entre machos y hembras desde la temprana clase J4, tanto para el cráneo (Fig. 116C), como por la mandíbula (Fig. 117C). El test de Mann Whitney encontró, para el cráneo, diferencias significativas entre machos y hembras para la clase A1, mientras para la mandíbula no se hallaron diferencias significativas (Tabla 51). La forma craneal (Fig. 116D) mostró una gran diferencia entre la clase B y J1, y luego una serie de valores parecidos en los que fue notable que a partir de la clase J4, son mayores para los machos que para las hembras. Se hallaron significancias en las diferencias entre machos y hembras de la clase A1 (Tabla 51). La forma mandibular (Fig. 117D) mostró un salto entre los valores de la clase B y J1, y luego una serie de valores similares. El test de Mann Whitney no encontró diferencias significativas entre sexos ni entre clases de edad (Tabla 51). 


\subsubsection{Ventajas mecánicas}

El tamaño de los músculos masticatorios (Fig. 118A) se incrementa, conforme aumenta la edad y se estabiliza en la clase A2, aunque se observa un ligero decrecimiento en la última clase (A3). Se observaron diferencias significativas entre las clases J4-A1 y A1-A2 (Tabla 51). La ventaja del masetero medida en el canino (Fig. 118B) muestra un aumento de los valores hasta la clase J3, un descenso en la clase J4, y una asíntota en la clase A1. No se observaron diferencias significativas entre las clases para esta ventaja mecánica (Tabla 51). Si bien los valores de $\mathrm{B}$ y de $\mathrm{J} 3$ son altos en la ventaja mecánica del masetero en el carnicero (Fig. 118C), se puede observar un aumento y una estabilización en la clase J4. Tampoco se hallaron diferencias significativas entre los diferentes estadios de edad para esta ventaja (Tabla 51). La ventaja mecánica del músculo temporal en el canino (Fig. 118D) muestra una serie de valores parecidos, la estabilización en la clase A1 y un ligero descenso en la clase de adultos más viejos, A3. La ventaja mecánica de este mismo músculo medida en el carnicero (Fig. 118E), muestra un aumento en los valores hasta la clase J4 donde se produce la estabilización. Ninguna de estas 2 ventajas, relacionadas con el músculo temporal, tuvieron diferencias significativas entre clases de edad, tampoco se observaron diferencias entre sexos en las distintas ventajas mecánicas para las distintas clases de edad (Tabla 51).

\subsection{Herpailurus yagouaroundi (Geoffroy Saint-Hilaire 1803)}

\subsubsection{Reproducción y ontogenia}

El período de gestación es de 70-75 días y las hembras dan a luz entre 1-4 cachorros (Redford \& Eisenberg 1992, Sunquist \& Sunquist 2009). Los cachorros 
empiezan a salir de la madriguera a los 28 días. Entre los 21 y 30 días las hembras le dan pequeñas cantidades de comida a sus crías, permitiéndoles jugar con ésta y masticarla, antes de que ella finalmente la coma. A los 42 días de edad los cachorros son capaces de comer por sí mismos (Hulley 1976, Oliveira 1998). Los cachorros pesan al nacer aproximadamente $186-190 \mathrm{~g}$, cuando pasa una semana 246-257 g, la segunda semana 344-359 g, la siguiente semana pesan 455-481 g (Buzas \& Gulyas 2012). Al mes pesan alrededor de 630-667, mientras que a los 2 meses entre 1000 y 1170 g (Gregory Breton observación personal, Buzas \& Gulyas 2012). En cautividad alcanzan la madurez sexual entre los 1,4-2,2 años (Redford \& Eisenberg 1992, Sunquist \& Sunquist 2009) y las hembras la alcanzan antes que los machos (Breton 2007). La longevidad en vida silvestre es desconocida, pero en los zoológicos se han registrado especímenes que vivieron casi 17 años (Sunquist \& Sunquist 2002, Breton 2007) (Fig. 4S).

\subsubsection{Suturas y sincondrosis}

De las 42 suturas estudiadas (Tabla 52, Fig. 119), 26 se fusionaron completamente, representando el 61,91\% del total. Las que se fusionaron más tempranamente, en la clase J1, fueron las suturas occipitointerparietalis y parietointerparietalis y la sincondrosis intraoccipitalis-squamolateralis, mientras que la sincondrosis intraoccipitalis basilateralis lo hizo en la clase J3. Estas suturas y sincondrosis que se fusionaron precozmente están relacionadas con la placa occipital y parte posterior del cráneo. El resto de las suturas y sincondrosis que se fusionaron lo hicieron en las clases de adultos A2 y A3. Tres suturas se fusionaron parcialmente, representando el $7,14 \%$. Trece suturas $(30,95 \%)$ no se fusionaron en ningún momento de la vida y estuvieron relacionadas con el rostro y los arcos zigomáticos. En relación al cambio del tipo de suturas, 6 modificaron su 
configuración $(14,28 \%)$, respetando la tendencia ya observada hacia el aumento de complejidad de la sutura. Es el caso de las suturas occipitomastoidea y occipitoparietalis que cambiaron de plana a escamosa, las sutura interfrontalis cranial y caudal e intermaxillaris cambiaron de plana a aserrada, y finalmente, la sutura palatomaxillaris mesial, que lo hizo de escamosa a aserrada (Tabla 52, Fig. 119).

\subsubsection{Análisis multivariado}

Los machos y las hembras presentaron la misma tendencia alométrica, encontrándose distribuidos de manera homogénea. El primer componente principal, incluyó el $81,44 \%$ del total de la varianza. De las 22 variables analizadas con trimmed y untrimmed (Tabla 53), 3 presentan diferencias en las tendencias cuando se analizan con ambas posibilidades, y son: la altura de la bulla auditiva (HB), la longitud de la hilera dentaria superior (LHS) y la altura del dentario (HD). El valor más bajo de sesgo lo presentó el análisis untrimmed $(0,0003)$, por lo que se discuten estos resultados. Ocho tendencias resultaron alométricas positivas $(36,36)$ : longitud cóndilo-incisiva (LCI), ancho de los arcos zigomáticos (AZ), longitud de los nasales (LN), longitud del rostro (LR), altura del hocico (HH), longitud del dentario (LD), altura del proceso coronoides (HC), y longitud del coronoides (LC). Siete fueron alométricas negativas $(31,82)$ : altura de la placa occipital (HPO), ancho del proceso mastoideo (AM), ancho de la caja craneana (AC), constricción postorbitaria (CPO), ancho de los caninos (Acan), ancho (AB) y longitud (LB) de la bulla auditiva. Las restantes 7 fueron isométricas $(31,82)$ : longitud de la órbita (LO), altura de la bulla auditiva (HB), ancho del paladar (Apal), longitud del paladar (Lpal), longitud de la hilera dentaria superior (LHS), altura del dentario (HD), y longitud de la hilera dentaria inferior (LHI). Quien más se alejó de la isometría fue la constricción postorbitaria (CPO), con un valor de 0,1871 y quien 
menos lo hizo fue la hilera dentaria inferior (LHI) que presentó una desviación de 0,0009 (Tabla 53).

\subsubsection{Morfometría geométrica}

Para el cráneo (Fig. 120A), el PC1 explica un porcentaje de 14,85\% de la varianza total, el PC2 un 10,55\% y el PC3 un 6,31\%. Hacia los valores negativos del PC1 se encontraron los especímenes juveniles de esta muestra y hacia los valores medios y positivos, los adultos. Los juveniles exhibieron cráneos redondeados, cortos, anchos y altos, hocicos cortos y anchos, paladares anchos, basicráneo ancho y corto, arcos zigomáticos no expandidos. Órbitas y bullas más grandes y foramen magnum grande y de posición ventral. Los adultos mostraron cráneos alargados, estrechos y bajos, hocicos más elongados y angostos, paladares más estrechos, basicráneo delgado y largo, arcos zigomáticos más expandidos. Órbitas y bullas más pequeñas y foramen magnum más pequeño y de posición posterior. Los PCs no mostraron asociaciones vinculadas al sexo y ni el PC2 ni el 3 mostraron asociaciones de interés (Fig. 120A).

Para la mandíbula (Fig. 121B), el PC1 representó un porcentaje del 20,89\%, el PC2 un 12,81\% y el PC3 un 9,88\% de la varianza total. Sólo el PC1 resultó de interesante desde el punto de vista ontogenético. Exhibió hacia los valores negativos a los juveniles y hacia los valores positivos a los adultos. Los jóvenes tuvieron cuerpos mandibulares más largos y rectos, y ramas ascendentes menos desarrolladas, más cortas y dirigidas hacia atrás. Los adultos tuvieron la configuración opuesta: I.e. cuerpos mandibulares más cortos y curvados, y ramas ascendentes más desarrolladas, más largas y anchas y dirigidas hacia arriba. No se hallaron agrupaciones relacionadas con los sexos (Fig. 121B). 


\subsubsection{Variación alométrica de la forma}

Para el cráneo (Fig. 121), el tamaño explicó el 10,75\% de la forma, con un $\mathrm{P}<0,0001$. Los especímenes más jóvenes estuvieron ubicados hacia los valores más bajos de tamaño de centroide (Fig. 121A), y los de la última clase (J4), se solaparon con los adultos que se encontraron ubicados homogéneamente en el espacio. En cuanto a los sexos (Fig. 121B), no se observaron agrupamientos. Las formas más pequeñas mostraron un cráneo más amplio y alto, con lira más corta, hocico corto y ancho. Órbitas y bullas más grandes, cóndilos occipitales paralelos a la placa occipital y foramen magnum de posición posterior al inion. Las formas más grandes exhibieron un cráneo más estrecho y bajo, con lira más larga, hocico más angosto y largo. Órbitas y bullas más pequeñas, cóndilos occipitales perpendiculares a la placa occipital y foramen magnum a la misma altura que el inion (Fig. 121).

Para la mandíbula (Fig. 122), el tamaño explicó el 8,65\% de la forma $(\mathrm{P}<0,0001)$. Los juveniles se ubicaron hacia los valores más bajos de tamaño de centroide (Fig. 122A), de manera progresiva, mezclándose los de las últimas clases con los adultos que no están diferenciados en estadios de edad. La distribución de los sexos (Fig. 122B) fue uniforme no hallándoselos agrupados por este motivo. Las formas más pequeñas tuvieron cuerpos mandibulares largos y anchos, con el borde anterior de la fosa masetérica retrasada, la rama mandibular más estrecha y curvada ventralmente. El proceso coronoides más corto y estrecho, el punto interno y externo del proceso condiloideo de posición paralela con respecto al proceso coronoides y el proceso angular más corto. Las formas más grandes presentan la configuración opuesta a la mencionada: cuerpos mandibulares más cortos y estrechos, con el borde anterior de la fosa masetérica adelantada, la rama mandibular más desarrollada, amplia y convexa ventralmente. El proceso 
coronoides más ancho y elongado, el punto interno y externo del proceso condiloideo recto y el proceso angular más alargado (Fig. 122).

\subsubsection{Cambio de tamaño y de forma durante la ontogenia}

Cuando no se tuvo en cuenta el sexo, el tamaño del cráneo (Fig. 123A) y la mandíbula (Fig. 124B) aumentaron de manera progresiva, conforme aumenta la edad, hasta la clase A2 donde se obtiene una asíntota. El test de Mann Whitney mostró, para el cráneo, diferencias significativas entre las clases J2-J3 y J4-A1, mientras que para la mandíbula no se hallaron diferencias significativas (Tabla 54). La forma muestra una diferencia importante entre la clase B y J1, luego un pequeño incremento hasta llegar a la clase J4 donde se estableció la forma definitiva para el cráneo (Fig. 123B), y A1 donde lo hizo para la mandíbula (Fig. 124B). Para el cráneo se observaron diferencias significativas para las clases J3 y J4, mientras que éstas no existieron para la mandíbula (Tabla 54). Al tener en cuenta el sexo de los especímenes, se observa un aumento en cuanto al tamaño. Para el cráneo (Fig. 123C) y la mandíbula (Fig. 124C), la diferenciación entre sexos es visible a partir de la clase de adultos A1. No se encontraron diferencias significativas entre machos y hembras para las distintas clases de edad (Tabla 54). La forma craneal (Fig. 123D) y mandibular (Fig. 124D) mostraron un incremento en los valores y luego una serie de valores similares. Se perciben valores mayores para machos de las clases A2 y A3 por sobre las hembras. No se hallaron diferencias significativas ni para el cráneo ni para la mandíbula al ser testeados con Mann Whitney (Tabla 54). 


\subsubsection{Ventajas mecánicas}

El tamaño de los músculos masticatorios (Fig. 125A), aumentó progresivamente con la edad, llegando a su valor definitivo en la clase A3. De todas formas, se encontraron diferencias significativas solo entre las clases de edad J4-A1 (Tabla 54). La ventaja mecánica del músculo masetero medida en el canino (Fig. 125B), mostró valores muy amplios en las distintas clases de edad y muy similares entre las distintas clases, arribando a la ventaja máxima en la clase A2. Un patrón similar ocurrió con la ventaja del músculo masetero medida en el carnicero (Fig. 125C), aunque la estabilización llegó antes, en la clase J3. No se hallaron diferencias significativas para ninguna de las ventajas del masetero (Tabla 54). A pesar de la importante variación presente, en la ventaja del temporal medida en el canino (Fig. 125D), se puede percibir un aumento hasta la clase A2 cuando se establece el valor definitivo. La ventaja mecánica del temporal en el carnicero (Fig. 125E) muestra una gran amplitud en los valores de las distintas clases, aun así es posible percibir un aumento en la ventaja hasta la clase J3, y luego la estabilización en el estadio de edad A2. Sin embargo, no se observaron diferencias entre sexos en las distintas ventajas mecánicas del temporal, para las distintas clases de edad (Tabla 54).

\subsection{Puma concolor (Linnaeus 1771)}

\subsubsection{Reproducción y ontogenia}

Las hembras tienen un período de gestación que dura entre 82 y 96 días y paren de 1 a 6 cachorros (Currier 1983). Al nacer, las crías tienen un peso de 400$500 \mathrm{~g}$ y miden alrededor de $300 \mathrm{~mm}$ (Young \& Goldman 1946). Abren los ojos a los 8 días (Gittleman 1986) y la madre permanece con ellas casi constantemente 
durante los primeros días de su nacimiento, los alimenta cada 8 a 12 veces por día, y a la semana de edad ya pueden quedarse solas por más tiempo mientras su madre caza. A las 2 semanas empiezan a caminar y a jugar, y a las 3 semanas se acicalan a sí mismos (Sunquist \& Sunquist 2002). Cuando tienen 1 mes y medio comienzan a comer pedazos pequeños de carne que les ofrece su madre y mantienen una alimentación mixta hasta que son destetados a los 2-3 meses de edad (Young \& Goldman 1946). Los cachorros empiezan a viajar y a cazar con sus madres alrededor de los 6 meses y son hábiles para cazar sus propias presas recién al año de edad (Sunquist \& Sunquist 2002, Nowak 2005). Los incisivos deciduos emergen entre 8-20 días, seguidos por los caninos entre 14-34 días y los premolares entre 30-50 días (Eaton \& Verlander 1977, Toweill 1986, Pierce \& Bleich 2003). Los incisivos permanentes reemplazan a los deciduos a la edad de 5 meses y medio, y los caninos definitivos emergen a los 8 meses (Currier 1983, Pierce \& Bleich 2003). El peso a los 4 días de edad fue de $768 \mathrm{~g}$, a los 6 días pesaron $791 \mathrm{~g}$, a los 9 días se registró un peso de 820 g, a los 20 días fue de 928 g, a los 27 días de 981 g y a los 36 días fue de $1080 \mathrm{~g}$ (Toweill 1986). El peso al destetar es de 3-4 $\mathrm{kg}$ y el del adulto es obtenido alrededor de los 4 años de edad (Redford \& Eisenberg 1992, Nowak 2005). Según Iriarte et al. (1990) el tamaño corporal definitivo está correlacionado con el tamaño de las presas, pero también es afectado por la presencia de jaguares (Panthera onca). La edad de madurez sexual en las hembras es 2-3 años de edad (Young \& Goldman 1946, Eaton \& Verlander 1977, Shaw et al. 2007), mientras que en el macho ocurre entre 1-2 años (Eaton \& Verlander 1977). Sin embargo, la actividad reproductiva regular no comienza hasta que los jóvenes no se han establecido en un área permanente (Nowak 2005). Los jóvenes permanecen con la madre hasta la edad de 1-2 años, y los hermanos siguen juntos por 2-3 meses más luego de la separación de su madre (Nowak 2005). Las hembras permanecen 
reproductivamente activas hasta los 12 años de edad, mientras los machos lo hacen (en cautiverio) hasta los 20 años de edad (Currier 1983). En vida silvestre la expectativa de vida de un puma es hasta los 18 años de edad (Nowell \& Jackson 1996, Nowak 2005) (Fig. 4T).

\subsubsection{Suturas y sincondrosis}

De las 42 suturas estudiadas (Tabla 55, Fig. 126), 27 se fusionaron completamente, representando el $64,28 \%$ del total. Las que se fusionaron más tempranamente fueron las sincondrosis intraoccipitalis squamolateralis y basilateralis, que lo hicieron en las clases $\mathrm{J} 1$ y J3, respectivamente., y estuvieron vinculadas con la placa occipital. Cinco suturas y sincondrosis $(11,91 \%)$ se fusionaron parcialmente durante el desarrollo y se relacionaron principalmente con el maxilar. Las otras 10 suturas $(23,81 \%)$ no se fusionaron nunca, y están relacionadas con los frontales y arcos zigomáticos. En relación al cambio del tipo de suturas, 11 modificaron su configuración, siempre mostrando una tendencia al aumento en la complejidad de las suturas. En el caso parietointerparietalis, sagittalis caudal, intermaxillaris, e interpalatina cambiaron de plana a aserrada. Las suturas occipitoparietalis, coronalis y squamosa lo hicieron de plana a escamosa. Las suturas palatomaxillaris dorsal, mesial y lateral cambiaron de escamosa a aserrada, mientras que la sutura frontopalatina lo hizo de escamosa a la combinación escamosa/aserrada (Tabla 55, Fig. 126).

\subsubsection{Análisis multivariado}

Tanto machos como hembras tuvieron la misma tendencia alométrica, mostrando una distribución homogénea. El primer componente principal, incluyó el $80,02 \%$ del total de la varianza. Ninguna de las 22 variables analizadas mostraron diferencias entre el análisis trimmed y untrimmed realizado con 99\% de 
intervalo de confianza (Tabla 56). Esto significa que no existen seudovalores extremos que afecten la estimación de Jackknife. Nueve fueron alométricas negativas (40,91\%): altura de la placa occipital (HPO), ancho del proceso mastoideo $(\mathrm{AM})$, ancho de la caja craneana (AC), constricción postorbitaria (CPO), longitud de la órbita (LO), ancho de la bulla auditiva (AB), ancho del paladar (Apal), longitud de la hilera dentaria superior (LHS), y longitud de la hilera dentaria inferior (LHI). Siete de ellas resultaron alométricas positivas (31,82\%): longitud cóndilo-incisiva (LCI), ancho de los arcos zigomáticos (AZ), longitud del rostro (LR), altura del hocico $(\mathrm{HH})$, longitud del dentario (LD), altura del proceso coronoides (HC) y longitud del coronoides (LC). Finalmente, 6 tendencias resultaron isométricas $(27,27 \%)$ : longitud de los nasales $(\mathrm{LN})$, ancho de los caninos (Acan), altura de la bulla auditiva (HB), longitud de la bulla (LB), longitud del paladar (Lpal) y altura del dentario (HD). Quien más se alejó de la isometría fue la constricción postorbitaria (CPO), con un valor de 0,1931 y quien menos lo hizo fue el ancho de los caninos (Acan), que presentó una desviación de 0,0034 (Tabla 56).

\subsubsection{Morfometría geométrica}

Para el cráneo (Fig. 127A), el PC1, explica un porcentaje del 21,06\%, el PC2 un 10,77\% y el PC3 un 5,50\% de la varianza total. El PC1 mostró a los adultos agrupados hacia los valores negativos y a los juveniles hacia los positivos. Los cráneos de los adultos fueron alargados, estrechos y bajos, con hocicos estrechos, basicráneos angostos y foramen magnum pequeño y posterior. Tuvieron órbitas y bullas más pequeñas y arcos zigomáticos muy desarrollados. Los de los juveniles fueron redondos, cortos, anchos y altos, con hocicos amplios, basicráneos anchos y foramen magnum grande y de posición ventral. Tuvieron órbitas y bullas grandes y arcos zigomáticos no expandidos. Los demás PCs no mostraron agrupaciones de 
interés y ninguno de los PCs mostraron grupos relacionados a los sexos (Fig. 127A).

Para la mandíbula (Fig. 127B), el PC1 representó un porcentaje del 33,31\%, el PC2 un 15,24\% y el PC3 un 12,72\% de la varianza total. El único PC que resultó de interés ontogenético fue el primero, que mostró hacia los valores negativos a los juveniles y hacia los valores positivos a los adultos. Los jóvenes tuvieron cuerpos mandibulares más largos y rectos y ramas ascendentes más débiles, cortas y dirigidas hacia atrás. Los adultos mostraron la configuración contraria: cuerpos mandibulares más cortos y curvados y ramas ascendentes más desarrolladas, alargadas y con una posición más dorso-ventral. No se encontraron agrupaciones vinculadas con los sexos (Fig. 127B).

\subsubsection{Variación alométrica de la forma}

Para el cráneo (Fig. 128), el tamaño explicó el 17,68\% de la forma, con un $\mathrm{P}<0,0001$. Los especímenes más jóvenes estuvieron ubicados hacia los valores más bajos de tamaño de centroide (Fig. 128A), y los de la última clase (J4), se solaparon con los adultos que se encontraron ubicados homogéneamente en el espacio. En cuanto a los sexos (Fig. 128B), no se observaron agrupamientos vinculados a ellos en ninguno de los casos. Los especímenes más pequeños tuvieron un cráneo ancho, corto y alto, con rostro y lira más amplios y cortos, arcos zigomáticos débiles y no expandidos. Bullas y órbitas más grandes, cóndilos occipitales paralelos a la placa occipital y foramen magnum a la altura del inion. Los especímenes más grandes mostraron un cráneo más estrecho, elongado y bajo, con rostro y lira más angostos y largos, arcos zigomáticos muy desarrollados y expandidos. Bullas y órbitas más pequeñas, cóndilos occipitales de posición más oblicua a la placa occipital y foramen magnum anterior al inion (Fig. 128). 
Para la mandíbula (Fig. 129), el tamaño explicó el 23,55\% de la forma $(\mathrm{P}<0,0001)$. Los juveniles tuvieron menores tamaños de centroide (Fig. 129A), y los de la clase B se hallaron separados de todo el resto de los especímenes. El resto de los jóvenes se distribuyeron progresivamente y las últimas clases se solaparon con los adultos, que no estuvieron agrupados por estadio de edad. Los sexos (Fig. 129B) se distribuyeron de manera uniforme sin agrupaciones de ningún tipo. Las formas más pequeñas tuvieron cuerpos mandibulares más largos y anchos, borde anterior de la fosa masetérica retrasado, rama mandibular más estrecha y curvada ventralmente. Procesos coronoides estrecho y corto y procesos condiloideo y angular más breves. Las formas más grandes tuvieron configuraciones exactamente opuestas: cuerpos mandibulares más cortos y estrechos, borde anterior de la fosa masetérica adelantado, rama mandibular ensanchada y convexa ventralmente. Proceso coronoides amplio y alargado y proceso condiloideo y angular elongados (Fig. 129).

\subsubsection{Cambio de tamaño y de forma durante la ontogenia}

Cuando el sexo no fue tenido en cuenta, el tamaño fue creciendo paulatinamente, mostrando un solo cambio brusco entre la clase B y J1. Finalmente, el tamaño definitivo se estableció en la clase A2 para el cráneo (Fig. 130A) y A3 para la mandíbula (Fig. 131A). Al testear los valores entre clases con Mann Whitney, para el cráneo y la mandíbula, fueron significativas las diferencias

entre las clases A1 y A2 (Tabla 57). Para la forma también se observó un salto entre la clase B y J1, luego una serie de valores similares, y la forma definitiva que llega en la clase A2 para el cráneo (Fig. 130B) y A3 para la mandíbula (Fig. 131B). De la misma manera, hubo significancias en las diferencias entre las clases A1 y A2 (Tabla 57). Cuando se tomó en cuenta el sexo de los individuos, el tamaño craneal 
(Fig. 130C) y el mandibular (Fig. 131C) aumentaron con un patrón similar a cuando no se tuvo en cuenta el sexo, mostrando diferencias importantes entre la clase B y J1. Luego, se observó a los machos con valores mayores que las hembras a partir de la clase A1. No se hallaron diferencias significativas entre los distintos sexos y para las distintas clases de edad (Tabla 57). La forma craneal (Fig. 130D) y mandibular (Fig. 131D) aumentó bruscamente entre las clases B y J1, luego se observó una progresión hasta la clase A1, donde se comenzaron a observar valores similares y luego un pequeño cambio en la clase de machos A3 que se mostró más desarrollada. No se observó gran diferencia entre sexos, y de hecho, esta no fue significativa al ser testeada con Mann-Whitney (Tabla 57).

\subsubsection{Ventajas mecánicas}

El tamaño de los músculos masticatorios (Fig. 132A), muestra un brusco aumento desde la clase B a la clase J1, creciendo con la edad, hasta su estabilización en la clase A2. Se encontraron diferencias significativas entre las clases de edad A1 y A2 (Tabla 57). La ventaja mecánica del masetero medida en el canino (Fig. 132B), muestra un aumento progresivo hasta la clase J2, luego un descenso para las clases J3 y J4 y nuevamente un aumento hacia las clases de adultos. Este crecimiento se estabiliza en la clase A3. Nuevamente, se encontraron diferencias significativas entre las clases de edad A1 y A2 (Tabla 57). La ventaja mecánica del masetero medida en el carnicero (Fig. 132C), aumenta progresivamente en las clases de jóvenes, mostrando un ligero descenso en la clase J4. Ese aumento prosigue en las clases de adultos, estabilizándose en la clase A3. No se hallaron diferencias significativas entre los distintos estadios de edad (Tabla 57). A pesar de la variación mostrada, la ventaja mecánica del temporal medida en el canino (Fig. 132D), muestra un incremento en relación a la edad, que se estabiliza en la clase de 
adultos A1. Aún teniendo en cuenta los erráticos valores de la clase B, se observa en la ventaja mecánica del temporal medida en el carnicero (Fig. 132E), un aumento que se estabiliza completamente en la clase de adultos más jóvenes A1. No se encontraron diferencias significativas entre las clases de edad para las ventajas del músculo temporal (Tabla 57).

\subsection{Panthera onca (Linnaeus 1758)}

\subsubsection{Reproducción y ontogenia}

El período de gestación dura entre 98 a 109 días y el tamaño de camada es 14 (Ewer 1973). Los cachorros miden al nacer $400 \mathrm{~mm}$ y pesan 680-990 g (Ewer 1973, Seymour 1989). Abren los ojos entre los 3-13 días (Nowak 2005), caminan a los 18 días (Hemmer 1979) y acompañan a sus madres a partir de los 2 meses (Sunquist \& Sunquist 2002). La erupción de los incisivos inferiores de leche ocurre entre los 9-19 días, los incisivos superiores entre los 11-23 días, los caninos superiores alrededor de los 30 días y los caninos inferiores entre 36-37 días. Los jóvenes son completamente dependientes de la leche de sus madres hasta los 2 meses de edad, cuando empiezan a comer pequeñas raciones de carne, aunque continúan mamando hasta los 5-6 meses de edad (Ewer 1973, Seymour 1989, Nowak 2005, Sunquist \& Sunquist 2009). En animales cautivos el peso ganado por día, los primeros 50 días, es de $48 \mathrm{~g}$ (Hemmer 1979). Los machos crecen más rápido que las hembras y a los 2 años de edad, los machos pueden tener un $50 \%$ más de peso que sus hermanas (Sunquist \& Sunquist 2009). La independencia nutricional ocurre al menos 2 meses antes de la dispersión, que ocurre alrededor de 1,5-2 años (Tewes \& Schmidly 1987, Redford \& Eisenberg 1992, Nowak 2005). Los jóvenes viajan de manera independiente, cazando sus propias presas, dentro del territorio de sus madres durante un tiempo más (Sunquist \& Sunquist 2009). Las hembras son 
maduras sexualmente entre los 2-2,5 años y los machos entre los 3-4 años, momento en el que además alcanzan el tamaño de adultos (Nowak 2005, Sunquist \& Sunquist 2009). La longevidad máxima registrada en vida silvestre es de 11 años (Tewes \& Schmidly 1987), mientras que un Jaguar de un zoológico de Alemania (Wuppertal Zoo) vivió 24 años (Nowak 2005) (Fig. 4U).

\subsubsection{Suturas y sincondrosis}

De las 42 suturas aquí analizadas (Tabla 58, Fig. 133), 28 se fusionaron completamente, representando un $66,67 \%$. Las que lo hicieron más tempranamente fueron las sincondrosis intraoccipitalis squamolateralis y basilateralis y la sutura parietointerparietalis, en la clase J3, y estuvieron vinculadas con la placa occipital y parte posterior del cráneo. Diez suturas y sincondrosis se fusionaron parcialmente (23,81\%) en algún momento del desarrollo y estuvieron relacionadas con los

frontales, nasales y palatinos. Las 4 restantes $(9,52 \%)$ no se fusionaron en ningún momento del desarrollo de los individuos de esta especie, y estuvieron relacionadas con el rostro y los arcos zigomáticos. En relación al cambio del tipo de suturas, siete sufrieron cambios de configuración, mostrando tendencia hacia el aumento de la complejidad. De esta forma, las suturas parietointerparietalis, sagittalis caudal, intermaxillaris e interpalatina cambiaron de plana a aserrada, la sutura occipitoparietalis cambió de plana a escamosa, mientras que las suturas palatomaxillaris mesial y lateral cambiaron de escamosa a aserrada (Tabla 58, Fig. 133).

\subsubsection{Análisis multivariado}

Machos y hembras tuvieron la misma tendencia alométrica, distribuyéndose de manera homogénea en el morfo-espacio. El primer componente principal, 
incluyó el 88,29\% del total de la varianza. De las 22 variables (Tabla 59), analizadas con trimmed y untrimmed al 99\% de intervalo de confianza, 2 presentan diferencias en las tendencias: el ancho del proceso mastoideo (AM) y la longitud de la hilera dentaria inferior (LHI). El valor más bajo de sesgo lo presentó el análisis untrimmed $(0,0010)$, por lo que se discuten estos resultados. Nueve tendencias fueron positivas (40,91\%): longitud cóndilo-incisiva (LCI), altura de la placa occipital (HPO), ancho de los arcos zigomáticos (AZ), longitud del rostro (LR), altura del hocico (HH), longitud del paladar (Lpal), longitud del dentario (LD), altura del proceso coronoides (HC) y longitud del coronoides (LC). Siete variables fueron alométricas negativas (31,82\%): ancho de la caja craneana (AC), constricción postorbitaria (CPO), longitud de la órbita (LO), ancho de la bulla auditiva (AB), longitud de la bulla (LB), ancho del paladar (Apal) y longitud de la hilera dentaria superior (LHS). Seis resultaron isométricas (27,27\%): ancho del proceso mastoideo (AM), longitud de los nasales (LN), ancho de los caninos (Acan), altura de la bulla auditiva (HB), altura del dentario (HD) y longitud de la hilera dentaria inferior (LHI). Quien más se alejó de la isometría fue la constricción postorbitaria (CPO), con un valor de 0,1523 y quien menos lo hizo fue la altura del dentario (HD), que presentó una desviación de 0,0006 (Tabla 59).

\subsubsection{Morfometría geométrica}

Para el cráneo (Fig. 134A), el PC1, explica un porcentaje de 25,02\% de la varianza total, el PC2 el 6,98\% y el PC3 el 5,63\%. El PC1 exhibió hacia sus valores negativos a los juveniles de la muestra y hacia los positivos a los adultos distribuidos en todos los casos, sin distinción de clases de edad. Para los jóvenes el cráneo se mostró redondeado con una caja craneana ancha, corta y alta, sobre todo en la parte posterior, con hocico y paladar ancho y corto, arcos zigomáticos débiles 
y poco expandidos. Órbitas y bullas más grandes, basicráneo amplio y foramen magnum grande y ventral. Los adultos tuvieron un cráneo elongado con una caja craneana estrecha y baja, con hocico y paladar largo y más estrecho, arcos zigomáticos muy fuertes y expandidos. Órbitas y bullas más pequeñas, basicráneo angosto y foramen magnum más pequeño y de posición posterior. Los otros PCs no mostraron agrupamientos interesantes y en ninguno de los casos los sexos fueron diferenciados en grupos (Fig. 134A).

Para la mandíbula (Fig. 134B), el PC1 representó un porcentaje del 27,95\%, el PC2 un 16,91\% y el PC3 un 10,65\% de la varianza total. No se encontraron agrupaciones vinculadas con los sexos. De los 3 PCs, el que resultó de mayor interés fue el 1 que mostró hacia los valores negativos a los juveniles y hacia los positivos a los adultos. El cuerpo mandibular de los jóvenes fue más ancho y elongado, con rama ascendente más corta y dirigida hacia atrás y los adultos presentaron la configuración opuesta: i.e. Un cuerpo mandibular más corto y estrecho, con rama ascendente más desarrollada, larga y dirigida hacia arriba (Fig. 134B).

\subsubsection{Variación alométrica de la forma}

Para el cráneo (Fig. 135), el tamaño explicó el 21,32\% de la forma, con un $\mathrm{P}<0,0001$. Los especímenes juveniles se hallaron hacia las zonas de valores de tamaño de centroide más bajos (Fig. 135A). Los ejemplares de las clases J3 y J4 se solaparon con los adultos de las distintas clases que no se agruparon y estuvieron distribuidos de manera homogénea. Con respecto a los sexos (Fig. 135B), no se observó ninguna agrupación en relación a ellos. Las formas más pequeñas exhibieron un cráneo redondeado, corto, ancho, de rostro breve y caja craneana alta, cóndilos occipitales paralelos a la placa occipital, placa occipital amplia y 
foramen magnum a la altura del inion, órbitas y bullas grandes, y arcos zigomáticos no expandidos. Las más grandes, mostraron un cráneo elongado, estrecho, de rostro más alargado y caja craneana baja, cóndilos occipitales perpendiculares a la placa occipital, placa occipital más pequeña y foramen magnum de posición anterior al inion, órbitas y bullas más pequeñas, y arcos zigomáticos muy expandidos (Fig. 135).

Para la mandíbula (Fig. 136), el tamaño explicó el 17,13\% de la forma, con un $\mathrm{P}<0,0001$. Los especímenes se encuentran distribuidos progresivamente desde los valores menores de tamaño de centroide (Fig. 136A), donde estuvieron los más jóvenes, a los valores más altos, donde estuvieron los adultos. Los juveniles de las últimas clases (J3 y J4) se hallaron integrados con los adultos que no están diferenciados en clases. Con respecto a los sexos (Fig. 136B), no hubo diferenciación alguna entre ellos. Las formas más pequeñas presentaron cuerpos mandibulares más anchos y largos, con borde anterior de la fosa masetérica retrasada, rama mandibular más estrecha, con borde inferior cóncavo. Proceso coronoides más angosto, corto y dirigido hacia atrás, procesos condiloideo y angular más cortos. Las formas más grandes mostraron la configuración opuesta: cuerpos mandibulares más estrechos y cortos, con borde anterior de la fosa masetérica adelantada, rama mandibular más amplia, con borde inferior convexo. Proceso coronoides más ancho, elongado y dirigido hacia arriba, procesos condiloideo y angular más alargados (Fig. 136).

\subsubsection{Cambio de tamaño y de forma durante la ontogenia}

Cuando el sexo no fue tenido en cuenta, el tamaño craneal (Fig. 137A) se incrementó hasta la clase A3, donde finalmente se obtuvo el definitivo. El tamaño mandibular (Fig. 138A) tuvo un patrón bastante similar, aunque arribó al valor 
definitivo en la clase A1. El test de Mann-Whitney reveló que no existieron diferencias significativas entre ninguna de las clases de edad para el tamaño (Tabla 60). La forma fue cambiando desde la clase B, hasta que se obtuvo la definitiva en la clase A3 para el cráneo (Fig. 137B) y en la A2 para la mandíbula (Fig. 138B). Tampoco en el caso de la forma se hallaron diferencias significativas entre los distintos estadios de edad (Tabla 60). Cuando se tomó en cuenta el sexo de los individuos, el tamaño craneal (Fig. 137C) y mandibular (Fig. 138C) fue aumentando progresivamente y se observaron a los machos más grandes que las hembras desde la clase A1. La forma craneal (Fig. 137D) y mandibular (Fig. 138D) fue desarrollándose conforme aumentó la edad, hasta la clase A3 donde se obtuvo la definitiva. Ninguno de estos valores resultaron ser estadísticamente diferentes, cuando fueron testeados con Mann-Whitney (Tabla 60).

\subsubsection{Ventajas mecánicas}

El tamaño de los músculos masticatorios (Fig. 139A) aumentó para esta especie en relación a la edad, mostrándose una asíntota en la clase A3. Usando el test U de Mann-Whitney, se hallaron diferencias significativas entre las clases J1-J2 y A1-A2 (Tabla 60). La ventaja del músculo masetero medida en el canino (Fig. 139B), se presenta con valores similares compartidos por las clases juveniles, luego se produce un salto en los valores para nuevamente ser compartidos, pero esta vez entre los adultos. La asíntota para esta ventaja se alcanza en la clase A1. La ventaja del masetero medida en el carnicero (Fig. 139C) muestra valores parecidos entre las primeras clases de juveniles, un salto en valores en la clase J4 y el crecimiento que se estabiliza y cesa en la clase de adultos A1. Para ninguna de las ventajas relacionadas con el músculo masetero se obtuvieron diferencias significativas (Tabla 60). La ventaja de los temporales medida en el canino (Fig. 139D) presenta 
valores similares en las primeras clases juveniles y un aumento importante desde la clase J4 en adelante. La ventaja definitiva se adquiere en la clase J4. Para la ventaja del músculo temporal medida en el carnicero (Fig. 139E), se observan 2 grupos de medidas: la de los valores que comparten las primeras clases de juveniles y la de los valores mayores que comparten desde la clase J4 en adelante. Para esta ventaja la estabilización se obtiene en la clase A1. Tampoco se hallaron diferencias significativas entre los distintos estadios de edad para las ventajas relacionadas con el músculo temporal, ni se observaron diferencias entre sexos en las distintas ventajas mecánicas para las distintas clases de edad (Tabla 60). 


\section{RESULTADOS COMBINADOS}

Oh fiera independiente

De la casa, arrogante

Vestigio de la noche,

Perezoso, gimnástico

Y ajeno,

Profundísimo gato,

Policía secreta

De las habitaciones,

Insignia

De un

Desaparecido terciopelo,

Seguramente no hay

Enigma

En tu manera,

Tal vez no eres misterio,

Todo el mundo te sabe y perteneces

Al habitante menos misterioso,

Tal vez todos lo creen,

Todos se creen dueños,

Propietarios, tíos

De gatos, compañeros,

Colegas,

Discípulos o amigos de su gato.

$\sim 158 \sim$ 


\subsection{Análisis de morfometría geométrica}

\subsubsection{Análisis de morfometría geométrica en cráneos y mandíbulas de cánidos}

Cuando se integraron especímenes de otras regiones zoogeográficas al análisis de componentes principales del cráneo de los cánidos, el PC1 representó un porcentaje del $29,98 \%$, el PC2 un 8,02\% y el PC3 un 5,45\% de la varianza total (Fig. 140). La mayoría de los adultos de las especies estudiadas se ubicaron hacia los valores negativos del PC1, mientras que los juveniles lo hicieron hacia los valores positivos. La especie que mostró la diferencia más importante fue Speothos venaticus con su trayectoria completa hacia los valores positivos del PC1 y negativos del PC2, y sin ningún solapamiento con el resto de las especies. El espacio ocupado por Chrysocyon brachyurus (valores negativos del PC1 y positivos del PC2), al igual que el que ocupó Lycalopex culpaeus (valores negativos del PC1 y del PC2) los destacaron ligeramente del resto. De un modo menos notable aún Atelocynus microtis, Lycalopex sechurae, L. vetulus y L. fulvipes se diferenciaron, ubicándose hacia los valores positivos del PC1 y negativos del PC2, aunque solapándose más con el resto en el morfoespacio. En relación a las clases de edad, se diferenciaron perfectamente los adultos de los jóvenes, solapándose en poca medida. La mayoría de las especies mostraron los adultos de las 3 clases hacia los valores negativos del PC1, donde se observaron cráneos alargados, estrechos, bajos, con bullas más estrechas, cóndilos occipitales perpendiculares a la placa occipital, pegados a la caja craneana, inion posterior al foramen magnum, rostro y nasales elongados. Hacia los valores positivos de este componente principal, los juveniles mostraron cráneos redondeados, altos, con bullas más grandes, inion a la misma altura que el foramen magnum, placa occipital más redondeada y rostro y nasales más cortos. Para el PC2 los valores negativos presentaron cráneos muy 
similares al consenso. La caja craneana se mostró ligeramente más estrecha y menos alta, con cresta sagital dispuesta en línea recta hacia la parte posterior del cráneo, placa occipital expandida hacia atrás, foramen magnum más pequeño, cóndilos occipitales perpendiculares a la placa occipital, inion que no sobrepasa el foramen magnum, bullas más pequeñas, y rostro y nasales ligeramente más cortos. Hacia los valores positivos del PC2, los cráneos se observaron más redondeados y altos, con lira y bullas más grandes, cresta sagital que desciende hacia la parte posterior del cráneo, inion que sobrepasa al foramen magnum, arcos zigomáticos más delgados y de posición más superior, rostro y nasales más largos (Fig. 140).

En relación a la mandíbula, el PC1 representó un porcentaje del 14,98\%, el PC2 un 14,34\% y el PC3 un 11,94\% de la varianza total (Fig. 141). La mayoría de las configuraciones se agruparon hacia los valores negativos del PC1, sin embargo, $S$. venaticus nuevamente se distanció mucho de los restantes, ubicándose hacia los valores positivos del PC1 y del PC2. También se diferenciaron $C$. thous hacia los valores positivos del PC1 y C. brachyurus que se ubicó hacia los valores negativos del PC1, pero positivos del PC2. Hacia los valores negativos del PC1, las mandíbulas mostraron cuerpos mandibulares gráciles y elongados. La rama mandibular fue más recta, estrecha, con proceso coronoides más estrecho y dirigido hacia atrás y borde anterior de la fosa masetérica retrasado. Hacia los valores positivos, el cuerpo mandibular se mostró ancho, curvado y corto, con el borde anterior de la fosa masetérica adelantado. La rama mandibular fue más alta, ancha, curvada en su parte inferior y con proceso coronoides dirigido hacia arriba. Para el PC2, hacia el extremo negativo, se observaron mandíbulas con cuerpo mandibular más estrecho, aunque curvado, borde anterior de la fosa masetérica retrasada, rama mandibular de un ancho intermedio a las configuraciones extremas del PC1, con proceso coronoides dirigido hacia arriba y el angular hacia $\sim 160 \sim$ 
atrás. Hacia el extremo positivo, el cuerpo mandibular fue más ancho, aunque mantuvo su curvatura, el borde anterior de la fosa masetérica estuvo adelantado, la rama mandibular fue intermedia en relación a las configuraciones negativas y positivas del $\mathrm{PC} 1$, con los procesos coronoides y condiloideo dirigidos hacia atrás, y el angular muy reducido (Fig. 141).

\subsubsection{Análisis de morfometría geométrica en cráneos y mandíbulas de félidos}

Cuando se integraron especímenes de otras regiones zoogeográficas al análisis de componentes principales de félidos, en relación al cráneo, el PC1 representó un porcentaje del 29,62\%, el PC2 un 12,81\% y el PC3 un 5,60\% de la varianza total (Fig. 142). En el PC1 se observa que las especies se distribuyeron en el morfo-espacio en 2 nubes que incluyeron por un lado al linaje Panthera, Acinonyx jubatus y Puma concolor, y por otro al resto de las especies, con Caracal caracal muy similar a P. concolor y en una posición intermedia entre las 2 nubes. El PC2 mostró hacia los valores positivos a los adultos y hacia los negativos a los juveniles. La configuración observada en el PC1 hacia los valores negativos fue un cráneo redondeado pero bajo, bullas pequeñas, lira angosta, arcos zigomáticos expandidos, cóndilos occipitales perpendiculares a la placa occipital, inion posterior al foramen magnum, rostro y nasales más anchos y largos. Hacia los valores positivos los cráneos fueron redondeados y altos, las bullas más grandes, arcos zigomáticos no tan expandidos, cóndilos occipitales paralelos a la placa occipital, inion a la misma altura que el foramen magnum y rostro y nasales más estrechos y cortos. Para el PC2, se observó hacia los valores negativos un cráneo ancho y alto, cóndilos occipitales y foramen magnum adelantados, inion a la misma altura del foramen magnum, rostro y nasales más anchos y cortos. Hacia los valores positivos se observó un cráneo más estrecho y bajo, con cóndilos occipitales más 
perpendiculares a la placa occipital, inion a la altura del foramen magnum y rostro más estrecho (Fig. 142).

En relación a la mandíbula, el PC1 representó un porcentaje del 24,29\%, el PC2 un 14,63\% y el PC3 un 9,23\% de la varianza total (Fig. 143). Se observa una distribución de las especies en el morfo-espacio bastante homogénea. Sin embargo, se observó a Panthera onca en valores negativos del PC1, pero positivos del PC2., a P. leo ocupando los valores negativos de ambos PCs, y a Leopardus geoffroyi hacia los valores positivos del PC1 y negativos del PC2. En el PC1, hacia los valores negativos se observaron mandíbulas con cuerpo mandibular más ancho y más recto, hilera dentaria más extendida, borde anterior de la fosa masetérica desplazado hacia atrás, rama mandibular más estrecha, borde inferior de la rama mandibular más curvado, proceso angular menos expandido y coronoides expandido hacia la parte posterior. Hacia los valores positivos, la mandíbula tuvo un cuerpo mandibular más estrecho y curvado, la hilera dentaria es más corta, el borde anterior de la fosa masetérica está adelantado, la rama mandibular es más ancha y presenta el proceso angular más alargado. En el PC2 se encontraron hacia los valores negativos cuerpos mandibulares con la parte anterior extendida hacia la cara dorsal, con el borde anterior de la fosa masetérica retrasado y rama mandibular con procesos coronoides y condiloideo más cortos. Hacia los valores positivos las mandíbulas mostraron el cuerpo mandibular más corto y estrecho, con borde anterior de la fosa masetérica adelantado y la rama mandibular con procesos coronoides y condiloideo más grandes y expandidos hacia la parte posterior de la mandíbula (Fig. 143). 


\subsubsection{Análisis combinado de morfometría geométrica en cráneos y mandíbulas de las Familias Canidae y Felidae}

En relación al cráneo, el PC1 representó un porcentaje del 53,13\%, el PC2 un 9,94\% y el PC3 un 5,20\% de la varianza total. Cuando se combinaron en un solo análisis los cráneos de las Familias Canidae y Felidae (Fig. 144), se observaron 2 nubes conspicuas completamente separadas y con diferente trayectoria. La nube de los cánidos se orientó de forma paralela al PC1, con los adultos ubicados hacia los valores negativos y los juveniles hacia el extremo positivo. Los félidos se ubicaron de forma paralela al PC2 en el morfo-espacio, aunque con cierto ángulo. Hacia los valores negativos se ubicaron los adultos, y hacia el extremo positivo los juveniles. De esta manera, hacia el extremo negativo del PC1 se hallaron cráneos elongados con cajas craneanas estrechas y bajas, hocicos y nasales largos y rectos, lira estrecha y alargada, arcos zigomáticos débiles y poco expandidos, órbitas y bullas más pequeñas, cóndilos occipitales perpendiculares a la placa occipital y foramen magnum a la misma altura del inion. Hacia los valores positivos, se encontraron cráneos cortos con cajas craneanas anchas y más altas, hocicos y nasales breves y curvados ventralmente, lira amplia y corta, arcos zigomáticos reforzados y expandidos, órbitas y bullas más grandes, cóndilos occipitales paralelos a la placa occipital y foramen magnum anterior al inion. Para el PC2, se observaron hacia los valores negativos, cráneos anchos y bajos, hocicos y nasales anchos y curvados ventralmente, lira estrecha y elongada, arcos zigomáticos robustos y bien expandidos, órbitas de posición más dorsal, bullas más pequeñas, de posición antero-posterior, y foramen magnum muy anterior al inion. Hacia los valores positivos, los cráneos fueron más cortos y altos, los hocicos y nasales más estrechos, cortos y rectos, la lira amplia y breve, los arcos zigomáticos débiles y no expandidos. Las órbitas tuvieron posición más ventral, las bullas fueron más 
grandes, de posición dorso-ventral y el foramen magnum tuvo una posición muy posterior al inion (Fig. 144).

Para la mandíbula, el PC1 representó un porcentaje del 37,57\%, el PC2 un 20,54\% y el PC3 un 7,87\% de la varianza total. Nuevamente, se hallaron ambas Familias distribuidas de manera separada en el morfo-espacio (Fig. 145), aunque no de manera tan evidente como cuando se realizó el análisis de cráneo. En el caso de los félidos la forma de la mandíbula presenta mayor variación que en el caso de los cánidos, pero es probable que esto sea un artefacto, producto de que existen más especies de félidos que de cánidos en este análisis. Por otro lado, las configuraciones no estuvieron vinculadas a la ontogenia, no pudiendo diferenciarse áreas del morfo-espacio donde se ubicaran los juveniles o los adultos, distribuyéndose de manera homogénea en este aspecto. Hacia los valores negativos del PC1, las mandíbulas presentaron cuerpos mandibulares más estrechos y largos, con el extremo anterior más elevado, la rama mandibular menos desarrollada y curvada ventralmente, el borde anterior de la fosa masetérica retrasado, el proceso coronoides más estrecho y de posición dorso-ventral, el proceso condiloideo paralelo a éste, y el proceso angular ligeramente elongado y posterior. Hacia los valores positivos, las mandíbulas tuvieron cuerpos mandibulares más anchos y macizos, la rama mandibular bien desarrollada y convexa ventralmente, el borde anterior de la fosa masetérica adelantado, el proceso coronoides más amplio y de posición posterior, el proceso condiloideo posterior, y el proceso angular corto y ventral. Para el PC2, los valores negativos mostraron mandíbulas con cuerpo mandibular más ancho, elongado y ventralmente recto, con el borde anterior de la fosa masetérica retrasado, la rama mandibular más estrecha y corta, y los 3 procesos breves y dirigidos hacia atrás. Hacia los valores positivos del mismo PC, los cuerpos mandibulares fueron más $\sim 164 \sim$ 
estrechos y cortos, ventralmente curvados y elevados anteriormente, con el borde anterior de la fosa masetérica adelantado, la rama mandibular muy desarrollada y convexa ventralmente, y los 3 procesos robustos, el coronoides dirigido hacia arriba, el condiloideo hacia atrás y el angular hacia abajo (Fig. 145).

\subsection{Análisis filogenéticos. Mapeos.}

\subsubsection{Intervalos de confianza}

Para el mapeo de los intervalos de confianza, se recuperaron sólo 8 sinapomorfías que sustentan clados ya conocidos (Fig. 146, Apéndice XII), distribuidas tanto en cánidos como en félidos. Quienes mostraron señal filogenética (Tabla 61), fueron solamente los caracteres ancho entre los procesos mastoideos (2: AM), longitud de los nasales (7: LN) y longitud de la hilera postcanina superior (18: LHS). De todas formas, el carácter 7 no constituyó una sinapomorfía para ninguno de los nodos de importancia en este árbol (Fig. 146).

Dentro de los félidos, para el linaje Puma (i.e. Puma concolor-Herpailurus yagouaroundi), el carácter 14: Ancho del paladar (Apal), tuvo un incremento en su tasa $(0,512-0,513)$ con respecto al estado plesiomórfico $(0,489-0,494)$ (Fig. 146Sinapomorfía 2). Este carácter fue alométrico negativo en las 2 especies.

El clado conformado por (Leopardus wiedii-L. pardalis), mostró un aumento en la tasa de crecimiento del carácter 11: Ancho de la bulla timpánica (AB). Éste presentó un valor de $0,451-0,452$, mayor con respecto al valor del ancestro $(0,441$ 0,442) (Fig. 146-Sinapomorfía 5). Este carácter se mantuvo alométrico negativo en ambas especies. 
Para el clado formado por (Leopardus colocolo (L. tigrinus (L. guigna-L. geoffroyi))) el estado de carácter plesiomórfico para el carácter 18: Altura del dentario (HD) fue de 0,563-0,574 que se incrementó a 0,599-0,602 (Fig. 146Sinapomorfía 7). Este carácter se mantuvo alométrico positivo.

El clado conformado por (Leopardus tigrinus (L. guigna-L. geoffroyi)), mostró un valor de intervalo de 0,479-0,486 para el carácter 2: Ancho entre los procesos mastoideos (AM). Esta tasa de crecimiento disminuyó en relación a la plesiomórfica (0,499-0,502) (Fig. 146-Sinapomorfía 9). Este carácter se presentó como alométrico negativo.

Dentro de los cánidos, para el clado conformado por: (Speothos venaticusChrysocyon brachyurus (Atelocynus microtis (Cerdocyon thous (Lycalopex sechurae (L. vetulus (L. gymnocercus (L. griseus-L. culpaeus))))))), existieron 2 sinapomorfías (Fig. 146-Sinapomorfía 14). El carácter 18: Altura del dentario (HD), tuvo un incremento de su tasa: 0,570-0,577, a partir de la ancestral $(0,539-0,564)$. Si bien el ancestro presentó una tendencia isométrica, para este clado cambió a alométrica positiva. Con respecto al carácter 20: Longitud del proceso coronoides (LC), también existió un incremento de la tasa de crecimiento. Los valores de intervalo pasaron de 0,669 0,681, que es la tasa del ancestro, a 0,690-0,705 y se mostraron alométricos positivos.

El clado conformado por: (Cerdocyon thous (Lycalopex sechurae (L. vetulus (L. gymnocercus (L. griseus-L. culpaeus))))), presentó 2 sinapomorfías (Fig. 146Sinapomorfía 18). El carácter 0: Longitud cóndilo-incisiva (LCI), tuvo un incremento de su tasa: $0,556-0,558$, a partir de la ancestral $(0,548-0,555)$. Tanto el ancestro como el clado mencionado mostraron una tendencia alométrica positiva. 
Con respecto al carácter 12: Altura de la bulla timpánica (HB), hubo una disminución de la tasa de crecimiento. Los valores de intervalo pasaron de 0,5040,516 (que es la tasa del ancestro) a 0,486-0,494 y se mostraron alométricos negativos.

Para el clado formado por el género Lycalopex: (Lycalopex sechurae (L. vetulus (L. gymnocercus (L. griseus-L. culpaeus)))) se observó una sinapomorfía que involucra al carácter 2: Ancho entre los procesos mastoideos (AM) (Fig. 146-Sinapomorfía 20). El estado de carácter plesiomórfico es el intervalo: 0,466-0,473, que incrementa su tasa en el clado mencionado $(0,475-0,479)$, siendo la tendencia alométrica negativa para ambos.

El clado conformado por: (Lycalopex vetulus (L. gymnocercus (L. griseus-L. culpaeus))), presentó 3 sinapomorfías (Fig. 146-Sinapomorfía 22). El carácter 5 (Ancho de la constricción postorbitaria, $\mathrm{CPO}$ ) tuvo un estado de carácter plesiomórfico de: 0,392-0,409, el cual disminuyó en el clado mencionado: 0,3670,373. Este carácter se mantuvo alométrico negativo. La tasa de crecimiento basal para el carácter 9 (Ancho del rostro entre los caninos, Acan) fue de 0,505-0,514, aumentando en el clado mencionado a 0,516-0,536. No se detectó cambio de tendencia alométrica, ya que ambos intervalos fueron negativos. Para el carácter 16: Longitud de la hilera post-canina superior (LHS), el estado basal es el intervalo 0,580-0,621, que desciende en el clado mencionado a 0,526-0,576. Si bien en el ancestro la tendencia es a la alometría positiva, en el clado (Lycalopex vetulus ( $L$. gymnocercus (L. griseus-L. culpaeus))) lo es a la isometría.

Se produjeron más cambios en las ramas terminales (autapomorfías) que en los nodos internos (sinapomorfías). Para los félidos, quienes exhibieron mayor 
número de autapomorfías mostraron 7: Leopardus colocolo (ancho de la caja craneana AC, ancho de los arcos zigomáticos AZ, longitud de la órbita LO, longitud del rostro LR, altura del hocico $\mathrm{HH}$, altura del proceso coronoides $\mathrm{HC}$, longitud de la hilera post-canina inferior LHI, Fig. 146-Autapomorfía 8) y 5: Panthera onca (altura de la placa occipital HPO, ancho mastoideo AM, ancho de los arcos zigomáticos AZ, ancho de los caninos Acan, altura del hocico HH, Fig. 146Autapomorfía 1), Puma concolor (ancho mastoideo AM, longitud de la bulla timpánica LB, longitud de la hilera post-canina superior LHS, altura del proceso coronoides HC, longitud de la hilera post-canina inferior LHI, Fig. 146Autapomorfía 3), y L. tigrinus (altura de la placa occipital HPO, ancho de los caninos Acan, ancho del paladar APal, altura del dentario HD, altura del coronoides HC, Fig. 146-Autapomorfía 10, Apéndice XII). Entre los cánidos, quienes presentaron mayor número de autapomorfías fueron Urocyon cinereoargenteus (Fig. 146-Autapomorfía 13) con 13 (longitud cóndilo-incisiva LCI, altura de la placa occipital $\mathrm{HPO}$, ancho de los arcos zigomáticos $\mathrm{AZ}$, longitud de los nasales LN, longitud del rostro LR, ancho de los caninos Acan, altura del hocico $\mathrm{HH}$, ancho de la bulla timpánica $\mathrm{AB}$, ancho del paladar Apal, altura del dentario HD, altura del coronoides HC, longitud del coronoides LC, longitud de la hilera post-canina inferior LHI), y Atelocynus microtis (Fig. 146-Autapomorfía 17) con 8 (longitud cóndilo-incisiva LCI, altura de la placa occipital HPO, ancho mastoideo $\mathrm{AM}$, ancho de los arcos zigomáticos $\mathrm{AZ}$, ancho de la constricción postorbitaria $\mathrm{CPO}$, ancho de la bulla timpánica $\mathrm{AB}$, altura de la bulla timpánica $\mathrm{HB}$, longitud del paladar LPal). Los caracteres que más cambiaron en los terminales fueron el ancho de los arcos zigomáticos AZ, la altura de la placa occipital HPO y la altura del coronoides HC, y en menor medida el ancho de los caninos Acan, el ancho mastoideo AM, la altura del hocico HH y la longitud de la hilera post-canina 
inferior LHI (Fig. 146, Apéndice XII). Además, en Lycalopex vetulus (Fig. 146, Autapomorfía 23) se acentuó el decremento de la constricción postorbitaria CPO (con una tendencia que permaneció negativa) y de la longitud de la hilera postcanina superior LHS, que cambió la tendencia de isométrica a alométrica negativa. En el caso de L. gymnocercus (Fig. 146, Autapomorfía 24), se incrementó la tasa del ancho de los caninos (Acan), aunque no cambió su tendencia alométrica negativa.

\subsubsection{Suturas: Considerando la semi-fusión como no fusión}

Para el mapeo de las suturas, considerando la semi-fusión como no fusión, se recuperaron 4 sinapomorfías que sustentan clados únicamente en félidos (Fig. 147, Apéndice XII). El único carácter que exhibió señal filogenética (Tabla 62) fue la sutura occipitointerparietalis (Oipa, 8).

El linaje Puma: (Puma concolor-Herpailurus yagouaroundi), presentó 2 sinapomorfías (Fig. 147-Sinapomorfía 2). El carácter 3 (sincondrosis intraoccipitalis squamolateralis, Isq) tuvo un estado de carácter plesiomórfico de fusión de suturas en la clase J2, que cambió a la clase J1 en el clado mencionado. El carácter 8 (sutura occipitointerparietalis, Oipa) tuvo un estado de carácter basal de fusión de suturas en la clase A1, el cual cambió a J4 en el linaje Puma.

Para el linaje Ocelote: (Leopardus wiedii-L. pardalis (L. jacobita-L. colocolo ( $L$. tigrinus (L. guigna-L. geoffroyi))), la sinapomorfía que los sustenta es la fusión del carácter 12: sutura interfrontalis, If (Fig. 147-Sinapomorfía 5). En el ancestro la fusión ocurre en la clase A3 y en este clado derivado, se produce en el estadio A2.

En el clado (Leopardus wiedii-L. pardalis), la sinapomorfía es la fusión del carácter 4, la sincondrosis intraoccipitalis basilateralis, Ib (Fig. 147-Sinapomorfía 6). 
Este carácter mostró fusión en J3 como estado plesiomórfico y en la clase J2 como estado derivado.

Para el clado que reúne (Leopardus guigna-L. geoffroyi), la sinapomorfía la constituye el carácter 15: sutura sagittalis caudal, Sgc (Fig. 147-Sinapomorfía 11). La fusión de este carácter ocurrió en la clase A1, para el ancestro, y en el estadio A2 para el derivado.

Aunque las sinapomorfías fueron pocas, se produjeron muchos cambios de estado en los terminales. Los que mayor número presentaron fueron: entre los félidos, Herpailurus yagouaroundi (Fig. 147-Autapomorfía 4) con 8 (sincondrosis intersphenoidalis Isp, sutura occipitoparietalis Opa, sutura occipitointerparietalis Oipa, sutura parietointerparietalis Paipa, sutura interfrontalis caudal Ifc, sutura sagittalis $\mathrm{Sg}$, sutura sagittalis caudal Sgc, sutura sphenoparietalis Sppa), y entre los cánidos Speothos venaticus (Fig. 147-Autapomorfía 15) con 7 (sincondrosis spheno-occipitalis Spo, sincondrosis intraoccipitalis squamolateralis Isq, sincondrosis intraoccipitalis basilateralis $\mathrm{Ib}$, sutura occipitoparietalis Opa, sutura sagittalis Sg, sutura sagittalis caudal Sgc, sutura sphenosquamosa Spsq) y Lycalopex vetulus (Fig. 147-Autapomorfía 20) con 6 (sincondrosis intersphenoidalis Isp, sincondrosis intermandibularis Imd, sincondrosis intraoccipitalis squamolateralis Isq, sincondrosis intraoccipitalis basilateralis $\mathrm{Ib}$, sutura occipitomastoidea Oma, sutura sphenofrontalis $\mathrm{Spf})$.

\subsubsection{Suturas: Considerando la semi-fusión como fusión}

Considerando la semi-fusión de las suturas como fusión, se recuperaron más sinapomorfías (7) que cuando la semi-fusión de las suturas fue considerada como no fusión, y éstas soportan clados tanto de cánidos como de félidos (Fig. 148, 
Apéndice XII), siendo siempre más numerosas las sinapomorfías en félidos. Sin embargo, no se halló señal filogenética en ninguno de los caracteres (Tabla 63).

Para el clado formado por: (Puma concolor-Herpailurus yagouaroundi (Leopardus wiedii-L. pardalis (L. jacobita-L. colocolo (L. tigrinus (L. guigna-L. geoffroyi)))) se halló el carácter 28: sutura zygomaticomaxillaris (Zmx) como sinapomorfía (Fig. 148-Sinapomorfía 2). Su fusión se produjo en la clase A3 para el ancestro y en el estadio A2 para el clado mencionado.

El linaje Puma: (Puma concolor-Herpailurus yagouaroundi) es soportado por dos caracteres como sinapomorfías (Fig. 148-Sinapomorfía 3). El carácter 3: Isq, se fusionó en la clase J2 en el ancestro y en el estadio J1 en el linaje mencionado. Por otro lado el carácter 8: sutura occipitointerparietalis Oipa, mostró un estado de carácter plesiomórfico de fusión en la clase A1 y en este linaje ocurrió en el estadio J4. Se halló idéntica información en la Sinapomorfía 2 cuando se tomó la semifusión como no fusión (Fig. 147-Sinapomorfía 3).

El linaje Ocelote (Leopardus wiedii-L. pardalis (L. jacobita-L. colocolo (L. tigrinus (L. guigna-L. geoffroyi))) es soportado por 2 sinapomorfías: los caracteres 37 sutura intermaxillaris (Imx) y 40 sutura palatomaxillaris mesial (Pmm) (Fig. 148Sinapomorfía 6). La sutura intermaxillaris Imx tiene un estado de carácter plesiomórfico de fusión en la clase de edad A3, que cambia en el linaje a A2. La sutura palatomaxillaris mesial Pmm, presenta un estado de carácter basal de fusión en el estadio A3, el cual cambia a A2 en este linaje derivado.

El clado formado por (Leopardus wiedii-L. pardalis), está soportado por una sinapomorfía (Fig. 148-Sinapomorfía 7), el carácter 4: sincondrosis intraoccipitalis basilateralis $\mathrm{Ib}$. El estado basal de carácter es la fusión de esta sutura en la clase de 
edad J3 y en este clado la fusión se obtiene en el estadio J2. Esta información es la misma que se ofreció en la sinapomorfía 6 cuando se tomó la semi-fusión como no fusión (Fig. 147-Sinapomorfía 6).

Para el clado formado por: (Leopardus jacobita-L. colocolo), existen 2 caracteres que lo soportan (Fig. 148-Sinapomorfía 10). El carácter 8: sutura occipitointerparietalis Oipa, presenta un estado de carácter basal, de fusión en la clase A1, mientras que en este clado en particular la fusión se produce en el estadio A2. Para el carácter 9: sutura parietointerparietalis Paipa, el estado de carácter plesiomórfico es la fusión en el estadio A1, y la derivada es en el estadio A2.

El clado conformado por (Leopardus guigna-L. geoffroyi) está sostenido por una sinapomorfía (Fig. 148-Sinapomorfía 14), basada en el carácter 6: sutura occipitoparietalis Opa. Este carácter presenta un estado ancestral de fusión en la clase de edad A2, mientras que en el clado derivado, mencionado arriba, la fusión ocurre en la clase A1.

Para el clado formado por: (Speothos venaticus-Chrysocyon brachyurus), la sinapomorfía que lo sustenta es el carácter 1: sincondrosis intersphenoidalis Isp (Fig. 148-Sinapomorfía 18). El estado del ancestro para este carácter fue la fusión en el estadio A2, mientras que en este clado derivado la fusión ocurrió en la clase A3.

Se presentaron muchos más cambios en los terminales que en los nodos internos. Quienes mayor número presentaron fueron, entre los félidos, Leopardus geoffroyi con 10 (sincondrosis spheno-occipitalis Spo, sincondrosis intersphenoidalis Isp, sutura occipitomastoidea Oma, sutura occipitointerparietalis Oipa, sutura parietointerparietalis Paipa, sutura interfrontalis caudal Ifc, sutura sagittalis Sg, sutura sagittalis caudal Sgc, sutura sphenopalatina Sppal, sutura zygomaticomaxillaris Zmx 
(Fig. 148-Autapomorfía 16), y entre los cánidos, Speothos venaticus con 8 (sincondrosis spheno-occipitalis Spo, sincondrosis intermandibularis Imd, sincondrosis intraoccipitalis squamolateralis Isq, sincondrosis intraoccipitalis basilateralis $\mathrm{Ib}$, sutura occipitoparietalis opa, sutura sagittalis $\mathrm{Sg}$, sutura sagittalis caudal Sgc, sutura sphenosquamosa Spsq (Fig. 148-Autapomorfía 19) y Lycalopex culpaeus con 7 (sincondrosis intraoccipitalis squamolateralis Isq, sutura occipitomastoidea Oma, sutura occipitoparietalis opa, sutura sagittalis $\mathrm{Sg}$, sutura sagittalis caudal Sgc, sutura sphenosquamosa Spsq, sutura palatomaxillaris mesial Pmm (Fig. 148-Autapomorfía 26).

\subsubsection{Crecimiento y desarrollo definitivos}

Durante el mapeo del crecimiento y desarrollo definitivos, se observaron 3 sinapomorfías que soportan clados pre-establecidos de cánidos y félidos (Fig. 149, Apéndice XII). El único carácter que presentó señal filogenética fue el tamaño del cráneo (0) (Tabla 64).

El clado conformado por (Leopardus jacobita-L. colocolo (L. tigrinus (L. guignaL. geoffroyi))) es soportado por la sinapomorfía (Fig. 149-Sinapomorfía 6) compuesta por el carácter 0: Tamaño del cráneo (TCr). Este carácter presenta un estado ancestral de obtención del tamaño definitivo en la clase de edad A2, mientras que en el clado derivado, mencionado arriba, esto ocurre en la clase A1.

Para el clado formado por: (Leopardus guigna-L. geoffroyi), existen 2 caracteres que lo soportan (Fig. 149-Sinapomorfía 7). El carácter 2: Tamaño de la mandíbula (TMd), presenta un estado de carácter basal, de obtención del tamaño definitivo en la clase A2, mientras que en este clado en particular se produce en el estadio A1. Para el carácter 6: Ventaja mecánica del masetero medida en el carnicero (Mcar), el 
estado de carácter plesiomórfico es la obtención de la ventaja mecánica definitiva en el estadio A2, y el carácter derivado es el arribo en el estadio J3.

Para el clado formado por: (Cerdocyon thous (Lycalopex sechurae (L. vetulus (L. fulvipes (L. gymnocercus (L. griseus-L. culpaeus)))))), el soporte está dado por 3 sinapomorfías (Fig. 149-Sinapomorfía 14). El carácter 0 Tamaño del cráneo (TCr) presenta un estado de carácter para el ancestro de arribo al tamaño craneal definitivo en el estadio A2, mientras en este clado ocurre en la clase A1. Para el carácter 5: Ventaja mecánica del masetero medida en el canino (Mcan), el estado ancestral es la obtención de la mayor ventaja mecánica del masetero en la clase de edad A2, mientras que en el clado citado, esto ocurre en el estadio de edad A1. Para el carácter 6: Ventaja mecánica del masetero medida en el carnicero (Mcar), el estado ancestral es la obtención de esta máxima ventaja mecánica en la clase de edad A2, mientras que en el clado derivado, ocurre en la clase A1.

Se observaron más cambios en los terminales que los registrados en los nodos internos. Las especies que más transformaciones tuvieron fueron Panthera onca (tamaño del cráneo TCr, forma del cráneo FCr, tamaño de la mandíbula TMd, tamaño de los músculos masticatorios $\mathrm{AZ}$, ventaja mecánica del masetero medida en el canino Mcan, ventaja mecánica del masetero medida en el carnicero Mcar, ventaja mecánica del temporal medida en el canino Tcan (Fig. 149-Autapomorfía 1), entre los félidos, y Atelocynus microtis (tamaño del cráneo TCr, forma del cráneo FCr, tamaño de la mandíbula TMd, forma de la mandíbula FMd, tamaño de los músculos masticatorios $\mathrm{AZ}$, ventaja mecánica del masetero medida en el canino Mcan, ventaja mecánica del masetero medida en el carnicero Mcar (Fig. 149Autapomorfía 13), entre los cánidos, ambos con 7. 


\section{DISCUSIÓN}

Yo no.

Yo no suscribo.

Yo no conozco al gato.

Todo lo sé, la vida y su archipiélago,

El mar y la ciudad incalculable,

La botánica,

El gineceo con sus extravíos,

El por y el menos de la matemática,

Los embudos volcánicos del mundo,

La cáscara irreal del cocodrilo,

La bondad ignorada del bombero,

El atavismo azul del sacerdote,

Pero no puedo descifrar un gato.

$\sim 175 \sim$ 


\subsection{Aspectos Funcionales y Estructurales}

\subsubsection{El Cráneo como un todo. División funcional}

El cráneo como un todo (i.e. cráneo y mandíbula), es una combinación de componentes diferentes, de distintos orígenes embrionarios, que pueden evolucionar independientemente, pero que se integran en una estructura compleja para funcionar como una unidad mecánica coherente (Moore 1981, Morriss-Kay 2001, Marroig et al. 2004, Goswami 2006, 2007, Goswami \& Polly 2010). El concepto de la división funcional del cráneo mamaliano en componentes neurocraneales (i.e. porción que incluye al cerebro y cápsulas sensoriales) que escalan negativamente, y esplacnocraneales (i.e. porción que incluye al aparato masticatorio) que escalan positivamente, fue mencionado por varios autores previamente (e.g. Radinsky 1981a, b, Emerson and Bramble 1993, Jiang et al 2002, Slater \& Van Valkenburgh 2009) y se observó también en esta muestra (e.g. Tablas 10, 20, 44, 56). En todas las especies se reconoció que las medidas neurocraneales, como el ancho del proceso mastoideo (AM), el ancho de la caja craneana (AC), la constricción postorbitaria $(\mathrm{CPO})$ y el ancho de la bulla auditiva (AB), fueron negativas (e.g. Tablas 7, 31, 34, 53). Medidas como la altura de la placa occipital (HPO), la longitud de la órbita (LO), la longitud de la bulla (LB) y el ancho del paladar (Apal), resultaron entre negativas e isométricas (e.g. Tablas 4, 23, 40, 50). Las medidas esplacnocraneales como la altura del proceso coronoides (HC), la longitud del coronoides (LC) y la longitud del dentario (LD) fueron, en la mayoría de los casos, positivas (e.g. Tablas 13, 28, 37, 59). Medidas como la longitud cóndilo-incisiva (LCI), el ancho de los arcos zigomáticos (AZ), la longitud de los nasales (LN) y la longitud del rostro (LR) se mostraron entre positivas e isométricas (e.g. Tablas 17, 26, 47, 59). Estudios previos de ontogenia (e.g. Abdala et al. 2001, Flores et al. 2010) expusieron que el 
neurocráneo y esplacnocráneo se modifican de diferentes modos y que estas modificaciones tienen profundas influencias recíprocas en el crecimiento de ambas regiones. Estos crecimientos desiguales, producen diferencias dramáticas y notables entre los cráneos de jóvenes y adultos, y revelan los diferentes compromisos del cráneo, la mandíbula y la musculatura asociada a la alimentación (Radinsky 1981a).

\subsubsection{Crecimiento y desarrollo de la caja craneana}

En los mamíferos placentarios, la morfogénesis del sistema nervioso central comienza temprano, antes que la del sistema somático, y se completa previamente a que la mayoría de las estructuras somáticas hayan empezado su diferenciación. Al comenzar tempranamente, hay poca inversión energética hacia otros tejidos, y el crecimiento y la diferenciación nerviosa se extienden a través de los largos períodos fetal y embrionario, cuando la nutrición es relativamente constante (Smith 1997). El sistema nervioso está involucrado en la inducción del hueso membranoso de la caja craneana (Smith 1997, Byron 2006, Rice 2008), que también se forma de manera precoz. De hecho, para el roedor Rhabdomys pumilio, se registró un crecimiento prenatal acelerado del cráneo, que escaló de manera positiva, para luego, durante el crecimiento postnatal, escalar negativamente (Wilson 2011). Este hallazgo, es coherente con lo observado para los juveniles de todas las especies analizados aquí: una caja craneana ancha, corta y alta, más grande proporcionalmente que la de los adultos, para alojar al encéfalo (e.g. Figs. 13A, 14, 42A, 43, 99A, 100, 134A, 135), que escaló negativamente durante el crecimiento somático postnatal (e.g. Tablas 7, 20, 44, 56), mientras otras estructuras de desarrollo y crecimiento posterior, como el rostro, escalaron positivamente (ver apartado 6.1.6.). Esto mismo se ha documentado previamente para muchas otras 
especies, por ejemplo en marsupiales como Didelphis albiventris: Abdala et al. 2001; Lutreolina crassicaudata: Flores et al. 2003; Dromiciops gliroides: Giannini et al. 2004; Dasyurus albopunctatus: Flores et al. 2006; Caluromys philander: Flores et al. 2010; en félidos como Puma concolor: Segura \& Flores 2009, Giannini et al. 2010; P. concolor, Acinonyx jubatus y Herpailurus yagouaroundi: Segura et al. 2013, y en cánidos como Lycalopex culpaeus: Segura \& Prevosti 2012, Segura 2013.

En respuestas a las señales transmitidas por el cerebro a través de la duramadre, el nuevo hueso se produce de manera perpendicular a la orientación de la sutura, mientras la caja craneana se expande para alojar el encéfalo en formación (e.g. Figs. 35A, 36, 63A, 64, 84A, 85, 127A, 128) (Byron 2006, McLaughlin et al. 2000, Opperman 2000, Wilson \& Sánchez Villagra 2009). Las suturas no fusionadas permiten el crecimiento continuo y el desarrollo normal del cerebro y las características cráneo-faciales. Cuando los juveniles nacen, los huesos están poco calcificados, y las suturas predominantes de la caja craneana son relativamente simples, del tipo plana o escamosa, con un grado de compresibilidad tal que le permiten atravesar el canal uterino durante el nacimiento (e.g. Figs. 34, 62, 126, 133) (Swischuk 1974, Jaslow 1990, Evans 1993, Nakahara et al. 2006). En los juveniles de todas las especies analizadas en esta tesis, se presentaron este tipo de suturas, aunque algunas de ellas cambiaron de forma en los adultos (e.g. Figs. 19, $41,90,112$, Tablas 6, 16, 33, 52). En los mamíferos, la sutura coronal y sagital son los mayores centros de crecimiento que están activos durante el período de desarrollo del encéfalo (Morris-Kay 2001). En esta muestra, las suturas del neurocráneo se fusionaron antes que las del esplacnocráneo (e.g. Figs. 12, 26, 76, 105, Tablas 3, 9, 36, 49). En algunos casos, las suturas del esplacnocráneo (como las rostrales) no se fusionaron en ningún momento de la vida (e.g. Figs. 5, 33, 83, 98, Tablas $12,15,39,55)$ (ver apartado 6.1.6.). Es claro que la mayoría de las suturas en $\sim 178 \sim$ 
muchos taxa son estructuras temporarias, y cuando se fusionan, el cráneo es literalmente un elemento de una sola pieza (Herring \& Teng 2000). La fusión le brinda rigidez a la caja craneana (para proteger el encéfalo) y a las áreas de inserción muscular temporal y cervical, y además indica la temprana finalización del crecimiento tanto de esta área como de las cápsulas sensoriales, lo cual está relacionado con su alometría negativa (e.g. Figs. 62, 133, Tablas 27, 28, 58, 59) (Herring \& Teng 2000, Margulies \& Thibault 2000, Popowics \& Herring 2007, Segura \& Flores 2009).

Con respecto a qué tipo de fuerzas son las que sufre la caja craneana, se asume que las producidas por la expansión del cerebro, son del tipo tensivas (en los márgenes de la sutura), y que de esta manera promueven la osteogénesis, y son las que resiste primero el cráneo. Mientras que las debidas a la función, como la masticación, son compresivas y se extienden hasta más tarde en la ontogenia (Herring \& Teng 2000, Cray et al. 2011). El estrés en las suturas está variando constantemente de acuerdo a la contracción muscular, y en cada una de ellas está dominado por los músculos más cercanos (Herring \& Teng 2000). Al crecer, la morfología de las suturas puede cambiar (Jaslow 1990) y se ha demostrado que incrementan su complejidad a través de la ontogenia (Byron et al. 2004, Cray et al. 2011) como ocurre en esta muestra y en otros grupos de mamíferos (ver Flores et al. 2006, Flores \& Barone 2011), donde en muchos casos pasaron de planas o escamosas a aserradas (e.g. Figs. 26, 55, 76, 98, Tablas 12, 25, 33, 43). Las suturas que experimentan predominantemente compresión, exhiben un mayor grado de interdigitación (aserradas) que las que están bajo tensión como fuerza predominante (Rafferty \& Herring 1999, Cray et al. 2011). Sin embargo, la contracción de la musculatura temporal durante la masticación produce una notable fuerza de tensión sobre la sutura coronal (Herring et al. 2001). 
Incrementando la complejidad y la interdigitación, se incrementa la posibilidad de absorber energía (tanto tensiva como compresiva), ya que las fibras de colágeno, responsables de hacerlo, aumentan su superficie disponiéndose en distintas direcciones (Jaslow 1990, Rafferty \& Herring 1999, Nicolay \& Vaders 2006).

\subsubsection{Crecimiento y desarrollo de la placa occipital}

El hueso exoccipital ha alcanzado un desarrollo independiente del resto de los huesos que componen el cráneo. Su osificación comienza luego de que el sistema nervioso se ha diferenciado, de hecho, las sincondrosis de la placa occipital (intraoccipitalis squamolateralis y basilateralis) fueron las primeras en fusionarse (e.g. Tablas 9, 19, 33, 55), y luego lo hicieron otras suturas vinculadas con esta área. En casi todos los casos, el alto y ancho de la placa occipital (HPO-AM) escalaron negativamente (e.g. Tablas 7, 31, 47, 56), lo cual significa que fue relativamente más ancha y alta en los juveniles que en los adultos. El patrón de Panthera onca fue diferente, con la altura de la placa occipital (HPO) positiva y el ancho del proceso mastoideo (AM) isométrico (Tabla 59). Esto es coherente con el hecho de que el género Panthera tiene la cresta sagital más pronunciada de todos los félidos (Fig. 133) (Duckler 1998). En este sentido, se observa una marcada interacción entre su estructura neurocraneana y la función depredadora (fuertemente relacionada con el esplacnocráneo). Sería interesante comparar los resultados hallados en esta especie con el resto de los pantherinos, para observar si es un patrón común a su linaje. Por otro lado, podría estar vinculado con el tipo de captura y procesamiento de las presas que existe en $P$. onca, donde a diferencia del sofocamiento, estrangulamiento y producción de una herida profunda en la garganta, utilizadas por el resto de los co-genéricos, provocan una importante mordida en el cráneo a sus víctimas (Antón \& Galobart 1999, Sicuro \& Oliveira 2011). 
Si bien el inicio del crecimiento de la caja craneana como un todo, incluyendo su área occipital, es promovido por la inducción del encéfalo, es probable que la fusión temprana de la placa occipital, que ocurre en las primeras clases de edad en esta muestra (desde J1) (e.g. Tablas 12, 22, 36, 55), se deba a la necesidad de fortalecer el área para poder proteger el cerebro y sostener la cabeza en los jóvenes (Segura y Flores 2009, Segura 2013), aunque también es una región fuertemente influenciada por la actividad muscular (Duckler 1998). De esta forma, lo que ocurre en esta zona tiene explicaciones tanto funcionales como estructurales. Conjuntamente, este evento muestra el final del crecimiento del neurocráneo, y es opuesto a lo documentado para los humanos, donde el crecimiento del encéfalo se prolonga en el tiempo, y también el de la caja craneana, por lo que la fusión de las suturas y sincondrosis occipitales está retrasada (ocurre alrededor de los 6 años, Nakahara et al. 2006).

Las reorganizaciones de la placa occipital están vinculadas también con el reordenamiento de la musculatura, que aumenta su importancia en los adultos, ya que deben realizar movimientos más complejos para someter a sus presas. Conforme el área se desarrolla, otorga mayor superficie para el anclaje de músculos más grandes y desarrollados. La parte posterior de la cresta sagital y la parte dorsal de la cresta nucal, determinan la zona de inserción de importantes músculos cervicales (Wickland et al. 1991, Richmond et al. 1992, Evans 1993, Duckler 1998, Antón et al. 2004), y son visibles en esta muestra como cambios en la relación entre el inion y el foramen magnum (e.g. Figs. 36, 64, 78, 107). El crecimiento de la cresta nucal (e.g. Figs. 19, 26, 126, 133), está vinculado con el del músculo splenius que se inserta en ella, con función de rotar el cuello y elevar la cabeza (Evans 1993, Duckler 1998). La porción mastoidea altamente desarrollada en ejemplares adultos (e.g. Figs. 5, 12, 83, 98), refleja la importancia del obliquus 
capitis cranialis y rectus capitis dorsalis, profundamente implicados en los movimientos latero-dorsales de la cabeza al nivel de la articulación atlantooccipital a la cual extienden (Argot 2003, Antón et al. 2004). Quien tiene función flexora de esa articulación es el rectus capitis lateralis, que se inserta en la superficie media del proceso paracondilar, el cual también se encuentra más desarrollado en adultos (e.g. Figs. 19, 27, 126, 133). Esta musculatura asociada a algunos movimientos de la cabeza, está relacionada además con la apertura mandibular, ya que eleva la línea dentaria superior mediante la fuerza ejercida en la zona occipitodorsal del cráneo, acompañando la contracción del músculo digastricus, el cual se inserta en el paracondilar y deprime ventralmente la mandíbula (Biknevicius \& Van Valkenburgh 1996; Antón et al. 2004, Segura \& Flores 2009).

El foramen magnum se origina en relación a múltiples estructuras de tejido blando de tamaño variable y tiene complejas interrelaciones funcionales con ellas. Es también la ruta constante para los fluidos y nervios impulsados entre el neurocráneo y la columna, los cuales son críticos para la viabilidad de un organismo (Richards \& Jabbourd 2011). En todos los juveniles de la muestra, el foramen magnum ocupó una posición ventral, que se tornó posterior (alineado con el plano horizontal) en los adultos (e.g. Figs. 7, 62, 85, 128), coincidiendo con observaciones hechas en Primates (ver Pucciarelli \& Dressino 1996, Berge \& Penin 2004). Cuando se forma el embrión, antes de que el animal alcance una actividad funcional, el rostro está ubicado en posición antero-inferior con respecto al neurocráneo, y luego durante el desarrollo ontogenético esta estructura pasa a estar delante del neurocráneo (Pucciarelli \& Dressino 1996, Jeffery \& Spoor 2002, Berge \& Penin 2004, Rohen \& Lutjen-Drecoll 2007). La placa occipital rota, cambiando el plano del foramen magnum (Hoyte 1971, Vilmann \& Moss 1979), en un proceso conocido como ortocefalización y del que también es parte la flexión de $\sim 182 \sim$ 
la base del cráneo (Pucciarelli \& Dressino 1996), que se observa más claramente en Lycalopex culpaeus y L. sechurae (Figs. 26, 27A, 48, 50). Aunque las relaciones entre la morfología de la placa occipital y las posturas de la cabeza y el cuello, y la relación de éstas con la postura corporal y la locomoción no son conocidas para estas Familias (Lieberman et al. 2000b), es probable que la orientación en ángulo de la cabeza con el eje corporal optimice las actividades que desarrollan los cachorros, como la lactancia, y la postura frontal del cráneo, alineada con el eje corporal, sea más óptima para las actividades predatorias activas que desarrollan los adultos.

\subsubsection{Crecimiento y desarrollo del basicráneo}

El basicráneo tiene un rol integrativo y funcional en el cráneo. Provee la plataforma sobre la cual crece el encéfalo y desde de la cual se proyecta y crece el rostro. Además, conecta el cráneo con el resto del cuerpo, articulándolo con la columna vertebral y la mandíbula y es una zona de interacción entre estructuras con función neural, esqueleto-motora, respiratoria, auditiva, masticatoria, digestiva y visual (e.g. Figs. 12, 19, 90, 97) (Lieberman et al. 2000b, Richards \& Jabbourd 2011). A pesar de que para algunos autores constituye un área conservadora del cráneo (de Beer 1985, Lieberman et al. 2000a), de gran estabilidad o de poco crecimiento en el período postnatal (Zelditch et al. 1992, Helm \& German 1996), para otros es relevante no sólo en sí misma, sino porque juega un rol importante en la covariación de otros componentes faciales (Lieberman et al. 2008, McBratneyOwen 2008, Schoenebeck \& Ostrander 2013). Es el principal sitio de crecimiento en el cual se incrementan las dimensiones lineales del eje basicraneal, a través de las sincondrosis basicraneales (e.g. Figs. 26, 69, 112, 119) (Michejda 1972, Moore 1981, García-Perea 1996, Jeffery \& Spoor 2004, Lieberman et al. 2008, Segura \& Flores 2009, Cendekiawan et al. 2010, Segura 2013), aunque el eje basicraneal también 
recibe incrementos por deposición de hueso a lo largo del margen interno del foramen magnum (Moore 1981, Lieberman et al. 2000b). Las sincondrosis basicraneales: spheno-occipitalis e intersphenoidalis se fusionan en todas las especies estudiadas en estadios de edad adultos, la primera de ellas, entre las clases A1 y A2: En especies como Lycalopex culpaeus, se fusiona en el primer año de vida (Crespo \& De Carlo 1963), en L. gymnocercus entre los 2-7 meses de vida (Crespo 1971), y en el género Lynx, al igual que en Canis lupus, se fusiona entre 3-4 años (García-Perea 1996, Landon et al. 1998) (Tablas 12, 19). La segunda de las sincondrosis, se oblitera entre las clases A2 y A3, es decir, en las dos últimas clases de edad de la vida de los individuos: En Lycalopex culpaeus se fusiona después del primer año de vida (Crespo \& De Carlo 1963), en L. gymnocercus a partir de los 9 meses (Crespo 1971), en el género Lynx se fusiona alrededor de los 8 años para algunas especies y permanece reducido a un pequeño orificio que no se fusiona nunca en otras (García-Perea 1996), y en C. lupus lo hace aproximadamente a los 4 años, o no se fusiona (Landon et al. 1998) (Tablas 12, 19). Este es un tiempo de fusión retardado (e.g. Tablas 6, 25, 43, 52) en relación a lo que ocurre en humanos, donde la sutura intersphenoidalis se fusiona al nacer y la spheno-occipitalis a partir de los 10 años de edad (Moore 1981). Los humanos adultos y muchos primates antropoides presentan una flexión de la base del cráneo, que no es vista en los adultos de cánidos o félidos estudiados aquí. Sin embargo, los juveniles mostraron flexión de sus cráneos hacia el lado ventral, muy evidentes en los análisis de morfometría geométrica, sobre todo para las especies L. culpaeus y L. sechurae (Figs 27A, 28, 49A, 50). Estudios previos propusieron que la torsión del basicráneo en el caso de los humanos, es un recurso para acomodar el encéfalo y el rostro sin afectar el ancho o largo craneal, aunque también se propuso que pudiera ocurrir por los procesos intrínsecos como la osificación endocondral (Michejda 1972, 
Jeffery \& Spoor 2004, Lieberman et al. 2008). Otra respuesta posible es que el cráneo, por la fusión temprana de las sincondrosis basicraneanas, se curva al estar restringido su crecimiento y no puede extenderse antero-posteriormente para alojar el encéfalo y acomodar el rostro, posibilidad que si existe en las Familias Canidae y Felidae. Por esto, la caja craneana de humanos crece mayormente en volumen y la de los cánidos y félidos estudiados crece mayormente en longitud, como lo demuestra la alometría entre positiva e isométrica de la longitud craneana y del rostro de las especies estudiadas (e.g. Tablas 7, 17, 53, 59).

\subsubsection{Crecimiento y desarrollo de las cápsulas sensoriales y estructuras que las alojan: Órbitas, bullas, nasales}

El tamaño de las órbitas está relacionado con el estilo de vida, pero también existe una correlación obvia con el tamaño corporal. En términos generales, los mamíferos de tamaños corporales pequeños tienen cráneos también pequeños sin espacio para grandes órbitas (Burton 2006). Sin embargo, en los juveniles se pudo observar grandes cabezas con grandes ojos en relación a pequeños tamaños corporales (e.g. Figs. 34, 35A, 69, 70A, 105, 106A, 112, 113A). Como la retina es una extensión del cerebro (Kiltie 2000), no sorprende que las cápsulas ópticas escalen como lo hace el cerebro (que en este caso es medido como ancho de la caja craneana), y las órbitas, que alojan las cápsulas, acompañen este proceso. Las órbitas (LO) escalaron entre isométrica y negativamente en los análisis multivariados (e.g. Tablas 17, 31, 47, 50), mientras fueron observadas como más grandes en los juveniles y proporcionalmente más pequeñas en los adultos en los análisis de morfometría geométrica (e.g. Figs. 35A, 36, 70A, 71, 106A, 107, 113A, 114). De todas maneras, para una mayor precisión y sensibilidad, los ojos deberían ser tan grandes como sea posible (Kiltie 2000, Howland et al. 2004, Burton 2006). 
Tener los ojos más grandes permite incrementar el tamaño de la imagen y maximizar la cantidad de luz que entra a la retina, lo cual es muy importante en animales nocturnos (Howland et al. 2004), como lo son muchos mamíferos predadores. En algunas especies se percibió también un cambio en la posición de las órbitas de más frontales en juveniles a más dorsales en adultos (e.g. Figs. 36, 71, $107,114)$. Esto aparentemente contradice la idea de que los adultos de las especies, donde el músculo dominante de la masticación es el temporal (como ocurre en estas dos Familias), tienden a tener las órbitas posicionadas anteriormente en el cráneo, ubicadas sobre la hilera dentaria (Cox 2008). Sin embargo, podría estar relacionado con una postura diferente de los arcos zigomáticos de los adultos, que se fortalecen y engrosan, produciendo un cambio de posición en la órbita visible en el análisis morfo-geométrico (e.g. Figs. 26, 28, 62, 64, 126, 128, 133, 135).

Si bien la clasificación de los taxa superiores de carnívoros se basa en la morfología de la región auditiva (Suborden Caniformia y Feliformia: Turner 1848, Flower 1869), la partición de las bullas puede ser considerada como indicador de un intento independiente por incrementar el tamaño de la cavidad del oído medio entre los infra-órdenes (Ivanoff 2000, 2001). Los cánidos y los félidos pertenecen a distintos subórdenes: Caniformia y Feliformia, y tienen septos (que dividen las bullas) incompletos y completos, respectivamente (Ivanoff 2001). Sin embargo, el crecimiento y desarrollo de la bulla como un todo fue similar en ambas Familias. Las bullas (ancho: AB; altura: HB y longitud: LB) escalaron negativamente en la mayoría de las especies (e.g. Tablas 7, 13, 44, 53), mostrando juveniles con bullas más anchas, cortas y grandes y adultos con bullas más pequeñas y gráciles (e.g. Figs. 19, 20A, 26, 27A, 112, 113A, 126, 127A). La excepción a esta tendencia fue la altura de la bulla (HB) que escaló positivamente en Atelocynus microtis y Leopardus guigna, aunque esto podría deberse a su bajo tamaño de muestra $(\mathrm{n}=17,18$, 
respectivamente) (Tablas 4, 40). Sería muy interesante obtener una buena muestra de Leopardus jacobita (Fig. 97), para poder observar si poseen grandes bullas auditivas como algunos roedores (Alvarez 2011, Verzi 2011) y félidos (Huang et al. 2002) de desierto reportados previamente. El mayor tamaño de las bullas está relacionado con un incremento en la sensibilidad a los sonidos de baja frecuencia, lo cual es beneficioso para la detección de las presas y de los depredadores (Hunt 1974, Huang et al. 2000). En regiones como los desiertos, los sonidos de alta frecuencia son atenuados rápidamente por la baja humedad de la atmósfera, permitiendo a los animales mayor precisión en la audición de los sonidos de baja frecuencia (Huang et al. 2002, Kitchener et al. 2010).

La región nasal ha evolucionado en dos funciones no relacionadas: olfatoria y respiratoria. El sentido del olfato y la refrigeración del aire inspirado están vinculados con los epitelios olfatorio y respiratorio, que tapizan los turbinales, por donde se transmiten las moléculas odoríferas desde el medio externo a las neuronas receptoras de olor (Lawson et al. 2012). Los turbinales se hallaron en mayor volumen (2 veces) en cánidos que en félidos (e.g. Figs. 5, 76), aunque se podría haber esperado que los félidos tuvieran mayor volumen para compensar la corta distancia por la cual pasa el aire inhalado, dado el corto hocico que tienen (Van Valkenburgh et al. 2004). La olfacción, que es el sentido asociado a las cápsulas nasales, tiene como función moderar una amplia variedad de comportamientos, que incluyen la alimentación, territorialidad, migración de los machos, crianza y cuidado de las crías, entre otros (Hammock 2005). Para las cápsulas nasales la situación fue diferente a las demás cápsulas sensoriales, por su compromiso con el rostro y esplacnocráneo. Los huesos nasales (LN), que alojan a las cápsulas mencionadas anteriormente, mostraron su longitud escalando entre isométrica y positivamente (e.g. Tablas 20, 31, 37, 53), exhibiendo en juveniles 
nasales cortos y anchos y en adultos más largos y estrechos (e.g. Figs. 42A, 70A, 84A, 120A). Sin embargo, los nasales estuvieron considerablemente más desarrollados en los cánidos que en los félidos, aunque los juveniles de ambos mostraron rostros con nasales cortos (e.g. Figs. 12, 34, 105, 133). Los largos nasales y rostros incrementan la cavidad nasal y presumiblemente enfatizan las funciones olfativas, lo cual no es extraño ya que los cánidos están más orientados a la olfacción mientras que los félidos lo están a la visión (Wang et al. 2008).

\subsubsection{Crecimiento y desarrollo del rostro y paladar}

La mayor variabilidad en los cráneos de los carnívoros se encuentra en la región facial (Goswami 2006), porque ésta, comparada con el neurocráneo, es la que posee suturas que se fusionan posteriormente, o que no lo hacen nunca (e.g. Tablas 12, 19, 39, 55), con lo cual tiene más tiempo para diferenciarse. Esto puede observarse en las Familias Canidae y Felidae, que presentan rostros muy disímiles, y es la tendencia opuesta a la que ocurre en marsupiales que muestran un desarrollo facial temprano y menor variabilidad (Goswami et al. 2010, Benet \& Goswami 2013). Sin embargo, los hocicos fueron más cortos en los juveniles y más largos y estrechos en los adultos de ambas Familias de esta muestra (e.g. Figs. 12, 13A, 34, 35A, 112, 113A, 133, 134A). Escalaron positivamente en los félidos y más isométricamente en los cánidos (e.g. Tablas 7, 17, 50, 59), produciendo en los cánidos mayor variación ontogenética en el crecimiento facial que en félidos (Wayne 1986). Con respecto a la altura del hocico, la tendencia estuvo más repartida (e.g. Tablas 10, 28, 34, 50).

La reducción del rostro de los félidos está asociada a la disminución de los premolares anteriores y molares posteriores. El efecto neto del acortamiento del rostro, es la disminución del brazo de palanca mecánica, lo que produce una 
mordida más poderosa (Wang et al. 2008). Los grandes félidos exhiben esqueletos faciales más largos y los félidos más pequeños lo presentan más reducidos (e.g. Figs. 105, 133) (Slater \& Van Valkenburgh 2008, 2009, Prevosti et al. 2010). En los cánidos, el cráneo tiene un plan más conservativo que no incluye la reducción de dientes. Exhiben un rostro relativamente largo, pero con la flexibilidad suficiente como para sean más cortos en las formas hipercarnívoras y más largos en las omnívoras (e.g. Figs. 41, 62) (Wang et al. 2008). Lo mencionado puede ser resultado del escalado (animales más grandes tienen rostros más grandes), puede estar relacionado con el modo en el que capturan y matan las presas (Slater \& Van Valkenburgh 2009), o con el diferente tamaño de éstas. Los carnívoros grandes (>15-20 kg) capturan presas de mayor tamaño, cercanas a sus propios pesos, y los pequeños (<15-20 kg), presas de menor tamaño (Carbone et al. 1999, 2007). Esto exige un compromiso diferente porque las presas más chicas, que son más abundantes, tienen un costo menor en captura y en el esfuerzo que sufre el cráneo para darles muerte, que el que involucran las presas mayores (Mc Donald et al. 2004, Carbone et al. 2007).

La causa genética tiene que ver con un factor de transcripción (identificado como Runt-related transcription factor 2, Runx2), una proteína que contiene un tándem de repetición de aminoácidos: glutamina y alanina (QA ratio). Está involucrada en la diferenciación de osteoblastos y, por lo tanto, en la regulación del desarrollo del hueso. Originariamente observada en razas de perros domésticos (Fondon \& Garner 2004), y luego en carnívoros en general, está fuertemente correlacionada con la longitud facial (Pointer et al. 2012). Su función es enfatizar la diferenciación de osteoblastos en estadios tempranos del desarrollo, a partir de células mesenquimáticas totipotentes (Depew et al. 2002), e inhibirlos en los estadios posteriores (Komori 2002). Cuando es sobre regulado, el hueso se $\sim 189 \sim$ 
desarrolla aceleradamente (se incrementa la proliferación) y se extiende (se retrasa la diferenciación terminal), y cuando es sub-regulado, el desarrollo del hueso es retrasado y truncado (Inada et al. 1999, Ueta et al. 2001). La alta variación de crecimiento facial en los Caniformia, provee más material crudo para que la selección natural actúe sobre los cambios en los tiempos de desarrollo (Wayne 1986). La sub-regulación del Runx2 potencialmente resultaría en el truncamiento temprano del desarrollo del hueso facial (progénesis/hipomorfosis) en los descendientes con respecto al ancestro, resultando en un acortamiento relativo del rostro. La sobre-regulación produciría hueso facial desarrollado que se extendería (hipermorfosis), lo cual resultaría en un rostro más largo en el Caniformia descendiente. Se espera entonces que existan menos efectos en la generación de la disparidad facial en los Feliformia que en los Caniformia, como resultado de que los primeros exhiben menos variación ontogenética sobre la cual los cambios en el tiempo de desarrollo puedan actuar (Sears et al. 2007, Segura et al. 2013).

La alometría negativa del ancho y la isométrica o positiva del largo del paladar (e.g. Tablas 13, 20, 37, 44) implica que es ancho y corto en los juveniles de estas Familias. Esta condición está probablemente relacionada a su función de plataforma sobre la cual actúa la lengua (el primer músculo en diferenciarse en todos los mamíferos), durante el amamantamiento, una actividad esencial durante la vida temprana de estos carnívoros, al igual que se describió previamente en marsupiales (German \& Crompton 1996, Smith 1997, Flores et al. 2010). El destete representa un hito en el desarrollo, que está asociado al cambio de composición dietaria, y que se sugiere ejerce un impacto epigenético en la morfología cráneofacial durante el crecimiento (Helm \& German 1996, Wilson 2011). No ocurre abruptamente, sino que el cachorro pasa de un período de lactancia, donde ingesta sólo leche, a uno de dieta semisólida donde consume leche junto a otros alimentos, 
al cual se llama "nutrición mixta", y luego la dieta se torna sólida (Langer 2003). El movimiento inicial es común para todos los mamíferos y es uno de los primeros comportamientos que realizan los jóvenes (Gordon \& Herring 1987, Wall \& Smith 2001). El movimiento incluye a la lengua que comprime y aplasta firmemente el pezón contra ese paladar ancho, produciendo una presión diferencial, y cuando la lengua se mueve hacia abajo, libera el pezón y provoca una diferencia de presión que hace que la leche fluya hacia la cavidad oral (German et al. 1992, Wall \& Smith 2001, Thexton et al. 2004). Entonces durante el tiempo que dura la lactancia, que en esta muestra fue variable, pero que en la mayoría terminó entre los 2 y 3 meses (e.g. Figs. 4D, J, M, Q), con algunas excepciones importantes (3-9 meses Leopardus pardalis, 5-6 meses Panthera onca) (e.g. Figs. 4P, U), los jóvenes dependieron nutricionalmente de sus madres, aunque fueron independientes de ellas en cuanto a su movilidad (Pond 1977).

\subsubsection{Crecimiento y desarrollo del aparato masticatorio: Musculatura}

La tendencia contrapuesta de la constricción postorbitaria y los arcos zigomáticos (i.e. CPO casi inexistente y $\mathrm{AZ}$ más estrechos en los jóvenes, y la situación inversa en los adultos, e.g. Tablas 13, 20, 53, 59), genera fosas temporales muy pequeñas en los juveniles y más amplias en los adultos (e.g. Figs. 26, 27A, 62, $63 \mathrm{~A}, 83,84 \mathrm{~A}, 126,127 \mathrm{~A})$. Esto fue observado previamente en félidos como Lynx (Kvam 1982, Saunders 1961, García-Perea 1996), Puma concolor (Segura \& Flores 2009, Giannini et al. 2010, Segura et al. 2013), Acinonyx jubatus y Herpailurus yagouaroundi (Segura et al. 2013), y también en cánidos: Lycalopex culpaeus (Segura \& Prevosti 2012, Segura 2013). La ampliación de la fosa temporal en los adultos, deja un espacio mayor para la disposición de la musculatura masticatoria que aumenta su volumen. Las fuerzas que producen las presas cuando son capturadas 
son fuerzas de resistencia que actúan hacia abajo y adelante. De los músculos masticatorios, el masetero actúa hacia arriba y adelante por lo que si se utilizara mayoritariamente este músculo, probablemente se dislocarían la mandíbula; mientras que el temporal actúa hacia arriba y hacia atrás, resistiendo mejor la fuerza de las presas, por eso es el que predomina en los Carnivora (Cox 2008). El temporal se origina en la cresta sagital y nucal, ocupa la fosa temporal y se inserta en la mandíbula. En esta muestra, se observa representado como el inion que sobrepasa el foramen magnum en los adultos de la mayoría de las especies (e.g. Figs. 20A, 21, 27A, 28, 77A, 78, 99A, 100). El incremento del volumen de este músculo implica una acción más poderosa (García-Perea 1996).

En definitiva, una caja craneana proporcionalmente pequeña, permite más espacio para los músculos masticatorios y viceversa. Es intrigante la posibilidad que los carnívoros hayan sacrificado la encefalización para tener un área masticatoria y fuerza de mordida mayor (Wroe et al. 2005, Wroe \& Milne 2007), en una inversión evolutiva contraria a lo que ocurre en Homo y en primates antropoides en general, que sacrifican masa muscular para incrementar el volumen endocraneal (Stedman et al. 2004, Yu et al. 2004, Wroe \& Milne 2007, Byron et al 2008).

\subsubsection{Crecimiento y desarrollo del aparato masticatorio: Mandíbula}

La alimentación es un comportamiento innato, pero hacerlo efectiva y eficientemente es algo que puede requerir experiencia para un carnívoro (Binder \& Van Valkenburgh 2000). El desempeño (performance) de un depredador incluye la habilidad de localizar, capturar y manipular sus presas (Wainwright \& Reilly 1994). Si bien los jóvenes no compiten directamente con los adultos por comida, en el desarrollo postnatal temprano, deberán ser hábiles para hacerlo en cuanto sean 
destetados (La Croix et al. 2011a). La morfología de un individuo, la cual cambia cuando crece, puede determinar los límites de esta performance, y puede influenciar su habilidad para prosperar en su medio ambiente (Binder \& Van Valkenburgh 2000, Habegger et al 2011). Como en un principio la nutrición de los jóvenes está a cargo de sus padres y existen muchos peligros cuando son tan pequeños, la performance locomotora, y de mecanismos defensivos, está a un nivel muy alto y la alimenticia a un nivel muy bajo (Herrel \& Gibb 2006).

De acuerdo a Biknevicius y Leigh (1997), la osificación postnatal de la mandíbula consta de dos fases que apuntan al reforzamiento del cuerpo mandibular, aumentando su resistencia mecánica. El cuerpo mandibular es una estructura que presenta diferencias en forma que ocurren a nivel de Familia, sugiriendo que hay una diferenciación morfológica temprana (Meloro et al. 2008), que puede ser moldeada por distintos factores, tener un componente ecológico como la dieta, aunque también presentar un patrón filogenético (Prevosti et al. 2012). Las mandíbulas de los juveniles (las cuales no estaban completamente desarrolladas) mostraron dentarios completamente curvados y cuerpos mandibulares anchos, y en los adultos un cuerpo mandibular más estrecho y recto (e.g. Figs. 12, 13B, 19, 20B, 90, 91B, 112, 113B). En relación a la alometría, el ancho y largo del cuerpo mandibular (LD/HD) fue positivo (e.g. Tablas 13, 20, 37, 50). Se pudo observar que los dentarios de los félidos (e.g. Figs. 105, 106B, 108, 133, 134B, 136) y de los cánidos hipercarnívoros como Speothos venaticus fueron más cortos (Figs. 62, 63B, 65), lo que les permite producir fuerzas de mordida más fuertes (Slater \& Van Valkenburgh 2009, Slater et al. 2009). Al aumentar la longitud del dentario, se compromete la ventaja mecánica de la musculatura de la mandíbula, en algún sentido, aunque es obvio que sigue siendo funcionalmente óptima para la dieta vinculada (Emerson \& Bramble 1993, Tanner et al. 2010). 
La rama ascendente de la mandíbula tuvo posición curvada hacia la parte posterior del cráneo en los juveniles y más vertical en los adultos (e.g. Figs. 20B, 22, 70B, 72, 84B, 86, 113B, 115, 127B, 129), y su ancho y longitud (HC/LC) fueron alométricos positivos para la mayoría de las especies estudiadas (e.g. Tablas 7, 13, 44, 53). Un proceso coronoides más alto está relacionado con una mejora de la palanca mecánica del músculo temporal (Sicuro 2011). Su carácter más amplio, junto a una posición más vertical brindan una mayor área para la inserción y una mayor resistencia para este músculo masticatorio, el cual comprende más de la mitad del total de la masa aductora en el Orden Carnivora (Hildebrand 1995, Segura \& Flores 2009). Estos cambios también tienden a aumentar la resistencia y el área de inserción del masetero, que es un músculo más pequeño en carnívoros y sirve en parte para estabilizar la articulación de la mandíbula (Hildebrand 1995, Segura \& Flores 2009). La fosa glenoidea se hace más profunda con los procesos pre y post-glenoideo bien desarrollados (e.g. Figs. 26, 27A, 62, 63A, 126, 127A, 133, 134A) contribuyendo a la firmeza de esta articulación, la cual está sometida a un fuerte estrés mecánico en los adultos (Segura \& Flores 2009). Adicionalmente, el crecimiento de estos procesos limita el desplazamiento rostro-caudal y los movimientos transversales, restringiendo la movilidad de la mandíbula a un plano vertical (Biknevicius \& Van Valkenburgh 1996, Segura \& Flores 2009).

Los dientes de los mamíferos se desarrollan secuencialmente, de acuerdo al espacio hábil que existe en el hueso y a los distintos genes que estimulan o inhiben su desarrollo (Boughner \& Dean 2004, Kavanagh et al. 2007). Son elementos invariantes temporalmente, que erupcionan en la mandíbula y maxila con el mismo tamaño que tendrán durante toda su existencia. Esto exige que exista un ajuste de la serie dentaria superior e inferior durante el crecimiento (Flores et al. 2013). Las hileras dentarias (LHS, LHI) fueron mayoritariamente isométricas (e.g. 
Tablas 4, 17, 34, 47), aunque también existieron especies en donde fueron alométricas positivas y negativas (e.g. Tablas 10, 26, 53, 56). En Lynx se observó una erupción asincrónica en los premolares superiores e inferiores que están relacionados con la mordida carnicera (García-Perea 1996), y esto también ocurrió también en los marsupiales, donde la hilera dentaria superior creció más rápido que la inferior (Abdala et al. 2001, Flores et al. 2010).

El cambio ontogenético de la dieta puede ser explicado por cambios en el hábitat o por la morfología del depredador (Herrel \& O’Reilly 2006, Habegger et al. 2011). El fin de la lactancia es un gran cambio en la dieta, los juveniles dejan de tener una alimentación líquida para comer alimentos sólidos. Con esto también cambian las fuerzas ejercidas sobre el cráneo y la mandíbula, porque el mayor estrés es debido a la masticación de la comida, ya que el acto de mamar hace poco uso de los músculos masticatorios (Helm \& German 1996). Esto puede alterar la forma y remodelado del hueso, ya que una dieta más blanda (o líquida) reduce el crecimiento del hueso porque decrecen las fuerzas mandibulares. De esta forma, la regulación de la dieta, tanto en relación a los valores nutricionales como en lo que respecta al esfuerzo muscular, puede alterar la tasa de crecimiento epigenéticamente (Smuts et al. 1978, Helm \& German 1996). También es importante entender el hecho de que el estrés que sufre el cráneo y la mandíbula de un depredador adulto, no es solamente por la masticación de la comida, sino también porque deben capturar y matar las presas (Barghusen 1972) haciendo uso de su aparato masticatorio, entre otros, a diferencia de la actividad que desarrolla un cachorro. 


\subsubsection{Crecimiento y desarrollo del aparato masticatorio: Ventajas mecánicas}

No existió un patrón común para las ventajas mecánicas. Éstas aumentaron, disminuyeron o se mantuvieron estables en distintas clases de edad para las distintas especies, sin que se puedan hacer generalizaciones (e.g. Figs. 11, 18, 104, 139). Los especímenes jóvenes tuvieron mandíbulas menos desarrolladas, lo que fue apoyado por los datos de esta Tesis, que mostraron una alometría positiva en el aparato masticatorio (e.g. Tablas 7, 31, 50, 59). Esto sugiere que los juveniles podrían no compensar su bajo nivel de performance alimenticia y se relaciona con la necesaria hipertrofia de la musculatura masticatoria que se produce durante la ontogenia (Binder \& Van Valkenburgh 2000; Thompson et al. 2003, Herrel \& Gibb 2006).

Teóricamente, los músculos con más pobre ventaja mecánica deberían generar más tensión para producir una fuerza de mordida equivalente a la producida con músculos con mejor ventaja mecánica (García-Morales et al. 2003). En algunos casos, los juveniles produjeron ventajas mecánicas más pequeñas que los adultos (Binder \& Van Valkenburgh 2000) que se incrementó con la edad (e.g. Figs. 11, 25, 82, 104); pero en otros casos, el desarrollo de la ventaja podría estar afectado por el cambio de la dentición juvenil (decidua) a la de adulto (permanente), o por la influencia de ambas en el comportamiento alimenticio (e.g. Figs. 18, 40, 89, 139). Es posible que la transición entre ambas denticiones esté acompañada de la reducción de eficiencia alimenticia, especialmente porque los dientes deciduos son muy delicados o se pierden cuando los definitivos erupcionan (Binder \& Van Valkenburgh 2000), motivo por el cual no resultó incoherente que en algunos casos la ventaja mecánica no aumente con la edad. En un trabajo realizado en cánidos domésticos por Ellis et al. (2008), se esperaba ver 
una relación inversa entre la ventaja mecánica y la longitud del hocico, y directamente proporcional al ancho del cráneo, aunque se encontraron resultados contradictorios con esta idea, al igual que ocurrió con los datos de esta tesis, donde ciertas ventajas mecánicas se incrementaron o decrecieron de manera independiente al largo del hocico (e.g. Figs. 25, 68, 89, 125). También se propuso que los jóvenes pueden compensar la debilidad de sus mandíbulas con dientes extremadamente puntiagudos (e.g. Figs. 12, 62, 119, 126) (Thompson et al. 2003), que facilitan la penetración de la carne de las presas porque concentran la fuerza en un área más pequeña de la superficie (Frazzetta 1988). Esto haría que la captura y procesamiento de presas sea exitoso aún en ausencia de altas fuerzas de mordida (Habegger et al 2011).

\subsubsection{Crecimiento y desarrollo del cráneo como un todo}

En términos generales se hallaron mayores cambios en tamaño y forma en el cráneo que en la mandíbula durante la ontogenia (e.g. Figs. 13, 16, 17, 120, 123, 124). De acuerdo a Herring (1993) y Helm \& German (1996), el desarrollo del cráneo es epigenético, ocurre a través de la musculatura que influencia la morfología craneal y mandibular, es decir que hay un gran impacto biomecánico. En esta muestra, aunque varios de los cambios ontogenéticos de forma del cráneo y la mandíbula se pudieron relacionar con el desarrollo de estructuras y musculatura que les permitieron a los jóvenes enfrentar su vida de adultos como depredadores activos, además del desarrollo del cerebro y de los órganos de los sentidos, muchos cambios no tuvieron una explicación directa funcional, estuvieron relacionados al hecho de crecer (escalado ontogenético), e inclusive a sus historias evolutivas. El cráneo es pequeño e inmaduro en los juveniles, mientras que la mandíbula es pequeña al nacer, pero presenta cambios más 
modestos en forma durante la ontogenia (e.g. Figs. 20, 23, 24, 113, 116, 117), conformaciones que fueron observadas también en coyotes (La Croix et al. 2011b). Las diferencias en información brindada entre cráneo y mandíbula (i.e. cambios más modestos en la mandíbula que en el cráneo) son esperables ya que la mandíbula tiene como función primaria la masticación, mientras que el cráneo es multifuncional, hay otros factores que actúan, como la necesidad de proteger a los órganos de los sentidos y cerebro, aunque también está implicado en la masticación. Esto produce, probablemente, mayor disparidad entre las distintas especies.

Sólo en 3 especies (Lycalopex griseus, L. sechurae, entre los cánidos y Leopardus pardalis, entre los félidos) el cráneo y la mandíbula tuvieron sincronía en el crecimiento (cambio en el tamaño) y desarrollo (cambio en la forma) para alcanzar el tamaño y/o la forma definitiva en el mismo estadio de vida (Figs. 38, 39, 52, 53, 102, 103). Para otras especies de esta muestra, esto no ocurrió, por lo que no se puede identificar un patrón general (e.g. Figs. 66, 67, 73,74, 109, 110, 137, 138). Inclusive, sólo el 47,37\% de las especies fueron sincrónicas en la obtención del tamaño y forma definitiva del cráneo (Figs. 16: Cerdocyon thous, 30: Lycalopex culpaeus, 38: L. griseus, 52: L. sechurae, 102: Leopardus pardalis, 109: L. tigrinus, 116: L. wiedii, 130: Puma concolor, y 137: Panthera onca), idéntico porcentaje se alcanzó para las mismas características de la mandíbula (Figs. 10: Atelocynus microtis, 39: Lycalopex griseus, 53: L. sechurae, 60: L. vetulus, 81: Leopardus colocolo, 88: L. geoffroyi, 103: L. pardalis, 110: L. tigrinus, y 131: Puma concolor). Lo único común a todas las especies es que el tamaño definitivo, tanto del cráneo como de la mandíbula, se obtuvieron en alguna de las 3 clases de adultos, mientras que la forma final de ambas estructuras se alcanzaron en esas clases o aún antes, es decir, naturalmente toma más tiempo obtener el tamaño definitivo que la forma. El patrón 
ontogenético de la mandíbula, de la maxila y del cráneo pueden divergir dentro de la misma especie, lo cual sugiere que hay un grado de independencia ontogenética y evolutiva entre la maxila y la mandíbula (Boughner \& Dean 2008). La performance óptima que brinda la forma definitiva, producto de la conformación final de los músculos, se obtiene antes (por lo general en la clase A2), para permitir el mayor rendimiento en la captura de presas y su masticación, aunque está claro que son aptos para alimentarse por sí mismos mucho antes en el tiempo.

Entre los mamíferos, las tasas de crecimiento son máximas cuando se acaba de nacer y decrecen durante el primer año (Helm \& German 1996). Muchas especies de mamíferos continúan creciendo luego de obtener la madurez sexual. En Lynx el crecimiento postnatal ocurre mayormente durante los primeros 2 años de vida (Saunders 1961, Andersen \& Wiig 1984, Kritzman \& Dudley 1986, GarcíaPerea 1991, 1996, Beltrán \& Delibes 1993) y en Panthera leo, después de los 3 años de edad, las dimensiones del cráneo se solapan con la de los leones más viejos (Smuts et al. 1978). En esta muestra, si bien se observaron los cambios más notables durante las primeras clases de edad (B, J1, J2, J3) (e.g. Figs. 16, 17, 38, 39, 87, 88, 102, 103) éstos se produjeron también durante la adultez e inclusive hasta la última clase de edad (A3) (e.g. Figs. 9, 10, 23, 24, 131, 138). Esto había sido reportado previamente para cráneos de Puma concolor donde se observaron a las hembras creciendo hasta los 5-6 años y los machos hasta los 7-9 (Gay \& Best 1996). Seymour (1999) también detectó que no sólo se producían cambios en los cráneos de los juveniles de Leopardus pardalis, sino que los adultos también continuaban cambiando de forma y tamaño en las últimas clases de edad. El 24\% de las especies estudiadas alcanzaron su forma y/o tamaño definitivo del cráneo y/o mandíbula en el último estadio (A3) (Figs. 9, 10, 23, 24, 60, 131, 137), el 38\% obtuvo alguna de sus ventajas mecánicas en él (Figs. 11, 25, 61, 82, 89, 125, 132, 139), y el 47\% fusionó su 
sincondrosis intersphenoidalis (Isp) en esta clase (Tablas 9, 12, 16, 19, 22, 27, 30, 42, 52). Como ya fue mencionado con anterioridad, esta sincondrosis está vinculada con el crecimiento longitudinal del cráneo. En pocas especies el arribo al tamaño definitivo del cráneo, y la fusión de esta sutura, fueron simultáneos (Fig. 23, Tabla 9). En la mayoría de los casos, el crecimiento finalizó antes de la fusión, brindando la posibilidad de crecer aún más (al menos potencialmente) por la no fusión de la sincondrosis hasta esta etapa final (e.g. Figs. 30, 38, 45, 123, Tablas 12, 16, 19, 52). Los cambios en forma y tamaño a una edad tan tardía como la clase A3 son contraintuitivos, ya que se espera que sean modificaciones que se producen temprano, a lo sumo cuando se produce la madurez sexual. Que en el último estadio de edad la cresta sagital continúe creciendo como ocurrió en L. pardalis (Seymour 1999), no indica una mejora en la ventaja mecánica del músculo temporal, ya que estos ejemplares cazaban activamente y de manera exitosa hasta ese momento, sino que probablemente esté vinculado más que a la función, al escalado ontogenético, o inclusive a la genética misma de la especie, como fue previamente propuesto para Didelphis (Gardner 1973).

\subsection{Aspectos Evolutivos}

\subsubsection{Comparación inter-Familias}

Muchas de las tendencias observadas en las Familias Canidae y Felidae fueron compartidas como se mencionó anteriormente (e.g. alometrías positiva del esplacnocráneo y negativa del neurocráneo, cambios orientados al reforzamiento del cráneo y tendientes a aumentar la performance en la alimentación en los juveniles, obtención del tamaño definitivo del cráneo y mandíbula en clases de adultos, fusión durante estadios juveniles tempranos de las sincondrosis de la placa occipital, etc.). Sin embargo, tanto la forma definitiva final, como la que 
exhibieron los juveniles de estas Familias fueron tan disímiles que conformaron dos grupos completamente separados al ser incluidos en el mismo morfo-espacio (Fig. 144). Esta separación fue tan marcada por la morfología diferente que presentan los félidos, con cráneos más cortos y anchos, y rostro extremadamente corto (Fig.142), en contraposición a los cánidos, que poseen cráneos más alargados, con nasales y rostro elongados (Fig. 140). Esto mismo, aunque de manera menos conspicua, se observó para las mandíbulas (Fig. 145), que fueron más cortas y anchas en los félidos (Fig. 143), y más alargadas y delgadas en los cánidos (Fig. 141).

Estas disimilitudes se suman al diferente tipo de mordida que presentan los representantes de estos clados. En los félidos, existe una reducción y pérdida de premolares anteriores y molares posteriores, y un acortamiento del rostro (e.g. Figs. 76, 98, 105). Esto ubica a los incisivos, caninos y premolares de manera más posterior y permite que la mordida sea la más poderosa de todos los carnívoros, en relación al tamaño corporal (e.g. Figs. 83, 112, 133) (Ewer 1973, Radinsky 1981a, Christiansen \& Adolfssen 2005). En contraste, los miembros de la Familia Canidae tienen un número mayor de dientes postcaninos y el rostro es relativamente largo (e.g. Figs. 5, 19, 55), con los incisivos y caninos ubicados hacia adelante, con lo cual poseen una de las mordidas más débiles de todos los carnívoros, utilizando los mismos músculos masticatorios (e.g. Figs. 34, 41, 69) (Radinsky 1981a, Christiansen \& Adolfssen 2005, Wang et al. 2008). Estas diferencias también están relacionadas con la dieta y el manejo de las presas, de modo que los félidos que son carnívoros estrictos, están especializados en una sola mordida que produce la muerte de sus presas, mientras que los cánidos que son mayoritariamente omnívoros, aunque también existen formas hipercarnívoras, usualmente matan sus presas 
produciendo numerosas y repetidas mordidas en el cuerpo (Ewer 1973, Biknevicius \& Van Valkenburgh 1996, Slater et al. 2009).

Los cánidos muestran una diversidad dietaria mayor que los félidos (Goswami et al. 2010), del mismo modo que los félidos muestran una variedad de tamaño que no se equipara con la de los cánidos (Mazák 1981, Sunquist \& Sunquist 2009). Sin embargo, esto no se traduce en la forma, ya que en cuanto a estructura craneana y mandibular, dentro de cada Familia, fueron bastante conservativos (Figs. 140-143). En contraposición, en el caso de los cánidos, existen trabajos donde se analizaron distintas variables dentarias (e.g. Van Valkenburgh 1991, Prevosti 2006) y se observó mayor variación del cráneo y mandíbula en relación a las dietas. Esto indica que la mayor diferenciación está dada por la dentición, más que por la morfología del cráneo en sí. Con respecto a las suturas y sincondrosis, se observó un patrón en el cual los cánidos presentaron mayor porcentaje de fusión en relación con la dieta (i.e. quienes presentaron una dieta exclusivamente carnívora, tuvieron mayor cantidad de suturas y sincondrosis fusionadas) (Fig. 150), mientras que en félidos estuvo más relacionado con el tamaño (i.e. quienes tuvieron mayor tamaño corporal, tuvieron mayor cantidad de suturas y sincondrosis fusionadas) (Fig. 151). El porcentaje de fusión tuvo la misma tendencia para asociarse que las configuraciones del cráneo (Figs. 140, 142, 150, 151). Este patrón es opuesto al de otra Familia de carnívoros (Ursidae), donde Ursus arctos (130-550 kg, omnívoro: Garshelis 2009) presenta un 100\% de suturas fusionadas, en contraposición con $U$. maritimus (300-800 kg, hipercarnívoro: Garshelis 2009) que presenta solamente un $50 \%$ del total de suturas fusionadas (Goswami et al. 2013). Es decir, que en el caso de los osos no existe mayor fusión ni para los de mayor tamaño, ni para los más carnívoros, en el sentido dietario. Esto permite vislumbrar que existe una 
tendencia, en relación a la fusión de suturas, que sería diferente y propia de cada Familia.

Los factores que dan forma al cráneo y la mandíbula puede estar vinculados a la selección natural (i.e. función), o a la historia evolutiva (i.e. la filogenia) (Figueirido et al. 2011). La similitud en la forma sugiere que las especies relacionadas comparten adaptaciones, y son más similares biológica y ecológicamente que lo esperado por azar. La similitud fenotípica puede ser cuantificada como "señal filogenética" (Meloro \& Raia 2010), sin embargo son muy pocos los caracteres que la mostraron (sólo AM, LN, LHS, Oipa y Tcr, Tablas 6164). Esto está vinculado al hecho de que los caracteres tuvieron poca estructuración filogenética, al menos en relación a los árboles aceptados comúnmente y que se usaron en esta Tesis (Apéndice XI). Se hizo evidente también por el hecho de que existen pocas sinapomorfías (21 para félidos y 12 para cánidos, Figs. 146-149) en relación a la cantidad de autapomorfías (Apéndice XII, Figs. 146-149), es decir, que se registraron mayores cambios individuales en las especies. Situación que podría significar que hubo una radiación adaptativa (divergencia evolutiva de miembros de un linaje filogenético) hace un corto tiempo, lo que permitió esas diferenciaciones específicas (Losos \& Miles 2002). Si bien existe una gran conservatividad morfológica en los cráneos y mandíbulas en los ejemplares de ambas Familias, que se refleja también en la gran estabilidad de los estados de carácter de los ancestros (Figs. 144, 145, 146-149, Apéndice XII), se observaron caracteres donde la tendencia evolutiva fue diferente.

Con respecto al esplacnocráneo, los valores de las tasas de crecimiento del ancho zigomático (AZ) se incrementaron en la Familia Felidae y se redujeron en la Familia Canidae (Fig. 146). Esto solo refuerza lo que fue evidente a simple vista, 
existe un mayor desarrollo en los félidos, tanto en el ancho como en la robustez de los arcos zigomáticos (e.g. Figs. 62, 133), producto de su tipo de dieta general hiper-carnívora. Esto se vincula también con el desarrollo de la musculatura masticatoria, el cual fuera mencionado en el apartado funcional de esta discusión. Así, resulta coherente también con lo observado en otros carnívoros con dietas más extremas como las hienas Crocuta crocuta que son durófagas. En éstas, el crecimiento y desarrollo del cráneo es más lento y el resultado final es un cráneo más reforzado y macizo (La Croix et al. 2011a) que el de los hipercarnívoros como los félidos (que serían un patrón intermedio, e.g. Figs. 126, 133), y el de los cánidos omnívoros (e.g. Figs. 19, 26), que es el menos desarrollado (Segura et al. 2013). Como era de esperar, aumentó la clase de edad de la obtención del tamaño craneano definitivo en las especies de mayor tamaño corporal (Fig. 149). Esto ocurrió en ambas Familias: en Panthera onca entre los félidos (31-121 kg, Sunquist \& Sunquist 2009) y Chrysocyon brachyurus entre los cánidos (20,5-30 kg, Sillero-Zubiri 2009), mostrando la correspondencia que existe entre desarrollar un cráneo de mayor tamaño y la mayor inversión de tiempo que esto implica (Figs. 23, 137, 149). De todas formas, el patrón fue disímil entre ambos: P. onca aumentó el tamaño y forma del cráneo, mientras que disminuyó, o mantuvo igual la mandíbula (Figs. 137, 138, 149), y por otro lado C. brachyurus aumentó la edad para el tamaño del cráneo y la mandíbula, y mantuvo constantes las formas en ambos (Figs. 23, 24, 149). Algo parecido ocurrió con las ventajas mecánicas definitivas que presentaron diferentes modelos (e.g. Figs. 32, 75, 96, 132), mostrando que no existe un patrón uniforme ni entre las Familias Canidae y Felidae, ni intra-Familias para los arribos al tamaño, forma y ventajas definitivas (e.g. Figs. 38, 39, 40, 59, 60, 61, 80, 81, 82, 109, 110, 111, 149). El patrón asincrónico había sido reportado previamente para el cánido Canis latrans, que obtuvo el tamaño definitivo del cráneo y la mandíbula, 
junto a la forma final del cráneo de manera sincrónica, mientras que la forma terminal de la mandíbula la obtuvo asincrónicamente (La Croix et al. 2011a).

La apariencia craneana y mandibular de un adulto también puede estar relacionada con la heterocronía, es decir con los cambios que ocurren en el tiempo o en la tasa de los eventos de desarrollo, relacionados a los mismos eventos en el ancestro (Alberch et al. 1979, Mc Kinney \& Mc Namara 1991). Existen 2 tipos de heterocronía: pedomorfosis, donde hay menos crecimiento ontogenético en el descendiente que en el ancestro, y peramorfosis, donde se percibe más crecimiento durante la ontogenia que en el ancestro. Pueden ocurrir por una variación en el tiempo de inicio del crecimiento, por variación en el tiempo de cese del crecimiento, o una variación en la tasa de crecimiento (McNamara 1986, Reilly et al. 1997). Ligeros cambios durante la ontogenia en cualquiera de estos factores pueden impactar directamente en la forma final.

Entre las sinapomorfías neurocraneales observadas, fueron interesantes las sincondrosis Isq, con un patrón compartido por el linaje Puma y (Lycalopex gymnocercus (L. griseus-L. culpaeus)), e Ib, con un patrón compartido por el clado (Leopardus wiedii-L. pardalis) y por (Lycalopex gymnocercus (L. griseus-L. culpaeus)), fusionándose ambas sincondrosis de manera más temprana, siendo caracteres pedomórficos, a la luz de las definiciones provistas anteriormente (Figs. 147, 148). Tanto Isq como Ib están vinculadas a la placa occipital y al sostén temprano del cráneo, como fuera discutido en el apartado funcional de esta discusión. Otra sinapomorfía vinculada a la placa occipital fue la sutura Oipa que dentro de los félidos (en el linaje Puma) se fusionó más temprano, mostrándose pedomórfica, y en el clado (Leopardus jacobita-L. colocolo) mostró la tendencia opuesta (i.e. peramórfica) (Figs. 147, 148). La parte posterior del cráneo, su ancho (AM), mostró 
una desaceleración de la tasa de crecimiento, siendo pedomórfica en los félidos (Leopardus tigrinus (L. guigna-L. geoffroyi)), y una aceleración, siendo peramórfica en los cánidos, dentro del género Lycalopex (Fig. 146). Sin embargo, su tendencia no cambió y fue sostenidamente alométrica negativa. Con respecto al tamaño definitivo del cráneo (Tcr), se vio un adelantamiento en su obtención (i.e. pedomorfosis), tanto en los félidos (Leopardus jacobita-L colocolo (L. tigrinus ( $L$. guigna-L. geoffroyi))), como en los cánidos (Cerdocyon thous (Lycalopex sechurae (L. vetulus (L. fulvipes (L. gymnocercus (L. griseus-L. culpaeus)))))) (Fig. 149). En relación al esplacnocráneo, se observó un incremento en la tasa para la HD, tanto en félidos (Leopardus jacobita-L. colocolo (L. tigrinus (L. guigna-L. geoffroyi))) como en cánidos (con excepción de Urocyon cinereoargenteus), siendo así caracteres peramórficos (Fig.146), lo cual se vincula a la obtención de una mandíbula más robusta. La situación para la ventaja mecánica definitiva del masetero (Mcar) fue la obtención más temprana en ambas Familias, entre los félidos (Leopardus guigna-L. geoffroyi) y entre los cánidos (Cerdocyon thous (Lycalopex sechurae (L. vetulus (L. fulvipes ( $L$. gymnocercus (L. griseus-L. culpaeus)))))) (Fig. 149). Además, Para los félidos (con excepción de Panthera onca) se observa la fusión más temprana de la sutura Zmx, siendo éste un carácter pedomórfico (Fig.147, 148).

Si se interpretan las fusiones de las suturas y sincondrosis (Isq, Ib, Oipa), la obtención del tamaño del cráneo definitivo y de la ventaja mecánica del masetero medida en el carnicero, como expresiones de adulto, que se obtienen a una edad más temprana (en una clase de edad menor en el descendiente que en el ancestro), estos caracteres serían peramórficos. Sin embargo, si se toman estos caracteres como el fin de un proceso, que determina que el crecimiento cesa, el truncamiento temprano implicaría menor crecimiento en el descendiente que en el ancestro y, 
por lo tanto, sería un carácter pedomórfico según las definiciones de heterocronía provistas por McNamara (1986) y Reilly et al. (1997) citadas anteriormente.

En términos generales, comparando las 2 Familias, los félidos presentaron más caracteres tendientes al menor crecimiento y a la reducción del tamaño que los tendientes al incremento, se observaron 16 sinapomorfías pedomórficas y 5 peramórficas, y también tuvieron mayor cantidad de sinapomorfías que en los cánidos. En la Familia Canidae, por otro lado, se observaron 6 sinapomorfías pedomórficas y 6 peramórficas, siendo evidente que la tendencia entre el aumento y la disminución estuvo repartida más equitativamente para los caracteres analizados (Fig. 146-149).

\subsubsection{Comparación intra-Familia Canidae}

Para el cráneo y la mandíbula de los cánidos, parece haber un patrón evolutivo bastante homogéneo en cuanto a la morfología (Fig. 140, 141). La separación más notable fue la de Speothos venaticus (Fig.62), con adultos que presentaron una caja craneana corta y maciza, bullas pequeñas y rostro corto (Fig. 140), mandíbulas con cuerpo mandibular ancho, corto y curvado (Fig. 141), todas estas características muy parecidas a las de los juveniles de las demás especies y por lo que fue calificado como pedomórfico por Biben (1983). También presentaron la caja craneana más estrecha, los arcos zigomáticos bien desarrollados (Figs. 62AF, 63A) y la mandíbula con un proceso coronoides amplio y dirigido hacia arriba (Figs. 62G-H, 63B). Esta especie resultó distinta a las demás especies durante toda su trayectoria ontogenética, ya que estuvo completamente separada del resto tanto en los cráneos de los juveniles, como en los de los adultos (Figs. 140, 141). Estas particularidades mostradas por el cráneo y la mandíbula de S. venaticus son habituales en un hiper-carnívoro. De hecho, el acortamiento de los brazos de

$$
\sim 207 \sim
$$


palanca, y el desarrollo de áreas para alojar músculos más masivos, le permite una mayor fuerza de mordida y una acción muscular más poderosa (Ewer 1973, Radinsky 1981a). Se observó también que otra especie integrada al análisis como Canis lupus, la cual también presenta una alimentación hiper-carnívora, no se separa morfológicamente del remanente de cánidos en los análisis de morfometría geométrica (Fig. 140), mostrando que es posible que existan explicaciones subyacentes que no pudieron ser percibidas en este primer abordaje a los datos. Wroe \& Milne (2007) explican que las especies que tienen caza social como C. lupus, pueden ser dolicocefálicas (y en este caso no distinguirse del resto de los cánidos) porque este tipo de caza les permite tomar presas que exceden su propia masa corporal, aún cuando este cráneo no sea el típico de un hiper-carnívoro. Tal vez esta separación morfológica se relacione con el hecho de que S. venaticus se habría separado de su grupo hermano (Chrysocyon brachyurus) hace aproximadamente 3 millones de años atrás (Apéndice XI) y del resto de los cánidos hace mucho más tiempo aún (4,3 millones de años) (Perini et al. 2010, Eizirik 2012, Austin et al. 2013).

También en el análisis de suturas realizado previamente, S. venaticus mostró diferencias con el resto de los cánidos, con una más temprana edad de fusión de suturas, y por ser la especie con más fusión en la Familia Canidae, con un 79,31\% del total de suturas obliteradas, seguida con mucha distancia por Lycalopex culpaeus (Fig. 26) con el 40\%, y el resto de las especies, con un promedio del $21,11 \%$ de fusión (Tabla 27, Fig. 150). Parece evidente que existe una relación entre la carnivoría y el grado de fusión, ya que $S$. venaticus se alimenta exclusivamente de carne, e inclusive puede tomar presas que exceden su tamaño corporal (Zuercher et al. 2004) y el siguiente en porcentaje de fusión es uno de los zorros del género Lycalopex considerado más carnívoro, dentro de la omnivoría del género (Fig. 150). 
$\mathrm{Al}$ analizarse las suturas de C. lupus, estas arrojaron una fusión del 60\%, apoyando el patrón observado.

Si bien en trabajos previos (e.g. Jaslow 1990, Rafferty \& Herring 1999, Byron et al. 2004, Rayfield 2005, Moazen et al. 2009) se postuló que entre las funciones de las suturas está el ser disipadoras de estrés, disipando la energía de manera más eficiente que si fuera hueso continuo, esta idea no fue desarrollada para carnívoros, y no fue testeada experimentalmente para ninguna de las especies de este Orden. Los resultados obtenidos aquí, muestran que la mayor fusión, sobretodo de las suturas rostrales, se produce justamente en los cazadores más activos con dietas hiper-carnívoras (Tablas 12, 27, Fig. 150), por lo que sería evidente que la mayor fusión de las suturas brinda un cráneo macizo, fortalecido y competente para soportar el esfuerzo de la captura, la fuerte tensión sobre él y la mandíbula que esta práctica produce, y el procesamiento posterior de las presas.

Otros cánidos Neotropicales como Chrysocyon brachyurus y Urocyon cinereoargenteus también resultaron diferentes. C. brachyurus (Fig. 19) tuvo un patrón craneano y mandibular similar a los restantes cánidos (Fig. 140), pero se mostró distinto en cuanto al tamaño, siendo los adultos más grandes que los restantes, y arrastrando un poco de la forma, tal como se pudo observar en los análisis de morfometría geométrica (Fig. 140). Coherentemente con su tamaño (discutido anteriormente), la sincondrosis craneana Isp en esta especie, se fusionó en un estadio posterior al de su ancestro, en la última clase de edad, A3, (Figs. 23, 145, 146). U. cinereoargenteus (Fig. 69) tampoco fue diferente morfológicamente en los análisis de cráneo y mandíbula de morfometría geométrica (Figs. 140, 141), pero presentó muchas autapomorfías relacionadas básicamente con la disminución de la tasa de crecimiento de las siguientes medidas: $\mathrm{HPO}, \mathrm{AZ}$, Acan, $\mathrm{HH}, \mathrm{AB}, \mathrm{Apal}, \mathrm{HD}$, 
HC y LC (Fig. 146). En relación a la longitud del hocico y del rostro (LN y LR), las tasas se incrementaron en el cánido $U$. cinereoargenteus (Fig. 146). La longitud de los nasales presentó señal filogenética (Tabla 61) y tal vez esté interrelacionada con la olfacción como se mencionó en el apartado funcional de la discusión. Estos resultados son coherentes con el hecho de que $U$. cinereoargenteus es una forma típica Norteamericana más que Neotropical, perteneciente a la tribu Vulpini, correspondiente a la base de la sub-Familia Caninae (Apéndice XI) y diferente del resto de los cánidos Neotropicales (Berta 1987, Prevosti \& Rincón 2007, Soibelzon \& Prevosti 2007, Perini et al. 2010, Prevosti \& Soibelzon 2012). Por esto, esta especie tiene características individuales, las cuales no comparte con el resto de los cánidos con los que está estrechamente relacionada (Figs. 146-149). S. venaticus y C. brachyurus por otro lado, pertenecen como el resto de los cánidos Neotropicales a la tribu Canini, por lo que presentan una historia evolutiva diferente (Apéndice XI). Tuvieron un ancestro común a partir del cual se habrían diversificado hace 3 millones de años atrás (Perini et al. 2010, Austin et al. 2013) y esto se ve reflejado en sus morfologías (Figs. 140, 141). La similitud morfológica que se presenta en el resto de los cánidos (Figs. 140, 141), al igual que su baja fusión de suturas (Fig. 150), podría deberse al hecho de que tienen una historia evolutiva muy reciente (Apéndice XI) (el género Lycalopex compartió un ancestro común hace 1,3 millones de años) y su especiación ocurrió muy rápidamente (Perini et al 2010, Eizirik 2012, Prevosti \& Soibelzon 2012, Austin et al. 2013), además de que su rango de distribución quedó restringido a Sudamérica (Eizirik 2012). Por este motivo es probable que presenten un patrón bastante similar morfológicamente hablando, aunque esta semejanza también podría estar anclada a una dieta omnívora que presentan la casi la totalidad de estos cánidos, y la morfología relacionada a esta alimentación, que implica cráneos más alargados, con nasales y rostros más largos, 
así como hileras dentarias elongadas (e.g. Figs. 5, 34, 48, 69) (Ewer 1973, Van Valkenburgh 2007, Figueirido et al 2010).

\subsubsection{Comparación intra-Familia Felidae}

Para el cráneo no existió un único patrón homogéneo, ya que los félidos mostraron 2 patrones evolutivos diferentes que parecieron estar relacionados al tamaño, concentrando a las especies más grandes (Pantherinos + Puma concolor + Acinonyx jubatus) en uno de ellos, y el resto de las especies, más pequeñas, en el otro (Fig. 142). La mandíbula sin embargo, presentó un patrón uniforme, ya que las de todas las especies se encontraron distribuidas sin agruparse de ningún modo (Fig. 143).

Panthera onca (Fig. 133) y Puma concolor (Fig. 126) son las especies Neotropicales de mayor tamaño (i.e. $31-121 \mathrm{~kg}, 30-72 \mathrm{~kg}$, respectivamente: Sunquist \& Sunquist 2009) y para el análisis de suturas son las que más se fusionaron en cuanto a porcentaje total (66,67\% y $64,28 \%$, respectivamente), en relación a las restantes especies que sólo alcanzan un promedio de $29,93 \%$ de fusión total (Fig. 151). Es excepcional el porcentaje de fusión de Herpailurus yagouaroundi (Fig. 119) (3-7,6 kg: Sunquist \& Sunquist 2009), especie hermana de Puma concolor (Fig. 126), considerada de tamaño pequeño (Lucherini et al. 2004b), pero con un $61,91 \%$ de fusión total (Fig. 151). Esto permite imaginar un patrón filogenético en la obliteración de las suturas craneales para el linaje Puma, aunque para poder hacer inferencias filogenéticas más precisas sería ideal conocer los porcentajes de fusión de una especie altamente relacionada como Acinonyx jubatus. De la misma manera, sería interesante sondear qué ocurre en otros linajes como en los Pantherinos, pero se escapa del objetivo inmediato de esta tesis que es abordar las especies Neotropicales. 
Para los félidos la situación es diferente a la planteada previamente para cánidos (Fig. 140), ya que todos son hiper-carnívoros y, por lo tanto, no presentan diferentes morfologías producto de, o relacionadas con las dietas (Fig. 142). Las soluciones morfológicas para ser un hiper-carnívoro parecen ser básicamente las mismas (Figueirido et al. 2011) y esa falta de flexibilidad dietaria produce una disminución en la variabilidad de la forma (e.g. Figs. 119, 126, 133) (Holliday \& Steppan 2004). Así, quien juega un rol importante en la diversidad morfológica entonces, es la variación de tamaño (Sicuro \& Oliveira 2011), cuya causa más probable son los mecanismos para reducir el solapamiento del nicho y la presión competitiva (Morales \& Giannini 2010, Sicuro 2011). Cuando se incrementa el tamaño, la forma tiende a modificarse (Fig. 142) (Wayne 1986) y se generan cambios en escala que pueden definir la habilidad de un organismo para llevar a cabo sus actividades (Emerson \& Bramble 1993, Wainwright 1994). Por ejemplo, en la Familia Felidae el esplacnocráneo fue alométrico positivo (e.g. Tablas 44, 53), y los de mayor tamaño (como los Pantherinos) presentaron esqueletos faciales mayores (Fig. 133, Tabla 59) que los más pequeños (e.g. Figs. 83, 105, 112, Tablas 37, 47, 50) (Biknevicius \& Van Valkenburgh 1996, Slater \& Van Valkenburgh 2008, 2009). Los félidos pequeños (e.g. Figs.76, 90), al igual que los cánidos pequeños (e.g. Figs. 34, 55), cazan presas menores (Ewer 1973, Sunquist \& Sunquist 2002), mientras que los félidos de mayor masa corporal capturan presas más grandes (e.g. Figs. 126, 133), que inclusive pueden excederlos en tamaño (Meachen-Samuels \& Van Valkenburgh 2009). Las presas grandes requieren un manejo y esfuerzo diferentes para soportar el alto estrés que significa someterlas, matarlas y procesarlas (Meers 2002, Christiansen \& Adolfssen 2005). Por otro lado, los félidos son en su mayoría solitarios y matan sus presas aplicando una fuerte mordida 
especializada en la garganta (Sheldon 1992, Meachen-Samuels \& Van Valkenburgh 2009).

Los félidos que resultaron más disímiles a lo largo de todos los análisis realizados fueron Acinonyx jubatus y Panthera onca (Fig.142). A. jubatus se separó en el análisis conjunto porque presenta un domo formado por senos nasales extensos, el cual alivia la alta demanda de oxígeno producida por la alta velocidad de las carreras que realiza (Marker \& Dickman 2003, Torregrosa et al. 2010), que no está presente en ninguna de las otras especies que se analizaron. Caza presas de chicas a medianas en rápidas corridas que ocurren mayoritariamente de día (Sunquist \& Sunquist 2009). La tendencia de Panthera onca (Fig. 133), por otra parte, fue básicamente al aumento en la tasa de las medidas: HPO, AM, AZ, Acan, HH (Fig. 144, Tabla 59), y al aumento de la edad en la que se alcanza el tamaño máximo en general (Figs. 137, 149). En lo que respecta al neurocráneo, mostró un aumento en la tasa de crecimiento de la altura y el ancho de la placa occipital (HPO y AM) (Fig. 146, Tabla 59). Si bien el ancho del mastoideo presentó una propensión a la alometría negativa (Tabla 59), esto no llamó la atención porque es la tendencia típica del neurocráneo, sin embargo, la altura de la placa occipital, y en definitiva, la altura del cráneo, fue alométrica positiva (Tabla 59). Este contraste está vinculado con el gran desarrollo de las crestas sagital y caudal que muestran los adultos (Fig. 133). Éstas le permiten tener mayor área para el anclaje de los poderosos músculos masticatorios que desarrollan, los cuales están en congruencia con el tipo de captura, manejo y procesamiento de presas que tiene la especie. Son predadores oportunistas que cazan casi cualquier presa que encuentren, inclusive aquellas que pesen 3 a 4 veces su propio peso. Las matan con una mordida en la parte posterior del cráneo, y usualmente son nocturnos (Sunquist \& Sunquist 2009). Por otra parte, los hallazgos de Fagen \& Wiley (1978) que encontraron a 
Leopardus tigrinus (Fig. 105) y L. wiedii (Fig. 112) pedomórficos, basados en el gran tamaño craneano, la corta longitud del hocico y los ojos grandes, no fueron soportados con los datos de esta Tesis (Fig. 146). En el caso de ambos, sus presas son de tamaño pequeño, siendo el ítem más común los roedores, y realizando sus actividades mayoritariamente durante la noche (Sunquist \& Sunquist 2009). Es probable que estas especies sean distintas en su modo de vida, pero es importante evaluar que estas diferencias pueden tener sus raíces en distintas historias evolutivas. Por ejemplo el linaje Puma, que incluye a Acinonyx jubatus, Puma concolor y Herpailurus yagouaroundi (Apéndice XI), divergió del resto hace 6,7 millones de años (Johnson et al. 2006) según lo muestran los análisis moleculares. Es notable que P. concolor (Fig. 126) y H. yagouaroundi (Fig.119) se separaron hace 4,9 millones de años (O’Brien \& Johnson 2007), antes del gran intercambio biótico, sugiriendo que se originaron en Norteamérica y colonizaron Sudamérica ya diversificadas (Werdelin et al. 2010, Eizirik 2012). El linaje Panthera que incluye a $P$. leo, P. onca, P. pardus, P. tigris, P. uncia y Neofelis nebulosa, es el más basal de los linajes que divergió hace 10,8 millones de años (Johnson et al. 2006) y radió en el sudeste de Asia, a partir desde donde se expandieron hacia otros continentes (Werdelin et al. 2010). El ancestro de P. onca invadió Norteamérica vía Beringia hace 1,5 millones de años (Christiansen \& Harris 2009), a partir desde donde colonizó Sudamérica después del gran intercambio biótico (Eizirik 2012).

Finalmente, el linaje Ocelote (=Género Leopardus) es un clado endémico de la región Neotropical, y probablemente el resultado de una radiación autóctona posterior al gran intercambio faunístico (Eizirik 2012). La divergencia de este linaje ocurrió hace 8 millones de años atrás (Johnson et al. 2006, Werdelin et al. 2010) y se separó en las distintas especies hace aproximadamente 2,9 millones de años ( $\mathrm{O}^{\prime}$ Brien \& Johnson 2007). Es entonces importante para interpretar la morfología craneana y 
mandibular tener en cuenta el legado histórico, porque este puede habilitar, o inhabilitar a los linajes para explorar nuevas combinaciones morfológicas (Figueirido et al. 2011). 


\section{CONCLUSIONES}

Mi razón resbaló en su indiferencia,

Sus ojos tienen números de oro.

Pablo Neruda

(Del libro: Navegaciones y regresos, 1959)

$\sim 216 \sim$ 
El objetivo general de esta Tesis fue estudiar las tendencias ontogenéticas del cráneo y la mandíbula en los cánidos y félidos de la región Neotropical. Ambas Familias presentan diferentes tamaños, dietas y modos de vida, lo que hacía interesante la posterior comparación.

Para testear las hipótesis de que las trayectorias ontogenéticas del cráneo como un todo resultaban de tendencias trazables en la filogenia y derivaban de la ancestralidad común, o que existía un correlato funcional asociado al cambio de dieta, se abordó la morfología craneana con las siguientes aproximaciones y análisis:

1. Análisis cualitativo de 40-42 suturas y sincondrosis, determinado grado de fusión y cambio de tipo.

2. Análisis multivariado, a partir de 22 medidas craneanas y mandibulares.

3. Análisis de componentes principales, a partir de 38 landmarks craneales y 18 landmarks mandibulares.

4. Regresiones multivariadas entre el tamaño (tamaño de centroide logtransformado) y la forma (distancia de Procrustes).

5. Obtención del tamaño de centroide (proxi de tamaño) y distancia de Procrustes (proxi de forma), y generación de gráficos de boxplots que permitieran conocer las clases de edad en donde se detiene el crecimiento y el desarrollo.

6. Análisis de ventajas mecánicas, a partir de 5 medidas craneanas y mandibulares 7. Mapeos de intervalos de confianza, suturas y de edad de crecimiento y desarrollo definitivos 
8. Obtención de señal filogenética

Esta información fue obtenida a diferentes niveles, intra-especie, intraFamilia e inter-Familia (entre Canidae y Felidae). A continuación se detallan las conclusiones más relevantes:

-Las suturas y sincondrosis aumentan su grado de fusión conforme aumenta la edad de los individuos. Las primeras que se fusionan son las correspondientes a la placa occipital, que lo hicieron en clases de juveniles. Por otra parte, las suturas rostrales son las últimas en fusionarse, o no lo hicieron en toda la vida de los individuos. Los juveniles presentan suturas simples que se van complejizando conforme aumenta la edad y la exigencia mecánica. Para la Familia Canidae, el grado de fusión de suturas está vinculado con la dieta, de modo que las especies más carnívoras presentan mayor grado de fusión que las omnívoras. Para la Familia Felidae, la fusión de suturas está vinculada con el tamaño, de modo que las especies más grandes presentan mayor grado de fusión que las pequeñas. El único carácter que exhibió señal filogenética fue la sutura occipitointerparietalis (Oipa).

-Las medidas vinculadas al neurocráneo como: Altura de la placa occipital (HPO), ancho entre los procesos mastoideos (AM), ancho de la caja craneana (AC), ancho de la constricción postorbitaria (CPO), longitud de la órbita (LO), ancho de la bulla timpánica $(\mathrm{AB})$, altura de la bulla timpánica $(\mathrm{HB})$, longitud de la bulla timpánica (LB), escalaron negativamente, mientras que aquellas vinculadas al esplacnocráneo como: Longitud desde los cóndilos occipitales a los incisivos (LCI), ancho máximo entre los arcos zigomáticos (AZ), longitud de los nasales (LN), longitud del rostro (LR), longitud del dentario (LD), altura del proceso coronoides (HC), longitud del proceso coronoides (LC), escalaron positivamente. De todas ellas, solo mostraron 
señal filogenética el ancho entre los procesos mastoideos (AM), la longitud de los nasales (LN) y longitud de la hilera post-canina superior (LHS).

-Los juveniles mostraron cráneos redondeados, con cajas craneanas cortas, anchas y altas, hocicos cortos y anchos, paladares anchos, basicráneos breves y ensanchados, y foramen magnum más grande y ventral, órbitas y bullas más grandes y arcos zigomáticos débiles y no expandidos. Los adultos, por otra parte tuvieron cráneos elongados, con cajas craneanas estrechas y bajas, hocicos más alargados y angostos, paladares estrechos, basicráneos alargados y delgados y foramen magnum más pequeño y posterior, órbitas y bullas más pequeñas y arcos zigomáticos bien desarrollados y expandidos.

-Los juveniles mostraron mandíbulas con el cuerpo mandibular más elongado y ancho, el borde anterior de la fosa masetérica retrasado, la rama mandibular poco desarrollada y estrecha, con los 3 procesos (coronoides, condiloideo y angular) más cortos. El proceso coronoides es poco desarrollado y dirigido hacia atrás. Los adultos, exhibieron mandíbulas con el cuerpo mandibular más corto y estrecho, el borde anterior de la fosa masetérica adelantado, la rama mandibular bien desarrollada y amplia, con los 3 procesos (coronoides, condiloideo y angular) más elongados. El proceso coronoides está bien desarrollado y dirigido hacia arriba.

-En términos generales, la información morfológica vinculada a la ontogenia brindada por la mandíbula, es menor que la brindada por el cráneo. El cráneo muestra diferente tamaño y forma en los juveniles en relación a los adultos, mientras que la mandíbula se muestra más homogénea para todas las clases de edad, tanto en su tamaño como en su forma. 
-La forma cambia, vinculada al tamaño, produciendo un solapamiento entre los juveniles que es más sutil y progresivo (los de la clase J1 se solapan en sus valores extremos con los de la clase J2, pero no con las demás clases de juveniles) que el que ocurre entre las 3 clases de adultos, donde no se diferencian conspicuamente una de otra. Los ejemplares de la clase $B$, un estadio de edad en la que los individuos aun no son destetados, mostraron una trayectoria diferente de la de los juveniles y adultos en las regresiones. Esto está relacionado con el hecho de que el modo de vida y la alimentación de un individuo lactante presenta exigencias y demandas craneanas completamente diferentes a las de un joven o un adulto con una alimentación activa.

-La obtención del tamaño definitivo del cráneo y de la mandíbula fueron sincrónicos, obteniéndose siempre en clases de adultos, mientras que la obtención de la forma definitiva del cráneo y la mandíbula fueron asincrónicos, ocurriendo tanto en las clases de juveniles como en clases de adultos. Además, el tamaño y la forma del cráneo en conjunto, al igual que el tamaño y la forma de la mandíbula arribaron sincrónicamente en menos de la mitad de los casos. El único carácter que presentó señal filogenética fue el tamaño del cráneo.

-El tamaño de los músculos masticatorios se incrementó conforme aumentó la edad de los individuos, tomando valores definitivos en las clases de adultos. Sin embargo, para el resto de las ventajas mecánicas no existieron patrones generales para la obtención de un valor definitivo, ni estuvo claro que aumentaran con la edad, alcanzaron la estabilización en clases tanto de jóvenes como de adultos.

-Los cráneos y mandíbulas de juveniles y adultos de los especímenes de la Familia Canidae, tanto los Neotropicales, como los de otras regiones zoogeográficas, tuvieron la misma trayectoria, con excepción de Speothos venaticus, que mostró una $\sim 220 \sim$ 
trayectoria diferente, siendo además el más carnívoro de todos los cánidos y que puede tomar presas que lo exceden doblemente en tamaño. A diferencia del resto, los cráneos de los adultos de S. venaticus fueron cortos, anchos y macizos, con hocico corto y amplio y bullas pequeñas. Las mandíbulas tuvieron cuerpo mandibular ancho, corto y curvado. Todas estas características craneanas y mandibulares fueron parecidas a las de los juveniles de todas las especies, aunque S. venaticus no solapó sus adultos con los juveniles de ninguna de las especies restantes. Es decir, que esta separación morfológica tiene raíces en la diferenciación dietaria de los especímenes, como ocurrió con el porcentaje de fusión de suturas. -Los cráneos de juveniles y adultos de los félidos Neotropicales, y aquellos de otras regiones zoogeográficas, mostraron 2 trayectorias que separaron a las especies de mayor tamaño corporal como Acinonyx jubatus, Panthera leo, P. onca, P. pardus, $P$. tigris y Puma concolor, de las especies restantes medianas y pequeñas. Esto muestra que esta diferenciación está basada en el tamaño corporal, aunque puede involucrar también el tamaño de presas elegidas por las especies. Sin embargo, las mandíbulas se integraron completamente, sin diferenciarse por clases de edad ni por especies y tampoco por tamaño corporal.

-El hecho de que especies de 2 Familias diferentes compartan los mismos patrones generales (como los mencionados anteriormente) no significa que el producto final sea el mismo. Cánidos y félidos ocuparon lugares disímiles en el morfo-espacio, de modo tal que tuvieron 2 trayectorias completamente diferentes que no se solapan ni en juveniles ni en adultos, y esto está relacionado con el hecho de que pertenecen a clados diferentes.

-Los factores que dan forma al cráneo y a la mandíbula estuvieron vinculados a la selección natural (i.e. función), a la historia evolutiva (i.e. la filogenia), o a una serie 
de factores combinados que incluyen además a la dieta, el tamaño de presa, el tamaño corporal de los individuos y/o el modo de vida de éstos. 
VIII BIBLIOGRAFÍA

$\sim 223$ 
Abdala F., Flores D.A. \& Giannini N.P. 2001. Postweaning ontogeny of the skull of Didelphis albiventris. Journal of Mammalogy 82:190-200.

Abdala F. \& Giannini N.P. 2000. Gomphodont cynodonts of the Chañares Formation: The analysis of an ontogenetic sequence. Journal of Vertebrate Paleontology 20:501-506.

Alberch P., Gould S.J., Oster G.F. \& Wake D.B. 1979. Size and shape in ontogeny and phylogeny. Paleobiology 5:296-317.

Alvarez A. 2011. Diversidad morfológica cráneo-mandibular de roedores caviomorfos en un contexto filogenético comparativo. Tesis de: Universidad Nacional de La Plata, Facultad de Ciencias Naturales y Museo.

Andersen T. \& Wiig O. 1984. Growth of the skull of Norwegian lynx. Acta Theriologica 29:89100.

Antón M. \& Galobart A. 1999. Neck function and predatory behavior in the scimitar toothed cat Homotherium latidens (Owen). Journal of Vertebrate Paleontology 19:771-784.

Antón M., Salesa M.J., Pastor J.F., Sánchez I.M., Fraile S. \& Morales J. 2004. Implications of the mastoid anatomy of larger extant felids for the evolution and predatory behaviour of sabretoothed cats (Mammalia, Carnivora, Felidae). Zoological Journal of the Linnean Society 140:207-221.

Argot C. 2003. Functional-adaptive anatomy of the axial skeleton of some extant marsupials and the paleobiology of the Paleocene marsupials Mayulestes ferox and Pucadelphys andinus. Journal of Morphology 255:279-300.

Asa C.S. \& Cossíos E.D. 2004. Sechuran fox Pseudalopex sechurae. Pp: 69-72. En: Canids: Foxes, Wolves, Jackals and Dogs. Status Survey and Conservation Action Plan. IUCN Species Programme, Gland (Sillero-Zubiri C., Hoffmann M. \& Macdonald D.W. eds.). IUCN, Gland, Switzerland y Cambridge, Reino Unido.

Asa C.S. \& Wallace M.P. 1990. Diet and activity pattern of the Sechuran desert fox (Dusicyon sechurae). Journal of Mammalogy 71:69-72.

Austin J.J., Soubrier J., Prevosti F.J., Prates L., Trejo V., Mena F. \& Cooper A. 2013. The origins of the enigmatic Falkland Islands wolf. Nature Communications 4:1552.

Bastir M. \& Rosas A. 2004. Comparative ontogeny in humans and chimpanzees: Similarities, differences and paradoxes in postnatal growth and development of the skull. Annals of Anatomy 186:503-509.

Beisiegel B.M. \& Ades C. 2002. The Behavior of the bush dog (Speothos venaticus Lund, 1842) in the field: A review. Revista de Etología 4:17-23.

Bekoff M. \& Jamieson R. 1975. Physical development in Coyotes (canis latrans), with a comparison to other canids. Journal of Mammalogy 56:685-692.

Beltrán J.F. \& Delibes M. 1993. Physical characteristics of Iberian lynxes (Lynx pardinus) from Doñana, southwestern Spain. Journal of Mammalogy 74:852-862.

$$
\sim 224 \sim
$$


Bennett C.V. \& Goswami A. 2013. Statistical support for the hypothesis of developmental constraint in marsupial skull evolution. BMC Biology 11:1-14.

Berge C. \& Penin X. 2004. Ontogenetic allometry, heterochrony, and interspecific differences in the skull of African apes, using tridimensional procrustes analysis. American Journal of Physical Anthropology 124:124-138.

Berta A. 1982. Cerdocyon thous. Mammalian Species 186:1-4.

Berta A. 1986. Atelocynus microtis. Mammalian Species 256:1-3.

Berta A. 1987. Origin, diversification, and zoogeography of the South American Canidae. Fieldiana Zoology 39:455-471.

Biben M. 1982a. Object play and social treatment of prey in bush dogs and crab-eating foxes. Behaviour 79:201-211.

Biben M. 1982b. Ontogeny of social behaviour related to feeding in the crab-eating fox (Cerdocyon thous) and the bush dog (Speothos venaticus). Journal of Zoology 196:207-216.

Biben M. 1983. Comparative ontogeny of social behaviour in three South American canids, the maned wolf, crab-eating fox and bush dog: Implications for sociality. Animal Behaviour 31:814826.

Biknevicius A.R. 1996. Functional discrimination in the masticatory apparatus of juvenile and adult cougars (Puma concolor) and spotted hyenas (Crocuta crocuta). Canadian Journal of Zoology 74:1934-1942.

Biknevicius A.R. \& Leigh S.R. 1997. Patterns of growth of the mandibular corpus in spotted hyenas (Crocuta crocuta) and cougars (Puma concolor). Zoological Journal of the Linnean Society 120:139-161.

Biknevicius A.R. \& Van Valkenburgh B. 1996. Design for killing: Craniodental adaptations of predators. Pp. 393-428. En: Carnivore behavior, ecology, and evolution, Vol. 2. (Gittleman J.L. ed.). Cornell University Press, Nueva York.

Binder W.J. \& Van Valkenburgh B. 2000. Development of bite strength and feeding behaviour in juvenile spotted hyenas (Crocuta crocuta). Journal of Zoology 252:273-283.

Birdseye C. 1956. Observations on a domesticated Peruvian desert fox, Dusicyon. Journal of Mammalogy 37:284-287.

Blomberg S.P. \& Garland T. 2002. Tempo and mode in evolution: Phylogenetic inertia, adaptation and comparative methods. Journal of Evolutionary Biology 15:899-910.

Bookstein F.L. 1991. Morphometric tools for landmark data. Geometry and biology. Cambridge University Press, Nueva York.

Bookstein F.L. 1997a. Morphometric tools for landmark data: Geometry and biology. Cambridge University Press, Cambridge. 
Bookstein F.L. 1997b. Shape and the information in medical images: A decade of the Morphometric Synthesis. Computer Vision and Image Understanding 66:97-118.

Boughner J.C. \& Dean M.C. 2004. Does space in the jaw influence the timing of molar crown initiation? A model using baboons (Papio anubis) and great apes (Pan troglodytes, Pan paniscus). Journal of Human Evolution 46:255-277.

Brady C.A. 1978. Reproduction, growth and parental care in crab-eating foxes (Cerdocyon thous) at the National Zoological Park, Washington. International Zoo Yearbook 18:130-134.

Breton G. 2007. European studbook for the jaguarundi (Herpailurus yaguarondi). Le Parc des Félins \& EAZA, Nesles, France.

Broom R. 1949. Notes on the milk dentition of the lion, leopard and cheetah. Annals Transvaal Museum 21:183-185.

Burton R.F. 2006. A new look at the scaling of size in mammalian eyes. Journal of Zoology 269:225-232.

Buzas B. \& Gulyas E. 2012. Hand-raising jaguarundis (Puma yagouaroundi). Feline Conservation Federation 56:1-4.

Byron C.D. 2006. Role of the osteoclast in cranial suture waveform patterning. The Anatomical Record 288A:552-563.

Byron C.D., Borke J., Yu J., Pashley D., Wingard C.J. \& Hamrick M. 2004. Effects of increased muscle mass on mouse sagittal suture morphology and mechanics. The Anatomical Record 279A:676-684.

Byron C.D., Maness H., Yu J.C. \& Hamrick M.W. 2008. Enlargement of the temporalis muscle and alterations in the lateral cranial vault. Integrative and Comparative Biology 48:338-344.

Callahan P. \& Dulaney M.W. 1997. Husbandry and breeding of the Pampas cat at Cincinnati Zoo \& Botanical Garden. International Zoo Yearbook 35:100-103.

Cardini A. \& Thorington R.W. 2006. Postnatal ontogeny of marmot (Rodentia, Sciuridae) crania: Allometric trajectories and species divergence. Journal of Mammalogy 87:201-215.

Caro TM. 1994. Cheetahs of the Serengeti plains: group living in an asocial species. Chicago, IL: University of Chicago Press.

Cassini G.H. \& Vizcaíno S.F. 2012. An approach to the biomechanics of the masticatory apparatus of early Miocene (Santacrucian age) South American ungulates (Astrapotheria, Litopterna, and Notoungulata): Moment arm estimation based on 3D landmarks. Journal of Mammalian Evolution 19:9-25.

Cendekiawan T., Wong R.W.K. \& Rabie A.B.M. 2010. Relationships between cranial base synchondroses and craniofacial development: A Review. The Open Anatomy Journal 2:67-75.

Christiansen P. \& Adolfssen J.S. 2005. Bite forces, canine strength and skull allometry in carnivores (Mammalia, Carnivora). Journal of Zoology 266:133-151.

$$
\sim 226 \sim
$$


Christiansen P. \& Harris J.M. 2009. Craniomandibular morphology and phylogenetic affinities of Panthera atrox: implications for the evolution and paleobiology of the lion lineage. Journal of Vertebrate Paleontology 29:934-94.

Christiansen P. \& Wroe S. 2007. Bite forces and evolutionary adaptations to feeding ecology in carnivores. Ecology 88:347-358.

Cossíos D. 2006. Dispersión y variación de la capacidad de germinación de semillas ingeridas por el zorro costeño (Lycalopex sechurae) en el santuario histórico Bosque de Pómac, Lambayeque. Tesis de: Universidad Nacional Mayor de San Marcos, Facultad de Ciencias Biológicas.

Courtenay O., Macdonald D.W., Gillingham S., Almeida G. \& Dias R. 2006. First observations on South America's largely insectivorous canid: The hoary fox (Pseudalopex vetulus). Journal of Zoology 268:45-54.

Courtenay O. \& Maffei L. 2004. Crab-eating fox Cerdocyon thous. Pp: 32-38. En: Canids: Foxes, Wolves, Jackals and Dogs. Status Survey and Conservation Action Plan. IUCN Species Programme, Gland (Sillero-Zubiri C., Hoffmann M. \& Macdonald D.W. eds.). IUCN, Gland, Switzerland y Cambridge, Reino Unido.

Cox P.G. 2008. A quantitative analysis of the Eutherian orbit: Correlations with masticatory apparatus. Biological Review 83:35-69.

Cray J., Cooper G.M., Mooney M.P. \& Siegel M.I. 2011. Timing of ectocranial suture activity in Gorilla gorilla as related to cranial volume and dental eruption. Journal of Anatomy 218:471-479.

Crespo J.A. 1971. Ecología del zorro gris Dusicyon gymnocercus antiquus (Ameghino) en la provincia de La Pampa. Revista del Museo Argentino de Ciencias Naturales “Bernardino Rivadavia" 5:1-205.

Crespo J.A. \& De Carlo J.M. 1963. Estudio ecológico de una población de zorros colorados Dusicyon culpaeus. Revista del Museo Argentino de Ciencias Naturales "Bernardino Rivadavia" 1:155.

Crowe D.M. 1975. Aspects of ageing, growth, and reproduction of bobcats from Wyoming. Journal of Mammalogy 56:177-198.

Cruz de Oliveira G., Marques Barcellos J.F. \& Weber Rosas F.C. 2007. Age estimation in giant otters (Pteronura brasiliensis) (Carnivora: Mustelidae) using growth layer groups in canine teeth. The Latin American Journal of Aquatic Mammals 6:155-160.

Currier M.J.P. 1983. Felis concolor. Mammalian Species 200:1-7.

Dalponte J.C. 2008. Lycalopex vetulus. Mammalian Species 847:1-7.

Dalponte J. \& Courtenay O. 2004. Hoary fox Pseudalopex vetulus. Pp: 72-76. En: Canids: Foxes, Wolves, Jackals and Dogs. Status Survey and Conservation Action Plan. IUCN Species Programme, Gland (Sillero-Zubiri C., Hoffmann M. \& Macdonald D.W. eds.). IUCN, Gland, Switzerland y Cambridge, Reino Unido. 
Davis B.W., Li G. \& Murphy W.J. 2010. Supermatrix and species tree methods resolve phylogenetic relationships within the big cats, Panthera (Carnivora: Felidae). Molecular Phylogenetics and Evolution 56:64-6.

De Beer G.R. 1985. The development of the vertebrate skull. Oxford University Press, Nueva York.

Depew M.J., Lufkin T., Rubenstein J.L.R. 2002. Specification of jaw subdivisions by Dlx genes. Science 298:381.

Dietz J.M. 1985. Chrysocyon brachyurus. Mammalian Species 234:1-4.

Dillon A. 2005. Ocelot density and home range in Belize, Central America: Camera-trapping and radio telemetry. Tesis de: Faculty of the Virginia Polytechnic Institute and State University.

Drake A.G. 2011. Dispelling dog dogma: An investigation of heterochrony in dogs using 3D geometric morphometric analysis of skull shape. Evolution and Development 13:204-213.

Dryden I.L. \& Mardia K.V. 1998. Statistical shape analysis. Wiley, Chichester.

Duckler G.L. 1998. An unusual osteological formation in the posterior skulls of captive tigers (Panthera tigris). Zoo Biology 17:135-142.

Eaton R.L. \& Verlander K.A. 1977. Reproduction in the puma: Biology, behavior and ontogeny. Pp: 45-70. En: The world's cats, Vol. 3, №3 (Eaton R.L. ed.). Carnivore Research Institute, Burke Museum, University of Washington, Seattle.

Eizirik E. 2012. A Molecular view on the evolutionary history and biogeography of Neotropical carnivores (Mammalia, Carnivora). Pp: 123-142. En: Bones, Clones, and Biomes: The History and Geography of Recent Neotropical Mammals. Cap. 7. (Patterson B.D. \& Costa L.P. eds.). The University of Chicago Press, Chicago, Illinois.

Ellis J.L., Thomason J.J., Kebreab E. \& France J. 2008. Calibration of estimated biting forces in domestic canids: Comparison of post-mortem and in vivo measurements. Journal of Anatomy 212:769-780.

Emerson S.B. \& Bramble D.M. 1993. Scaling, allometry and skull design. Pp: 384-416. En: The skull (Hanken J. \& Hall B.K. eds.). The University of Chicago Press, Chicago, Illinois.

Emmons L. 1987. Comparative feeding ecology of felids in a Neotropical forest. Behavioral Ecology and Sociobiology 20:271-283.

Emmons L. 1988. A field study of ocelots (Felis pardalis) in Peru. Revue d'Ecologie: La Terre et la Vie 43:133-157.

Evans H.E. 1993. Miller's anatomy of the dog, 3rd edition. W.B. Saunders Company, Philadelphia.

Ewer R.F. 1973. The Carnivores. Cornell University Press, Ithaca. 
Fagen R.M. \& Wiley K.S. 1978. Felid paedomorphosis, with special reference to Leopardus. Carnivore 1:72-81.

Farris J.S. 1970. Methods of computing Wagner trees. Systematic Zoology 19:83-92.

Feldman H.N. 1993. Maternal care and differences in the use of nests in the domestic cat. Animal Behaviour 45:13-23.

Fiero B.C. \& Verts B.J. 1986. Comparison of techniques for estimating age in raccoons. Journal of Mammalogy 67:392-395.

Figueirido B., MacLeod N., Krieger J., De Renzi M., Pérez-Claros J.A. \& Palmqvist P. 2011. Constraint and adaptation in the evolution of carnivoran skull shape. Paleobiology 37:490-518.

Figueirido B., Serrano-Alarcón F.J., Slater G.J. y\& Palmqvist P. 2010. Shape at the cross-roads: homoplasy and history in the evolution of the carnivoran skull towards herbivory. Journal of Evolutionary Biology 23:2579-2594.

Flores D.A., Abdala F. \& Giannini N.P. 2010. Cranial ontogeny of Caluromys philander (Didelphidae: Caluromyinae): a qualitative and quantitative approach. Journal of Mammalogy 91:539-550.

Flores D.A., Abdala F. \& Giannini N.P. 2013. Post-weaning cranial ontogeny in two bandicoots (Mammalia, Peramelomorphia, Peramelidae) and comparison with carnivorous marsupials. En prensa en Zoology.

Flores D.A. \& Barone L. 2011. Cranio-facial sutures of the black-capped squirrel monkey Saimiri boliviensis (Primates: Cebidae): gross morphology and postnatal ontogeny. Mammalia 76:9198.

Flores D.A. \& Casinos A. 2011. Cranial ontogeny and sexual dimorphism in two New World monkeys: Alouatta caraya (Atelidae) and Cebus apella (Cebidae). Journal of Morphology 272:744-757.

Flores D.A., Giannini N.P. \& Abdala F. 2003. Cranial ontogeny of Lutreolina crassicaudata (Didelphidae): a comparison with Didelphis albiventris. Acta Theriologica 48:1-9.

Flores D.A., Giannini N.P. \& Abdala F. 2006.Comparative postnatal ontogeny of the skull in an Australidelphian Metatherian, Dasyurus albopunctatus (Marsupialia: Dasyuromorpha: Dasyuridae). Journal of Morphology 267:426-440.

Flower W.H. 1869. On the value of the characters of the base of the cranium in the classification of the order Carnivora, and on the systematic position of Bassaris and other disputed forms. Proceedings of the Zoological Society of London 4-37.

Fondon J.W. \& Garner H.R. 2004. Molecular origins of rapid and continuous morphological evolution. PNAS USA 1010:18058-18063.

Foreman G.E. 1997. Breeding and maternal behaviour in Geoffroy's cats Oncifelis geoffroyi. International Zoo Yearbook 35:104-115.

Fox M.W. 1969. Ontogeny of prey-killing behavior in Canidae. Behaviour 35:259-272.

$$
\sim 229 \sim
$$


Frazzetta T.H. 1988. The mechanics of cutting and the form of shark teeth (Chondrichthyes, Elasmobranchii). Zoomorphology 108:93-107.

Freer R.A. 2004. The spatial ecology of the güiña (Oncifelis guigna) in Southern Chile. Tesis de: Department of Biological Sciences, University of Durham, Reino Unido.

Fuller T.K. \& Cypher B.L. 2004. Gray fox Urocyon cinereoargenteus. Pp: 92-97. En: Canids: Foxes, Wolves, Jackals and Dogs. Status Survey and Conservation Action Plan. IUCN Species Programme, Gland (Sillero-Zubiri C., Hoffmann M. \& Macdonald D.W. eds.). IUCN, Gland, Switzerland y Cambridge, Reino Unido.

Galatius A., Berta A., Schou Frandsen M. \& Goodall R.N.P. 2011. Interspecific variation of ontogeny and skull shape among porpoises (Phocoenidae). Journal of Morphology 272:136-148.

García-Morales P., Buschang P.H. \& Throckmorton G.S. 2003. Maximum bite force, muscle efficiency and mechanical advantage in children with vertical growth patterns. European Journal of Orthodontics 25:265-272.

García-Perea R. 1991. Variabilidad morfológica del género Lynx Kerr, 1792 (Carnivora: Felidae). Tesis de: Universidad Complutense, Madrid, España.

García-Perea R. 1994. The pampas cat group (genus Lynchailurus Severtzov, 1858) (Carnivora: Felidae), a systematic and biogeographic review. American Museum Novitates 3096:1-35.

García-Perea R. 1996. Patterns of postnatal development in skull of lynxes, Genus Lynx (Mammalia: Carnivora). Journal of Morphology 229:241-254.

García-Perea R. \& Baquero R.A. 1999. Age estimation in Iberian wildcats Felis silvestris, by canine tooth sections. Acta Theriologica 44:321-327.

Gardner A.L. 1973. The systematics of the genus Didelphis (Marsupialia: Didelphidae) in North and Middle America. Special Publications. The Museum Texas Tech University 4:1-81.

Garshelis D.L. 1984. Age estimation of living sea otters. The Journal of Wildlife Management 48:456-463.

Garshelis D.L. 2009. Family Ursidae. Pp: 448-497. En: Handbook of the mammals of the world, Vol. 1. Carnivores (Wilson D.E. \& Mittermeier R.A. eds.). Lynx Editions, Barcelona.

Gay S.W. \& Best T.L. 1995. Geographic variation in sexual dimorphism of the puma (Puma concolor) in North and South America. The Southwestern Naturalist 40:148-159.

Gay S.W. \& Best T.L. 1996. Age-related variation in skulls of the puma (Puma concolor). Journal of Mammalogy 77:191-198.

German R.Z. \& Crompton A.W. 1996. Ontogeny of suckling mechanisms in Opossums (Didelphis virginiana). Brain, Behavior and Evolution 48:157-164.

German R.Z., Crompton A.W., Levitch L.C. \& Thexton A.J. 1992. The mechanism of suckling in two species of infant mammal: Miniature pigs and long-tailed macaques. The Journal of Experimental Zoology 261:322-330.

$$
\sim 230 \sim
$$


Giannini N.P., Abdala F. \& Flores D.A. 2004.Comparative postnatal ontogeny of the skull in Dromiciops gliroides (Marsupialia: Microbiotheriidae). American Museum Novitates 3460:1-17.

Giannini N.P., Segura V., Giannini M.I. \& Flores D.A. 2010. A quantitative approach to the cranial ontogeny of the puma. Mammalian Biology 75:547-554.

Gilbert S.G. 1997. Pictorial anatomy of the cat. University of Washington Press, Seattle.

Gittleman J.L. 1986. Carnivore brain size, behavioral ecology, and phylogeny. Journal of Mammalogy 67:23-36.

Goloboff P., Farris J.S. \& Nixon K. 2008. T.N.T. Tree Analysis Using New Technology. Version 1.1. Program and documentation. Disponible en: www.zmuc.dk/public/phylogeny.

Goloboff P.A., Mattoni C.I. \& Quinteros A.S. 2006. Continuous characters analyzed as such. Cladistics 22:589-601.

González del Solar R. \& Rau J. 2004. Chilla Pseudalopex griseus. Pp: 56-63. En: Canids: Foxes, Wolves, Jackals and Dogs. Status Survey and Conservation Action Plan. IUCN Species Programme, Gland (Sillero-Zubiri C., Hoffmann M. \& Macdonald D.W. eds.). IUCN, Gland, Switzerland y Cambridge, Reino Unido.

Goodall C. 1991. Procrustes methods in the statistical analysis of shape. Journal of the Royal Statistical Society 53:285-339.

Gordon K.R. \& Herring S.W. 1987. Activity patterns within the genioglossus during suckling in domestic dogs and pigs: Interspecific and intraspecific plasticity. Brain, Behavior and Evolution 30:249-262.

Goswami A. 2006. Morphological integration in the Carnivoran skull. Evolution 60:169-183.

Goswami A. 2007. Cranial modularity and sequence heterochrony in mammals. Evolution \& Development 9:290-298.

Goswami A. 2010. Introduction to Carnivora. Pp: 1-24. En: Carnivoran Evolution: New views on Phylogeny, Form and Function. (Goswami A. \& Friscia A. eds.). Cambridge University Press.

Goswami A., Foley L. \& Weisbecker V. 2013. Patterns and implications of extensive heterochrony in carnivoran cranial suture closure. Journal of Evolutionary Biology doi: 10.1111/jeb.12127.

Goswami A., Milne N. \& Wroe S. 2010. Biting through constraints: Cranial morphology, disparity and convergence across living and fossil carnivorous mammals. Proceedings of the Royal Society 278:1831-1839.

Goswami A. \& Polly P.D. 2010. The influence of modularity on cranial morphological disparity in Carnivora and Primates (Mammalia). PLoS ONE 5:e9517.

Green R. 1991. Wild cat species of the world. Basset publications, Plymouth, Reino Unido. 
Habegger M.L., Motta P.J., Huber D.R. \& Deban S.M. 2011. Feeding biomechanics in the Great Barracuda during ontogeny. Journal of Zoology 283:63-72.

Hammer Ø., Harper D.A.T. \& Ryan P.D. 2001. PAST: Paleontological statistics software package for education and data analysis. Palaeontologia Electronica 4:1-9. Disponible en: http://palaeo-electronica.org/2001_1/past/past.pdf

Hammock J. 2005. Structure, function and context: The impact of morphometry and ecology on olfactory sensitivity. Tesis de: Massachusetts Institute of Technology and Woods Hole Oceanographic Institution.

Hattori K., Burdin A.M., Suzuki M. \& Ohtaishi N. 2003. Age-related change and allometry of skull and canine of sea otters, Enhydra lutris. Journal of Veterinary Medical Science 65:439-447.

Helm J.W. \& German R.Z. 1996. The epigenetic impact of weaning on craniofacial morphology during growth. The Journal of Experimental Zoology 276:243-253.

Hemmer H. 1979. Gestation period and postnatal development in felids. Carnivore 2:90-100.

Herrel A. \& Gibb A.C. 2006. Ontogeny of performance in vertebrates. Physiological and Biochemical Zoology 79:1-6.

Herrel A. \& O'Reilly J.C. 2006. Ontogenetic scaling of bite force in lizards and turtles. Physiological and Biochemical Zoology 79:31-42.

Herring S.W. 1993. Formation of the vertebrate face: Epigenetic and functional influences. American Zoologist 33:472-483.

Herring S.W, Rafferty K.L., Liu Z.J. \& Marshall C.D. 2001. Jaw muscles and the skull in mammals: the biomechanics of mastication. Comparative Biochemistry and Physiology 131:207-219.

Herring S.W. \& Teng S. 2000. Strain in the braincase and its sutures during function. American Journal of Physical Anthropology 112:575-593.

Hildebrand M. 1995. Analysis of vertebrate structure. John Wiley \& Sons, Estados Unidos.

Holliday J.A. \& Steppan S.J. 2004. Evolution of hypercarnivory: The effect of specialization on morphological and taxonomic diversity. Paleobiology 30:108-128.

Holm S. 1979. A simple sequentially rejective multiple test procedure. Scandinavian Journal of Statistics 6:65-70.

Howland H.C., Merola S. \& Basarab J.R. 2004. The allometry and scaling of the size of vertebrate eyes. Vision Research 44:2043-2065.

Hoyte D.A.N. 1971. Mechanisms of growth in the cranial vault and base. Journal of Dental Research 50:1447-1461.

Huang G.T., Rosowski J.J. \& Peake W.T. 2000. Relating middle-ear acoustic performance to body size in the cat family: Measurements and models. Journal of Comparative Physiology 186:447465.

$$
\sim 232 \sim
$$


Huang G.T., Rosowski J.J., Ravicz M.E. \& Peake W.T. 2002. Mammalian ear specializations in arid habitats: structural and functional evidence from sand cat (Felis margarita). Journal of Comparative Physiology 188:663-681.

Hulley J.T. 1976. Maintenance and breeding of captive jaguarondis Felis yagouaroundi at Chester Zoo and Toronto. International Zoo Yearbook 16:120-122.

Hunt R.M. 1974. The auditory bulla in Carnivora: An anatomical basis for reappraisal of carnivore evolution. Journal of Morphology 143:21-75.

Inada M., Yasui T., Nomura S., Miyake S., Deguchi K., Himeno M., Sato M., Yamagiwa H., Kimura T., Yasui N., Ochi T., Endo N., Kitamura Y., Kishimoto T. \& Komori T. 1999. Maturational disturbance of chondrocytes in Cbfa1-deficient mice. Developmental Dynamics 214:279-290.

Iriarte J.A., Franklin W.L., Johnson W.E. \& Redford K.E. 1990. Biogeographic variation of food habits and body size of the American puma. Oecologia 85:185-190.

Ivanoff D.V. 2000. Origin of the septum in the canid auditory bulla: Evidence from morphogenesis. Acta Theriologica 45:253-270.

Ivanoff D.V. 2001. Partitions in the carnivoran auditory bulla: Their formation and significance for systematic. Mammal Review 31:1-16.

Jackson D.L., Gluesing E.A. \& Jacobson H.A. 1988. Dental eruption in bobcats. The Journal of Wildlife Management 52:515-517.

Jantschke F. 1973. On the breeding and rearing of bush dogs Speothos venaticus at Frankfurt Zoo. International Zoo Yearbook 13:141-143.

Jaslow C.R. 1990. Mechanical properties of cranial sutures. Journal of Biomechanics 23:313321.

Jeffery N. \& Spoor F. 2002. Brain size and the human cranial base: A prenatal perspective. American Journal of Physical Anthropology 118:324-340.

Jeffery N. \& Spoor F. 2004. Ossification and midline shape changes of the human fetal cranial base. American Journal of Physical Anthropology 123:78-90.

Jiang X., Iseki S., Maxson R.E., Sucov H.M. \& Morriss-Kay G.M. 2002. Tissue origins and interactions in the mammalian skull vault. Developmental Biology 241:106-116.

Jiménez J.E. \& McMahon E. 2004. Darwin's fox Pseudalopex fulvipes. Pp: 50-55. En: Canids: Foxes, Wolves, Jackals and Dogs. Status Survey and Conservation Action Plan. IUCN Species Programme, Gland, (Sillero-Zubiri C., Hoffmann M. \& Macdonald D.W. eds.). IUCN, Gland, Switzerland y Cambridge, Reino Unido.

Jiménez J.E. \& Novaro A.J. 2004. Culpeo Pseudalopex culpaeus. Pp: 44-49. En: Canids: Foxes, Wolves, Jackals and Dogs. Status Survey and Conservation Action Plan. IUCN Species Programme, Gland, (Sillero-Zubiri C., Hoffmann M. \& Macdonald D.W. eds.). IUCN, Gland, Switzerland y Cambridge, Reino Unido. 
Johnson N.F., Brown B.A. \& Bosomworth J.C. 1981. Age and sex characteristics of bobcat canines and their use in population assessment. Wildlife Society Bulletin 9:203-206.

Johnson W.E. \& Franklin W.L. 1994. Role of body size in the diets of sympatric gray and culpeo foxes. Journal of Mammalogy 75:163-174.

Johnson W.E., Eizirik E., Pecon-Slattery J., Murphy W.J., Antunes A., Teeling E. \& O’Brien S.J. 2006. The late Miocene radiation of modern Felidae: A genetic assessment. Science 311:73-77.

Johnson W.E., Pecon Slattery J., Eizirik E., Kim J., Raymond M.M., Bonacic C., Cambre R., Crawshaw P., Nunes A., Seuánez H.N., Martins Moreira M.A., Seymour K.L., Simon F., Swanson W. \& O'Brien S.J. 1999. Disparate phylogeographic patterns of molecular genetic variation in four closely related South American small cat species. Molecular Ecology 8:S79-S94.

Jolicoeur P.1963a. The multivariate generalization of the allometry equation. Biometrics 19:497-499.

Jolicoeur P. 1963b. The degree of generality of robustness in Martes americana. Growth 27:127.

Jones K.E. \& Goswami A. 2010. Quantitative analysis of the influences of phylogeny and ecology on phocid and otariid pinniped (Mammalia; Carnivora) cranial morphology. Journal of Zoology 280:297-308.

Kavanagh K.D., Evans A.R. \& Jernvall J. 2007. Predicting evolutionary patterns of mammalian teeth from development. Nature 449:427-433.

Kiltie R.A. 2000. Scaling of visual acuity with body size in mammals and birds. Functional Ecology 14:226-234.

Kitchener A. 1991. The natural history of the wild cats. Cornell University Press, Ithaca.

Kitchener A.C., Van Valkenburgh B. \& Yamaguchi N. 2010. Felid form and function. Pp: 83106. En: Biology and Conservation of Wild Felids. Cap. 3. (MacDonald D.W \& Loveridge A.J. eds.). Oxford University Press, Nueva York.

Kitching I.J., Forey P.L., Humphries C.J. \& Williams D.M. 1998. Cladistics. The theory and practice of Parsimony analysis. Oxford University Press, Nueva York.

Kleiman D.G. \& Eisenberg J.F. 1973. Comparisons of canid and felid social systems from an evolutionary perspective. Animal Behaviour 21:637-659.

Klingenberg C.P. 1998. Heterochrony and allometry: The analysis of evolutionary change in ontogeny. Biological Review 73:79-123.

Klingenberg CP. 2011. MorphoJ: An integrated software package for geometric morphometrics. Molecular Ecology Resources 11:353-357.

Komori T. 2002. RUNX2, a multifunctional transcription factor in skeletal development. Journal of Cellular Biochemistry 87:1-8. 
Kremenak C.R. 1969. Dental eruption chronology in dogs: Deciduous tooth gingival emergence. Journal of Dental Research 1177-1184.

Kremenak C.R., Russell L.S. \& Christensen R.D. 1969. Tooth-eruption ages in suckling dogs as affected by local heating. Journal of Dental Research 427-430.

Kritzman E.B. \& Dudley J.C. 1986. Skull morphometry of Western Washington bobcats (Felis rufus fasciatus). Actas of 66th Annual Meeting of American Society of Mammalogists. University of Wisconsin.

Kvam T. 1982. Age determination in European lynx (Lynx lynx lynx, L.) based on cranial development. Fauna Norvergica (Ser A) 4:31-36.

La Croix S., Holekamp K.E., Shivik J.A., Lundrigan B.L. \& Zelditch M.L. 2011a. Ontogenetic relationships between cranium and mandible in coyotes and hyenas. Journal of Morphology 272:662-674.

La Croix S., Zelditch M.L., Shivik J.A., Lundrigan B.L. \& Holekamp K.E. 2011b. Ontogeny of feeding performance and biomechanics in coyotes. Journal of Zoology 285:301-315.

Laack L.L. 1991. Ecology of the ocelot (Felis pardalis) in south Texas. Tesis de: Texas A\&I University, Kingsville, Texas.

Laack L.L., Tewes M.E., Haines A.M. \& Rappole J.H. 2005. Reproductive life history of ocelots Leopardus pardalis in southern Texas. Acta Theriologica 50:505-514.

Landon D.B., Waite C.A., Peterson R.O. \& Mech L.D. 1998. Evaluation of age determination techniques for gray wolves. The Journal of Wildlife Management 62:674-682.

Langer P. 2003. Lactation, weaning period, food quality, and digestive tract differentiations in Eutheria. Evolution 57:1196-1215.

Larivière S. 2002. Vulpes zerda. Mammalian Species 714:1-5.

Laundré J.W., Hernandez L., Streubel D., Altendorf K. \& Gonzalez C.L. 2000. Aging mountain lions using gum-line recession. Wildlife Society Bulletin 28:963-966.

Laurin M. 2004. The evolution of body size, Cope's rule and the origin of Amniotes. Systematic Biology 53:594-622.

Lawson M.J., Craven B.A., Paterson E.G. \& Settles G.S. 2012. A computational study of odorant transport and deposition in the canine nasal cavity: Implications for olfaction. Chemical Senses 37:553-566.

Leite Pitman M.R.P. \& Williams R.S.R. 2004. Short-eared dog Atelocynus microtis. Pp: 26-31. En: Canids: Foxes, Wolves, Jackals and Dogs. Status Survey and Conservation Action Plan. IUCN Species Programme, Gland, (Sillero-Zubiri C., Hoffmann M. y Macdonald D.W. eds.). IUCN, Gland, Switzerland y Cambridge, Reino Unido.

Levangie P.K. \& Norkin C.C. 2005. Joint structure and function: A comprehensive analysis. F.A. Davis Company.

$$
\sim 235 \sim
$$


Leyhausen P. 1979. Cat behavior: The predatory and social behavior of domestic and wild cats. Garland STPM Press. Nueva York \& Londres.

Leyhausen P. \& Falkena M. 1966. Breeding the Brazilian ocelot-cat Leopardus tigrinus in captivity. International Zoo Yearbook 6:176-178.

Lieberman D.E., Hallgrímsson B., Liu W., Parsons T.E. \& Jamniczky H.A. 2008. Spatial packing, cranial base angulation, and craniofacial shape variation in the mammalian skull: Testing a new model using mice. Journal of Anatomy 212:720-735.

Lieberman D.E., Pearson O.M. \& Mowbray K.M. 2000a. Basicranial influence on overall cranial shape. Journal of Human Evolution 38:291-315.

Lieberman D.E., Ross C.F. \& Ravosa M.J. 2000b. The primate cranial base: Ontogeny, function, and integration. Yearbook of Physical Anthropology 43:117-169.

Lindblad-Toh K., Wade C.M., Mikkelsen T.S., Karlsson E.K., Jaffe D.B., Kamal M., Clamp M., Chang J.L., Kulbokas E.J., Zody M.C., Mauceli E., Xie X., Breen M., Wayne R.K., Ostrander E.A., Ponting C.P., Galibert F., Smith D.R., deJong P.J., Kirkness E., Alvarez P., Biagi T., Brockman W., Butler J., Chin C., Cook A., Cuff J., Daly M.J., DeCaprio D., Gnerre S., Grabherr M., Kellis M., Kleber M., Bardeleben C., Goodstadt L., Heger A., Hitte C., Kim L., Koepfli K., Parker H.G., Pollinger J.P., Searle S.M.J., Sutter N.B., Thomas R., Webber C., Broad Institute Genome Sequencing Platform \& Lander E.S. 2005. Genome sequence, comparative analysis and haplotype structure of the domestic dog. Nature 438:803-819.

Losos J.B. \& Miles D.B. 2002. Testing the hypothesis that a clade has adaptively radiated: Iguanid lizard clades as a case study. The American Naturalist 160:147-157.

Lucherini M. \& Luengos Vidal E.M. 2008. Lycalopex gymnocercus (Carnivora: Canidae). Mammalian Species 820:1-9.

Lucherini M., Manfredi C., Luengos E., Dias Mazim F., Soler L. \& Casanave E. 2006. Body mass variation in the Geoffroy's cat (Oncifelis geoffroyi). Revista Chilena de Historia Natural 79:169174.

Lucherini M., Pessino M. \& Farias A.A. 2004a. Pampas fox Pseudalopex gymnocercus. Pp: 63-68. En: Canids: Foxes, Wolves, Jackals and Dogs. Status Survey and Conservation Action Plan. IUCN Species Programme, Gland, (Sillero-Zubiri C., Hoffmann M. y Macdonald D.W. eds.). IUCN, Gland, Switzerland y Cambridge, Reino Unido.

Lucherini M., Soler L. \& Luengos Vidal E.M. 2004b. A preliminary revision of knowledge status of felids in Argentina. Mastozoología Neotropical 11:7-17.

Manly B.F.J. 1997. Randomization, bootstrap, and Monte Carlo methods in biology. Chapman \& Hall, Nueva York.

Mao J.J. 2002. Mechanobiology of craniofacial sutures. Journal of Dental Research 81:810-816.

Mao J.J., Wang X. \& Kopher R.A. 2003. Biomechanics of craniofacial sutures: Orthopedic implications. Angle Orthodontist 73:128-135.

$$
\sim 236 \sim
$$


Margulies S.S. \& Thibault K.L. 2000. Infant skull and suture properties: Measurements and implications for mechanisms of pediatric brain injury. Transactions of the ASME 122:364-371.

Marker L.L. \& Dickman A.J. 2003. Morphology, physical condition, and growth of the cheetah (Acinonyx jubatus jubatus). Journal of Mammalogy 84:840-850.

Marroig G., De Vivo M. \& Cheverud J.M. 2004. Cranial evolution in Sakis (Pithecia, Platyrrhini) II: evolutionary processes and morphological integration. Journal of Evolutionary Biology 17:144-155.

Martin L.D. 1996. Fossil history of the terrestrial Carnivora. Pp.: 536-568. En: Carnivore behavior, ecology, and evolution, Vol 1. (Gittleman J.L. ed.). Cornell University press, Nueva York.

Mattern M.Y. \& McLennan D.A. 2000. Phylogeny and speciation of felids. Cladistics 16:232253.

Mazák V. 1981. Panthera tigris. Mammalian Species 152:1-8.

McBratney-Owen B., Iseki S., Bamforth S.D., Olsen B.R. \& Morriss-Kay G.M. 2008. Development and tissue origins of the mammalian cranial base. Developmental Biology 322:121132.

McKinney M.L. \& McNamara K.J. 1991. Heterochrony: The evolution of ontogeny. Plenum Press, Nueva York.

McLaughlin E., Zhang Y., Pashley D., Borke J. \& Yu J. 2000. The load-displacement characteristics of neonatal rat cranial sutures. Cleft Palate-Craniofacial Journal 37:590-595.

McNamara K.J. 1986. A guide to the nomenclature of heterochrony. Journal of Paleontology 60:4-13.

McNamara KJ. 2012. Heterochrony: The evolution of development. Evolution: Education and Outreach 5:203-218.

Meachen-Samuels J. \& Van Valkenburgh B. 2009. Craniodental indicators of prey size preference in the Felidae. Biological Journal of the Linnean Society 96:784-799.

Mech L.D. 1974. Canis lupus. Mammalian Species 37:1-6.

Meers M.B. 2002. Maximum bite force and prey size of Tyrannosaurus rex and their relationships to the inference of feeding behavior. Historical Biology: An International Journal of Paleobiology 16:1-12.

Meiri S., Dayan T. \& Simberloff D. 2005. Variability and correlations in carnivore crania and dentition. Functional Ecology 19:337-343.

Meloro C. \& O'Higgins P. 2011. Ecological adaptations of mandibular form in fissiped Carnivora. Journal of Mammalian Evolution 18:185-200.

Meloro C. \& Raia P. 2010. Cats and dogs down the tree: The tempo and mode of evolution in the lower carnassial of fossil and living Carnivora. Evolutionary Biology 37:177-186.

$$
\sim 237 \sim
$$


Meloro C., Raia P., Piras P., Barbera C. \& O'Higgins P. 2008. The shape of the mandibular corpus in large fissiped carnivores: Allometry, function and phylogeny. Zoological Journal of the Linnean Society 154:832-845.

Michejda M. 1972. The role of basicranial synchondroses in flexure processes and ontogenetic development of the skull base. American Journal of Physical Anthropology 37:143-150.

Mitteroecker P., Gunz P., Bernhard M., Schaefer K. \& Bookstein F.L. 2004. Comparison of cranial ontogenetic trajectories among great apes and humans.

Moazen M., Curtis N., O’Higgins P., Jones M.E.H., Evans S.E. \& Fagan M.J. 2009. Assessment of the role of sutures in a lizard skull: A computer modelling study. Proceedings of Royal Society of London 276:39-46.

Moehlman P.D. 1996. Intraspecific variation in canid social system. Pp.: 143-163. En: Carnivore behavior, ecology, and evolution, Vol 1. (Gittleman J.L. ed.). Cornell University press, Nueva York.

Moore W.J. 1981. The mammalian skull. Cambridge University Press, Cambridge.

Morales M.M. \& Giannini N.P. 2010. Morphofunctional patterns in Neotropical felids: Species co-existence and historical assembly. Biological Journal of the Linnean Society 100:711-724.

Morris-Kay G.M. 2001. Derivation of the mammalian skull vault. Journal of Anatomy 199:143-151.

Münkemüller T., Lavergne S., Bzeznik B., Dray S., Jombart T., Schiffers K. \& Thuiller W. 2012. How to measure and test phylogenetic signal. Methods in Ecology and Evolution 3:743-756.

Murray J.L \& Gardner G.L. 1997. Leopardus pardalis. Mammalian Species 548:1-10.

Nakahara K., Utsuki S., Shimizu S., Iida H., Miyasaka Y., Takagi H., Oka H. \& Fujii K. 2006. Age dependence of fusion of primary occipital sutures: A radiographic study Child's Nervous System 22:1457-1459.

Nakanishi N., Ichinose F., Higa G. \& Izawa M. 2009. Age determination of the Iriomote cat by using cementum annuli. Journal of Zoology 279:338-348.

Nicolay C.W. \& Vaders M.J. 2006. Cranial suture complexity in white-tailed deer (Odocoileus virginianus). Journal of Morphology 267:841-849.

Niklas K.J. 1994. Plant allometry. The scaling of form and process. The University of Chicago Press, Chicago, Illinois.

Novaro A.J. 1997. Pseudalopex culpaeus. Mammalian Species 558:1-8.

Nowak R.M. 2005. Walker's Carnivores of the world. The John Hopkins University Press, Baltimore, Londres.

Nowell K. \& Jackson P. 1996. Status survey and conservation action plan Wild Cats. IUCN/SSC Cat Specialist Group.

$$
\sim 238 \sim
$$


O’Brien S.J. \& Johnson W.E. 2007. The evolution of cats. Scientific American 68-75.

O'Higgins P. \& Jones N. 2006. Tools for statistical shape analysis. Hull York Medical School, North Yorkshire.

O'Regan H.J. \& Kitchener A.C. 2005. The effects of captivity on the morphology of captive, domesticated and feral mammals. Mammal Review 35:215-230.

Oliveira T. 1993. Neotropical cats. Ecology and conservation. Edufma, São Luis, Brasil.

Oliveira T. 1998a. Herpailurus yagouaroundi. Mammalian Species 578:1-6.

Oliveira T. 1998b. Leopardus wiedii. Mammalian Species 579:1-6.

Opperman L.A. 2000. Cranial sutures as intramembranous bone growth sites. Developmental Dynamics 219:472-485.

Pereira J.A. 2010. Activity pattern of Geoffroy's cats (Leopardus geoffroyi) during a period of food shortage. Journal of Arid Environments 74:1106-1109.

Perini F.A., Russo C.A.M \& Schrago C.G. 2010. The evolution of South American endemic canids: A history of rapid diversification and morphological parallelism. Journal of Evolutionary Biology 23:311-322.

Petersen M.K. \& Petersen M.K. 1978. Growth rate and other postnatal developmental changes in margays. Carnivore 1:87-92.

Pierce B.M. \& Bleich V.C. 2003. Mountain lion. Pp: 744-757. En: Wild Mammals of North America (Feldhamer G.A., Thompson B.C. \& Chapman J.A. eds.). The Johns Hopkins Press, Baltimore.

Pointer M.A., Kamilar J.M., Warmuth V., Chester S.G.B., Delsuc F., Mundy N.I., Asher R.J. \& Bradley B.J. 2012. RUNX2 tandem repeats and the evolution of facial length in placental mammals. BMC Evolutionary Biology 12:1471-2148.

Pond C.M. 1977. The significance of lactation in the evolution of mammals. Evolution 31:177199.

Popowics T.E. \& Herring S.W. 2007. Load transmission in the nasofrontal suture of the pig, Sus scrofa. Journal of Biomechanics 40:837-844.

Prestrud P. \& Nilssen K. 1995. Growth, size, and sexual dimorphism in Arctic foxes. Journal of Mammalogy 76:522-530.

Prevosti F.J. 2006. Grandes cánidos (Carnivora, Canidae) del Cuaternario de la República Argentina: Sistemática, filogenia, bioestratigrafía y paleoecología. Tesis de: Universidad Nacional de La Plata, Facultad de Ciencias Naturales y Museo. La Plata, Buenos Aires.

Prevosti F.J. 2009a. Phylogeny of the large extinct South American Canids (Mammalia, Carnivora, Canidae) using a "total evidence" approach. Cladistics 25:1-26. 
Prevosti F.J. 2009b. Reseña de "Handbook of the Mammals of the World. 1. Carnivora" de D. E. Wilson y R. A. Mittermeier (edits.). Mastozoología Neotropical 16:527-528

Prevosti F.J. \& Lamas L. 2006. Variation of cranial and dental measurements and dental correlations in the pampean fox (Dusicyon gymnocercus). Journal of Zoology 270:636-649.

Prevosti F.J. \& Rincón A.D. 2007. A new fossil canid assemblage from the Late Pleistocene of northern South America: The canids of the Inciarte asphalt pit (Zulia, Venezuela), fossil record and biogeography. Journal of Paleontology 81:1053-1065.

Prevosti F.J. \& Soibelzon L.H. 2012. Evolution of the South American Carnivores (Mammalia, Carnivora) A Paleontological Perspective. Pp: 102-122. En: Bones, Clones, and Biomes: The History and Geography of Recent Neotropical Mammals. Chapter 6. The University of Chicago press. Chicago, IL, Estados Unidos.

Prevosti F. J., Turazzini G.F. \& Chemisquy M.A. 2010. Morfología craneana en tigres dientes de sable: alometría, función y filogenia. Ameghiniana 47:239-256.

Prevosti F.J., Turazzini G.F., Ercoli M.D. \& Hingst-Zaher E. 2012. Mandible shape in marsupial and placental carnivorous mammals: a morphological comparative study using geometric morphometrics. Zoological Journal of the Linnean Society 164:836-855.

Pucciarelli H.M. \& Dressino V. 1996. Orthocephalization in the postweaning squirrel monkey. American Journal of Physical Anthropology 101:173-181.

Quenouille M.H. 1956. Notes on bias in estimation. Biometrika 43:353-360.

Quillen P. 1981. Hand-rearing the little spotted cat or oncilla. International Zoo Yearbook 21:240-242.

R Development Core Team. 2004. R: A language and environment for statistical computing. R Foundation forStatistical Computing, Vienna. Disponible en: http://www. rproject.org

Radinsky L.B. 1981a. Evolution of skull shape in carnivores. 1. Representative modern carnivores. Biological Journal of the Linnean Society 15:369-388.

Radinsky L. 1981b. Evolution of skull shape in carnivores. 2. Additional modern carnivores. Biological Journal of the Linnean Society 16:337-355.

Rafferty K.L. \& Herring S.W. 1999. Craniofacial sutures: Morphology, growth, and in vivo masticatory strains. Journal of Morphology 242:167-179.

Rayfield E.J. 2005. Using Finite-Element Analysis to Investigate Suture Morphology: A Case Study Using Large Carnivorous Dinosaurs. The Anatomical Record 283A:349-365.

Reddy D.P., Kim J. \& Raaum Y.R. 2007. Resample.exe. Disponible en: http://pages.nycep.org/nmg/programs.html.

Redford K.H. \& Eisenberg J.F. 1992. Mammals of the Neotropics: The Southern Cone, Vol. 2 Chile, Argentina, Uruguay, Paraguay. The University Chicago Press, Chicago, IL, Estados Unidos. 
Reilly S.M., Wiley E.O. \& Meinhardt D.J. 1997. An integrative approach to heterochrony: The distinction between interspecific and intraspecific phenomena. Biological Journal of the Linnean Society 60:119-143.

Rice D.P. 2008. Craniofacial sutures development, disease and treatment. Frontiers of Oral Biology Vol. 12. Karger, Basel Suiza.

Richards G.D. \& Jabbour R.S. 2011. Foramen magnum ontogeny in Homo sapiens: A functional matrix perspective. The Anatomical Record 294:199-216.

Richmond F.J.R., Thomson D.B \& Loeb G.E. 1992. Electromyographic studies of neck muscles in the intact cat. Experimental Brain Research 88:41-58.

Rohen J.W. \& Lutjen-Drecoll E. 2007. Embriología funcional: Una perspectiva desde la biología del desarrollo. Editorial Médica Panamericana, Buenos Aires, Argentina.

Rohlf F.J. 1999. Shape statistics: Procrustes method for the optimal superimposition of landmarks. Systematic Zoology 39:40-59.

Rohlf F.J. \& Marcus L.F. 1993. A revolution in morphometrics. Trends in Ecology and Evolution 8:129-132.

Root D.A. \& Payne N.F. 1984. Evaluation of techniques for aging gray fox. The Journal of Wildlife Management 48:926-933.

Sakamoto M. \& Ruta M. 2012. Convergence and divergence in the evolution of cat skulls: Temporal and spatial patterns of morphological diversity. PlosOne 7:1-13.

Santymire R.M., Wisely S.M., Livieri T.M. \& Howard J. 2012. Using canine width to determine age in the black-footed ferret Mustela nigripes. Small Carnivore Conservation 46:17-21.

Saunders J.K. 1961. The biology of the Newfoundland lynx. Tesis de: Cornell University, Ithaca, Nueva York.

Scheffel W. \& Hemmer H. 1975. Breeding Geoffroy's cat Leopardus geoffroyi salinarum in captivity. International Zoo Yearbook 15:152-154.

Schoenebeck J.J. \& Ostrander E.A. 2013. The Genetics of Canine Skull Shape Variation. Genetics 193:317-325.

Sears K.E., Goswami A., Flynn J.J. \& Niswandera L.A. 2007. The correlated evolution of Runx2 tandem repeats, transcriptional activity, and facial length in Carnivora. Evolution \& Development 9:555-565.

Segura V. 2013. Skull ontogeny of Lycalopex culpaeus (Carnivora: Canidae): Description of cranial traits and craniofacial sutures. Mammalia 77:205-214.

Segura V. \& Flores D. 2009. Aproximación cualitativa y aspectos funcionales en la ontogenia craneana de Puma concolor (felidae). Mastozoología Neotropical 16:169-182. 
Segura V. \& Prevosti F. 2012. A quantitative approach to the cranial ontogeny of Lycalopex culpaeus (Carnivora: Canidae). Zoomorphology 131:79-92.

Segura V., Prevosti F. \& Cassini G. 2013. Cranial ontogeny in the Puma lineage, Puma concolor, Herpailurus yagouaroundi, and Acinonyx jubatus (Carnivora: Felidae): a three-dimensional geometric morphometric approach. Zoological Journal of the Linnean Society 169:235-250.

Seymour K.L. 1989. Panthera onca. Mammalian Species 340:1-9.

Seymour K.L. 1999. Taxonomy, morphology, paleontology and phylogeny of the South American small cats (Mammalia: Felidae). Tesis de: Department of Zoology, University of Toronto.

Shaw H.G., Beier P., Culver M. \& Grigione M. 2007. Puma field guide. The Cougar Network.

Sheldon J.W. 1992. Wild dogs. The natural history of the non-domesticated Canidae. Academic Press, San Diego, Estados Unidos.

Sicuro F. 2011. Evolutionary trends on extant cat skull morphology (Carnivora: Felidae): A three-dimensional geometrical approach. Biological Journal of the Linnean Society 103:176-190.

Sicuro F. \& Oliveira L.F.B. 2011. Skull morphology and functionality of extant felidae (Mammalia: Carnivora): A phylogenetic and evolutionary perspective. Zoological Journal of the Linnean Society 161:414-462.

Sillero-Zubiri C. 2009. Family Canidae. Pp: 352-447. En: Handbook of the Mammals of the World, Vol. 1. Carnivores (Wilson D.E. \& Mittermeier R.A. eds.). Lynx Editions, Barcelona.

Singleton M. 2002. Patterns of cranial shape variation in the Papionini (Primates: Cercopithecinae). Journal of Human Evolution 42:547-578.

Slater G.J., Dumont E.R. \& Van Valkenburgh B. 2009. Implications of predatory specialization for cranial form and function in canids. Journal of Zoology 278:181-188.

Slater G.J. \& Van Valkenburgh B. 2008. Long in the tooth: Evolution of sabertooth cat cranial shape. Paleobiology 34:403-419.

Slater G.J. \& Van Valkenburgh B. 2009. Allometry and performance: The evolution of skull form and function in felids. Journal of Evolutionary Biology 22:2278-2287.

Slaughter B.H., Pine R.H. \& Pine N.E. 1974. Eruption of cheek teeth in Insectivora and Carnivora. Journal of mammalogy 55:115-125.

Smith K.K. 1997. Comparative patterns of craniofacial development in eutherian and metatherian mammals. Evolution 51:1663-1678.

Smuts G.L., Anderson J.L. \& Austin J.C. 1978. Age determination of the African lion (Panthera leo). Journal of Zoology 185:115-146.

Soibelzon L.H. \& Prevosti F.J. 2007. Los carnívoros (Carnivora, Mammalia) terrestres del Cuaternario de América del Sur. Pp 49-68. En: Geomorfología litoral i Quaternari. Homenatge a 
Joan Cuerda Barceló (Pons G.X. \& Vicens D. eds.). Societat d'Història Natural de les Balears, Palmas de Mallorca, España.

Stander P.E. 1997. Field age determination of leopards by tooth wear. African Journal of Ecology 35:156-161.

StatSoft Inc. 2004. STATISTICA (data analysis software system), version 7. Disponible en www.statsoft.com.

Stedman H.H., Kozyak B.W., Nelson A., Thesier D.M., Su L.T., Low D.W., Bridges C.R., Shrager J.B., Minugh-Purvis N. \& Mitchell M.A. 2004. Myosin gene mutation correlates with anatomical changes in the human lineage. Nature 428:415-418.

Stuart C.T. \& Stuart T.D. 1985. Age determination and development of foetal and juvenile Felis caracal Schreber, 1776. Säugetierkundliche Mitteilungen 32:217-229.

Sun Z., Lee E. \& Herring S.W. 2007. Cell proliferation and osteogenic differentiation of growing pig cranial sutures. Journal of Anatomy 211:280-289.

Sunquist M.E. \& Sunquist F.C. 2002. Wild cats of the world. The University Chicago Press. Chicago.

Sunquist M.E. \& Sunquist F.C. 2009. Family Felidae. Pp: 54-168. En: Handbook of the Mammals of the World, Vol. 1. Carnivores (Wilson D.E. y Mittermeier R.A. eds.). Lynx Editions, Barcelona, España.

Swischuk L.E. 1974. The normal newborn skull. Seminars in Roentgenology IX:101-113.

Tanner J.B., Zelditch M.L., Lundrigan B.L. \& Holekamp K.E. 2010. Ontogenetic change in skull morphology and mechanical advantage in the spotted hyena (Crocuta crocuta). Journal of Morphology 271:353-365.

Tewes M.E. 1986. Ecological and behavioral correlates of ocelot spatial patterns. Tesis de: Graduate School University of Idaho.

Tewes M.E. \& Schmidly D.J. 1987. The Neotropical felids: Jaguar, ocelot, margay and jaguarundi. Pp: 695-712. En: Wild Furbearer Management and Conservation in North America (Novak M., Baker J.A., Obbard M.E. y Malloch B. eds.). Ministry of Natural Resources, Ontario, Canada.

Thexton A.J., Crompton A.W., Owerkowicz T. \& German R.Z. 2004. Correlation between intraoral pressures and tongue movements in the suckling pig. Archives of Oral Biology 49:567-575.

Thompson E.N., Biknevicius A.R. \& German R.Z. 2003. Ontogeny of feeding function in the gray short-tailed opossum Monodelphis domestica: Empirical support for the constrained model of jaw biomechanics. The Journal of Experimental Biology 206:923-932.

Torregrosa V., Petrucci M., Pérez-Claros J.A. \& Palmqvist P. 2010. Nasal aperture area and body mass in felids: Ecophysiological implications and paleobiological inferences. Geobios 43:653661. 
Toweill D.E. 1986. Notes on the development of a cougar kitten. The Murrelet 67:20-23.

Travaini A., Juste J., Novaro A.J. \& Capurro A.F. 2000. Sexual dimorphism and sex identification in the South American culpeo fox, Pseudalopex culpaeus (Carnivora: Canidae). Wildlife Research 27:669-674.

Tukey J.W. 1956. Bias and confidence in not quite large samples. Annals of Mathematics and Statistic 23:614.

Tumlison R. \& McDaniel V.R. 1984. Morphology, replacement mechanisms, and functional conservation in dental replacement patterns of the bobcat (Felis rufus). Journal of Mammalogy 65:111-117

Turner H.N. 1848. Observations relating to some of the foramina at the base of the skull in Mammalia, and on the classification of the order Carnivora. Proceedings of the Zoological Society of London 63-88.

Turner A. \& Antón M. 1997. The big cats and their fossil relatives: An illustrated guide to their evolution and natural history. Columbia University Press, Nueva York.

Ueta C., Iwamoto M., Kanatani N., Yoshida C., Liu Y., Enomoto-Iwamoto M., Ohmori T., Enomoto H., Nakata K., Takada K., Kurisu K. \& Komori T. 2001. Skeletal malformations caused by overexpression of Cbfa1 or its dominant negative form in chondrocytes. The Journal of Cell Biology 153:87-99.

Van Horn R.C., McElhinny T.L. \& Holekamp K.E. 2003. Age estimation and dispersal in the spotted hyena (Crocuta crocuta). Journal of Mammalogy 84:1019-1030.

Van Valkenburgh B. 1991. Iterative evolution of hypercarnivory in canids (Mammalia: Carnivore): Evolutionary interactions among sympatric predators. Paleobiology 17:340-362.

Van Valkenburgh B. 1996. Carnivore dental adaptations and diet: A study of trophic diversity within guilds. Pp: 410-436. En: Carnivore behavior, ecology, and evolution, Vol 1. (Gittleman J.L. ed.). Cornell University press, Nueva York.

Van Valkenburgh B. 2007. Déjà vu: the evolution of feeding morphologies in the Carnivora. Integrative and Comparative Biology 47:147-163.

Van Valkenburgh B., Theodor J., Friscia A., Pollack A. \& Rowe T. 2004. Respiratory turbinates of canids and felids: A quantitative comparison. Journal of Zoology 264:281-293.

Veado B.V. 2005. Paternal behaviour of maned wolf Chrysocyon brachyurus at Fundação ZooBotânica de Belo Horizonte. International Zoological Yearbook 39:198-205.

Verzi D. 2001. Phylogenetic position of Abalosia and the evolution of the extant Octodontinae (Rodentia, Caviomorpha, Octodontidae). Acta Theriologica 46:243-268.

Vilmann H. \& Moss M.L. 1979. Studies on orthocephalization. 2. Flexions of the rat head in the period between 14 and 60 days after gestation. Gegenbaurs Morphologisches Jahrbuch 125:572582. 
Wagemans P.A.H.M., Van de Velde J.P. \& Kuijpers-Jagtman A.M. 1988. Sutures and forces: A review. American Journal of Orthodontics and Dentofacial Orthopedics 94:129-141.

Wainwright P.C. \& Reilly S.M. 1994. Ecological Morphology. University of Chicago Press, Chicago.

Wall C.E. \& Smith K.K. 2001. Ingestion in Mammals. Encyclopedia of life sciences. John Wiley \& Sons Ltd, Chichester. http://www.els.net, doi: 10.1038/npg.els.0001837.

Wang X., Tedford R.H. \& Antón M. 2008. Dogs: Their fossil relatives and evolutionary history. Columbia University Press, Nueva York.

Wang X., Tedford R. H, Van Valkenburgh B. \& Wayne R.K. 2004. Phylogeny, classification, and evolutionary ecology of the canidae. Pp: 8-20. En: Canids: Foxes, Wolves, Jackals and Dogs. Status Survey and Conservation Action Plan. IUCN Species Programme, Gland (Sillero-Zubiri C., Hoffmann M. \& Macdonald D.W. eds.) IUCN, Gland, Switzerland y Cambridge, Reino Unido.

Wayne R.K. 1986. Cranial morphology of domestic and wild canids: The influence of development on morphological change. Evolution 40:243-261.

Webb J.N., Houston A.I., McNamara J.M. \& Székely T. 1999. Multiple patterns of parental care. Animal Behaviour 58:983-993.

Werdelin L. 1983. Morphological patterns in the skulls of cats. Biological Journal of the Linnean Society 19:375-391.

Werdelin L., Yamaguchi N., Johnson W.E. \& O'Brien S.J. 2010. Phylogeny and evolution of cats (Felidae). Pp: 59-82. En: Biology and Conservation of Wild Felids. (Macdonald D.W. \& Loveridge A.J. eds.). Oxford University Press, Nueva York.

Wickland C.R., Baker J.F. \& Paterson B.W. 1991. Torque vectors of neck muscles in the cat. Experimental Brain Research 84:64-659.

Wiley E.O., Siegel-Causey D., Brooks D.R. \& Funk V.A. 1991. The compleat Cladistic. A Primer of Phylogenetic procedures. The University of Kansas, Museum of Natural History.

Wilson L.A.B. 2011. Comparison of prenatal and postnatal ontogeny: cranial allometry in the African striped mouse (Rhabdomys pumilio). Journal of Mammalogy 92:407-420.

Wilson L.A.B. \& Sánchez-Villagra M.R. 2009. Heterochrony and patterns of cranial suture closure in hystricognath rodents. Journal of Anatomy 214:339-354.

Wood J.E. 1958. Age structure and productivity of a gray fox population. Journal of Mammalogy 39:74-86.

Wozencraft W.C. 1996. The phylogeny of the recent Carnivora. Pp: 569-593. En: Carnivore Behavior, Ecology, and Evolution, Vol 1 (Gittleman J.L. ed.). Cornell University press, Nueva York.

Wozencraft W.C. 2005. Order Carnivora. Pp: 532-628. En: Mammal Species of the World. A Taxonomic and Geographic Reference, Vol.1. (Wilson D.E. y Reeder D.M. eds.). The Johns Hopkins University Press, Baltimore.

$$
\sim 245 \sim
$$


Wroe S., McHenry C. \& Thomason J. 2005. Bite club: Comparative bite force in big biting mammals and the prediction of predatory behaviour in fossil taxa. Proceedings of the Royal Society 272:619-625.

Wroe S. \& Milne N. 2007. Convergence and remarkably consistent constraint in the evolution of carnivore skull shape. Evolution 61:1251-1260.

Ximenez A. 1975. Felis geoffroyi. Mammalian Species 54:1-4.

Yamaguchi N., Kitchener A.C., Gilissen E. \& Macdonald D.W. 2009. Brain size of the lion (Panthera leo) and the tiger (P. tigris): Implications for intrageneric phylogeny, intraspecific differences and the effects of captivity. Biological Journal of the Linnean Society 98:85-93.

Young S.P. \& Goldman E.A. 1946. The puma, mysterious American cat. The American Wildlife Institute., Washington D.C.

Yu J.C., Borke J.L. \& Zhang G. 2004. Brief synopsis of cranial sutures: Optimization by adaptation. Seminars in Pediatric Neurology 11:249-255.

Zapata S.C., Funes M. \& Novaro A. 1997. Estimación de la edad en el zorro colorado patagónico (Pseudalopex culpaeus). Mastozoología Neotropical 4:145-150.

Zar J.H. 1999. Biostatistical analysis, 4th edn. Prentice-Hall, Upper Saddle River.

Zelditch M.L., Bookstein F.L. \& Lundrigan B.L. 1992. Ontogeny of integrated skull growth in the cotton rat Sigmodon fulviventer. Evolution 46:1164-1180.

Zelditch M.L. \& Carmichael A.C. 1989. Mammalogists growth and intensity of integration through postnatal growth in the skull of Sigmodon fulviventer. Journal of Mammalogy 70:477-484.

Zelditch M.L., Lundrigan B.L. \& Garland T. 2004. Developmental regulation of skull morphology. I. Ontogenetic dynamics of variance. Evolution \& Development 6:194-206.

Zelditch M.L., Lundrigan B.L., Sheets H.D. \& Garland T. 2003. Do precocial mammals develop at a faster rate? A comparison of rates of skull development in Sigmodon fulviventer and Mus musculus domesticus. Journal of Evolutionary Biology 16:708-720.

Zollikofer C.P.E. \& Weissmann J.D. 2011. A bidirectional interface growth model for cranial interosseous suture morphogenesis. Journal of Anatomy 219:100-114.

Zuccarelli M.D. 2004. Comparative morphometric analysis of captive vs. wild African lion (Panthera leo) skulls. Bios 75:131-138.

Zuercher G.L., Swarner M., Silveira L. \& Carrillo O. 2004. Bush dog Speothos venaticus. Pp: 7680. En: Canids: Foxes, Wolves, Jackals and Dogs. Status Survey and Conservation Action Plan. IUCN Species Programme, Gland, (Sillero-Zubiri C., Hoffmann M. \& Macdonald D.W. eds.). IUCN, Gland, Switzerland y Cambridge, Reino Unido.

Zunino G.E., Vaccaro O.B., Canevari M \& Gardner A.L. 1995. Taxonomy of the genus Lycalopex (Carnivora: Canidae) in Argentina. Proceedings of the Biological Society of Washington 108:729-747.

$$
\sim 246 \sim
$$

